\title{
Georg Witte
}

\section{Die sowjetische Kolchos- und Dorfprosa der fünfziger und sechziger Jahre}

\section{Zur Evolution einer literarischen Unterreihe}

Verlag Otto Sagner München · Berlin · Washington D.C.

Digitalisiert im Rahmen der Kooperation mit dem DFG-Projekt „Digi20“

der Bayerischen Staatsbibliothek, München. OCR-Bearbeitung und Erstellung des eBooks durch den Verlag Otto Sagner:

http://verlag.kubon-sagner.de

() bei Verlag Otto Sagner. Eine Verwertung oder Weitergabe der Texte und Abbildungen, insbesondere durch Vervielfältigung, ist ohne vorherige schriftliche Genehmigung des Verlages unzulässig. 


\title{
SLAVISTISCHE BEITRÄGE
}

\author{
BEGRÜNDET VON \\ ALOIS SCHMAUS \\ HERAUSGEGEBEN VON \\ JOHANNES HOLTHUSEN - HEINRICH KUNSTMANN \\ PETER REHDER - JOSEF SCHRENK \\ REDAKTION \\ PETER REHDER

\section{Band 163}

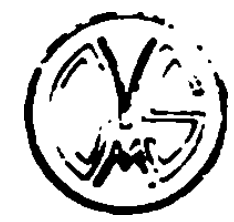

VERLAG OTTO SAGNER

MÜNCHEN 


\section{GEORG WITTE}

\section{DIE SOWJETISCHE KOLCHOS- UND DORFPROSA DER FÜNFZIGER UND SECHZIGER JAHRE}

Zur Evolution einer literarischen Unterreihe 
Bayerische

Munchen

ISBN 3-87690-253-3

c Verlag Otto Sagner, München 1983

Abteilung der Firma Kubon \& Sagner. München

Druck: D. Gräbner, Altendorf 
VORBEMERKUNG

Diese Untersuchung wurde im Marz 1982 als Magisterarbeit an der Ruhruniversităt Bochum angenommen. Eine längere Auseinandersetzung liber Fragen der russischen Gegenwartsliteratur im Rahmen des hiesigen studiums ging voraus. Mein Dank gilt hier besonders Herrn Professor Dr. Karl E i m e $r \mathrm{~m}$ a $c h$ e $r$, der auch die vorliegende Arbeit betreute.

Bochum, Ende Dezember 1982

Georg Witte 


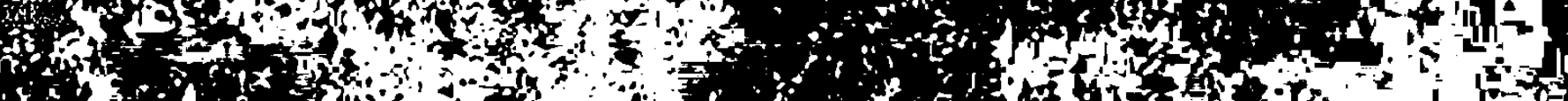

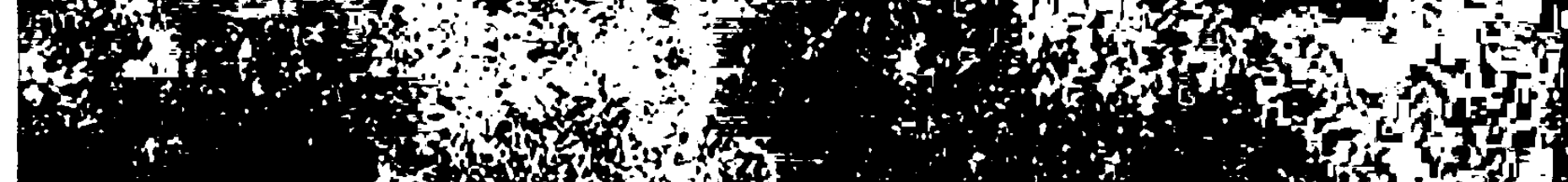

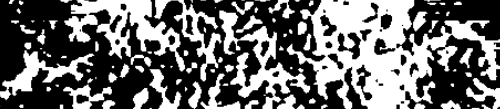
H. B

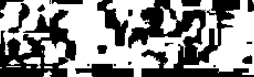

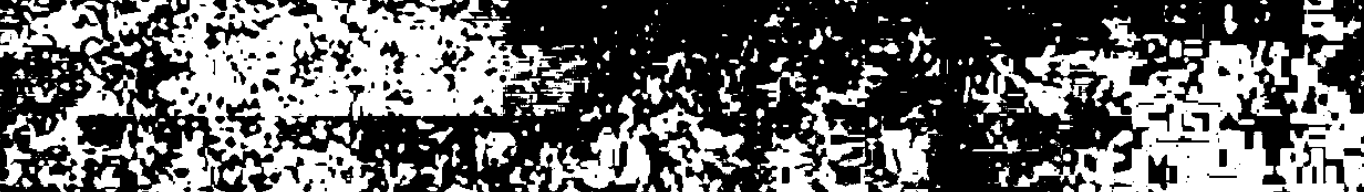

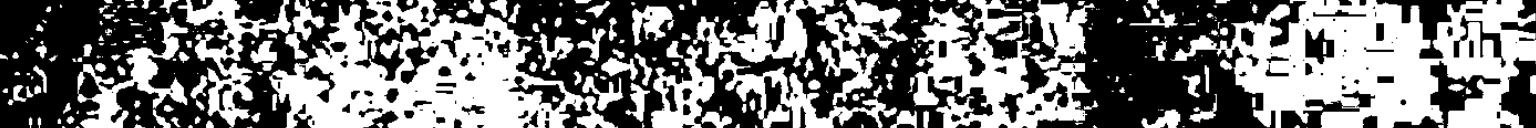

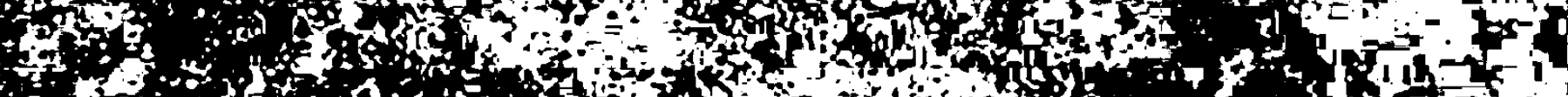
ato

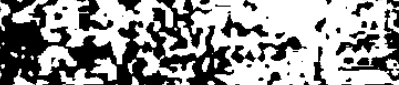

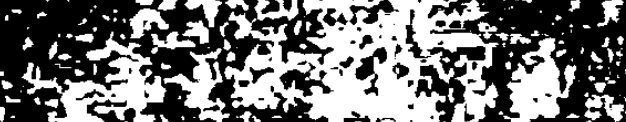

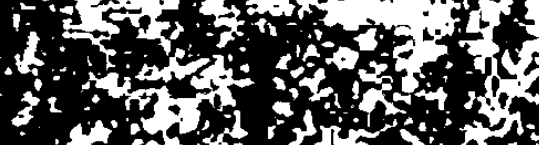

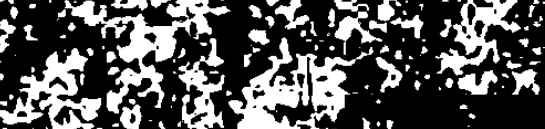

ats

and

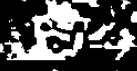
ST:

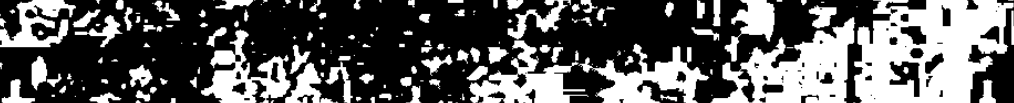

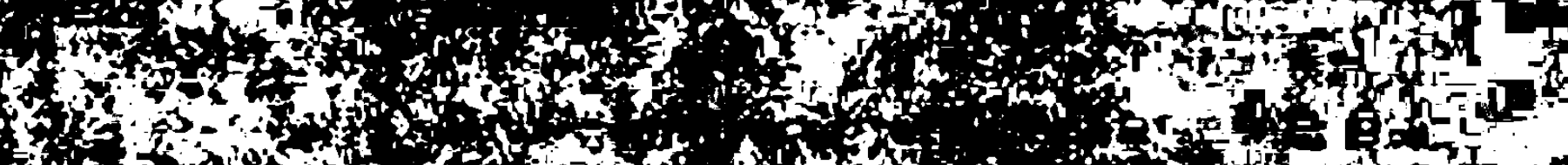
se. anting

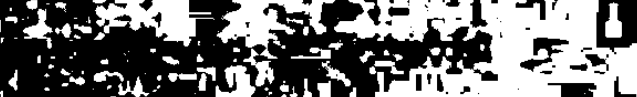
-

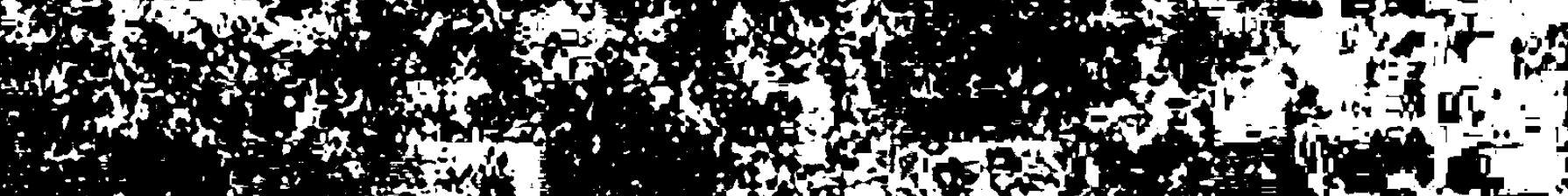
(1) (1) tot

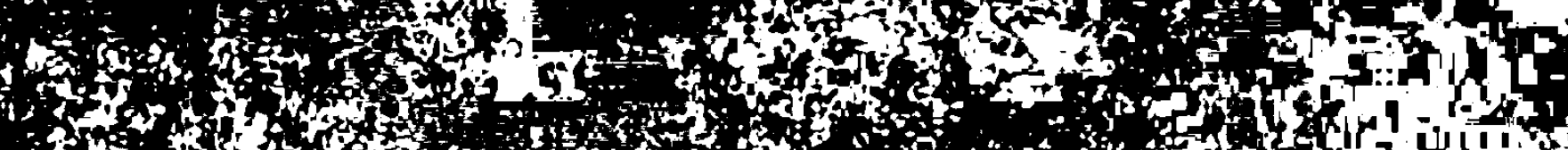

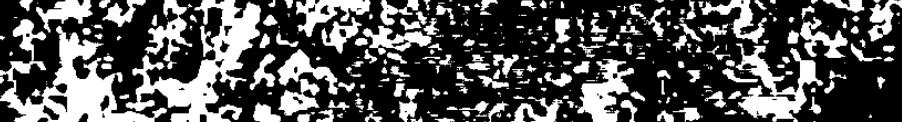
ate

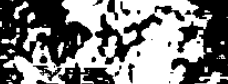
(n)

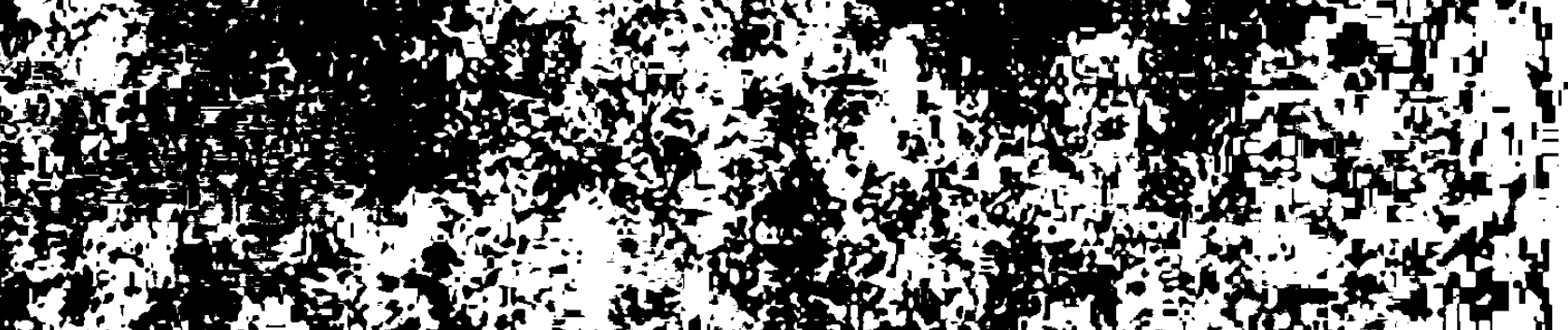
(1)

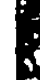
(it.

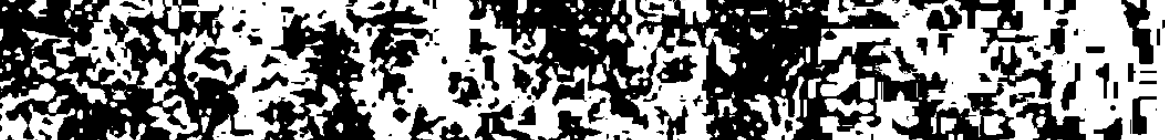

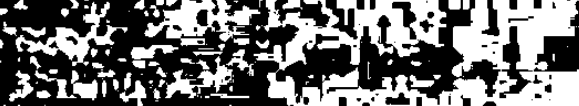
$2+10$

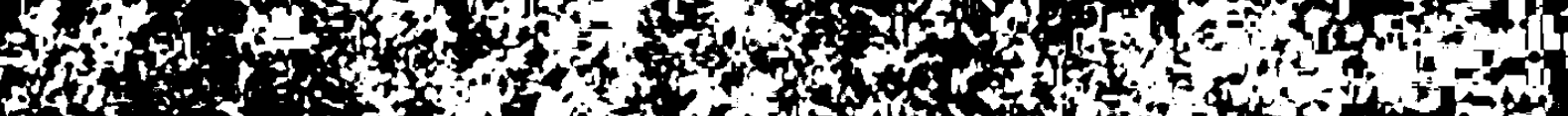

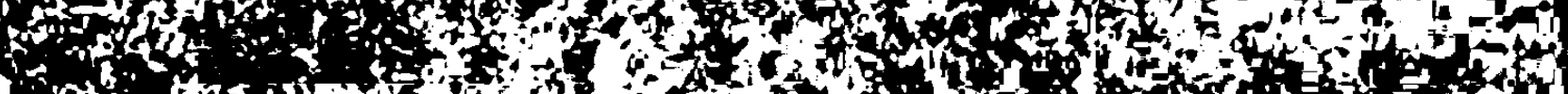

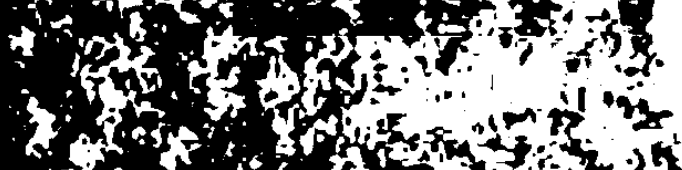 (n)
and
ind is. 1 
Inhaltsverzeichnis

I. Zur Analyse literarischer Evolution S.1

I.1. Modell und Einzeltext S.1

I.2. Norm als literaturhistorische Kategorie 5.4

I.2.1. Norm und Evolution 5.4

I.2.2 Literarische und auberliterarische Normen. Ideologizität der künstlerischen struktur 5.9

I.3. Konsequenzen S.13

I.3.1. Normbildende Instanzen S.13

I.3.2. Eingrenzung des Gegenstands und Text-

I.3.3. Modellebenen S.19

II. Kolchos- und Dorfprosa in literaturwissenschaftlichen Rezeptionszusamenhängen $\quad 5.27$

II.1. Sowjetische Rezeption 5.27

II.2. Westliche Rezeption S.30

II.3. Rezeptionskontext der Emigration S.33

II.4. Normeninnovation als Forschungsaspekt S.36

III. Zur Entwicklung des Genresystems $\mathbf{S . 4 1}$

III.1. Der Terminus "Zanr" in der sowjetischen
Forschung

III.2. Ołerk und Rasskaz in den funfziger Jahren 5.44

III.3. Rasskaz und Povest' in den sechziger/ siebziger Jahren $\$ .50$

III.4. Lyrische Prosa 5.54

IV. Literaturkritik S.57

IV.1. Fünfziger Jahre $\$ .57$

IV.1.1. 1953-1955: Wahrhe1tsgetreue Darstellung
im Dienst der Landwirtschaftsreform

IV.1.2. Normenkonflikte seit $1956 \quad$ S.64

IV.2. Sechziger Jahre $\$ .67$

IV.2.1. Die Diskussion un den bauerlichen Helden $\$ .67$

IV.2.2. Die Diskussion um lyrische und analytische Prosa in den Jahren 1967 und 1968. Aufbrechen eines auberliterarischen Normenkonflikts 
IV.2.3. Fortsetzung der Heldendiskussion.

Das Problem des "narodnyj charakter" 5.75

IV.2.4. Angriffe der orthodoxen Kritik gegen die analytische Prosa

S. 78

IV.2.5. Die nationalistisch-ruralistische strömung un die Zeitschrift "Molodaja Gvardija" $\quad$.80

IV.2.6. Exkurs: Zum Verhältnis von Junger Prosa und Dorfprosa

IV. 3 . Siebziger Jahre

IV.3.1. Normenkonflikt um thematische Aktualität. Die soziologische Funktionalisierung der Literatur

IV.3.2. Aufbrechen des nationalistisch-ruralistisch/orthodoxen Konsens

IV.3.3. Die neue Qualität des Funktionalisierungskonflikts: Soziologische Apologetik vs. philosophische Problematisierung

v. Zdanov-Xra: Das Modell des umfassend integrierten Makrokosmos (M.1) 5.99

V.1.

Konfigurationsstruktur

S. 100

V.1.1.

Dominanz der positiven Figuren.

Nebenfiguren als Charakterisierungsfolie

S. 100

V.1.2. Aquivalenzbeziehungen der figurencharakteristischen Dimensionen.

Die gesellschaftlich-offentlichen

Funktionsträger

S. 102

v.1.3. Die Figurengemeinschaft der umfassenden Integration

S. 104

v.2. Handlungsstruktur.

Integration privater und gesellschaftichoffentlicher Strănge

V.3.

Raum/zeit-Struktur

v.3.2. Zeitliches Kontinum und Homologie von Naturzeit und historischer zeit. Chronotopizitat der unfassenden Integration

V.4. Standpunktkomposition. Monologische Wertung

VI. Fünziger Jahre: Das Modell des reduziert integrierten Makrokosmos

VI. 1 . Konfigurationsstruktur

S. 120

VI.1.1.

Die Opposition zwischen negativem und 
VI.1.3. Aufhebung charakterlicher Naturwichsigkeit

S. 123

VI.1.3. Darstellung bäuerlicher Nebenfiguren

S. 125

VI.1.4. Modellvariante: Bauern als Hauptfiguren (G. Troepol'skij, "Sosedi")

S. 128

VI.2. Handlungsstruktur

S. 138

VI.2.1. Die beiden dominanten Handlungsschemata

S. 138

VI.2.2. Die einseitige Handlungsfunktion der

'Erziehung' im Schema a

(Ju. Nagibin, "Novyj predsedatel'")

S. 139

VI.2.3. Agentenhierarchie im Schema b

(V. Tendrjakov, "Padenie Ivana Cuprova") 5.141

1.2.3. Die transfigurale Handlungsinstanz des

offentlichen Mediums

S. 144

VI.3. Raum/Zeit-Struktur

S. 146

VI.3.1. Entsprechung räumlicher und gesellschaftlicher Integration

(Ju. Nagibin, "Chazarskij ornament") $\quad$ S. 146

VI.3.2. Der modellspezifische Chionotop der

Versammlung

S. 151

VI.4. Standpunktkomposition

S. 153

VI.4.1. Der Erzahler als "Schatten des

Vorsitzenden"

S. 153

VI.4.2. Kontinuitat der Wertungsmonologizitat

S.155

VII. Von der Integration zur Desintegration. Negation der modelikonstitutiven Normen (A. Jasin, Rycagi")

VII.1. Die Folie der alten Normen S.162

VII.2. Konfigurationsstruktur S.163

VII.2.1. Von interfiguralen zu intrafiguralen Oppositionen

S. 163

VII.2.2. Nonverbale Interaktion als Indikator der sozialen Kommunikationssituation S.165

VII.3. Handlungsstruktur.

Entmündigung der Agenten $\quad$ S.168

VII.4. Raum/Zeit-Struktur S.170

VII.4.1. Räumliche Extegration der Versammlung $\mathbf{S . 1 7 0}$

VII.4.2. Zeitliche Extegration der Versammlung S.173

VII.5. Standpunktkomposition S.175

VII.5.1. Verfremdete Wertungskompetenz der Figuren S.175

VII.5.2. Normenkonkurrenz im Verhältnis des Erzählsubjekts $z u$ den Figuren

S. 178

$\begin{array}{ll}\text { VII.6. Zusammenfassung S.181 } & \text { S. }\end{array}$ 
VIII. Sechziger Jahre: Das Modell des autonom integrierten Mikrokosmos (M.3)

S. 184

VIII.1. Konfigurationsstruktur

S. 185

VIII.1.1. Konfrontation der figurencharakteristischen WertmaBstäbe von Makro- und Mikrokosmos (V. Suksin, "Kosmos, nervnaja sistema i smat sala")

VIII.1.2. Die Fanilie als gesellschaftliches Integrationsfeld

VIII.1.3. Modellvariante: Der Funktionstrăger als Hauptfigur

(F. Abramov, "Vokrug da okolo")

VIII.2. Handlungsstruktur

VIII.2.1. Autonomes Bewegungsgesetz: Naturzyklus (V. Belov, "Privycnoe delo")

VIII.2.2. Autonomes Bewegungsgesetz: Schicksalhaftes Ereignis

(A. SolZenicyn, "Matrenin dvor") S.208

VIII.2.3. Modellvariante: Handlungsfeld Makrokosmos. Der autonome bauerliche Agent

(B. Mozaev, "Iz Kizni Fedora Kuz'kina")

VIII.3. Raum/Zeit-Struktur

VIII.3.1. Modellvariante: Das uberlegene Raum/ZeitSystem des Mikrokosmos

(E. Nosov, "za dolami, za lesami")

VIII.3.2. Modellvariante: Das zerstorte Raum/ZeitSystem des Mikrokosmos

(A. Solzenicyn, "Matrenin dvor")

S. 230

VIII.4. Standpunktkomposition. Annäherung der Standpunkte von Erzahlsubjekt und büuerlichen Figuren

VIII.4.1. Die Ebenen der Psychologie und der Phraseologie

VIII.4.2. Standpunktannaherung auf der Ebene der Wertung

IX. Der desintegrierte Mikrokosmos

(V. Suksin, "Srezal") $\quad$ S.255

IX.1. Konfigurationsstruktur S.258

IX.1.1. Interaktion der Hauptfiguren als Ausdruck sozialer Desintegration

IX.1.2. Funktion der Nebenfiguren.

Reproduktion der sozialen Hierarchie

im Mikrokosmos

S. 265

IX.2. Standpunktkomposition

S. 272

IX.3. Raum/Zeit-Struktur

S. 276

Literaturverzeichnis 
I. Zur Analyse literarischer Evolution

I. 1. Modell und Einzeltext

Mit "Kolchosprosa" (kolchoznaja proza) und "Dorfprosa" (derevenskaja proza) greift die vorliegende Arbeit zwei im literarischen Leben der Sowjetunion entstandene Kategorien auf, die sich auf einander ablösende synchrone Schnitte im EvolutionsprozeB einer spezifischen literarischen Unterreihe beziehen. Die Grenze zwischen den beiden Schnitten entspricht ungefahr der Grenze zwischen den füfiziger und sechziger Jahren.

wir beziehen uns nicht deshalb auf diese Kategorien, un die Analyse literarischen Normenwandels auf Stoff-bzw. Themengeschichte $2 u$ reduzieren, sondern gehen davon aus, daB mit ijnen zwei 'lextgruppen erfabt werden, die sich generell, d.h. auf allen relevanten strukturebenen unterschiedlichen literarischen Normensystemen zuordnen lassen, wobei die thematische Bewegung vom Kolchos zum Dorf lediglich einen Aspekt darstellt. Entscheidend ist, daB diese Textgruppen als solche für eine bestimmte zeit, nämlich die füfziger und sechziger Jahre, in den ProzeB der allgemeinen literarischen Normenbildung eingehen, als solche von diesem beeinflubt als auch diesen beeinflussend literaturevolutionäres potential bilden.

Analysegegenstand ist also ein Textkorpus, der einerseits nicht isoliert von dem der gesamtliterarischen Entwicklungsreihe zugrundeliegenden Normenwandel zu verstehen ist, andererseits innerhalb dieser Reihe gel."rend Autonomie besitzt, um eigene Modelle herauszubilden, die ihrerseits wieder auf einer spezifischen Normenevolution basieren. Auf diese historische Relativitat der Modelle muB hinsichtlich ihrer Funktionalisierung fur eine literaturhistorische Fragestellung besonderer Wert gelegt werden.

H. Stachowiak nennt in seinen "Gedanken $z$ u einer allgemeinen Theorie der Modelle" ") drei Hauptmerkmale eines jeden Modells:

1) H. Stachowiak, Gedanken $z u$ einer allgemeinen Theorie der Modelle, in: Studium Generale, 1965, Nr.7, S.423-467. 
das Abblldungsmerkmal (jedes Modell ist ein Modell von etwas, jedem Modell steht ein Original gegenuber), das Verkurzungsmerkmal (nicht alle Eigenschaften des originals werden erfaBt) und das Subjektivierungsmerkmal (Modelle sind ihren Originalen nicht per se eindeutig zugeordnet, sondern für bestimnte subjekte unter Einschränkung auf bestimmte Operationen und zeitspannen). 2) Das Subjektivierungsmerkmal können wir für unseren Ansatz mit der Kategorie des Normenwandels konkretisieren. Daraus ergeben sich Konsequenzen für die anderen Merkmale, die hier nur vorgreifend angedeutet werden (s.Kap.I.3.):

1) Der Normenwandel als soziales Faktum (unabhängig davon, wie weit die soziale Dimension gefabt wird, ob man sich beschränkt auf den sozialen ProzeB innerhalb des literarischen Lebens oder inn ausdehnt auf auBerliterarische Bereiche) setzt der Modellbildung Rahmen (bezogen auf das Abbildungsmerkmal, d.h. Eingrenzung des Originals) und Kriterien (bezogen auf das Verkürzungsmerkmal, d.h. Bestimnung der Analyseebenen).

2) Die dem Normbegriff inhärente dialektische Antinomie zwischen absolutem Gültigkeitsanspruch auf der einen Seite und der Möglichkeit ihrer Verletzung auf der anderen Seite - als Voraussetzung für die Existenz von Normen uberhaupt d.h. die gleichzeitige, wechselseitig sich bedingende Existenz von Norm und Normverletzung in jedem künstlerischen Werk verbietet die schematische Vorstellung von idealtypischen Texten. Stattdessen mulssen wir ein offenes, dynamisches Verhältnis zwischen Modell und Original voraussetzen. Das Modell ist nicht mehr und nicht weniger als ein heuristisches Behelfsmittel, es schematisiert die vielfalt, es schneidet synchron, was nur in der Einheit aus Synchronie und Diachronie existiert.

Diese prinzipiellen Uberlegungen gewinnen zusäzliches Gewicht angesichts der spezifischen Geschichts-situation unseres Gegenstands. Die Aktiv-zeit der Kolchosprosa und

1) Stachowiak, aaO, S.438. 
Dorfprosa fällt in die breite Zwischenphase zwischen der nahezu ausschlieblichen Vorherrschaft eines einzigen literarischen Normensystems während der Źdanov-Ära und der im Verlauf der siebziger Jahre sich stabilisierenden Dominanz neuer Normensysteme (wobel der Gebrauch des Singulars hier bereits problematisch erscheint). Dieser zwischenzeitraum kann vorläufig unterteilt werden in die Phase eines Minus-Normensystems in der zweiten Halfte der funfziger Jahre (einsetzend bereits seit $1953 \mathrm{mit}$ dem ersten Tauwetter) - d.h. Ablehnung der alten bei noch nicht herausgebildeten neuen Normen ${ }^{1)}$ - und die Phase der Herausbildung neuer Normen bei gleichzeitiger Fortexistenz der alten in den sechziger Jahren.

Die Modelle können also nicht etwa den Anspruch von Urtexten erheben, auf die sich generativ alle Einzeltexte zurückfuhren lieben, sondern stellen lediglich Eckwerte dar, an denen die Einzeltexte zu messen sind.

Vom literaturhistorischen standpunkt bleibt die stufe ier :iociellbildung ein notwendiger, gleichzeitig jedoch zu lberuindender statischer, Funktionszusammenhänge rein synchron aufdeckender Schnitt. Erst die Einbeziehung der diachronen Dynamik entfaltet das funktionale Prinzip voll und ganz. Die Funktion eines Textes beschränkt sich nicht auf sein synchrones Verhätnis zum Modell (gleichsam als statische und passive Varianten-(Invariantenrelation), sondern sie steht in einem diachron aktiven - hemmenden oder beschleunigencion - Verhältnis zu ihm. Dies erst macht die Dynamik des historischen Prozesses aus.

Historische sodellbildung kann darum nicht von der Gesamtstrukturanalyse einzelner Texte absehen, da nur hier das konkrete Nebeneinander, der lebendige Konflikt der Normen als Triebkraft der Evolution ersichtlich sind. Dem soll Rechnung getragen werden mit exemplarischen Textanalysen, wozu wir Texte an den jeweiligen diachronen Schaltstellen auswăhlen, die die Normenkonkurrenz besonders deutlich manifestieren.

1) Vgl. K. Eimermacher, Der literarische Normenwandel in der russischen Literatur der füfinger Jahre, in: Wiener Slawistischer Almanach, 1980, Bd.6, S.109-129. 
So scheint ein Weg gebahnt, der Dialektik zwischen dem Einzelnen, Besonderen, historisch Konkreten und dem Allgemeinen, der klassifizierenden Abstraktion gerecht zu werden. Man kann generalisierend formulieren: Gerade das Verständnis des literarischen Textes als eines historischen, sozialen erfordert als Bedingung, um ihm in seiner Funktion gerecht werden zu können, um seinen individuellen, besonderen, unwiederholbaren status innerhalb des Gesant-Textes erfassen zu können, die modellierende und damit abstrahlerende Klassifikation dieses Gesant-Textes. Umgekehrt bedarf die Modellbildung inrer Uberprüfung und historischen Relativierung sowie Dynamisierung durch Anwendung ihrer Masstăbe auf den konkreten Text.

\section{I.2. Norm als literaturhistorische Kategorie}

I.2.1. Norm und Evolution

Der Normbegriff erhält den Status einer wissenschaftlichen Kategorie zuerst in der Soziologie. E. Durkheim begründet mit dem "Kollektivbewubtsein" als Existenzort von Normen den uberindivicuellen Charakter der Kategorie. " ${ }^{1)}$ Generell bezeichnet man mit Norm einen "Standard des vorgeschriebenen Verhaltens"2), der in bestimnten Regeln fabbar ist und in irgendeiner Form sanktioniert sein muB. Trotz der Konstanz vieler Normen (und ihres Anspruchs darauf) ist das Normensystem dynamischer Natur; Normen bezeichnen nicht absolute Invarianzen des Lebens. ${ }^{3)}$

Diesen ursprünglich soziologischen Normbegriff greifen tschechische und polnische (modifiziert auch sowjetische) Strukturalisten unter z.T. explizitem Bezug auf Durkheim fur eine Theorie ästhetischer Normen auf. Dabei scheinen folgende Uberlegungen wesentlich:

1) Zum Begriff des Kollektivbewustseins bei Durkheim vgl. R. Königs Einleitung in: E. Durkheim, Die Regeln der soziologischen Methode, Neuwied-Berlin 1961, bes. S.29-38. zur Unterscheidung von Kollektiv- und Individualbewubtse in vgl. Durkheim, ebd., S.92-97.

2) R. Lautmann, wert und liorm. Begriffsanalysen fur die Soziologie, Opladen (2.Aufl.) 1971, S.108.

3) Vgl. R. König, Soziale Normen, in: h. Bernstorf (Hg.), worterbuch der Soziologie, Stuttgart (2.Aufl.) 1969, S. 978-983. 
1) Sie wenden diesen Eegriff auf den ästhetischen Bereich (bzw. einzelne künstlerische Bereiche) an, der in sich bereits als sozialer Bereich verstanden wird. In Ablehnung einer "psychologischen Asthetik", die dem überindividuelien Charakter des Kunstwerks keine Bedeutung beimiBt und in der individuellen Psyche des Künstlers das gesamte Erklärungspotential zu finden glaubt, betont J. Mukałovskł die asthetische Norm als "soziales Faktum". ") Er stellt für die asthetische Norm die grundsătzliche Eigenschaft aller Normen, nämlich "ihre Fahigkeit, mit Uberindividuellem Druck auf das Handeln des Individuums einzuwirken", fest. 2)

2) Die Norm als soziales Faktum verfügt uber soziale Instanzen threr Bildung. Diese Instanzen sind die Quellen zur historischen Rekonstruktion einer Norm. F. Vodidka beschrelbt drei hauptsăchliche Instanzen:

"1. Normen sind in der Literatur selbst enthalten, d.h. in den Werken, die gelesen werden, popular sind und an denen neue oder die ubrigen literarischen Werke gemessen werden und gewertet werden.

2. Normative Poetiken oder 11 terarische Theorien einer zeit ermöglichen es uns, die 'Regeln' zu erkennen, nach denen sich die Literatur einer gegebenen Etappe richten 'soll'. 3. AuBerungen einer kritischen Wertung der Literatur, die Gesichtspunkte und Methoden dieser Wertung und kritische Forderungen an das literarische Schaffen sind die ergiebigste Quelle."3)

3) Normen haben entgegen ihrem eigenen Anspruch keine absolute Gültigkeit, sie setzen die Möglichkeit ihrer Verletzung voraus. Das resultiert daraus, daB es keine "objektiven", anthropologischen Pri. ilpien gleichen Normen gibt. ${ }^{4)}$ Ler iormbegriff liquidiert also nicht die Indivi-

1) J. Mukafovskł, Ästhetische Funktion, Norm und asthetischer Wert als soziale Fakten, in: Ders., Kapitel aus der Asthetik, Frankfurt/M. (3.Aufl.) 1978, S.35ff. Vgl. ebf. Ders., Probleme der àsthetischen Norm, in: P. Zima (Hg.), Textsemiotik als Ideologiekritik, Frankfurt/M. 1977, S.165ff

2) Mukafovsk' (1977), aao, S.166.

3) F. Vodizka, Die Literaturgeschichte, ihre Probleme und Aufgaben, in: Ders., Die Struktur der literarischen Entwicklung, München 1976, S.65.

4) Vgl. Mukafovsky (1978), aao, S.40ff. 
dualität, sondern macht gerade die Dialektik zwischen Uberindividuellem System und individueller Verwendung dieses Systems bewußt. Die Norm stellt die Grenze für die individuelle Verwendungsmöglichkeit dar, sie bletet ein Kriterium für den erlaubten Abweichungsgrad der individuellen Tatigkeit. " Das bedeutet ungekehrt: sie liefert erst den notwendigen Maßstab fur die Feststellung individueller Radikalitat.

Der so verstandene Normbegriff geht in eine Theorie literarischer Evolution ein, die in ihren wesentlichen zügen bereits von den russischen Formalisten entwickelt wurde.

Die Formalisten treffen die grundlegende Unterscheidung zwischen genetischer und evolutionarrer Betrachtung des 11 teraturhistorischen prozesses. ${ }^{2)}$ wahrend die genetische Betrachtung den literarischen Gegenstand lediglich als Produkt auBerer Faktoren, selne Entstehung aufgrind individueller, zufalliger Bedingungen erfaBt, d.h. dem literarischen ProzeB eine eigenstandige Gesetzmabigkelt abspricht, orientiert die evolutionare Betrachtung auf die Eigengesetzlichke1t des literarischen prozesses, halt der zufalligkelt die Systemhaftigkeit des Prozesses entgegen. Der Gedanke der Normenevolution als Wesensmerkmal dieser Systemhaftigke1t, als inr inneres Gesetz, wird dabel im fruhen Formalismus schon weitgehend vorbereitet, besonders durch $v$. Sklovskijs und $B$. Ejchenbaums Auffassung von der permanenten Kanonisierung und Entkanonisierung als Trjebkraft literarischer Evolution. hir gehen hier nicht auf die Unzulanglichkeiten ihrer Auffassung ein, die vor allem in der schematischen und immanent-reduktionistischen Bestimmung des substrats dieses Kanonisierungs- und Entkanonisierungsprozesses

1) J. Slawitiski, Literatur als System und ProzeB. Strukturalistische Aursatze zur semantischen, komunikativen, sozialen und historischen Dimension der Literatur, München 1975, S. $157 f$.

2) Vgl. (auch im weiteren) A.A. Hansen-Löve, Der russische Formalismus. Methodologische Rekonstruktion seiner Entwicklung aus dem Prinzip der Verfremdung, Wien 1978, lijer bes. S.369-396 und S.470-476; vgl. ebf. H. Gunther, Die Konzeption der literarischen Evolution im tschechischen Strukturalismus, in: alternative, 1971, Nr.80, S.183-200. 
bestehen, welches auf isolierte Verfahren (und dies ausschlieblich hinsichtlich des Rezeptionskriteriums der Wahrnehmungsautomatisierung bzw. -entautomatisierung) eingeschrănkt wird. ") wichtiger ist die prinzipielle Tatsache, das die Literatur als System zum Substrat eines historischen Prozesses gemacht wird, was einerseits dessen uberindividuellen Charakter betont, andererseits kausaldeterministische Reduktion von Literatur auf reinen Ausdruck sozialer oder ideologischer verhaltnisse ablehnt und die Literatur als autonome Reihe versteht.

In der Endphase des Formalismus wird diese Theorie weiterentwickelt durch Ju. Tynjanov und R. Jakobson, die entscheidende Grundpfeiler für die spătere Theoriebildung eines prozeborientierten Strukturalismus setzen.

1) Das Verhältnis von Synchronie und Diachronie erfährt eine systematische Neuformulierung:

"Die Geschichte eines Systems ist inrerseits ein System. Der reine Synchronismus erweist sich als Illusion: jedes synchrone system hat seine Vergangenheit und seine Zukunft /.../. Die Gegenüberstellung von Synchronie und Diachronie war eine Gegenuberstellung von Systembegriff und Evolutionsbegriff. Sie verliert ihr prinzipielles Gewicht, sofern wir anerkennen, daß jedes System notwendig als Evolution vorliegt und andererseits die Evolution zwangsiaufig Systemcharakter besitzt." 2)

Zur Fassung dieses gleichzeitig synchronen und diachronen Aspekts des literarischen Systems verwenden Tynjanov und Jakobson den Begriff der "geltenden Norm" bzw. des "geltenden Normenkomplexes. " 3 )

Dieser Gedanke wird vom tschechischen und polnischen Strukturalismus aufgegriffen. Der evolutionäre Wert eines Texts definiert sich durch die spezifische Kombination von Normerfullungen und Normbrechungen vor dem Hintergrund der historisch geltenden Normen. Die paradoxe Spezifik asthetischer Normen als besonders 'antinormativer' (d.h. auf ihre eigene

1) Vgl. Hansen-Löve, aaO, S.369-376.

2) R. Jakobson/Ju. Tynjanov, Probleme der Literatur- und Sprachforschung (1928), in: R. Jakobson, Poetik. Ausgewählte Aufsătze 1921-1971, Frankfurt/M. 1979, S.64.

3) Ebd., S.65. 
Brechung bei Strafe ihrer Indifferenz angewiesener) bedingt die diachrone Dynamik jedes synchronen strukturanalytischen Schnitts ("die Struktur des Werks als labiles Gleichgewicht von Normen"1), Historische Textanalyse muB gerade diese Normenkonkurrenz im Blick haben. Auch ein radikal normbrechender Text kann seinen Anspruch nur einlösen, wenn dcr Normbruch vor einer Folie der alten Normen erkenntlich wird. Eine isolierte Betrachtung des einzelnen Textes findet keine Kriterjen für Normerfüllung oder Normbruch:

"Zugleich aber enthält das einzelne Werk, isoliert betrachtet, in seiner Struktur keinerlei Signale, die eine Unterscheidung von konventionellen und nicht-konventionellen Elementen erlaubten. Konventionen werden erst erkennbar, wenn das Werk auf ubergeordnete Kontexte bezogen wird. $d . h$. eben auf jene allgemeinen Systeme von Konventionen." 2)

2) Der immanente Reduktionismus wird überwunden. Die literarische Reihe, deren Autonomie erkannt, aber verobsolutiert $z u$ haben das widersprüchliche Verdienst des frühen Formalismus war, wird in Beziehung $z u$ auBerliterarischen Reihen gesetzt. Doch anstelle eines deterministischen Abhängigkeitsverhältnisses sieht man ein Verhältnis der Korrelation. ${ }^{3)}$ Die immanente Gesetzlichkeit der literarischen Re'the bleibt bestehen, Tempo und Richtungswahl jedoch werden durch die Korrelation mit den anderen historischen Reihen bestimmt. Tynjanov und Jakobson lobsen damit das Problem der Beziehungen zwischen literarischer und auBerliterarischen Reihan noch nicht endgultig. (Das betrifft v.a. die Frage der Reihenhierarchie, das Problem der "nächstliegenden Reihen" sowie die gesamte literatursoziologische Theorie.) ${ }^{4)}$ Dies geschieht erst im Rahmen einer semiotischen Auffassung des gesamtkulturellen Systems. Der Gedanke der Korrelation

1) F. Vodixka, Die Totalităt des literarischen Prozesses. zur Entwicklung des theoretischen Denkens im Werk Jan Mukafovskłs, in: Ders., Die struktur der literarischen Entwicklung, aao, S.19.

2) A. Okopieh-slawithska, Die Rolle der Kommunikation im literarischen ProzeB, in: R. Fieguth (Hg.), Literarische Kommunikation. Sechs Aufsatze zum sozialen und kommunikativen Charakter des literarischen Works und des literarischen Prozesses von K. Bartoszytski, M. Gloritski, W. Grajewski und A. Okopieh-Slawitska, Kronberg/Taunus 1975, S.37.

3) Jakobson/Tynjanov, aaO, S.63.

4) Vgl. Hansen-Löve, aaO, S.382ff. 
beinhaltet jedoch bereits wesentliche Prinzipien literaturevolutionärer Betrachtung. Er legt den Grundstein funktionsorientierter Literaturgeschichtsschreibung, indem als Funktion die Korrelation jedes systemelements a) $z u$ anderen Elementen des gleichen systems und b) zu analogen Elementen in anderen Systemen (einschlieblich anderer Reihen) definiert wird. " Tynjanov entwickelt mit dem Begriff der Dominante ${ }^{2)}$ zugleich ein wesentliches Instrument zur Analyse der Funktionen: Ein literarisches System (sowohl die gesamte Reihe als auch der einzelne Text) besteht nicht aus gleichzeitiger Wechselwirkung aller Elemente, sondern exponiert einzelne Elemente, die die Funktion des gesamten systems bestimmen und dieser die anderen Elemente unterordnen.

1.2.2. Literarische und auBerliterarische Normen rdcologizitat der künstlerischen struktur

Die vom späten Formalismus bereits prinzipiell erkannte doppelte (innere und auBere) Motiviertheit jedes literaturhistorischen Phănomens wird auf der einen Seite im tschechischen strukturalismus, auf der anderen seite in der auf $M$. Bachtin gründenden sowjetischen Semiotik $2 u$ einer höheren Form der Synthese gebracht.

Mukałovsky entwickelt den Gedanken vom zusammenhang asthetischer und auBerästhetischer Normen, die sich wechselseitig beeinflussen. ${ }^{3)}$ Als Beispiel einer Beeinflussung der ästhetischen durch eine ethische Norm füht er den Gegensatz zwischen guten und schlechten Helden an. ${ }^{4}$ Dieses Beispiel mag zur Verdeutlichung eines wichtigen Unterschieds dienen: Der Zusammenhang der Literatur mit auBerliterarischen Normen besteht einerseits hinsichtlich ihrer spezifischen Funktion der Vermittlung auBerliterarischer Normen letwa

1) Ju. Tynjanov, Uber die literarische Evolution, in: Ju. Striedter ( $\mathrm{Hg}$.$) , Russischer Formalismus. Texte zur$ aligemeinen Literaturtheorie und zur Theorie der Prosa, 3d.1, München 1969, S.449.

2) Ebd. , S.451.

3) Vsl. Mukałovsks (1978), aaO, S.65.

4) vgl. ebd., S.65. 
durch Vorbildfiguren). Diese normvermittelnde (erzieherische, propagandistische etc.) Funktion kann, muB aber nicht zur dominanten Funktion von Literatur werden. Entscheidender als diese auBerăsthetische Funktionsbestimung ist hingegen die Integration der literarischen Norm als solcher (d.h. in ihrer primär ästhetischen Funktion) in den Kontext des kollektiven Bewubtseins als ort aller Normen des jeweiligen kulturellen Systems. Auf unser Beispiel bezogen: Die Tatsache, daB die Konfigurationsstruktur eines Textes uberhaupt von einer deutlich werthaltigen Heldenopposition bestimnt wird, verweist bereits unabhangig von den konkreten (ethischen, politischen etc.) Norminhalten auf auberliterarische strukturen im kollektiven Bewrutsein der entsprechenden Kultur.

Die theoretische Lobsung dieses zusammenhangs ist der Gedanke einer "Struktur der strukturen", der Vereinigung der einzelnen kulturellen Entwicklungsreihen, die nicht beziehungslos nebeneinanderlaufen, zu einer struktur hoherer Ordnung, die "ihre Hicrarchie und ihre Dominante (dominante Reihe) besitzt". " Damit ist einerseits das Einwirken der ubergeordneten auf untergeordnete strukturen erfaBt, andererseits die Spezifik der untergeordneten Strukturen gewăhrleistet, die durch ihre eigenen Gesetze die Bedingungen für das Einwirken der ubergeordneten Strukturen vorschreiben.

In modifizierter Form wird dieser Gedanke bereits vom Bachtin-kreis entwickelt, der die Literaturwissenschaft in den Gesamtrahmen einer semiotischen Ideologiewissenschaft integriert. 2) volosinov/Medvedev/Bachtin fassen den gesamten Ideologischen Bereich als Zeichensystem auf. Dieser Bereich (das "ideologische Milieu") als "Gesamtheit von Zeichen-

1) J.Mukařovskł, Polákova "Vznełenost płlrody". Pokus o rozbor a vyvojové zařaděn ĺ básnické struktury, zit. nach Günther (1971), aaO, S.191.

2) Vgl. bes. V. Vološinov, Marxismus und Sprachphilosophie. Grundlegende Probleme der soziologischen Methode in der Sprachwissenschaft, Frankfurt/M. 1975 und P. Medvedev, Die formale Methode in der Literaturwissenschaft, Stuttgart 1976. - Beide Texte werden $z u$ weiten Teilen M. Bachtin zugeschrieben. Vgl. ebf. Hansen-Löve, aaO, S.438-442. 
qualität besitzenden Objekten" aller Art (wissenschaftlicher, religiöser, künstlerischer etc.) ist das "inkarnierte, materialisierte, nach auBen gewendete soziale Bewubtsein eines gegebenen Kollektivs"i), was einer semiotischen Modifizierung des Durkheimschen "KollektivbewuBtseins" gleichkommt. (Es besteht sleichzeití eine Affinitat zum Normbegriff. Dieser Begriff will ja ebenfalls - unter anderem, soziologischen Aspekt - die uberindividuelle Erscheinungs form des kollektiven Bewubtseins definieren in seinen Auswirkungen auf das individuale Bewubtsein. Er impliziert ebenso wie der semiotische Ideologiebegriff eine Werthaftigkeit, d.h. eine Bezogenheit auf die Funktionen für das gegebene Kollektiv bzw. seine Mitglieder.) Im Gegensatz zur mechanistischen Widerspiegelungstheorie wird das Verhältnis zwischen Ideologie und von ihr bezeichneter und bewerteter Realitat als eines der Brechung (bzw. gebrochenen Widerspiegelung) gefaBt. Die Realität wird den GesetzmäBigkeiten des ideologischen zeichensystems unterworfen und entsprechend deformiert. ${ }^{2}$ )

Die Besonderheit der kunst besteht nun darin, daB sie eine doppelte Brechung der Realität, d.h. eine Brechung uber den Umweg der bereits erfolgten Brechung in anderen Bereichen des ideologischen Milieus vornimmt. Man hat also arei schritte $z u$ unterscheiden:

1) Medvedev, aaO, S.16.

2) Vgl. Hansen-Löve, aao, S.439. - Mit dieser semiotischen Definition ist die in der hegelianischen und marxistischen Tradition ubliche widerspruchliche Verwendung des Ideologiebegriffs - einerseits im Sinne von "falschem BewuBtsein", andererseits im Sinne von "gesellschaftlichem BewuBtsein", "geistiger Arbeit Uberhaupt" - korrigiert. Zwischen beiden Bedeutungen besteht erst dann kein widerspruch, wenn man die Zeichenhaftigkeit aller BewuBtseinstatigkeit sowie deren prinzipielien Deformationseffekt - zunächst ohne pejorative Wertung ("falsch") - anerkennt. Vgl. zu den verschiedenen Implikationen des Ideologiebegriffs H.R. Schlette, Ideologie, in: H. Krings/H.M. Baumgartner/Ch. Wild (Hg.), Handbuch philosophischer Grundbegriffe, Bd.3, München 1973, S.720-728.

Vgl. ebf. G. Lichtheim, Das Konzept der Ideologie, Frankfurt/M. 1973, S.18-31. 
1) Die Literatur steht wie jede andere ideologische Erscheinung in bezeichnender und bewertender Beziehung zur gesamten historischen Realitä.

2) Diese Beziehung ist nicht direkt, sondern vermittelt uber das ideologische Milieu als der Atmosphäre,

"auBerhalb derer sich das Leben als Gegenstand der literarischen Darstellung nicht vollziehen kann.

Das Leben als Gesamtheit bestimmter Handlungen, Ereignisse oder Erlebnisse wird zum Sujet, zur Fabel, $z$ um Thema, zum Motiv nur dann, wenn es durch das Prisma des ideologischen Milieus gebrochen ist, wenn es in einem konkreten ideologischen Körper inkarniert ist. Die von der ideologischen Widerspiegelung nicht erfaBte, sozusagen rohe Wirklichkeit kann nicht in den Inhalt von Literatur eingehen." 1)

3) Dieses Verhaltnis zwischen Ideologie und Literatur ist kein Isomorphie-Verhaltnis der Element-zu-ElementAbbildung, sondern vermittelt sich uber die kinstlerische struktur. AuBerkünstlerische Ideologeme finden sich nicht als identische 'inhaltliche' Ideologeme im literarischen Werk.

Die künstlerische struktur ist selber ideologisch: Hierin liegt dic gleichzeitige Uberwindung von immanenter strukturbetrachtung und soziologischem bzw. vulgärideologiekritischem Reduktionismus. Es bleibt noch hinzuzufügen, daB dies genauso wie für die Struktur des Einzelwerks auch für die uberindividuelle struktur der literarischen Norm gilt.

Schlieblich sei noch auf einen weiteren Aspekt dieses Ideologieverständnisses hingewiesen: nămlich auf die Anziehungskraft gerade der noch nicht fertigen, sondern erst in Entstehung begriffenen Ideologischen systeme in ihrem "embryonalen, unausgegorenen, noch intuitiven zustand" auf die Literatur, bzw. auf die Făhigkeit der literatur, "direkt in das soziale Laboratorium der Herausbildung und Formierung von Ideologien einzudringen". 2)

1) Medvedev, aaO, S.20.

2) Ebd., S.27. 


\section{I.3. Konsequenzen}

\section{I.3.1. Normbildende Instanzen}

Am Ausgangspunkt der von uns betrachteten zeitspanne liegt ein gesamtliterarisches Normensystem in extrem monolithischer Form - d.h. alle Strukturebenen einheitlich funktional ausrichtend - vor, welches explizit formuliert ist und beinahe lückenlose Geltung besitzt. Das Charakteristische dieses Systems ist die dominant auBerliterarische Funktionsbestimmung von Literatur (Erziehung) und die ausschliebliche Definition literarischer Normen unter diesem Aspekt. ${ }^{1)}$

Die Modifizierungen dieses Systems in der Folgezeit sind unter zwei Gesichtspunkten zu betrachten: a) hinsichtlich des Inhalts der Normen (was besonders die Lockerung des exklusiv definierten Kausalverhältnisses 2 wischen auBerliterarischen und literarischen Normen betrifft bis hin zur Problematisierung der Erziehungsfunktion iberhaupt), b) hinsichtlich der Erscheinungsweise der Normen, womit wir auf die normbildenden Instanzen zurückkommen. Im Verhăltnis der von Vodilka genannten drei Instanzen vollzieht sich ein grundlegender bandel. War wăhrend der Nachkriegsjahre (ždanov-Aira) die

1) Dieses Normensystem ist in den vier kulturpolitischen Beschlüssen der Partel aus den Jahren 1946 und 1948 komprimiert formuliert (0 zurnalach "Zvezda" 1 "Leningrad", 14.8. 1946: O repertuare dramaticeskich teatrov i merach po ego uluţeniju, 26.8.1946; O kinofil'me "Bol'śaja そ̌izn'", 4.7. 1946; Ob opere "Velikaja druzba" V. Muradeli, 10.2.1948; dt. in: A. Shdanow, Uber Kunst und Wissenschaft, Kiel o.J., S.117-146). - Im Unterschied zum noch vorhandenen Spielraum innerhalb eines weltanschaulich und funktional abgesteckten Rahmens in den dreiBiger Jahren wird der sozialistische Realismus hier zu einem Regelkanon, der u.a. einschliebt: - das Diktat und das Verbot bestimmer Themen ("moderne Sowjetthemen" vs. Themen aus dem individuell-personlichen Bereich)

- Gebote $2 u$ Darstellung und Auswahl von Figuren (die erzieherische Bedeutung des Konflikts zwischen positiven und negativen Figuren wird geringer geschäzt als die eines möglichst homogenen Kollektivs positiver Figuren)

- das Gebot, die entscheidende Rolle der Partel darzustellen.

Vgl. Eimermacher, aaO, S.112ff und H. Günther, Sozialistischer Realismus, in: Reallexikon der deutschen Literaturgeschichte. Begründet von P. Merker und W. Stammler, Bd.4 (Hg. K. Kanzog/A. Masser), Berlin-New York (2.Aufl.) 1979, S. $58 \mathrm{ff}$. 
zentrale normbildende Instanz eine ausformulierte literarische Theorie (sozialistischer Realismus), büBt diese in der Folgezeit inre theoretische Einheitlichkeit immer mehr ein und wird gescriwächt zugunsten eines Wechselverhältnisses der anderen beiden Instanzen. Der Niedergang des sozialistischen. Realismus als ästhetisch normbildende Instanz ist bereits in einigen materialreichen Arbeiten untersucht worden, auf die hier anstelle einer eigenen Darstellung verwiesen wird. ") Bei im einzelnen unterschiedlichen Akzentuierungen besteht grundsäzlich Konsens darüber, daB der sozialistische Realismus seinen ursprünglichen Anspruch als ästhetisches Programm verloren hat und sich in zunehmender Isolation von der ästhetischen Praxis auf ein weltanschauliches Grundlagenpostulat reduziert.

Im zentrum unserer Untersuchung sollen die Instanz der Literatur sowie die Instanz der kritischen Wertungen und Forderungen (Instanzen 1 und 3 bei vodicka) stehen. Die Instanz der kertungen und Forderungen mu $B$ cabei auf die gesar.te literaturpolitische Hierarchie cier somjetunion (parteioffizielle Richtlinien, Schriftstellerverband, Literaturkritik) bezogen werden. Diese Instanz soll in ihrer normbildenden Funktion für die Dorfprosa in einem eigenen Kapitel dargestellt werden. Den Schwerpunkt wird die Literaturkritik bilden, da hier die gemeinsame Funktion der gesamten Instanz - nämlich Ausrichtung der Literatur auf auBerliterarische Normvermittlung - genügend deutlich und bezogen auf die Unterreihe am konkretesten $z$ um Ausdruck kommt. Man kann hypothetisch davon ausgehen, daB in dem MaBe, wie sich die Literatur als eigenständiger Faktor in der Heraus-

1) - E. Mozejko, Der sozialistische Realismus. Theorie, Entwicklung und Versagen einer Literaturmethode, Bonn 1977.

- J.U. Peters, Réalisme sans rivages? Zur Diskussion über den sozialistischen Realismus in der Sowjctunion seit 1956, in: Zeitschrift für slavische Philologie, 1974, S.291-324.

- H. Günther (1979), aao, S.57-64.

- M. Hayward, The Decline of Socialist Realism, in: Survey, 1972, Nr.1, S.73-97.

- Vgl. in der sowjetischen Diskussion bes. G.N. Pospelov, $K$ sporam o socialistiCeskogo realizma, in: FilologiCeskie nauki, 1975, Nr.1, S.3-16. 
bildung literarischer Normen entwickelt, die Kritik einen eindeutigen Schwerfunkt auf die 'koordinierung' dieser Normen mit auBerliterarischen Normen setzt. Der Inhalt dieser Normen, die von der Literatur als sozialpädagogischem Instrument vermittelt werden sollen, wechselt. In den füfziger Jahren geht es v.a. um die propagierung des landwirtschaftlichen Reformprograms, in den sechziger Jahren um die nationale 'moralische Erneuerung', wobei sich hier allerdings ein scharfer Konflikt zwischen verschiedenen Auffassungen (soziologischer Pragmatismus vs. vergangenheits- und nationalorientierte Wertsuche) zeigt. In den sechziger Jahren erweist sich die Literaturkritik zum groBen Teil als reagierend auf einen ProzeB, der sich innerhalb der Literatur vollzieht. Für die späten sechziger und cile siebziser Jahre scheint die Kritik wieder mehr regulative Potenz zu gewinnen, auf deren EinfluB die Renaissance der Rolchosprosa zurlickzufuhren ist.

\section{I.3.2. Eingrenzung des Gegenstands und Textauswahl}

Basis der eigenständigen Modellbildung von Kolchos- und Dorfprosa ist die jeweilige thematische Einheit. Sie garantiert die Bündelung der beiden Textgruppen zu einer literarischen Unterreihe, in der man die Kolchosprosa als reduzierte Form der Dorfprosa ansehen kann, da auch in der ersteren eine dörfliche problematik, allerdings in enger sozialokonomischer Spezifizierung, das Thema bildet. Diesen zusammenhang $z$ wischen Thematik und Modellbildung behaupten wir nicht als methodologisches literaturhistorisches Axiom, sondern lediglich für unseren Gegenstand als historisches Faktum. In der literarischen Praxis der von uns behandelten Zeitspanne werden Texte mit cem dominanten thematischen Merkmal 'Dorf' zur Trägergruppe einer spezifischen literarischen Normenentwicklung, die zur konstitution eicener yodelle fuhrt. Das thematische Merkmal 'Dorf' bildet somit das abgrenzungskriterium für die behandelte literarische Unterreihe, es ist bezüglich des Abbildungsmerkmals (s.o.) als definitorische Eingrenzung des originals anzusehen. Die von der Modellbildung erfabten Eigenschaften jieses 
Originals (Verkürzungsmerkmal) hingegen beschränken sich nicht auf die thematische Ebene, sondern beziehen sich auf die Normenentwicklung in verschiedenen literarischen Strukturebenen (s.I.3.3.). Dabei werden wir solange von einer literaturhistorisch relevanten Existenz der Unterreihe ausgehen können, wie eine spezifische Normenentwicklung dieser Reihe in wechselseitiger Beeinflussung mit der Normenentwicklung der gesamtliterarischen Reihe erkenntlich ist.

Wir können nach diesen Uberlegungen folgende synchronen und diachronen Grenzen unseres Gegenstands bestimmen: - Synchron werden die beicen Textgruppen von Texten aus der jeweiligen Phase begrenzt, deren thematische Dimension nur eingeschränkt auf das geosoziale Merkmal 'Dorf' bezogen ist. Für die fünfziger Jahre wăre etwa $V$. Zakrutkins Erzahlung "Podsolnuch" (1958) zu nennen, die zwar im sozialen Bereich 'Kolchos' spielt (sämtliche Figuren sind Kolchoshirten), jedoch primär durch andere thematische Merkmale (Kriegserinnerung/'pamjat"') bestimnt ist; für die sechziger Jahre betrifft das etwa $v$. Vojnovics Rcman "Źizn" i neobycajnye prikljuCenija soldata Ivana Cenkina" (1963), der zwar zum größten Tell auf dem Dorf spielt, primar jedoch einen anderen Sozialbereich (Militär) zum. Thema hat.

- Diachron ist die Grenze Ende der sechziger/Anfang der siebziger Jahre anzusetzen, da ab hier die Unterrethe als solche ihr literaturevolutionäres potential einbübt (und gleichzeitig thematisch kaum noch $z$ vereinheitlichen ist). Dafür sprechen folgende Faktoren:

a) Die Literatur, welche weiterhin durch das dominante thematische Merkmal 'Dorf' bestimnt ist, reproduziert im wesentlichen nur epigonal die vorher herausgebildeten iormen, wobei sie sich wieder stärker auf die Kolchosprosa der fünziger Jahre bezieht (Renaissance einer an aktuellen sozialökonomischen Aufgaben ausgerichteten Ołerk-Literatur). ablesbar ist das z.B. an der seit Anfang der siebziger Jahre 
herausgegebenen Buchreihe "Pis'ma iz derevni"1), die sich zum gröBeren Tell aus Texten dieser neuen Kolchosliteratur, zum kleineren Teil aus Neuauflagen von bereits in den sechziger Jahren veroffentlichten Texten der Dorfprosa zusammensetzt.

b) Für die nicht-epigonale Literatur, die sich aus der Tradition der sechziger Jahre weiterentwickelt, wird das geosoziale thematische Merkmal 'Dorf' sekundär gegenuber ethischen und/oder psychologischen und/oder metaphysischen Problematiken. Beziehungen zwischen den späteren Povesti c. Ajtmatovs und $v$. Rasputins sowie der neuen Kolchosliteratur L. Ivanovs und I. Vinitenkos aufgrund des gemeinsamen thematischen Merkmals 'Dorf' herstellen zu wollen, ware im Sinne historischer Modellbildung irrelevant. Resonanz findet dieser Proze $B$ in der Terminusdiskussion der sowjetischen Literaturkritik (s.IV.3.3.).

c) Der evolutionare prozeB wird zunehmend durch die künstlerische Individualitat der Autoren anstelle literarischer 'Schulen' oder Strömungen markiert. Dieser ProzeB schlägt sich in cier kritischen und wissenschaftlichen Rezeption nieder, welche stärker als früher die Entwicklung hervorragender Personalstile (V. Suksin, v. Rasputin, C. Ajtmatov, v. Tendrjakov, s. Zalygin) verfolgt. 2)

1) Diese Serie wird vom Verlag "Sovetskaja Rossija" auf Beschlus des "Otvetsvennyj sovet po derevenskoj literature pri komitete po pe丈ati RSFS" vom April 1970 herausgegeben. Vgl. G. Radov, Na novom étaue, in: Znamja, 1971, Nr.7, S.203-216 und F. Kuznecov, "Dobs.-at'sja do pervopricin!", in: Literaturnaja Gazeta, 21.3.1973, S.4. Bereits 1967 wird mit der Verbffentilchung des von G. Radov und I. Vinicenko herausgegebenen Sammelbands "Nam pisut iz derevni" (Moskau 1967) ein erstes veroffentlichungspolitisches zeichen für die Forcierung einer neuen Kolchosliteratur gesetzt. Vgl. zum neuen Kolchosoxerk insgesamt $L$. Terakopjan, Pafos preobrazovanija. Zametk1 o sovremennoj derevenskoj proze, Moskau 1974, das Kapitel "Ot ocerka do ocerka" bes. S.314-319.

2) Vgl. N.N. Shneidman, Soviet Literature in the 1970's: Artistic Diversity and Ideological Conformity, TorontoBuffalo-London 1979, S.19. - Shneidman spricht hier von "elner gewissen Disintegration der 'Dorfprosa' als eines literarischen Trends". 
d) Hiermit steht die Tatsache in engem zusammenhang, daB wesentliche Vertreter der ehemaligen 'Schule' den thematischen Bezug zum Dorf vollständig aufgeben (Tendr.jakov, zalygin). 1)

e) Schlieblich kann man als genreevolutionäres Indiz für das Ende eines Entwicklungsprozesses bzw. für die Kanonisierung der in diesem ProzeB herausgebildeten Normen den AbschluB mehrerer, meist auf dem Roman-Genre basierender zyklen hinweisen. ${ }^{21}$

\section{zur Textauswahl}

Die Untersuchung erhebt nicht den Anspruch statistischer Vollständigkeit, sondern ist exemplarisch. Dabei ist ein gewlsser willkurlichkeltsgrad bei der Textauswahl nicht zu vermeiden. Wir schränken ihn ein, indem wir

a) uns genremäBig an den Hauptformen der jeweiligen Phasen orientieren (Ocerk, Rasskaz und eingeschränkt Povest ' in den funfziger Jahren; Rasskaz und Povest' bzw. Ihre Mischform in den sechziger Jahren) (s.Kap.III)

b) das Kriterium der Resonanz in den normbildenden Instanzen - Literaturkritik, ggf. Nachdruck oder Neuaufnahme in Sammelbănde, literaturpolitische Direktiven - zuhilfenehmen

c) uns innerhalb des Variationsspektrums des thematischen Gesamtkomplexes der einzelnen Phasen auf die dominanten Themengruppen konzentrieren (Kolchosreform fur die funfziger Jahre, Dorfgegenwart seit der Nachkriegszeit und Kollektivierungsperiode fur die sechziger Jahre)

1) Vql. Shneidman, aao, das Kapitel uber S. Zalygin, S.61-74 und G. Hosking, Beyond Socialist Realism, Soviet Fiction since Ivan Denisovich, London 1980 , das Kapitel uber $V$. Tendrjakov, S.84-100.

2) 1973 erscheint mit "Puti-pereput'ja" der dritte Teil von F. Abramovs Romantrilogie "Prjasliny". 1979 erscheint das zweite Buch von V.Astaf'evs "Poslednij poklon".

S. Zalygin schlieBt mit "Kommissija" (1975) eine historische Trilogie ab. $V$. Belov veroffentlicht seit 1968 einen Erzahlzyklus mit der Erzahlerfigur Konstantin zorin im zentrum. - $2 u$ diesem genreevolutionären Aspekt vgl. v. Akimov, Cto otkryvaet derevenskaja proza?, in: V konce semidesjatych. Literatura nasich dnej (Hg. I.S. Éventov), Leningrad 1980, S.59 und Ju. Kuz'menko, Sovetskaja literatura veera, segodnja 1 zavtra, Moskau 1981, S.313. 
d) ein möglichst breites Autorenspektrum (anstelle einer Schwerpunktanalyse individueller Oeuvres) berücksichtigen.

Gesondert ist darauf hinzuweisen, daB wir uns bis auf eine Ausnahme (C. Ajtmatov) nur auf russische Autoren beziehen, da dies der eindeutigen Dominanz russischer Texte im sowjetischen Rezeptionskontext bis in die sechziger Jahre entspricht. Erst seit Ende der sechziger Jahre wird in der I.iteraturkritik stärker auf Autoren nichtrussischer Nationalität Wert gelegt.

\section{I.3.3. Modellebenen}

Der Gedanke der Normenevolution muB die Bestimung der Modellebenen leiten. Für die verschiedenen Phasen müssen erstens - als Vergleichsbedingung - einheitliche Ebenen festgelegt werden, die tatsăchlich normenevolutionăre Relevanz besitzen, d.h. auf denen sich Normen mit einem MindestmaB an Verbindlichkeit feststellen lassen (modellkonstitutive Normen). Dabei kann der modellkonstitutive Stellenwert der einzelnen Ebenen - u.a. abhăngig vom Verbindlichkeitsgrad der in ihnen wirkenden Normen, von derenevolutionärem Wert gegenüber der vorherigen Phase, vom strukturellen Stellenwert der Ebenen in den Texten von Phase zu Phase schwanken.

Zweitens müssen die Kriterien, unter denen die Ebenen analysiert werden, der besonderen Beziehung zwischen 1iterarischen und auBerliterarischen strukturen konkret-historisch gerecht werden.

Unter Berücksichtigung beider Aspekte lassen sich vier modellkonstitutive Ebenen unterscheiden; diese sind nicht Produkt axiomatischer Setzung, sondern Resultat sukzessiver Systematisierung im ProzeB der Textlektüre:

1) die Ebene der Konfigurationsstruktur

2) die Ebene der Handlungsstruktur

3) die Ebene der Raum/Zeit-Struktur

4) die Ebene der Standpunktkomposition. 
Ad 1) Der Stellenwert der Konfigurationsstruktur ergibt sich aus ihrer engen Verbindung mit dem Problem des "Helden", welches das zentrale Problem in der Bestimmung des Erziehungsauftrags der Literatur bildet und literarische Entwicklung wie literaturkritische Rezeption entscheidend prägt.

Wesentliche Faktoren der "Heldendarstellung", des

"Charakters", des "Menschenbildes" hängen mit dieser Ebene zusamen, welche unfast:

- Dimensionen und Merkmale der Eigurencharakterisierung

- Auswahl der Figuren aus dem sozialen, geographischen, altersmabigen etc. Spektrum der dargestellten Welt

- interfigurale Relationen (Oppositionen bzw. Aquivalenzen, antagonistischer bzw. nicht-antagonistischer Charakter der Oppositionen, Beziehung zwischen Haupt- und Nebenfiguren).

All dies sind spezifisch literarische strukturelemente. die in ihrer Elgengesetzlichkeit mit auBerliterarischen strukturen in Verbindung stehen.

Ad 2) Die Handlungsstruktur organisiert die Bewegungsgesetze der dargestellten Welt. Diese spezifisch literarisch strukturierten Bewegungsgesetze stehen wiederum in Beziehung zu Bewegungsgesetzen der auBerliterarischen Welt. Faktoren, aus denen sich diese Bewegungsgesetze bilden, sind Bewegungsrichtungen (Progredienz, Rejredienz, zyklik), Bewegungseigenschaften (Kontinuitat, Bruch, Statik, Dynamik) sowie bewegende Instanzen (gesellschaftliche Subjekte, Natur, Schicksai). 1)

1) Ein Wort dazu, warum nicht Fabel und Sujet als Kategorien der Ebenenklassifizierung verwendet werden: Diese Kategorien bezeichnen strukturschichten narrativer Texte, die fur die Textanalyse unabdingbar sind, als solche jedoch noch keine modellanalytische bzw. modeliunterscheidende Relevanz besitzen. Unter Kriterien wie Linearitat bzw. Nichtlinearitat der Fabel, Ereignishaitigkeit bzw. Ereignislosigkeit des Sujets lassen sich modellkonstitutive Normen mit einem entsprechenden Verbindlichkeitsgrad nicht feststellen. Diese Kriterien lassen sich wahrscheinlich nur unter dem Aspekt 
Der Begriff Handlung bezeichnet die Rolle des Menschen - im literarischen Text: der Figur - innerhalb dieser Bewegungsgesetze. Die figurale Handlungsinstanz wird mit der Kategorie des Agenten erfaBt. ${ }^{11}$

Die Grundeinheit der Handlungsstruktur ist die situation. Bewegung ist eine Abfolge von situationen, die sich in verschiedenen Formen (Raumwechsel, Wechsel in der Figuren-

kulturtypologischer Vergleiche modellanalytisch funktionalisieren. (Vgl. etwa Ju. Lotmans Verstandnis des Ereignisses als zentraler Sujeteinheit in Abhängigkeit vom Kulturtyp, in: Ju. Lotman, Die Struktur literarischer Texte, Munchen 1972, S. $330 \mathrm{ff}$ und Ders.. Die Entstehung des Sujets typologisch gesehen, in: Ders.. Aufsätze zur Theorle und Methodologie der Literatur, Kronberg/Taunus 1974, S.30-36.) Bezogen auf historische Modellvergleiche innerhalb eines relativ kleinen zeitraums scheint hingegen eine konkretisierte Ebenenklassifizierung den anfangs genannten Forderungen der normenevolutionären Relevanz eher zu entsprechen. (Die Ebene der Handlungsstruktur kann dabei sowohl Fabel- als auch Sujetelemente umfassen; ahnliches gilt für die Ebenen der Raum/zeit-struktur und der Standpunktkomposition, wobei die letzteren beiden Ebenen primär Konkretisiefungen des Sujets betreffen.)

1) Vgl. T. Todorov, Die Kategorien der ilterarischen Erzählung, in: H. Blumensath (Hg.), Strukturalismus in der Literaturwissenschaft, Köln 1972, S.275. - Dieser Begriff scheint sinnvoller als der Greimassche "Aktant", der nicht individuell-figuralen, sondern uberjndividueli-anthropomorphen Charakter hat und im Rahmen einer generativen narrativen

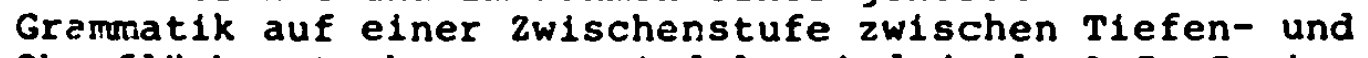
Oberflächenstruktur angesiedelt vird (vgl. A.J. Greimas, Elemente einer narrativen Gramatik, in: Blumensath,aao, S. 47-67.) Angesichts des engen zusammenhangs 2 wischen Figur und Handlung in den meisten modernen narrativen Textypen (1m Gegensatz zu folkloristischer Narration, in der die Figuren häufig nur Repräsentanten relativ allgemeiner, archetypischer Handlungsfunktionen sind, vgl. Todorov, aao, S.271), ist eine Individualisierung der Handlungsinstanzen auf figurale Dimensionen notwendig. 
konstellation, Wechsel in den interfiguralen Beziehungen etc.) realisiert. Das Grundschema jeder handlung besteht aus den drei Gliedern Situation - Veränderung der situation/ bzw. Verănderungsversuch - neue situation. Damit wird zugleich die Unterscheidung von handlung und Geschehen notwendig: Handlung setzt eine situationsveranderung durch ein oder mehrere intentional wăhlende menschliche Subjekte voraus, wăhrend Geschehen dann vorliegt, wenn entweder gar keine situationsveränderung stattfindet oder diese sich unabhängig von den menschlichen subjekten, die einer intentionalen wahl nicht fahig sind, vollzieht."

Ad 3) Die Bedeutung der Raum/zeit-Struktur für künstlerische Weltdarstellung ist besonders von M. Bachtin und Ju. Lotman erkannt worden. Lotman sieht das Kunstwerk als "Weltmodell" deutlich mit raumlichen Merkmalen ausgestattet, begrundet im besonderen visuellen Charakter der menschlichen Wahrnehmung der welt. Fur den :ienschen seien in der Mehrzahl der Falle die Denotate verbaler zeichen irgendwelche raumlichen, sichtbaren objekte, was $z$ einer spezifisch räumlichen Rezeption verbalisierter Modelle füre. ${ }^{21}$

Auf den besonderen zusammenhang von Raum und zeit hingewiesen $2 u$ haben, ist das Verdienst Bachtins. ${ }^{3)}$ Bachtins Begriff des Chronotopen meint die zeit als vierte Dimension des Raums: konkret: die Verdichtung, Fullung, Sichtbarmachung von zeit im Raum sowie die Erstreckung des Raums in der zeitbewegung. " Die Raum/Zeitlichkeit des kunstlerischen zeichens wird als Spezifikum künstlerjscher Weltdarstellung - einschlieblich der "Sinnsphare" (smyslovaja sfera) verstanden; abstrakte Werte, Bedeutungen, Sinnbestimmungen nehmen "raumzeitliche Ausdrucksformen" an, "jeder Eintritt in die Sinnsphare fuhrt durch die Pforten des

1) Diese linterscheidung, die ursprunglich in der Dramentheorie entwickelt wird Ivgl. M. Pfister, Das Drama. Theorie und Analyse, München 1971, S.270f), besitzt für alle narrativen Strukturen Gultigkeit.

2) Lotman (1972), aao, S.312f.

3) M. Bachtin, Formy vremeni i chronotopa $v$ romane. Oterki po 2 storiceskoj poetike, in: Ders., Voprosy literatury i estetiki. Issledovanija raznych let, Moskau 1975, S.234-407.

4) Vgl. ebd., S.235. 
Chronotopen". ") Ungekehrt sind die raum/zeitlichen

Dimensionen der künstlerischen Welten extrem werthaltig, stehen in engem - verfremdendem oder bestätigendem Zusammenhang zura jeweils herrschenden Wertesystem einer Gesellschaft und besonders $z$ um Bild des Menschen darin. 21

Auf der Basis dieser allgemeinen Uberlegungen unterscheidet Bachtin verschiedene Funktionen des Chronotopen im Text, wobei er den Begriff sowohl zur Bezeichnung der allgemeinen raum/zeitlichen Dimensioniertheit künstlerischer Welten verwendet (im Falle der sog. Gattungschronotopen, 2.B. "Chronotop des Abenteuerromans", "Chronotop der Idylle" etc.) als auch zur Bezeichnung konkreter Paum/Zeit-Einheiten (wie etwa das "Treffen" oder der "Weg" als Schnittpunkte räumlicher und zeitlicher Linien) bzw. konkreter Raumeinhelten als Trägern, Substraten, Verkörperungen von zeit ("SchlOB", "Salon" etc.). Diese Einzelchronotopen haben eine "Sujetbedeutung" (sjužtnoe znacenie), d.h. sie werden $z u$ Konzentrationspunkten der sujetkonstitutiven Erelgnisse, sowie eine "darstellende Bedeutung" (izobrazitel'noe znacenie), womit die Verdichtung und Konkretisation von zeitmerkmalen auf bestimmten Raumabschnitten gemeint ist, in deren Folge das Ereignis zum "Bild" (obraz) wird. ${ }^{3)}$

Für die Dorfprosa wird sich diese Ebene von zentralem modellkonstitutiven Stellenwert erweisen, wie vorläufig bereits aus der räumlichen Merkmalhaltigkeit cer Bezeichnung erahnt werden kann.

Wir werden im Sinne einer klareren Unterscheidung von Chronotopen immer dann sprechen, wenn es sich um konkrete Raum/Zeit-Einheiten handelt, von Raum/Zelt-System brw. dessen Chronotopizitat hingegen dann, wenn die allgemeine raum/ zeitliche Dimensioniertheit der dargestellten Welt gemeint ist.

Ad 4) Mit standpunkt ist zunächst ganz allgeme in die Perspektive gemeint, aus der etwas betrachtet, berichtet, cargestellt, bewertet wird. Die Ebene der Perspektivierung

1) Bachtin, aao, S. 406 .

2) Vgl. ebd. , S.286,342,390.

3) Ebd., S.398ff. 
hat in ihrer spezifisch literarischen strukturgesetzlichkeit (verschiedene Unterebenen der Perspektivierung sowie deren Komposition) eine entscheidende Funktion für das besondere Brechungsverhältnis mit auBerliterarischen Strukturen (vorherrschende Perspektive auf bestimnte objekte, Variabilität bzw. Invariabilităt der Perspektiven etc., wobei hier besonders die Wertungsperspektive von Interesse ist).

B. Uspenskij ${ }^{1)}$ entwickelt im Rahmen einer elaborierten point-of-view-Typologie vier Ebenen der Standpunktkomposition:

- die Ebene der Ideologie (bzw. der Wertung)

(Wertung als "System ideengebundener Weltauffassung" 2) ;

Kriterium: Eindeutigkeit oder Polyphonie der Wertungsstandpunkte)

- die Ebene der Phraseologie

(Relation zwischen fremder Rede und Subjektrede, konkret: zwischen Figurenrede und Erzählerrede; zwei Grundtypen der Standpunktinterferenz: a) Beeinflussung des "Autorenworts" durch das fremde Wort b) Beeinflussung des fremden Worts durch das "Autorenwort" (zum Begriff des "Autors" s. Anm. 1 auf S.25)

- die Ebene der Psychologie

(Innen- bzw. AuBenstandpunkt bezüglich des BewuBtseins der Figuren)

- die Ebene der Raum-Zeit-Charakteristik

("Perspektive" im engeren, situativen Sinne).

Damit ist ein einheitliches Instrumentarium geschaffen, mit dem die Perspektivuberlagerungen, Kongruenz- und Inkongruenzbeziehungen erfaBt werden können. Auf Besonderheiten der einzelnen Ebenen wird ggf. im Analyseteil verwiesen.

Von grundlegender Bedeutung ist die Definition der Standpunktsubjekte. Mit der Ebene der Standpunktkomposition

1) B.A.Uspenskij, Poetik der Komposition. Struktur des künstlerischen Textes und Typologie der Kompositionsform, Franfurt/M. 1975.

2) Ebd., S.17. 
meinen wir ausschlieblich das Verhältnis zwischen der erzählenden Instanz und den Figuren. Die erzăhlende Instanz wird als Erzählsubjekt bezeichnet, womit auf der einen Seite inre Rolle als standpunkteignendes subjekt erfast wird, auf der anderen seite die terminologische Verwirrung un den Begriff des Erzählers ungangen wird. Ausschlieblich im Fall figuraler Erzahlsubjekte soll der Begriff des Erzählers verwendet werden.

Von dieser erzählenden Instanz ist prinzipiell die textkonstituierende Instanz (das subjekt des Werkganzen ") bzw. Textsubjekt) zu unterscheiden. Diese Abgrenzung wird besonders hinsichtlich der Wertungsproblematik entscheidend. Die Wertung im Rahmen der Standpunktkomposition bezleht sich ausschlieblich auf das Erzählsubjekt (bzw. die Figuren). Bezogen auf das Textsubjekt ist die Wertungsperspektive des Erzăhlsubjekts jedoch nur eln - hăufig verfremdendes - Verfahren innerhalb der von ihm durch den gesamtstrukturellen Bedeutungsaufbau vollzogenen Wertung.

Nachdem die Modellebenen festgelegt sind, mus noch die Frage nach den Kriterien aufgeworfen werden, die sie funktional vereinheitlichen. Es ist dies die Frage nach einem gemeinsamen, modellkonstitutiven semantischen Prinzip.

Dieses Prinzip kann zunächst nur hypothetisch formuliert werden. Es wird sich zeigen, dab sich in sämtlichen Modellen und auf sämtlichen Ebenen zwei Sphären unterscheiden lassen, die nach den semantischen Grundmerkmalen 'groB'

1) Vgl. A. Okopieh-Slawitiska, Die personalen Relationen in der literarischen Kommunikation, in: Fieguth, aao, S.137ff. - Das "Subjekt des Werkganzen" bezeichnet die für die Gesamtstruktur des Textes verantwortliche Instanz, den Regeldisponenten hochsten Grades. - Ohne hier auf den sehr uneinheitlichen Begriff des "Autoren" im einzelnen eingehen zu können, sei darauf hingewiesen, daB das "Subjekt des Werkganzen" in etwa dem "inneren Autor" bzw. dem "obraz avtora" entspricht. Der Begriff "Autor" (avtor) wird hingegen in der sowjetischen Forschung häufig synonym fur das nichtfigurale Erzählsubjekt verwendet. Auch Uspenskijs Terminologie ist in dieser Hinsicht nicht einheitlich (vgl. seinen Begriff des "Autorenworts"). 
bzw. 'klein' differenzierbar sind. Diese beide Sphären sollen sehr allgemein als Makrokosmos und Mikrokosmos bezeichnet werden, um ihre verschledenen Dimensionen (raumzeitliche, gesellschaftliche, sprachliche, wertungsmäBige etc.l einbeziehen zu können. Zwischen diesen beiden Kosmen bestehen für jedes Modell spezifische Beziehungen der Integration bzw. Desintegration. Diese bilden das eigentliche Vergleichs-Dritte zwischen den einzelnen Modellen.

Abschliebend sind noch einige Anmerkungen zur Verfahrenswelse notwendig. Als zweckmäBigstes Darstellungsverfahren unseres exemplarischen Analyseansatzes erscheint die Auswahl von Paradigmatexten für die einzelnen Model1ebenen. Dies sind Texte, welche in ihrer struktur die jewellige Ebene besonders stark auspragen und hier eine normenevolutionäre Funktion einnehmen. Unter dieser Voraussetzung rechtfertigt sich auch die darstellungstechnisch notwendige Reduktion der Paradigmatexte auf die jeweils behandelte Modellebene. Gleichzeitig kann selbstverständlich die Ebenentrennung nicht schematisch betrieben verden; die oft sehr engen funktionalen zusammenhänge zwischen den Ebenen müssen ggf. berücksichtigt werden. 
II. Kolchos- und Dorfprosa in literaturwissenschaftlichen Rezeptionszusammenhängen

II. 1. Sowjetische Rezeption

Die sowjetische Rezeption geschieht hauptsächlich im Rahmen der "Literaturkritik" (literaturnaja kritika), welche einen weiteren Bereich unfaBt als die bei uns normalerweise unter Literaturkritik verstandene Buchrezension, sondern literaturtheoretische und literaturhistorische Fragestellungen einbezieht, dabei aber immer unter wertendem Aspekt mit unterschiedlich starkem normativem Anspruch steht (im Unterschied zum primär analytischen Anspruch der "Literaturwissenschaft" (literaturovedenie)). Die aktuelle, primär weltanschaulich vertende und ausrichtende Literaturkritik wird als normbildende Instanz in Kap. IV behandelt. Hier soll auf einige Arbeiten eingegangen werden, die an einer umfassenderen historischen Problemstellung orientiert sind. ${ }^{1)}$

Den Schwerpunkt dieser llbersichtsdarstellungen bildet die thematische Entwicklung von den fünziger Jahren $z u$ den

1) - V.A. Apuchtina, Sovremennaja sovetskaja proza (60-e natalo 70-ch godov), Moskau 1977, das Kapitel "Proza o derevne", s.60-67.

- Ju. Kuz'menko, aaO, das Kapitel "Mez gorodom i selom", S. 301-326.

- V.I. Protzenko, Povest' 60-ch - nakala 70-ch godov, in: N.A. Gromova/V.A. Kovalev (Hg.), Sovremennaja russkaja sovetskaja povest', Leningrad 1975, S.161-223, hier bes. S. 181-199.

- Ders., Nekotorye voprosy razvitija "derevenskoj prozy", in: V.A. Kovalev (Hg.), Problemy russkoj sovetskoj literatury. 50-e - 70-e gody, Leningrad 1976, S.58-107.

- V. Surganov, Celovek na zemle. Istoriko-literaturnyj oterk, :loskau 1975 (eine Gesamtdarstellung seit Jahrhundertbeginn).

- Ders., Idušcim dal'క̌e. Zametki o knigach pisatelej"derevenstikov", in: voprosy literatury, 1971, Nr.8, S.3-25 (ein Vortrag im Schriftstellerverband auf einer Tagung über Literaturkritik, der sich periodisch klassifizierend auf die Entwicklung der Kolchos- und Dorfprosa seit den fünfiger Jahren bezieht).

- L. Terakopjan, aao (eine themenchronologisch aufgebaute Darstellung, eingeteilt in: Texte über die vorrevolutionäre zeit, über Revolution und Bürçerkrieg, uber die Kollektivierung, über den Krieg, uber die Nachkriegszeit, uber die fünfiger und über die sechriger Jahre). 
sechziger Jainren, d.h. die Bewegung von der eng sozialökonomisch verstandenen kolchosthematik $2 u$ einer tiefer dimensionierten Dorfthematik. Die Literatur der fünfiger Jahre wird dabei in engem zusammenhang mit der landwirtschaftlichen Reformpolitik Chruskevs gesehen und in ihrer thematischen Konkretisierung ganz von dieser her definiert (Leitungskader- und Spezialistenproblematik, Neulanderschließung), wobei ihr z.T. eine begrenzte vorläuferfunktion als "Kundschafter" (razvedtik) zugeschrieben wird, die aber nie den Rahmen des von der Partei initiierten Prozesses verlasse.

Für die sechziger Jahre tritt zunehmend der "bäuerliche Charakter" (krest'janskij charakter) ${ }^{2)}$ in den Mittelpunkt. Bereits Ende der fünfiger Jahre gewinnt der "gewöhnliche kolchosbauer" (rjadovoj kolchoznik) zunehmend an Bedeutung gegenüber den Funktionärs-Figuren, jetzt aber geht es um eine grundlegende Vertiefung der figurencharakteristischen Dimensionen: Die "innere Vlelt"3) des Bauern und sein "privates Leben" - "innerhalb seiner eigenen vier wände". abseits von Kolchosverwaltung und Berufsleben ${ }^{4)}$ - rücken ins zentrum. Die Landwirtschaftsreform wird von anderen Themenschier punkten abgelost. Als dominant werden genannt das neu erwachende Interesse für die eigene historische Vergangenheit (Bürgerkrieg ${ }^{5)}$ und v.a. Kollektivierung ${ }^{6)}$ ) sowie der dörfliche "byt" und seine Traditionen."

Für die zweite Hälfe der sechziger Jahre wird eine nochmalige Vertiefung der thematischen Dimension auf "allgemeinmenschliche" Probleme festgestellt; ${ }^{8}$ ) im zusammenhang damit, daß die sog. Dorfprosa immer mehr die "probleme der geistigen Entricklung der Gesellschaft im Ganzen"

1) Surganov (1971), aaO, S.8.

2) Vgl. u.a. Apuchtina, aao, s.60.

3) Protcenko (1975), aao, S.189.

4) Kuz'menko, aaO, S.311.

5) Vgl. Proťenko (1976), aao, S. $84 \mathrm{ff}$.

6) Vgl. ebd., S.84ff; Apuchtina, aaO, S.60ff; Surganov (1975), aaO, S.382-451.

7) Vgl. Surganov (1971), aao, S.19; Apuchtina, aao, S.63ff; Prottenko (1976), aao. S.86ff.

8) Surganov (1971), S.21 
beleuchte ${ }^{1)}$, wird die dörfliche Thematik als Klassifizierungsmaistab in Frage gestellt. Als spezifisch neue Thematik wird v.a. das Verhältnis Dorf - Stadt (Stadtsiedlerproblematik) genannt: auch dies als Sprengung eines ausschlieblich dörflichen Themenkomplexes. ${ }^{2)}$

All diese Darstellungen stehen in engem Bezug zur literaturkritischen Diskussion der siebziger Jahre und nehmen besonders in der Frage des Helden sowie in den normativen Festlegungen fur die weitere Entwicklungsperspektive der Dorfprosa 2.T. entgegengesetzte Positionen ein (s.IV.3.3.).

Weitere Aspekte, unter denen die Dorfprosa in der sowjetischen Literaturtheorie (der "literaturnaja kritika" wie auch der "literaturovedenie") rezipiert wird, sind Genrefragen, Stil- und Kompositionsentwicklung sowie historisch-vergleichende Fragestellungen. Die GenreForschung wird in Kap. III behandelt. Auf Untersuchungen zu Stilistik und Standpunktkomposition soll im Analyseteil verwiesen werden.

Ein Aspekt, der uns nicht weiter beschätigen wird, ist der der literaturhistorischen Analogien. Diese werden in der sowjetischen Literaturkritik permanent (und meistens eklektizistisch im jeweiligen Verwertungsinteresse) gezogen. Gesonderte Erwăhnung verdient eine Untersuchung A. Makinas, die sich mit den Fnalogiebeziehungen zwischen der Dorfprosa der sechziger Jahre und der Literatur der sog. "bäuerlichen Plejade" (krest'janskaja plejada) in den ersten beiden Jahrzehnten des Jahrhunderts beschäfigt. 3) zur "Plejade" werden vier Schriftsteller (S. Pod-jacev, S. Semenov. I. Kasatkin. I. Vol'nov) gerechnet, die bäuerlicher Herkunft waren und auf dem Dorf lebten. Die beiden hauptsächlichen Analogien werden gezogen

a) hinsichtlich des Bauern-Bildes: Die "Plejade" habe ahnlich wie die Dorfprosa den Blick geóffnet für die

1) FrotCenko (1976), aao, S.95.

2) Vgl. Kuz'menko, aao, S.314ff.

3) M.A. Makina, Tvorלestvo krest'janskoj "plejady" v russkoj literarature načala $X X$ veka $i$ "derevenskaja" proza nasich dnej, in: Russkaja literatura, 1980, Nr.4, S.73-91. 
positiven Charaktereigenschaften des russischen Bauern, sie habe das verzerrte Bild des entweder niedlichen oder verwilderten Bauern geradegerückt und seine tatsächlichen Existenzbedingungen gezeigt: ${ }^{11}$

b) hinsichtlich der Sprachgestaltung: In beiden Gruppen gewinne die direkte Rede der bäuerlichen Figuren in ihrer Vielstimigkeit eine über die koloritbildung hinausgehende Bedeutung und tendiere zur Dominanz uber die "Autorenrede", was sich auch in dieser selbst bis hin zur Ununterscheidbarkeit von der Figurenrede niederschlage. ${ }^{21}$

Die Grundlage der Analogiebeziehungen sieht Makina in den ähnlich gelagerten Problemen der Dorfdiskussion in der literarischen offentlichkeit der zehner Jahre und der Dorfdiskussion der sechziger/siebziger Jahre, die beide eng mit der Frage nach den Grundlagen des russischen Nationalcharakters zusammenhingen. ${ }^{3)}$

Diese Eigenschaften unterscheiden nach Makina die beiden untersuchten literarischen Stromungen von zwei anderen, die ebenfalls - unter anderen Vergleichspunkten - analog gesetzt werden: die sozialanalytisch und sozialreformerisch orientierte okerk-Literatur G. Uspenskijs, V. Veresaevs u.a. sowie die ocerk-Literatur der fünfiger Jahre. ${ }^{4}$ )

\section{II.2. Westliche Rezeption}

In den siebziger Jahren erscheinen mehrere westliche Arbeiten zur Kolchos- und Dorfprosa, die sich ebenfalls auf den thematischen Wandel vom Kolchos $z$ um Dorf konzentrieren und damit zusammenhängend besonderes Gewicht auf die

1) Makina, aao, S. $75 f f$.

2) Ebd., S.79ff und $88 \mathrm{ff}$.

3) Ebd. S. S $75 f$.

4) Ebd., S.85ff. 
Entwicklung der bäuerlichen Figur legen. "' Dabei steht für die fünfziger Jahre das Verhältnis zwischen Bauern und Funktionären im Mittelpunkt. Perret-Gentil stellt fest, daB die bäuerliche Figur "Objekt" bleibt und nur vom Interesse der ihr Leben bestimmenden Funktionäre her dargestellt wird. 2) Für die sechziger Jahre wird eine Gewichtsverlagerung auf die bäuerliche figur festgestellt, wobei unterschiedliche Wertungen vorgenommen werden. Brown betont den wenig idealisierten Charakter der Figuren und hebt auBerdem den antinormativen zug der Figurencharakterisierung hervor, die den Leser $2 u$ den Figuren in ein Verhältnis ähnlich dem " $z u$ seinen Nachbarn" brächten ${ }^{3)}$, während Perret-Gentil stärker die Sentimentalisierung des Landlebens, die "der Vergangenheit zugewandte Idealisierung" ${ }^{4}$ ) betont und besonders für die siebriger Jahre eine wachsende Tendenz sieht, "die Bauern ihre Lage vergessen $2 u$ lassen, indem die Literatur in idealisierendem licht eine grandiose, patriarchalische oder kriegerische Vergangenheit und die hochgehaltenen

1) - D. Brown, Nationalism and Buralism in Recent Soviet Russian Literature, in: Review of National Literatures, 1972, Nr.1, S.183-209.

- Ders.., Soviet Russian Literature since Stalin, Cambridge 1978, das Kapitel "The village writers", S.218-252.

- L. Daetz, Die băuerliche Literatur und inre Traditionen, in: G. Lindemann ( $\mathrm{Hg}$.$) , Sowjetliteratur heute,$ München 1979, S.100-122.

- G. Hildebrandt, Ein Beitrag zur sowjetischen Dorfprosa der Gegenwart, in: Die Welt der Slawen, 1973, S.190-200.

- G.A. Hosking, The Russian Peasant Rediscovered: "Village Prose" of the 1960s, in: Slavic Review, 1973, Nr.4, S. 705-724.

- Ders., Beyond Socialist Realism, aao, das Kapitel "Village Prose: Vasily Belov, Valentin Rasputin", S.58-83.

- Y. Perret-Gentil, Der Kolchosbauer in der heutigen russischen Dorf-Literatur, in: Osteuropa, 1978, Nr.9., S. 794-810.

- G. Zekulin, Aspects of Peasant Life as Portrayed in Contemporary Soviet Literature, in: Canadian Slavic Studies, 1967, Nr.4, S.552-565.

- Ders., The Contemporary Countryside in Soviet Literature: A Search for New Values, in: J.R. Millar (Hg.), The Soviet Rural Community, Urbana 1971, S.376-404

2) Perret-Gentil, aaO, S.795f.

3) Brown (1978), aaO, S.247.

4) Perret-Gentil, aaO, S.798. 
'Tugenden der Erde' beschwört." 1 )

Konsens besteht uber den generellen wandel von einer primär sozialkritischen Funktion in den fünfiger Jahren ${ }^{2)}$ (in Abgrenzung von der "Lackiererei" in den Nachkriegsjahren) zu einer primär bewubtseinskritischen Funktion (bezogen auf eine allgemeine gesellschaftliche BewuBtseinskrise), wobei im Mittelpunkt stehen die kritische ${ }^{3)}$ oder idealisierende ${ }^{4)}$ Neuorientierung an der eigenen Geschichte und v.a. die suche nach neuen nationalen Werten mit dem Bauern als Quelle moralischer Erneuerung im Gegensatz zu der an falschen Werten orientierten Urbanisierung und Bürokratisierung der Gesellschaft. ${ }^{5)}$ Den besonderen Zusammenhang zwischen Nationalismus und Ruralismus in der Literatur untersucht Brown (1972), wobei er auf die Idealisierung des "Bodens" und seiner Bewohner, der "guten Erde" (gegen den "schlechten Asphalt") 6) und auf den Stellenwert des "Heimatbodens" (native soil) als Bestandteil nationalistischen BewuBtseins hinweist. ${ }^{7)}$

Auf die weitere thematische Vertiefung in Richtung einer zunehmend philosophischen Dimensionierung des Menschenbildes

1) Perret-Gentil, aaO, S.802.

2) Hier wird unterschiedlich akzentuiert: wahrend Brown (1978) den sozialkritischen Charakter sehr radikal versteht ("the frankest and most penetrating body of social criticism that has been allowed in recent years", S.222), verweist Daetz auf die Begrenztheit der Kritik, welche nie systemkritisches Potential entfalte und negative Erscheinungen auf menschliches Versagen bzw. Fehlplanungen zurulckführe (S.121). Im Sinne von Brown äuBert sich Zekulin (1967), S.555.

Eine interessante Nebenerscheinung ist die Verwendung von Dorfprosa-Texten als quasi-soziologisches Quellenmaterial, etwa bei A. McCauley, Kolkhoz Problens in Recent Literary Magazines, in: Soviet Studies, 1964, Nr.3, S.308-330, mit der Begrulndung, die Literatur sei die einzig signifikante Materialquelle eines offentlichen Meinungsbildes iber diese Probleme (S.309).

3) Vgl. Hildebrandt, aaO, S.191f.

4) Vgl. Anm. 1 .

5) Vgl. Hosking (1973), aaO, s.705f und 712: Hosking (1980), aao, S. $58 \mathrm{ff}$.

6) Brown (1972), aao, S.191.

7) Ebd., S.201. 
in den spaten sechziger und den siebziger Jahren verweist Hosking (1980) in einer exemplarischen Darstellung zweier bedeutender Vertreter der neueren Dorfprosaisten-Generation: "It is striking that both Belov and Rasputin should have come to this vision of man as ruled by subconscious collective and ancestral spirits - ruled by them because he tries to deny them and has thereby lost his conscious, moderating and creative contact with them. Man in his pride has in effect tried to deny the roots of his own being, and has thereby released destructive forces within hinself, over which he has no control: this ist the grim warning that emerged from the work of these two writers." 1)

Man kann die westliche Rezeption zusammenfassend als zwischen Ansätzen literaturhistorischer Analyse (Themenentwicklung, Figurengestaltung) und interpretativen Wertungen schwankend charakterisieren. Der Versuch der Einordnung der Literatur in auBerliterarische zusamenhänge ist verdienstvoll, findet aber analytisch auf zu niedriger Stufe statt, da das Verhaltnis zwischen literarischer und auberliterarischer Normenentwicklung kaum reflektiert, geschweige denn strukturanalytisch erfaBt wird.

\section{II.3. Rezeptionskontext der Emlgration}

In belden bisher dargestellten Rezeptionskontexten wurde der aktuelle stellenwert der Dorfprosa im gesamtgesellschaftlichen Bewubtseinsprozes betont. Dieser Stellenwert bildet den ausschlieblichen Interpretationsgesichtspunk: im Rezeptionskontext der Emigration, wobei es zu extrem gegensatzlichen Resultaten komnt.

Die radikalste Kritik formuliert Ju. Mal'cev. ${ }^{2)}$ Ihn besciaftigt prinzipiell die Funktion der 'Zwischenraumlite:atur" (promezutocnaja literatura) , d.h. der vermeintlich neutialen, "weder sowjetischen noch aissidenten literatur", die er in scharfer Abgrenzung von der würdigung ihres Kritikpotentials und Realitatsgehalts seitens der westlichen Forsihung in zwel zentralen Argumentationsinien

1) Hosking (1980), aaO, S.81.

2) J. Mal'cev, Promezutocnaja literatura i kriterij podlinnosti, in: Kontinent, 1980, Bd.25, S.285-321. 
bestimut:

1) Der Realismus der " $\mathrm{w} w 1$ schenraumliteratur" sei ein Pseudorealismus. Im Gegensatz zum "Pathos der Aufrichtigkeit" (pafos istiny), zur "Katharsis der Wahrheit" (katarsis pravdy) bei den kritischen Realisten des 19. Jahrhunderts wiederhole die "Zwischenraumliteratur" lediglich allseits Bekanntes und erweitere in keiner Weise das Verstandnis der sowjetischen Gesellschaft. ${ }^{1)}$

2) Angesichts des Abwirtschaftens der alten Schreibnormen füge sich die " $Z$ wischenraumliteratur" genau in das literaturpolitisch erwinschte Konzept, eine Literatur mit kritischem Anstrich zu fordern, die gerade die Besonderheiten des sowjetischen Systems als einer ideokratischen, extrem repressiven und moralisch verfallenen Gesellschaft "maskiere", indem sie diese als normale, mit Fehlern und Mange in wie jede andere Gesellschaft behaftete darstelle. ${ }^{2}$

iervorzuheben ist, daB Mal'cev sich bis auf 2 wei Ausnahmen (Ju: Trifonovs "Dom na naberežnoj", 1976 und $v$. Tendrjakovs "Zatmenie", 1977) ausschlieblich auf Dorfprosa-Texte bezieht. Die spezifische Funktion des Dorfthemas im genannten System beschreibt er so:

"Tut prose izbezat' fal' 1 i. Opisyvaj sebe voschody 1 zakaty, kos'bu 111 pachotu, devic'ju guljanku, nechitryj govor muzikov. Oni ved' ne vedut razgovorov o Staline 1 Brezneve (ill mozno sdelat' vid, tto ne vedut), o rynočnom chozjajstve i socializme, o totalitarizme 1 pljuralizme 1 t.d." 3 )

Den Dorfschriftstellern wirft er eine weitgehende Verharmlosung des tatsächlichen AusmaBes der historischen "Tragodie des russischen Bauerntums" (besonders der Kollektivierung), seiner sozialen und moralischen "Entwurzelung" vor sowie ein "Ubergehen all dessen, was die Beziehungen zwischen staatsmacht und Bauern betrifft". ")

Mal'cevs Problematisierung des literarischen " $2 w i s c h e n-$ rauns" im Spannungsfeld zwischen extegrierter Literatur

1) Mal'cev, aaO, S.292.

2) Ebd., S.317f.

3) Ebd. , S.298.

4) Ebd., S. $298 \mathrm{f}$. 
einerseits und dogmatisch sozialistisch-realistischer

Literatur andererseits ist grundsätzlich sehr verdienstvoll, ${ }^{1}$ beruht in ihrer Konkretisierung allerdings auf Wertung statt Analyse.

Mal'cev stützt sich auf eklektizistische, im Einzelfall sicher zutreffende Beobachtungen, die jedoch aus dem textstrukturellen Zusammenhang gerissen werden. Die "Zwischenraumliteratur" wird darüberhinaus als Ganze aus dem Zusammenhang eines literarischen Entwicklungsprozesses gelost und unabhängig von dessen eigenen Gesetzen unmittelbar auf auBerliterarische Funktionszusammenhänge projiziert. Der Rigorismus in der eigenen Funktionsbestimmung von Literatur - Entlarvung des Gesar:tsystems anstelle Detailkritik ${ }^{2}$, politisch domestizierte Themenstellung (Lager, Parteidiktatur etc.) - ist nicht so weit von der sozialistisch-realistischen Theorie entfernt, nur die politischen Inhalte scheinen ausgewechselt. Die 'kleine Wahrheit' steht einmal der Entlarvung, ein andermal der Verherrlichung der 'großen Wahrheit' im Wege.

Ein Gegenbeispiel ist D. Stoks Aufsatz uber V. Belov. ${ }^{3)}$ (Interessant ist bereits, daB ein in der sowjetischen Kritik besonders 'unkämpfter' Autor, s. IV.2., auch im Emigrationskontext die unterschiedlichsten Funktionalisierungen erfährt.) Stok interpretiert Belov im Sinne eines pantheistischen Ruralismus. Dies seschieht, indem die Figuren dem eigenen Konzept entsprechend interpretatorisch zurechtgeschnitten werden:

"V rasskazach Vasilija Belova nigde, $v$ obstem, ne govoritsja - Boge, potti vse ego geroi - neverujustie, oni o Boge vrode by 1 ne dumajut, no vse ze neizmenno ołxuscaes' Ego nezrimoe prisutstvie $v$ dusach ich, a potomu - $i$ vo vsej toj Zizni, Cto episyvaet Belov." 4)

1) Vgl. zu dieser Problematik bes. E. Etkind, Unblutige Hinrichtung. Warum ich die Sowjetunion verlassen muBte, München-Zürich 1978, den "Exkurs uber 'Leben, ohne $2 u$ lügen'", S.192-202.

2) Mal'cev, aaO, S.309. - Vgl. ebf. die bereits zitierten Vorwüre gegen die Dorfprosa.

3) D. Stok, Zemlja moja rodnaja.... in: Grani, 1978, Nr.110, S. 182-198.

4) Eba., S. 190. 
Es wundert nicht, daB Stok verallgemeinernd $z u$ einer Mal'cev diametral entgegengesetzten Position gelangt. Er exterritorialisiert die neue Dorfprosa gleichsam aus der "sowjetischen 'Kolchosprosa'". ")

Schlieblich sei noch darauf hingewiesen, dab auch in G. Svirskijs "Na lobnom meste" ${ }^{21}$ die Dorfprosa einen nicht geringen Stellenwert zugeschrieben bekommt - d.h. prinzipiell im Kontext der nonkonformen, vom system nicht integrierbaren Literatur verstanden wird. Svirskijs Interpretation von "Na Irtyse" (S. Zalygin, 1964) wirft ein weiteres problem auf: Svirskij macht der sowjetischen Kritik das Recht streitig, den Text "unter ihre Fittiche zu nehmen" 3 ), ohne allerdings die Entsprechungen zwischen Text und Kritik einer Prúfung zu unterziehen. Generell scheint die Tatsache, daB ein nicht unwesentlicher Teil der sowjetischen $\mathrm{Krit}$ k ausgesprochen enthusiastisch auf die Dorfprosa reagierte, und daB gerade die Diskussion uber diesen Text $z u$ den kontroversesten in der gesamten Dorfprosa-Diskussion gehorte, keiner weiteren Problematisierung wert.

\section{II.4. Normeninnovation als Forschungsaspekt}

Abseits von den dargestellten Rezeptionskontexten steht ein bislang vereinzelter Versuch, die Dorfprosa der sechziger Jahre im Rahmen einer strukturevolutionären Analyse der gesamtliterarischen Reihe einzuordnen. In seinem Aufsatz "Thesen zur innovatorischen Poetik der russischen Gegenwartsprosa"4) geht es $w$. Schmid um den Nachweis einer grundlegenden Ablosung des sozialistisch-realistischen Normensystems durch eine "ganzheitlich innovatorische Poetik".

1) Stok, aao, S.197.

2) G. Svirskij, Na lobnom meste, London 1979, die Kapitel "Sergej Zalygin: 'Na Irtyకe"", S.362-367, "Boris Moßaev i Cingis Ajtmatov", S.369-374, "Fedor Abramov", S.375-384, "Vasilij Belov", S. 385-391.

3) Ebd.. S.368

4) W. Schmid, Thesen zur innovatorischen Poetik der russischen Gegenwartsprosa, in: Wiener Slawistischer Almanach, 1979, Bd.4, S.55-93. 
die "auf das Herzstück des sozialistischen Realismus, die Dominanz der sozialpädagogischen Funktion" ziele. " Das Einsetzen des Ablösungsprozesses setzt Schmid mit dem zweiten Tauwetter (1956) an, den eigentlichen Beginn der neuen Literatur sieht er Ende der fünziger/Anfang der sechziger Jahre mit der "Jungen Prosa" (molodaja proza) gegeben, deren führende stelle in der literarischen Hierarchie im Verlauf der sechziger Jahre von der Dorfprosa, der Prosa aus dem Milieu der städtischen Intelligenz (Ju. Trifonov) und den Erzählungen A. Bitovs ubernommen werde. ${ }^{2)}$ zwischen sechziger und siebziger Jahren wird nicht mehr explizit differenziert. Schmid scheint jedoch davon auszugehen, das sich in den sechziger Jahren alle wesentlichen Merkmale der neuen Poetik auf den verschiedenen Strukturebenen herausbilden, sodaB in den siebziger Jahren in cen Personalstilen einzelner Autoren (A. Bitov, Ju. Trifonov, $V$. Rasputin) nur noch eine "Konsolidierung" 3 ) der neuen Poetik auf gesamtstruktureller Ebene erfolgt.

Gerade weil dieser Ansatz unserem eigenen Interesse am nächsten kommt, sind jedoch einige prinzipielle Vorbehalte methodenkritisch $z$ formulieren. Inr Kern besteht darin, das Schmids "idealtypologisches" Vorgehen" $2 u$ einer ahistorischen und afunktionalen Betrachtungsweise tendiert.

1) Es werden alle narrativen Strukturebenen unterschiedslos abgehandelt. Die Frage nach dem verschieden starken Konventionalisierungsgrad auf den einzelnen Ebenen wird nicht aufgeworfen. Insofern entsteht ein radikal 'innovatorisches' Bild, da scheinbar alle wesentlichen strukturebenen mit gleicher Intensität und Repräsentativität am Normenbruch beteiligt sind. - So ist wohl kaum zu bezweifeln, das auf der Ebene des "Themas" die "wiederentdeckte Persönlichkeit", der "komplexe Charakter"
1) Schmid, aao, 5.56 .
2) Vgl. ebd.. S.59.
3) Ebd., S.86.
4) Ebd.. S.56. 
repräsentativ geworden sind. ") schwieriger scheint eine solche Verallgemeinerung jedoch beispielsweise auf den Ebenen des "Sujets" und des "Textaufbaus". Schmid stellt als dominantes Merkmal "der" neuen Poetik auf der Ebene des Textaufbaus den hohen Interferenzgrad zwischen Erzäl.lertext und Personentext heraus ${ }^{2)}$, der mit einer auf der Sujet-Ebene generell zu beobachtenden Tendenz zur Destruktion des für den sozlalistischen Realismus typischen autorbeherrschten sujets korreliere. ${ }^{3)}$ Eine der wesentlichsten Quellen, auf die sich Schmid hier beruft, M. Cudakovas "Zametki o jazyke sovremennoj prozy"4), stellt diese stufe jedoch als berelts von einer neuen, klar autorbeherrschten Erzählweise uberholt dar. Während in der vorhergehenden Stufe die "Person des Autors" (liknost" avtora) verschwunden sei, entwickele sich nun eine Prosa mit klarer, offener Anwesenheit des Autors, der über elne eigene Stimme verfüge. Dieser nehme eine Erzählposition ein. "die uberzeugt ist von ihrer moralischen und sprachlichen Kompetenz". 5)

Insgesamt entsteht so ein $z u$ einheitliches, glattes Bild vom literaturevolutionären ProzeB. Idealtypologisches Vorgehen darf nicht heiBen, die tatsächlich vorhandene Normenkonkurrenz zugunsten einer postulierten einheitlichen neuen Norm $2 \mathrm{u}$ übersehen.

2) Zweifelhaft erscheint die Repräsentativität der behandelten Texte. Schmid tendiert mit der Ablösung der 'Schulen' (Junge Prosa, Dorfprosa) zu einer Paradigmatisierung

1) Vgl. Schmid, aao, S.56.

2) Ebd.. S.79ff.

3) Ebd.., S.64.

4) M. Cudakova, Zametki o jazyke sovremennoj prozy, in: Novyj Mir, 1972, Nr.1, S.212-245.

5) Ebd., S.238. - Inwieweit diese These ihrerseits repräsentative Gültigkeit beanspruchen kann, sei dahingestellt. (Sie ist mit normativem Anspruch formuliert und beruft sich lediglich auf den zum Paradigma erhobenen Autor $F$. Iskander.) Sie kann jedoch nicht als eindeutige Antithese mit Schweigen ubergangen werden. 
einzelner Autoren, hier v.a. A. Bitovs, deren Spezifika zur Norm erklärt werden. ${ }^{1)}$ Hinsichtlich der Dorfprosa betrifft das die ausschliebliche Konzentration auf v. Suksin und V. Rasputin, zwei Autoren, die bereits früh ausgeprägt individuelle Personalstile entwickeln, welche den Rahmen der Dorfprosa am Ende sprengen.

3) Die Bestimmung der Kriterien für die Normenentwicklung auf den einzelnen Ebenen ist ahistorisch. Schmid kommt letztlich nicht uber die Vorstellung von einer Pendelbewegung verabsolutierter ästhetischer Normen hinaus, die zwar im Hinblick auf die kulturtypologische opposition 'Dialogizität' vs. 'Monologizität' ideologisiertwerden, 2) dabei jedoch nicht in ihrem konkret-historischen zusammenhang reflektiert werden, sodaB die historische spezifik der Gegenwartsprosa beispielsweise gegenüber der häufig analog gesetzten dialogischen Prosa Dostoevskijs nicht erhellt. Wenn 2.B. als ein wesentliches Kennzeichen der Dialogizität der neuen Prosa das "Pehlen eindeutiger sinngebungen", die "tiefverwurzelte Skepsis gegenuber monologisch-auktorialen wahrheiten" genannt wird, ${ }^{3)}$ ist dies für die Dorfprosa zunächst einmal in Frage zu stellen angesichts der ihr in den bisher dargestellten Rezeptionskontexten vorherrschend zugeschriebenen Funktion einer positiven Sinnbildung in der Situation einer gesellschaftlichen BewuBtseinskrise. Zur Lösung dieser Frage gelangt man nur, indem man historische Kriterien fur die Normenbeschreibung auf den einzelnen Ebenen findet. Zwei Beispiele:

a) Der Textaufbau ist nicht losgelost von der historisch konkreten Qualität der verwendeten Sprachen, ihren sozialen Trägergruppen etc. zu analysieren. Dies betrifft besonders das Verhältnis zwischen Junger Prosa und Dorfprosa. Für Schmid besteht das innovatorische Potential

1) Dies betrifft 2.B. Bitovs Montageprinzip, vgl. Schmid, aaO, S.86.

2) Vgl. ebd., S.64f,67,70f,86f.

3) Ebd., S.71. 
der Jungen Prosa in der stilistischen "Entliterarisierung" des Personen- und Erzählertexts ("rublenaja rassełennaja fraza", "), wobei der Personentext noch eingebettet bleibe "in die weitgehend auktoriale Narration eines deutlich profilierten Ich-Erzählers". 2) Erst die Dorfprosa innoviere auch das Verhältnis zwischen beiden Textzonen zugunsten einer Dominanz des Personentextes bzw. einer hochgradigen Interferenz, ${ }^{3)}$ womit die Dorfprosa auf eine gesamtinnovatorisch höhere stufe gestellt wird. Dabei gerät auBer Betracht, ob nicht die Rückkehr zu einem "grundsätzlich homogenen Stil"4) (bzw. dem "narodnyj jazyk", s.IV.2.6.) im Gegensatz zu einem aus verschiedenen sprachwelten "montierten Stil"5) (bzw. dem "beznacional'nyj jazyk", s.IV.2.6.) eine entscheidendere (und zwar retardierende) Funktion hat als die Beeinflussung des Erzahlertextes durch den eben jenen homogenen stil realisierenden Personentext.

b) Nur durch die Bestimmung des historisch konkreten Charakters der Wertungskompetenz, die sich das Erzählsubjekt zumiBt, ist auch eine Entscheidung uber dessen monologische oder dialogische Funktion zu fallen. Der profilierte "junge Erzähler" legt beispielsweise besonderen Wert auf seine marginale position, die auch den betont nicht-reprăsentativen, willkürlichen und flexiblen Charakter seiner liertungen bestimmt. Der wertungsauktoriale Ich-Erzähler der Jungen Prosa scheint somit, indem er sich gerade das Recht auf die personliche, individuelle Bewertung der Umwelt nimmt, kulturtypologisch gesehen eher eine dialogische Funktion einzunehmen angesichts eines kulturellen Kontexts, welcher einer solchen Bewertung die Kompetenz abspricht.

1) Schmid, aao, S.74.

2) Ebd., S.75.

3) Vgl. ebd., S.75ff.

4) Ebd.. S.76.

5) Ebd.. S.76. 
III. Zur Entwicklung des Genresystems.

Veränderungen im Genresystem sind wichtige Indices literarischer Evolution. Sie können die Form innerhierarchischer Positionswechsel - z.B. Wechsel der Dominanten oder Absinken eines Genres an die literarische Peripherie annehmen. Sie können auch die Unterscheidungsmerkmale der Genres betreffen und treten in solchen Fälen als verschiebungen oder Aufhebungen der Genregrenzen in Erscheinung. Dieser ProzeB soll unter einigen Aspekten dargestellt werden, die für die Kolchos- und Dorfprosa von Bedeutung sind. Es handelt sich um einen gesamtliterarischen ProzeB; die Genreevolution ist nicht aus den Bedingungen einer literarischen Unterreihe abzuleiten. Von Interesse sind für uns dabei aber die Erscheinungen, die in der Unterreihe einen besonders typischen Niederschlag finden bzw. wesentlich auf ihren Einflus zurückzuführen sind. Die Darstellung gründet sich auf verschiedene, meist in der sowjetunion erschienene Untersuchungen und Kritiken.

III.1. Der Terminus "Zanr" in der sowjetischen Forschung

Bei der Quellendurchsicht entstehen terminologische Probleme. Die sowjetische Forschung besitzt unterschiedliche Verwendungsbereiche für den Terminus "Zanr", vergleichbar mit der uneinheitlichen Verwendung des Terminus "Gattung" im Deutschen. "Zanr" wird sowohl im sinne von "rod" - das entspricht den Textarten Lyrik, Epik und Dramatik - als auch von "vid" - das entspricht den Genres") als Untergliederungen der Textarten - verwendet.

1) Zur Präzisierung des Gattungsbegriffs in "Textarten", "Typen". "Genres/Gattungen" und "Formen/patterns" vgl. die Ubersicht von G. Knapp, Textarten - Typen - Gattungen Formen, in: H.L. Arnold/V. Sinemus (Hg.), Grundzüge der Literatur- und Sprachwissenschaft, Bd.1: Literaturwissenschaft, München (5.Aufl.) 1978, S.258-268. Dieser Beitrag ist weniger um eigene begriffliche Herleitungen als un eine systematisierung des terminologischen Chaos bemulht. Wichtig ist, daB Gattung/Genre (wir verwenden im weiteren ausschlieblich Genre) hier im Unterschied $2 u$ den Textarten (als "Arten der Präsentation 
Dominierend ist die dem Genrebegriff entsprechende Bedeutung ("vid"), doch werden uneinheitliche Konkretisierungen damit verbunden. Das betrifft z.B. den Begriff der "Zanrovaja forma", im "Slovar' literaturoved Keskich terminov"1) als nochmalige Untergliederungen der "vidy" definiert. Die "Zanrovye formy" werden als eigentliche historische Erscheinungsformen der "vidy" und als entscheidender Faktor der Genreevolution verstanden. Sie werden nicht systematisch definiert, sondern lediglich genetisch aus "den Besonderheiten des Lebens, den Besonderheiten des Materials und den Besonderheiten des schriftstellerischen Talents" erklärt. 2) zu den "Zanrovye formy" werden 2.B. sowohl der satirische Roman als 3uch die "lyrische Prosa" (liriteskaja proza) gerechnet. Der Terminus dient also einerseits zur Untergliederung eines Prosagenres (Roman), andererseits zur Bezeichnung einer Mischform von Textarten (Iyrische Prosa). "Zanr" und "Zanrovaja forma" werden oft synonym verwendet, die lyrische Prosa z.B. wird in der Regel als "zanr" bezeichnet.

Man kann für den gegenwärtigen Stand der historischen Genreforschung zwei hauptsächliche Verwendungsweisen des Terminus "zanr" feststellen. Einmal sind die traditionellen Prosagenres (Roman, Povest", Rasskaz, Očerk = "vidy") gemeint, für die es jedoch immer schwerer fällt, andere genreunterscheidenden Merkmale als das der Länge zu

von Texten; S.259) und 2 u den Typen (als "anthropologischgreifbaren Ausdrucksformen" wie dem Tragischen, Komischen etc.. S.261) als "historisch-praomatisch definierte Einheit" (S.262) verstanden wird. Die Konkretisierung der Genres in ihren historischen Erscheinungs formen stützt sich dabei auf ahnlich pragmatisch-relativistische Kriterienauswahl (Thema, Lange, Textarten - z.B. Kriminalroman, Kurzgeschichte, episches Theater, S.264) wie die im folgenden dargestellten Konkretisierungen des sowjetischen "zanr"-Begriffs.

1) Slovar' literaturovedKeskich terminov (Red.-sost. L.I. Timofeev/S.V. Turaev), Moskau 1974.

2) Ebd., S.82f. 
finden. Man spricht häufig synonym von kleinen, mittleren und großen Formen. ') Ergebnis ist die Konstatierung verschiedener Mischformen, die oft einer Auflösung der klassischen Genregrenzen nahkommen.

Dem entgegen steht eine von den traditionellen "vidy" unabhängige Untersuchung der "Kanry". Auf der in Tomsk 1975 veranstalteten Konferenz "Problemy literaturnych Kanrov" wird dieses Begriffsverständnis in einem programmatischen Beitrag A. Subbotins expliziert: Nicht nur die "rody", sondern auch die "vidy" werden als ahistorische Kategorien, als "unbewegliches Koordinatensystem" abgelehnt; stattdessen wird der "Zanr" als historische Kategorie relativistisch definiert:

" Zanr, s tocki zrenija istorika literatury - eto charakternoe, tipicnoe obrazovanie dannogo otrezka 'l1teraturnoj osy', forma celogo, imejustaja preimusxestvennoe 111 dostatolno zametnoe rasprostranenie." 2)

Beispiele solcher "Zanry" sind die "Bekenntnispovest" " (ispovedal'naja povest'), "soziale Phantastik" (social'naja fantastika), lyrische Prosa und "Dorfpovest" " (derevenskaja povest'). Sie können also durch Merkmale unterschiedlichster Art - Thema, Textart, Genre, Typ - in verschiedenster Kombination definiert sein; Kriterium für ihre Konstituierung zum "zanr" ist einzig und allein ihre "Verbreitung".

1) Vgl. L.I. Timofeev, Osnovy teorii literatury, Moskau 1971, S.359f. - Timofeev spricht sich für eine Ersetzung der traditionellen Termini durch "kleine" "mittlere" und "grobe Formen" aus. Obwohl als Unterscheidungsmerkmal die Darstellung des Menschen genannt wird, ist diese Klassifizierung als Ausdruck der Schwierigkeit anzusehen, andere als quantitative (Längen-) Kriterien zur Genreunterscheidung aufrechtzuerhalten. Das Kriterium der Menschendarstellung wird dementsprechend in rein zeitliche Dimensionen präzisiert: Die kleine Form zeige den Menschen in einer einzelnen Episode, die mittlere zeige ihn in einer Lebensperiode bzw. einer Reihe von Episoden, die große während des gesamten Lebenswegs.

2) A.S. Subbotin, o kategorii Kanra i ee otnosenijach s "rodami" 1 "vidami", in: Problemy literaturnych Kanrov. Materialy vtoroj nautnoj mezvuzovskoj konferencii 30 sentjabrja - 4 oktjabrja 1975 goda, Tomsk 1975, S.4. 
Im Zusammenhang der Forschung über die lyrische Prosa wird die Forderung nach einer prinzipiell neuen GenreTerminologie angesichts des herrschenden Begriffs-Wirrwarrs erhoben. 1)

III.2. Oxerk und Rasskaz in den fünfziger Jahren

Für die fünfiger und sechziger Jahre gilt generell die Dominanz kleiner und mittlerer Formen uber die Grobform des Romans. Eindeutige Dominanz in den fünfziger Jahren besitzen Oterk und Rasskaz. Für die Kolchosprosa wird dieses Verhältnis von $V$. Oveckin im Hauptreferat der vom Schriftstellerverband veranstalteten Konferenz der Kolchosschriftsteller (1955) unterstrichen. ${ }^{2)}$

Die Funktion des orerk in gesamtliterarischen ProzeB wird in mehreren Beitragen des 1958 von der journalistischen Fakultăt an der MGU herausgegebenen Sammelbands "Ob očrke" 3) behandelt. Um die neuen, nachstalinistischen gesellschaftlichen Bedingungen, die Umbrucherscheinungen in den verschiedenen Lebensbereichen, kurz: das "neue Lebensmaterial" (novyj ziznennyj material) darstellen zu können, sei die lberwindung der "toten Schemen", besonders der pseudograndiosen, verschönernden Monumentalwerke notwendig geworden; dieses Verdienst wird dem oxerk zugeschrieben. ${ }^{4}$

Innerhalb der Initiativfunktion des oxerk besitzt der Kolchos-oterk eine Schlüsselrolle. In der Einleitung

1) Vgl. E.A. Bal'burov, Liriteskaja proza v literaturnom processe 1950 - 1960-ch gocov, in: Russkaja literatura, 1979, Nr.2, S.57.

2) Die Materialien dieser Diskussion sind veröffentlicht im Sammelband ' $Z_{i z n}$ ' kolchoznoj derevni $i$ literatura. TvorCeskaja diskussija v sojuze Pisatelej SSSR" (Red. K.I. Bukovskij), Moskau 1956. Das Referat Oveckins wird im weiteren zitiert nach der Erstverbffentlichung: V. Overkin, Kolchoznaja $Z_{i z n}$ i literatura, in: Novyj Mir, 1955, Nr.12, S.116-145.

3) Ob oterke. Sbornik statej (Red. P.F. Jušin), Moskau 1958.

4) V. Calmaev, Problemy charaktera $v$ oxerkach v. Tendrjakova, in: Ob ocerke, aaO, S.119; vgl. ebf. A. Kogan, Zizn', Zanr, masterstvo, in: Ob ocerke, aao, S.145 und Ovečkin, aao, S.131. 
des Sammelbands wird die ausschliebliche Behandlung von Kolchos-okerki mit ihrer quantitativen und qualitativen Dominanz begründet. Diese hänge damit zusammen, daB das Kolchosthema das "wichtigste Gegenwartsthema" sei. 1)

Deutlichen Ausdruck der innovatorischen Funktion des oxerk (sowie des genreevolutionären Faktors im literarischen Normenwandel uberhaupt) gibt bereits die Kolchosschriftstellerversammlung von 1955, auf der sich mit $v$. Overkin und G. Nikolaeva die Hauptrepräsentanten des innovatorischen und des konservativen Flügels der Kolchosschriftsteller gegenüberstehen (s.IV.1.1.). Overkin verbindet sein Engagement fur eine unverfälschte Darstellung der Wirklichkeit mit einer scharfen Kritik an der iblichen Abwertung des Orerk zu einem minderwertigen, an der literarischen Peripherie befindichen, rein dokumentarischen Genre. ${ }^{2)}$ Nikolaeva macht demgegenuber das Prinzip des "Typischen" (tipiCnost') - im Sinne der Abgrenzung von blober Detailtreue - geltend; der "informatorischen" Analyse sozialökonomischer Bedingungen stellt sie die "literarische" Darstellung der "Menschenseele" entgegen. ${ }^{3)}$ Mit einer polemischen Auberung gegen Oveðkin, dessen Referat sie als "Auftritt eines oxerkisten anstelle eines Schriftstellers" bezeichnet, ") schliebt sie den oxerk gleichsam aus der Literatur aus. Diese Polemik trägt ihr die Kritik der Mehrheit der Diskussionsteilnehmer ein.

Auffallig an der oxerk-Diskussion der funfziger Jahre ist die Schwierigkeit, die Spezifik des Genres zu bestimen. Gegenuber der Abwertung des Oxerk zum nichtliterarischen Dokument wird immer wieder die besondere Form der Verbindung von fiktionalen und nichtfiktionalen, kunstlerischen

1) Ob ocerke, aao, S.4.

2) Oveckin, aao, S.130. - Dieses Enqagement für die Literarizität des OCerk macht gleichzeitig den Abstand der neuen oderkistengeneration zum faktographischen Anspruch der Oxerk-Bewegung in den zwanziger Jahren deutlich.

3) G. Nikolaeva, o nesostojatel'nosti vystuplenija $v$. Oveckina, in: $Z_{i z n}{ }^{\prime}$ kolchoznoj derevni, aao, s.184ff.

4) Ebd., S.182f. 
und journalistischen Darstellungsweisen betont. P. Jusin ${ }^{1)}$ lehnt die Trennung von "fakt" und "vymysel" als schematisch ab und betont die dialektische Einheit beider sowohl im Rasskaz als auch im ocerk. Die Differenzqualität sieht er in der unterschiedlichen Funktion beider Elemente in den jeweiligen Genres. Im Rasskaz spiele der "fakt" eine untergeordnete, dienende Rolle gecenüber der Charaktergestaltung des Helden und anderen Faktoren des "vymysel",2) ir. oterk sei letzterer hingegen der Analyse eines konkreten Ereignisses der Realität untergeordnet. 3 )

In der Anwendung auf Texte erweisen sich auch solcherart relativierte Genremerkmale als klassifikatorisch irrelevant. v. Calmaev hebt für die oterki v. Tendrjakous den hohen Stellenwert der Charakterdarstellung hervor: im Gegensatz zur Genrespezifik des physiologischen oterk (V. Dal': Skizze ohne Schatten) seien die "psychologischen Schatten" der Charaktere von besonderer Bedeutung. ${ }^{4)}$ Die zentrale Bedeutung des "vymysel" in den oterki v. Ovetkins wird von $M$. Lapsin betont. ${ }^{5)} M$. Xerepachov sieht in der literarischen Praxis der fünfiger Jahre den Beweis, daB das "Bild" (obraz) im oxerk nicht von den Bildern in Rasskaz, Povest' und Roman $z u$ unterscheiden sei. ${ }^{6)}$

1) P. JuŠin, o Zanre očerkovoj literatury, in: ob ołerke, aao, S. 36-54.

2) Ebd., S.42.

3) Ebd.. S.45. - Zum Verhältnis von "fakt" und "vymysel" im očerk der fünfiger Jahre vgl. ebf. Slovar' literaturoved ceskich terminov, aaO, S.254f. Im oterk sei zwar das "Dokumentarische" vorherrschend, doch enthalte der sowjetische ozerk obligatorisch die revolutionäre Leicenschaft und den historischen optimismus als Faktoren des "vymysel". Im Gegensatz zum faktographischen Dokumentarismus wird die Darstellung des "verallgemeinerten" (obobscennyj) Helden "ohne Adresse" (neadresnyj) betont.

4) Calmaev, aaO, S.107.

5) M. Lapšin, "Rajonnye budni" Valentina Ovečkina, in: $\mathrm{Ob}$ ołerke, aao, S.64ff.

6) M. Cerepachov, Glubokie korni. Ob okerkach Anatolija Kalinina, in: ob oðerke, aao, s.220f. 
Faktisch wird für alle behandelten Autoren die Aufhebung der Grenze zwischen Oterk und Rasskaz (bzw. Povest') sowie die Bildung von Mischformen konstatiert.

"Rajonnye budni" (V.Ovečkin, 1952) viird als "ołerkovaja povest."1), "Lunnye noti" (A. Kalinin, 1955) als "oterk-povest." 2 ) bezeichnet; "Razgovor s Pisleginym" (S. Zalygin, 1954) enthalte mindestens so viele RasskazElemente wie oxerk-Elemente. ${ }^{3)}$

Die enge Verwandtschaft zwischen oterk und Rasskaz wird auch in der neueren Rasskaz-Forschung betont. Als deutliches Indiz gilt die Doppelbetätigung der meisten Kolchosschriftsteller als OXerk- und Rasskaz-Autoren.

Von besonderem Interesse ist der EinfluB des ocerk auf die Entwicklung des Rasskaz. Auf der Tomsker GenreKonferenz halt E.A. Safronova ein Referat zu diesem Thema. ") Die Bedingungen der Umbruchperiode seien die Ursache dafür, daB das Gravitationszentrum samtlicher Prosagenres jener Zeit die "OCerk-Spezifik" (ołerkovaja specifika) bilde. ${ }^{5)}$ Der oxerk habe die Möglichkeit der für den Rasskaz der fünziger und sechziger Jahre typischen Vermischung von objektiver Erzăhlweise und subjektiver Darstellung gegeben. Die Polyfunktionalität der Erzăhlerfigur als Charakteristikum des ocerk sei die Grundlage für die Trennung von "Autor" und "Erzähler" sowie für die Wertungsvielfalt (mnokestvennost' ocenok odnogo 1 togo Ze javlenija) im Rasskaz. 6)

Dasselbe Problem untersucht K. Kasper. ") In den behandelten Texten (wie bel Safronova ausschlieblich Kolchostexten) sieht er die genrespezifischen Merkmale

1) Laptin, aao, S.62.

2) Cerepachov, aaO, S.209.

3) Kogan, aao, S.156.

4) E.A. Safronova, Rasskaz i oterk 50-ch godov. K probleme vzaimovlijanija Zanrov, in: Problemy literaturnych Zanrov, aao, S.159-160.

5) Ebd., S.159.

6) Ebd.., S.160.

7) K. Kasper, Die Entfaltung der sowjetischen Skizze und ihr EinfluB auf die Erzahlung in der Nachkriegszeit, in: Zeitschrift für Slawistik, 1971, S.419-430. 
des Oterk (Problemdarstellung) und des Rasskaz (Charakterdarstellung) zu einer unauflöslichen Genreheterogenität vereinigt. Der EinfluB des ocerk auf den Rasskaz wird an der starken orientierung des letzteren an aktuell zu lösenden Problemen festgemacht. ') Einen weiteren zusammenhang sieht Kasper in der zyklisierten Erzählform. Die für den ołerk der fünfiger Jahre typische Erscheinungsform in zyklen mit einem gemeinsamen Erzähler/Journalisten als verbindendem Zentrum habe die beispielsweise furr $G$. Troepol'skij charakteristischen Rasskaz-zyklen sowie die späteren zyklisch strukturierten gröBeren Formen (s.III.3.) beeinfluBt. 2)

Im gesamtliterarischen Maßstab wird allgemein der Rasskaz als seit 1953 dominierendes Genre betrachtet. Die für die Kolchosprosa konstatierte Mischform wird in das Genre integriert. E. Subin bezeichnet den oxerk als "Spielart des Rasskaz" 3). A. Ognev nennt als Haupterscheinung der fünfiger Jahre den "problemnyj rasskaz" und rechnet dazu typische Beipiele der Mischform wie "Rajonnye budni" und "Na srednem urovne" (A. Kalinin, 1953). 4)

Ähnlich wie beim Ocerk wird die Ursache für die Verbreitung des Genres in der situation der gesellschaft-

1) VGl. Kasper, aaO, S.422f. Vgl. ebf. Terakopjan, aao, S.262: "Takie fundamental'nye zanry prozy, kak povest" $i$ roman, poroj slovno by pytalis' sorevnovat'sja s oterkom $v$ bystrote otklika na proischodjastee, $v$ praktiteskom vmesatel'stve $v$ Kizn'." Zum "duch issledovanija" bzw. "pafos issledovanija" als Merkmal der Oterkhaftigkeit aller Prosagenres vgl. F. Kuznecov, Novoe v zizni i novoe $v$ Iiterature, in: Novyj Mir, 1961, Nr.1, S.235.

2) Vgl. Kasper, aaO, S.429. Allgemein zu den Beziehungen zwischen oxerk und Rasskaz vgl. ebf. A.I. Pavlovskij. Rasskaz 50-ch godov, in: Russkij sovetskij rasskaz. OZerki istorii Kanra (Red. V.A. Kovalev), Leningrad 1970, S.573-625, hier bes. S.575ff.

3) E. Subin, Zanr rasskaza $v$ literaturnom processe, in: Russkaja literatura, 1965, Nr.3, S.46.

4) A. Ognev, Russkij sovetskij rasskaz 50 - 70-ch godov, Moskau 1978, S.28. Zur "Problemhaftigkeit" (problemnost') als Merkmal des Rasskaz der fünfziger Jahre vgl. ebf. T.P. Zamorij, Sovremennyj russkij rasskaz, Kiev 1968, S.9. 
lichen Erneuerung gesehen, wobei neben den ökonomischen und politischen Aspekten besonders der moralische Aspekt betont wird. Der Rückbesinnung auf das Individuum und seine moralische Eigenverantwortlichkeit entspreche der Rasskaz mit seiner Konzentration auf die Verhaltensweisen des einzelnen Menschen in einer bestimmten situation. ${ }^{1}$ Die Konzentration auf den Ausschnitt, die Situation, das Detail im Gegensatz zur Totalen verbinde sich mit einer unabgeschlossenen Fabelkonstruktion (offenes Ende) als Ausdruck der Unfertigkeit des neuen welt- und Menschenbildes. Subin generalisiert den Rasskaz zum typischen Genre historischer Ubergangsepochen:

"V 'perechodnye' periody istorii, kogda probuzdajustajasja obstestvennaja tendencija esce ne oboznacalas' $v$ dostatoknoj mere, kogda u pisatelja exte net vozmoznosti uvidet' 1 osmyslit étot novyj obscestvennyj process $v$ celom, $v$ ego perspektivnom razvitii, imenno $v$ éti 'perechodnye' periody zanr rasskaza stanovitsja dominirujustim po svoej social'noj znacimosti $11 i$ voobste $v$ literature dannogo vremeni, $11 i$ ze $v$ razrabotke kakich-libo ee otdel 'nych tem 1 problem." 2)

\section{Als Indices für die Dominanz des Genres gelten:}

- die Veröffentlichungspolitik der zeitschriften (Ognev bestimnt u.a. aufgrund der Quantitatsrelationen in den Prosateilen wichtiger Literaturzeitschriften zwei Dominanzphasen des Genres: 1941 - 1945 unf 1953 - 1970.3),

1) Vgl. Subin (i965), aaO, S.51: "Pravilen ili neveren, étičen $11 i$ neetiłen byl 'Zest', otvetnaja reakcija otdel'nogo Celoveka na vozdejstvie izvne, na slozivłujusja situaciju, vnesnjuju ili vnutrennjuju - vot na tem stroitsja osnovnaja problematika sovremennogo rasskaza." Generell wird die Entwicklung einer moralischen Problematik erst mit der zweiten Hälfte der fünfiger Jahre angesetzt. Entsprechendes gilt fur die Kolchosprosa, wo mit $V$. Tendrjakovs und $E$. Doross seit 1956 erschienenen Erzählungen die zunehmende Konzentration auf die moralische Eigenverantwortlichkeit des Menschen betont wird. Vgl. Terakopjan, aaO, das Kapitel "Utverzdenie otvetstvennosti", S.262-287; Surganov (1975i, S. 312ff; Pavlovskij (1970), aaO, S.581ff.

2) Subin (1965), aaO, S.40.

3) Vgl. Ognev, aaO, S.8f. 
- das Erscheinen mehrerer Rasskaz-Sammelbände seit 1952 ${ }^{11}$

- verschiedene literaturkritische Diskussionen über den Rasskaz ${ }^{21}$

- metapoetische AuBerungen von Schriftstellern über den Rasskaz ${ }^{3)}$.

III.3. Rasskaz und Povest' in den sechziger/siebziger Jahren

Seit Mitte der sechziger Jahre gewinnt die Povest ' an Bedeutung und wird Ende der sechziger Jahre zum literaturkritischen Diskussionsgegenstand. ") Ihre Dominanz in der Dorfprosa stellt $V$. Protłenko (1970) bereits für die Jahre

1) 1952 erscheint eine dreibändige Anthologie sowjetischer Rasskazy seit 1917, deren Auswahl noch stark vom Normenkanon der Żdanov-Ära geprägt ist, auf der anderen Seite aber die extreme Nichtbeachtung des Genres im Verhälnis zu den groBen Formen beendet (Rasskazy russkich sovetskich pisatelej v trech tomach, Moskau 1952). Diese Anthologie wird 1957 mit modifizierter und durch aktuelle Erzählungen erweiterter Auswahl neu herausgegeben. 1954 erscheint ein Sammelband mit Erzählungen aus den Jahren 1951 und 1952 (Rasskazy 1951-1952, Moskau 1954). Rasskazy der Jahre 1955-1962 werden in jahrlich folgenden Sammelbänden (Rasskazy 1955 goda, Moskau 1956 ... Rasskazy 1962 goda, Moskau 1963) herausgegeben. Rasskazy dominieren auch im Prosabereich des normeninnovatorisch bedeutsamen Veróffentlichungsprojekts namhafter Tauwetter-Repräsentanten, Literaturnaja Moskva, Bd.2, Moskau 1956.

2) Seit 1953 erscheinen mehrere literaturkritische Grundsatzartikel zum Rasskaz. Vgl. bes. Zvezda, 1953, Nr.3 mit einem Artikel über S. Antonovs Erzählungen (A. Soskin, Vozmoźnosti Kanra, S.145-158), einem Vergleich zwischen Kechovs und Antonovs Erzählungen ( $\mathrm{K}$. Barskaja/M. Sneerson, 2a osvoenie masterstva, S.159-166) und einer Rezension der 1952er-Anthologie (L. Gladkovskaja, Sovetskij rasskaz, S.169-175). In den sechziger Jahren vgl. bes. das Rundtischgespräch "Rasskaz Segodnja" in: Voprosy literatury, 1967, Nr.7, S.55-93.

3) 1952 erscheinen in mehreren Nummern der "Literaturnaja Gazeta" S. Antonovs "Pis'ma o rasskaze", oft zitiert und 1964 als Buch neu herausgegeben (Pis'ma o rasskaze, Moskau 1964). Für die sechziger Jahre vgl. bes. v. Astaf'ev, Rasskaz - ljubimyj Zanr, in: Literaturnaja Gazeta, 19.4.1967, S.4.

4) Vgl. bes. die Diskussion uber die Povest' in: Zvezda, 1968, Nr.5, S.190-215. 
1967 und 1968 fest. ${ }^{1)}$ Die umfangreiche Diskussion uber die Dorfprosa, welche in den Jahren 1967 und 1968 in der "Literaturnaja Gazeta" gefürt wird (s.IV.2.2), hat ausschlieblich Povesti zum Gegenstand.

Der genreevolutionăr entscheidende zusammenhang besteht zwischen Povest' und Rasskaz. ') Seit Anfang der siebziger Jahre vollzieht sich der Niedergang des Rasskaz. ¿. Ajtmatov stellt auf dem 5. KongreB des Schriftstellerverbandes der UdSSR (1971) die qualitative Erstarrung des Genres fest. ${ }^{3)}$ Ognev konstatiert den quantitativen Rückgang in den Zeitschriften seit 1970. ${ }^{4)}$

1973 wird in der "Literaturnaja Gazeta" eine Diskussion uber den Rasskaz geführt, in der das Schicksal des Genres insgesamt zur Sprache kommt. M. Xudakova und A. Xudakov sehen die Ursache für den Aufstieg der Povest' zum dominanten Genre in der Konventionalisierung und Abnutzung des Rasskaz. 5) Der Rasskaz sei zu einem festgefügten, reglementierten Genre geworden, das stark von der literarischen Tradition (Bunin, Cechov) vorgeprăgt sel. Die "kurze Povest" " (korotkaja povest') entledige sich - bei Wahrung aller Vorteile cier kleinen Form - dieser Einschränkungen. Die Fabel bleibe unabgeschlossen, es fehle aber der für den

1) V.I. Protとenko, Sovremennaja povest' o derevne. K probleme narodnogo charaktera, in: Russkaja literatura, 1970, Nr.4, S.62-74.

2) Die Povest' zählt nicht zu den groBen Formen. Die Grenze zwischen groBen und kleinen bzw. mittleren Formen verlauft zwischen Povest' und Roman. Protkenko (1970) sieht das Unterscheidungsmerkmal der Povest' zum Roman in der Konzentration auf einen konkreten Bereich, auf den Charakter und die Verhaltensweisen der darin lebenden Menschen und ihre Lebensbedingungen (S.63). In der deutschen Terminologie gehoren Povest' und Rasskaz zur "Erzăhlung" oder "kleinen Prosa".

3) Pjatyj s-ezd pisatelej SSSR. 29 ijunja - 2 ijulja 1971 goda. StenografiCeskij ottet, Moskau 1972, S.83f.

4) Vgl. Ognev, aaO S. 30 .

5) M. Cudakova/A. Cudakov, .... togda prichodit povest', in: Literaturnaja Gazeta, 29.8.1973, S.6 (im weiteren $21 t$. nach ebd.). - Hier steht der evolutionare Untersuchungsaspekt (genresystem-immanente Funktionszusammenhänge) im Vordergrund gegenüber dem allgemein dominierenden genetischen Aspekt. 
Rasskaz obligatorisch gewordene metaphorische letzte Satz. Die "Autorenposition" sei weniger eindeutig festgelegt als im Rasskaz. In Raum- und zeitstruktur sowie in der Figurenkonstellation seien weniger kompositorische Beschränkungen vorhanden. Cudakova und Xudakov bezeichnen diese neue Form als Mischform der "povest'-rasskaz". Auf einen weiteren Zusammenhang zwischen Povest' und Rasskaz weist ein Aufsatz $E$. Subins über verschiedene Typen der Beziehung zwischen Sujet und Charakterdarstellung im Rasskaz hin. ') Subin unterscheidet drei Typen. Die ersten beiden - a) unerwartete Situation, die zur Enthullung des Charakters des Helden fuhrt, b) unerwartete situation, die zu Veränderung bzw. Bruch im Charakter des Helden fuhrt - sind mit der traditionellen Novellenform (unerhörtes Ereignis) verwandt; sie werden besonders mit der Umbruchsituation der funfiger Jahre in Verbindung gebracht. Ein dritter Typ hingegen, der erst in der zweiten Halfte der fünziger Jahre entwickelt wird - als Paradigmatext gilt "Sud'ba ¿eloveka" (M. Solochov, 1956) - und in den sechziger Jahren Verbreitung findet, stellt einen ganzen "Lebensabschnitt" (kusok Zizni) dar, in dem sich der Charakter des Helden entwickelt oder in seiner Konstanz beweist. Dieser Typ wird als eine typische Povest'-Konstruktion bezeichnet. ${ }^{21}$

Subins dritter Typ deckt sich z.T. mit dem sog. "fabellosen Rasskaz" (besfabul'nyj rasskaz). Damit wird eine Erzăhlung bezeichnet, deren Fabel nicht auf einem Ereignis oder einer handlungstrukturierenden Ereignisabfolge beruht. T.I. Rybal'Cenko ${ }^{3)}$ untersucht die evolutionäre Funktion dieses Typs furr die Povest' der sechziger Jahre. Als Funktionen des "fabellosen Rasskaz" werden genannt: die Darstellung menschlichen Verhaltens auBerhalb besonderer situationen

1) É. Subin, Principy raskrytija charaktera $v$ sovremennom russkom rasskaze, in: Russkaja literatura, 1966, Nr.2, S.29-43.

2) Ebd., S.40. Vgl. zu dieser Spielart des Rasskaz ebf. Pavlovskij (1970), aao, S.598ff.

3) T.I. Rybal' Cenko, Besfabul'nyj rasskaz 60-ch godov 1 razvitie sovremennoj povesti, in: Problemy literaturnych Kanrov, aaO, S.180-183. 
sowie die extreme Verbergung des "Autorenstandpunkts".

Als spezifische Merkmale gelten

a) die Ausgrenzung eines Lebensabschnitts

b) die Dominanz der psychischen Reaktion des Helden uber äuBeres Handeln

c) die deutlich auf den Helden orientierte phraseologische Perspektivierung (Ich-Erzăhlung bzw. uneigentlichdirekte Rede)

d) die Destruktion der sujetkontinuität durch "zufälige" Einzelheiten, Details, Figuren

e) das Fehlen des klassischen Handlungsaufbaus. 1)

Die Povest' der sechziger Jahre ubernehme die Funktion der Darstellung menschlichen Verhaltens auBerhalb besonderer Situationen, die Darstellung des "Lebensflusses" (potok Xizni) sowie die Konzentration auf BewuBtseinsmechanismen, besonders auf den prozeB der Herausbildung von Entscheidungen oder auf die Situation des Bilanzziehens. 2)

Eine andere Erscheinungsform der Genreheterogenitat ist die "Povest" in Novellen" (povest' $v$ novellach, bzw. roman $v$ novellach). Hier werden in zyklischer Form mehrere Rasskazy (die allerdings entgegen dem miBverständlichen Begriff "Novelle" nicht unbedingt ereignishaft sein mulssen) miteinander verbunden; der Zusammenhang wird v.a. uber den identischen Erzăhler, meist auch über die räumliche Einheit hergestellt. ${ }^{3)}$ Diese Form findet in der Dorfprosa ihre besondere Ausprägung in Texten wie "Kaplja rosy" (V. Solouchin, 1960), "Chleb - imja sušXestvitel'noe" (M. Alekseev, 1964), "Ilpjagi" (S. Krutilin, 1965), in denen ein Dorf den Rahmen für verschiedene, z.T. auf einzelne Hauser verteilte Episoden bildet. Diese Form ist Gegenstand unterschiedlicher genreterminologischer Bestimmungen. Sie wird wieder stark mit dem okerk in Verbindung gebracht, da sie in oft foto-

1) Rybal' 'enko, aao, S.181f.

2) Vgl. ebd., S.182f.

3) Zur "Povest" in Novellen" vgl. bes. G.I. Sakun, Nekotorye Zanrovye Certy povesti $v$ novellach, in: Zanry i stili literatury socialistiCeskogo realizma. Sbornik trudov (Red. F. Vlasov u.a.), Moskau 1973, S.234-246. 
graphischer Detailtreue Dorfrealität dokumentiere und durch autobiographische Elemente den Fiktionscharakter einschränke. ") Unter anderen Aspekten wird v.a. "Kaplja rosy" zum Prototyp der lyrischen Prosa.

\section{III.4. Lyrische Prosa}

Der Begriff "lyrische Prosa" (liriCeskaja proza) wird unterschiedlich verwendet. Meist wird darunter ganz allgemein eine besonders emotionale, gefühlvolle Prosa verstanden. Gegen diese unbestimmte, eher stilorientierte Verwendung wird von anderer seite geltend gemacht, daB die genremäBige spezifik nicht erfaBt wird.

Eine genremäBige Definition wird im "Slovar' literaturovedXeskich terminov" angestrebt. ${ }^{2)}$ Die lyrische Prosa wird als lyrisch-epische Mischgattung bezeichnet; hier steht also der "rod"-Aspekt des "Zanr"-Begriffs im zentrum. Als spezifisch lyrische Eigenschaften werden das "Erleben" (perezivanie) - im Gegensatz zum epischen Erzählen - und die damit verbundenen Merkmale der "Unmittelbarkeit" und des "Augenblickscharakters" (neposredstvennost', sijuminutnost') genannt. Das für die Lyrik charakteristische Fehlen eines sujets und die epische sujethaftigkeit vermischten sich im sog. "lyrischen sujet", das durch den Strom der Erlebnisse und nicht durch Handlungskontinuität und damit verbundene Kausalzusammenhänge strukturiert sei. Vorherrschend sei ein assoziatives Kettungsprinzip, die Dimension zeitlicher Erstreckung könne ganz fehlen. Als Hauptformen gelten das Reisetagebuch und die lyrische Autobiographie. Als Prototyp der letzteren gelten "Dnevnye zvezdy" (0. Berggol'C, 1959) und "Kaplja rosy".

Das Erleben und sein Augenblickscharakter, ausgedrückt in der assoziativen Sujetkonstruktion bis hin zur Aufhebung jeglicher zeitdistinguiertheit, macht auch für V. Pavlovskij

1) VGl. G.I. Sakun, Nekotorye osobennosti tipizacii v sovremennoj povesti o derevne, in: Russkaja literatura, 1973. Nr.2, S. 165 .

2) Timofeev/Turaev, aao, S.175ff (im weiteren zit. nach ebd.). 
den eigentlich lyrischen Bestandteil dieses eigenständigen "Zanr" aus. "1)

Andere Kriterien der Definition fordert $\dot{\mathrm{E}}$. Bal'burov. ${ }^{2}$ Auch für ihn steht der "rod"-Aspekt im zentrum, allerdings setzt er die Differenzqualität zwischen Epik und Lyrik in der unterschiedlichen subjektstruktur, konkret: in der unterschiedlichen Position und den unterschiedlichen Eigenschaften des "Autors" an. In der Lyrik sei das künstlerische Bild unmittelbar und ausschlieBlich mit der Person des "Autors" verbunden, wenn Figuren existierten, dann ohne eigenes Sehen und Verstehen der Welt. In der Epik gebe es hingegen eine vielschichtige subjektstruktur (sub-ektnaja mnogoplannost'), welche "Autor" und Figuren einschlieBe. ${ }^{3)}$ Mithilfe dieses Kriteriums wird die Unterscheidung zwischen lyrischer und "psychologischer" bzw. "subjektiver" Prosa möglich. Wăhrend die erste als eigenständige Genre-Grenzform mit unmittelbarer Anwesenheit des "Autors" in Werk definiert wird, welche monologisch und ausschlieBlich von der "Autorenrede" geprägt sel, zeichne sich die psychologische prosa als figurenorientierte Prosa gerade durch sozialsprachliche Charakteristik, stilistische Mehrschichtigkeit etc. aus. ")

Alle Definitionen sind sich einig in der Bestimung des funktionalen zusamenhangs der lyrischen Prosa mit Veränderungen im gesellschaftlichen BewuBtsein. Diese Veränderungen betreffen das Verhältnis zwischen Individuum bzv. Persönlichkeit (licnost') und Gesellschaft bzw. Geschichte. In mehr oder minder deutlicher Formulierung erklärt man die lyrische Prosa als Reflex auf die Neuentdeckung des Individuums und seines Eigenwerts im Gegensatz zu einem deterministischen Weltbild, welches dem Individuum die bloBe Funktion der vollstreckung sozialer und histori-

1) A.I. Pavlouskij, o liriłeskoj proze. Ol'ga Berggol'c i Vladimir Solouchin, in: Vremja, Pafos, Stil'. Chudoßestvennye teไ̌nija $v$ sovremennoj sovetskoj literature (Red. V.V. Buznik/V.A.Kovavleva), Moskau-Leningrad 1965, $S .254 \mathrm{f}$ und $260 \mathrm{f}$.

2) Vgl. Anm. 1 auf S.44.

3) Bal'burov, aaO, S.65.

4) Ebd.. S.67. 
schen GesetzmäBigkeiten überläBt. Bal'burov faBt dies in der Opposition "Mensch in der Geschichte" vs. "Geschichte im Menschen" (Celovek v istoril, istorija v Celoveke, zusammen. ") Diese Rückbesinnung auf die Eigenwertigkeit (und Eigenverantwortlichkeit) des Individuums erklart auch das Pathos des "Bekenntnisses" (ispovedanie), welches vielen Texten der lyrischen Prosa zugeschrieben wird.

In der Literaturkritik wird die lyrische prosa nur unter diesem Aspekt des Verhältnisses zwischen Individuum und Gesellschaft diskutiert. Dabei wird der Begriff nicht genrespezifisch, sondern in der eingangs erwähnten erweiterten Bedeutung verwendet. (Ein zweites Verwendungsgebiet, besonders unter dem Aspekt des "Bekenntnisses", ist die Junge Prosa, - oft auch synonym: "Bekenntnisprosa". 2), Die entscheidende Opposition ist die zwischen lyrischer und "analytischer" Prosa. Im Kern geht es um das alte Problem des Verhältnisses zwischen Subjektivität und Objektivităt der Darstellung. Lyrische Prosa wird häufig pejorativ verstanden im sinne eines subjektivismus, der sich besonders in der isolierten Darstellung der Person (iilnost') vom Volk (narod), im fehlenden Interesse für die Weiterentwicklung der sozialökonomischen Bedingungen und als Resultat im Pathos der Passivität und des Leidens ausdrücke. Die Dorfprosa-Diskussion von 1967 und 1968 steht ganz im zeichen dieser Opposition (s.IV.2.2.).

1) Bal'burov, aaO, S.59.

2) Zur Diskussion der lyrischen Prosa im Zusamenhang der Jungen Prosa vgl. bes. A. Siskina, Zizn', liriłeskaja ispoved' i voprosy masterstva, in: Neva, 1964, Nr.2, s.181-188. - Siskina meint mit der lyrischen Prosa die "Bekenntnisprosa" (ispovedal'naja proza) der zeitschrift "Junost". Sie wirft den Autoren einen an der "westlichen Krise des Incividuums" orientierten Subjektivismus, besonders hinsichtlich der Erzählergestalt (malen'kij Celovek), und Privatismus vor. Das subjektive und bekenntnishafte Pathos ist hier ausreichendes Kriterium für die Verwendung des Begriffs "lyrische Prosa". 
IV. Literaturkritik

Das Spektrum literaturkritisch normenbildender Instanzen reicht von Rezensionen einzelner Texte bis hin zu GesantEinschätzungen der sowjetischen Iiteratur und umfaBt sowohl die literaturkritische Publizistik als auch offizielle Werturteile auf der Ebene von Schriftstellerkongressen oder Parteidokumenten. Innerhalb dieses Spektrums soll im folgenden der Schwerpunkt auf einige Grundsatzartikel und Diskussionen gelegt werden, welche die zentralen Aspekte der literaturkritischen Normenbildung für die gesamte Unterreihe verdeutlichen. Die Normenformulierung auf den Schriftstellerkongressen soll einbezogen werden, insofern sie sich uber allgemeine Richtlinien fur die gesamtliterarische Reihe hinaus auf die Kolchos- und Dorfprosa bezieht. Zur normenbildenden Instanz der kritischen Wertungen und Forderungen zählen auch Wertungsäuberungen von Schriftstellern als Tellnehmern des literarischen Lebens. Die Art und Weise ihrer Integration in den literaturkritischen Diskussionszusamenhang gibt dabei einigen Aufschlub uber das jeweilige Verhaltnis zwischen literarischem Innovationsdrang und auBerliterarischer Funktionalisierung.

Die Diskussion in den siebziger Jahren soll einbezogen werden, da sich hier - mit einer gewissen zeitlichen Verschiebung - das Ende der Dorfprosa als literaturevolutionăr relevanter Unterreihe in der normbildenden Instanz Literaturkritik niederschlägt.

IV. 1. Füfziger Jahre

THESE: Die erste Hälfte der funfziger Jahre ist gekennzeichnet von der Absage an die verschonernde Kolchosliteratur der Zdanov-Aira und der Hinwendung zu einer wahrheitsgetreuen Darstellung der sozialokonomischen situation der Rolchosen. Dabel scheinen literarische Innovation und eng pragmatische Funktionalisierung (Landwirtschaftsreform) harmonisierbar. Ausdruck dessen ist die weitgehende Integration der Schriftsteller in den normenbildenden ProzeB. Diese Einheit bricht 
jedoch seit Mitte der fünfiger Jahre auf. Die Hauptpunkte des des Normenkonflikts sind: die Frage der Realitätsdarstellung zwischen Lackiererei und Schwarzmalerei, die Frage der thematischen Aktualitat, die Frage der Figurenauswahl (Funktionär oder Bauer).

IV.1.1. 1953-1955: Wahrheitsgetreue Darstellung im Dienst der Landwirtschaftsreform

Einer der exponiertesten Artikel des ersten Tauwetters ist F. Abramovs "Ljudi kolchoznoj derevni $v$ poslevoennoj proze" $^{11}$. Er beinhaltet eine scharfe Kritik an der Kolchosliteratur der Zdanov-Aira wegen ihrer verschönernden Darstellung des Kolchoslebens. Einige Grundelemente der vorherrschenden Auffassung vom Sozialistischen Realismus werden implizit revidiert. Das betrifft v.a. die Frage des zukunftsoptimismus als vorwand für eine "revolutionäre Romantik", die von Abramov als "pastoraler Realismus" 2) bezeichnet wird. Der gröste Mangel wird im Verschweigen sämtlicher Schwierigkeiten und widerspruche gesellschaftlicher wie naturlicher Art gesehen, was die Konfliktlosigkeit der Handlungen bzw. die stereotype Beschränkung der Konflikte auf die Auseinandersetzung zwischen fortschrittlichen und rückschrittlichen Mitgliedern einer familie zur Folge habe. Als nicht wahrheitsgetreu, "papieren und ausgedacht " ${ }^{3}$ ) wird die Darstellung des positiven Helden als Träger gleichsam naturgegebener uberragender charakterlicher Eigenschaften kritisiert. Als positive Aufgabe für die Kolchosprosa formuliert Abramov:

"Zadaca sostoit $v$ tom, Ctoby dat' zivuju kartinu Zizni, kartinu povsednevnogo trudnogo podviga kolchoznogo krest'janstva, naprjaženno borjustegosja za realizaciju istoriteskich postanovlenij partii po voprosam sel'skogo chozjajstva,

1) F. Abramov, Ljudi kolchoznoj derevni v poslevoennoj proze, in: Novyj Mir, 1954, Nr.4, S.210-231.

2) Ebd.. S.218.

3) Ebd., S.222. 
sozdat' proizvedenija, uvlekatel'no 1 pravdivo rasskazyvajuštie o zizni našej derevni." (Hvh. G.W.) 1)

Die Ocerki V. Oveckins, A. Kalinins, G. Troepol'skijs und v. Tendrjakovs werden als Beispiele angeführt.

Im Kern formuliert Abramov hier eine Interdependenz zwischen literarischem und auBerliterarischem InnovationsprozeB, welche in der Funktionalisierbarkeit wahrheitsgetreuer literarischer Darstellung fur die landwirtschaftliche Reformpolitik begrundet scheint.

Diese ursprünglich angestrebte Einheit zwischen literarischer und auBerliterarischer Innovation bleibt bis 1955 dominante Tendenz. Sie wird allerdings einschränkenden Modifikationen unterworfen, welche v.a. auf Kosten des

1) Abramov, aao, S.227. - Mit den historischen Parteibeschlüssen ist v.a. das "Septemberplenum" der Partel von 1953 gemeint. Es deckte in bisher ungewohnter offenheit die MiBstande in der Landwirtschaft auf, wobei neben den Produktionslücken in Viehzucht, Getreide- und Gemüseanbau besonders der krasse soziale Unterschied zwischen Stadt und Land (Löhne, Preise), die technische Rückständigkeit sowie die burokratische Erstarrung des Verwaltungsapparats als primär $2 u$ behebende Ursachen angegeben wurden. Die Beschlüsse dieses Plenums - gleichzeitig mit ihrer Veroffentlichung wurde die Wahl Chruscevs $z$ un ersten Parteisekretär bekanntgegeben - sind der Beginn des geplanten landwirtschaftilichen Reformprogramms, welches auf zwel Hauptpfeilern beruhen sollte: erstens der Förderung des materiellen Anreizes durch gerechtere und an der Leistung der Kolchosen orientierte Entlohnungs- und Steuerverhältnisse und zweitens der Umstrukturierung des Leitungsapparats. Hunderttausend landwirtschaftliche Spezialisten sollten aus dem Verwaltungsapparat an die 'Front' geschickt werden, ca. 50000 Parteimitglieder in den städten sollten nach freiwilliger Meldung unsiedeln und ständige Funktionärsaufgaben im Dorf ubernehmen. Seit Anfang 1954 kamen die Ausweitung des MTS-Systems und ein gigantisches NeulanderschlieBungsprogramm hinzu.

Vgl. O. Schiller, Der neue Kurs der sowjetischen Agrarpolitik, in: Osteuropa, 1953, Nr.6, S.403-412; Redaktion Osteuropa, Umwege zur Agrostadt?, in: Osteuropa, 1954, Nr.2, S.124-129; Dies.. Neulandgewinnung, das neue Program, in: Osteuropa, 1954, Nr.4, S.304-313. - Bereits im Dezember findet eine Sitzung des Sekretariats des Schriftstellerverbands und der Redaktion der "Iiteraturnaja Gazeta" unter Beteiligung mehrerer Kolchosschriftsteller statt, auf der die neuen Aufgaben der Kolchosprosa angesichts der Parteibeschlusse diskutiert werden (Literaturnaja Gazeta, 10.12 .1953 .1 
Realitätsprinzips gehen. ${ }^{1)}$

Auf der Konferenz der Kolchosschriftsteller von 1955 sind diese Modifikationen im wesentlichen entwickelt. Der innovatorische Flügel der Kolchosprosa, repräsentiert v.a. von $v$. Ovexkin - der seit dem Erscheinen seiner "Rajonnye budni" (1952) als vater der neuen Ołerk-Bewegung gilt - , setzt sich hier zwar insgesamt durch gegen eine von G. Nikolaeva repräsentierte konservative Strömung. Dies manifestiert sich in der einhelligen Kritik an der 1954 von Nikolaeva veröffentlichten "Povest' o direktore MTS i glavnom agronome" (im weiteren: "Povest" "), die zunächst von der konservativen Kritik als Alternative zur Literatur des ersten Tauwetters gefördert worden war. Die "Povest" " wird nun von fast allen Rednern als Negativbeispiel eines idealisierten Bildes vom positiven Helden zitiert. Hauptkritikpunkt ist die Darstellung der hauptfigur Nastja als "Einzelkampferin"2), die nicht mithilfe der Partei, sondern gegen deren Widerstand, aus "ubermenschlichen" ${ }^{3)}$ Fahigkeiten heraus ihre Erfolge erziele.

Hinter dieser weitgehenden Einheit in der Ablehnung einer extrem idealisierten Heldenkonzeption tritt jedoch ein neuer ilormenkonflikt zutage. Im zentrum steht die Frage der Typisierung in der heldengestaltung. Der "subjektive Faktor", das "Bewubtsein" werden von Nikolaeva als wichtigste Elemente in der Gestaltung typischer Charaktere geltend gemacht gegenuber der Darstellung der auberen Umstande ihres Handelns. ") Auch Kritiker cier zu icealisierencien Darstellung der Heldin Nikolaevas heben deren "psychologische Wahrheit" (psichologiceskaja pravda) hervor, welche entscheidender sei

1) Zum gesamtliterarischen Zusammenhang, insbesondere der einschränkenden Tendenz des zweiten Kongresses des Schriftstellerverbands der UdSSR (1954) als Reaktion auf das erste Tauwetter vgl. A. Steininger, Literatur und Politik in der Sowjetunion nach Stalins Tod, Wiesbaden 1965, S.42ff.

2) G. Troepol'skij, Bez pravdy Kizni net literatury, in: Zizn' kolchoznoj derevni i literatura, aao (im weiteren: Zizn'...l, S. 143. Vgl. ebf. A. Kalinin, Bol'saja tema sovremennosti, in: Kizn'..., aao, S.68.

3) Ovetkin, aao, 5.139.

4) Nikolaeva, aan, S. $182 \mathrm{f}$. 
für die Erfassung des Typischen als die "Wahrheit der Umstände" (pravda obstojatel'stv). 1)

Eine andere Gruppe betont demgegenüber die Darstellung der "Umstände" und wendet sich gegen die Reduzierung des Helden auf seine "Innenwelt"; die Besonderheiten seiner Umgebung, oft gerade die spezifisch lokalen Besonderheiten seien entscheidend fur das Verständnis seines charakters. ${ }^{2}$ ) Der Begriff des Typischen wird von dieser Gruppe nicht abgelehnt, sondern im Sinne einer Einheit aus Charakter und Umwelt interpretiert; er wird auberdem auf die Typisierung des Negativen ausgedehnt. ${ }^{31}$

Die stärkere Hinwendung $z u$ den realen Lebensbedingungen wird von der Mehrheit der Diskussionsteilnehmer unterstutzt. In der Konkretisierung jedoch läbt sich eine deutliche Abschwächung des antilackiererischen Pathos von 1953 feststellen. Als ebenso gefährlich wie die Lackiererei wird von S. Voronin das Erscheinen mehrerer Oterki, die sich nur noch auf die negativen Seiten des Kolchoslebens konzentrierten, betrachtet. ${ }^{4)}$ Auch ove $\boldsymbol{X}_{k i n}$ wendet sich in seinem Hauptreferat scharf gegen die "Lumpensammler", die mit dem selben stock, mit dem sie in den Abfallgruben wihlten, aus den Redaktionen gejagt werden sollten. 5)

Das Negative ebenfalls, aber in der korrekten Relation zum Positiven darzustellen, - einen "Seitenblick" auf es $2 u$ werfen $^{6)}$ - , dies kann als weitgehender Konsens der Diskussion betrachtet werden. Seinen deutlichsten Niederschlag findet er in der allgemein betonten Notwendigkeit, den negativen Helden positive Alternativen gegenuberzustellen.

1) v. Dorofeev, Pravda tipov i obstojatel'stv, in: $\chi_{i z n}$..., aaO, S.254.

2) Vgl. E. Doros, Derevenskie zametki, in: $\chi_{i z n} \ldots$,.. aao, S. 339 und G. Fis, Literatura perednego kraja, in: $\mathrm{K}_{\text {izn }} \mathrm{n}^{\prime} \ldots$ $\mathrm{aaO}, \mathrm{S} .368$.

3) Vgl. Oveckin, aao, S.143f.

4) S. Voronin, Protiv otstuplenij ot pravdy, in: $x_{i z n} \ldots .$. aao, S.304f. Vgl. ebf. A. Dement'ev, Poézija i pravda,

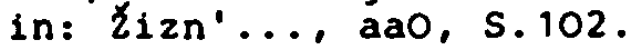

5) Ovekkin, aao, S.144.

6) Fis, aaO, S.367. 
Die Diskussion ist schlieblich aufschluBreich hinsichtlich der auBerliterarischen Funktionalisierung der Literatur und des diesbezüglichen Selbstverständnisses der Schriftsteller. Mit I. Antonov, G. Baklanov, E. Doros, A. Kalinin, G. Nikolaeva, V. Ovełkin, V. Tendrjakov, G. Troepol'skij, S. Voronin und S. Zalygin beteiligen sich die namhaftesten Kolchosschriftsteller an literaturkritischer Normenformulierung, die eine enge Funktionalisierung der Literatur im Dienst der Landwirtschaftsreform zur Grundlage hat. Für die literarische Normenbildung wirkt sich das in erster Linie auf der thematischen Ebene aus. Das betrifft zunächst die einem Gebot gleichkommende ausschliebliche Anerkennung aktueller Themen. Nur ein Redner, R. DŹaparidze, wendet sich gegen diese Festlegung und bestreitet generell das Recht, den Autoren Themen vorzuschreiben. ') Er ist jedoch isoliert und wird im Schlubreferat scharf kritisiert. ${ }^{2}$

Das prinzipielle Gebot der Aktualitat wird daruberhinaus in enger orientierung an den konkreten Reformprojekten der Partei spezifiziert. Auf der Grundlage der Beschlüsse des Septemberplenums formuliert Oveðkin einen Katalog der dringendsten Themen (Landsiedlungsbewegung der ehemaligen städtischen Funktionäre, Erziehung der "Kader", Arbeiterklasse auf dem Land). "3) Die "Frage aller Fragen" sei die "Kaderfrage"4), sie musse die Auswahl der Figuren bestimmen.

In der Bestimnung der Wertkriterien für die Charakterisierung der Funktionärs-Figuren werden Normen formuliert, die sich an den aktuellen Aufgaben der antibürokratischen Reform der Führungstätigkeit orientieren. Zivilcourage, Initiative, Verbundenheit mit den Menschen, Lebenskenntnis werden als Charaktereigenschaften der positiven Funktionărsfiguren, Karrierismus, bürokratisches Verhalten, Desinteresse für die Menschen als Eigenschaften der negativen Figuren

1 i R. Džaparidze, ob aktual'nom i neaktual'nom, in:

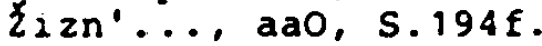

2) $\therefore$ Lesjư̌evskij, Vključajas' $v$ polemiku, in: $\chi_{i z n^{\prime}} \ldots$ S. $383 \mathrm{E}$.

3) Oveckin, aao, S.121ff.

4) Ebd., S.121. 
bestimmt. ") In dieser Hinsicht besteht allgemeiner Konsens. Als Paradigmafiguren gelten v.a. die Parteifunktionăre Martynov und Borzov aus "Rajonnye budni".

An der Frage der Auswahl der Figuren bricht jedoch der Konsens auf. Gegen die einseitige Orientierung auf die "natal'niki" wird von einigen, noch in der Minderheit befindlichen Diskussionsteilnehmern die Darstellung der einfachen Kolchosbauern als Hauptaufgabe bezeichnet. F. Pevnev sieht im Fehlen solcher Figuren die Ursache für die mangelnde Verbreitung der Kolchosliteratur unter den Kolchosbauern. ${ }^{2)}$ Der entschiedenste Verfechter dieser Position, G. Troepol'skij, gelangt in der Konsequenz bis zur Ablehnung einer eng definierten Funktionalisierung der Literatur. Die einseitige Orientierung auf die "Kader" sei das Resultat einer kampagnenmäigen, "saisonhaften" Aufgabenbestimnung für die Literatur; stattdessen gehe es un die prinzipielle und langfristige Aufgabe der Erziehung der der Kolchosbauernschaft. 3 )

1) Vgl. Oveðkin, aaO, S.123. Vgl. ebf. V. Tendrjakov, Rol'kritiki v Zizni i literature, in: $i 2 n \ldots \ldots$ aao, s.174. Tendrjakov bezeichnet des Kampf des "Initiativreichen" mit dem "Bürokratischen" als die aktuelle Konkret'sierung des Konflikts zwischen positivem und negativem Helden.

2) F. Pevnev, Citatel' i geroj, in: $Z_{i z n} \ldots . .$, aao, $S .282$. Pevnev wendet sich besonders gegen eine Idealisierung der sog. "30000er" (gemeint sind die umgesiedelten parteifunktionare aus der stadt), die oft nach dem Prinzip "kam, sah und siegte" dargestellt würden. Er gibt auberdem einige Hinweise auf die sehr bedingte 'Freiwilligkeit' dieser Bewegung.

3) Vgl. Troepol'skij, aao, S.147. Im Sinne Troepol'skijs spricht auch S. Zalygin, der Troepol'skijs literarische Praxis den anderen Kolchosschriftstellern entgegenhält, welche weniger als die Schriftsteller der zarenzeit uber den einfachen Bauern schrieben. Vsl. S. Zalygin, Misli posle sovešanija, in: lovyj Xir, 1956, :ir.1, S.224f (eine leicht revidierte Fassung seines Diskussionsbeitrags auf der Versammlung). Der entschiedenste Parteigänger Oveckins in diesem Punkt ist G. Baklanov. Erstrangige Aufgabe der Literatur sei es, ein Bild vom kommunistischen Führer zu schaffen, betont er unter Kritik an Troepol'skij. Vgl. G. Baklanov, Charaktery i obstojatel'stva, in: zizn'..., aao, S. 362 . 
IV.1.2. Normenkonflikte seit 1956

Seit 1956 erscheinen Erzählungen, die die sozialen und politischen MiBstände des Kolchoslebens in krasserer Form und mit weniger hoffnungsvollem Blick auf die Landwirtschaftsreform darstellen. Der Konflikt zwischen den Funktionärs- und Bauernfiguren bekommt z.T. antagonistische Akzente. Hier sind v.a. die beiden in "Literaturnaja Moskva", Bd.2 (1956), erschienenen Erzählungen "Ruðagi" (A. Jašin) und "Poezdka na rodinu" (N. Zdanov) zu nennen. Die kritik reagiert darauf mit einer stärkeren orientierung auf den Kampf gegen die "Schwarzmalerei" (Cernitel'stvo) und mit einer besonderen Betonung der Interessenidentität zwischen "Volk" und Partei. "RyCagi" wird wegen der Darstellung von Parteifiguren als Heuchler und Lügner sowie wegen der Gestaltung eines antagonistischen Gegensatzes zwischen Individuum und kollektiv kritisiert. ${ }^{1)}$

Diese beiden Aspekte stehen auch im Mittelpunkt der seit 1957 intensivierten Einschaltung von Partei und Fürung des Schriftstellerverbandes in den normenbildenden ProzeB. Hier sind besonders die Reden ChrusCevs von 1957, der erste KongreB des Schriftstellerverbandes der RSFSR (1958) und der dritte KongreB des Schriftstellerverbandes der UdSSR (1959) zu nennen.

Chrustev veröffentlicht im August 1957 in "Kommunist" den richtungsweisenden Artikel " $2 a$ tesnuju svjaz' literatury i iskusstva s Zizn'ju naroda", in dem die stoBrichtung seiner Reden vom Mai und Juli ${ }^{2}$ zusammengefaBt wird. Chrustev besteht auf der Unzertrennbarkeit der Begriffe "Parteilichkeit" und "Volkstumlichkeit" und begründet dies damit, daB die Partei die grundegenden Interessen des Volkes zum Ausdruck bringe. ${ }^{31}$

1) Vgl. N. Saloma, Celovek v kollektive, in: Kommunist, 1957. Nr.5, S.79. Vgl. ebf. V. Ozerov, im, Kest' 1 sovest' nasej épochi, in: Novyj Mir, 1957, Nr.10, S.215.

2) Vgl. Steininger, aaO, s.77.

3) Vgl. N.S. Chruschtschow, Reden zur Kulturpolitik. 1956-1963, Berlin 1964, S.39f. 
Die beiden Schriftstellerkongresse von 1958 und 1959 stehen deutlich im zeichen einer konservativen Ausrichtung. ") Chrustev halt 1959 eine Rede, in der er den Begriff der "Lackiererei" verwirft und den diesbezüglich kritisierten Schriftstellern die Darstellung der "lebensspendenden Kraft des Neuen, Kommunistischen" bescheinigt. ${ }^{2}$ )

Ein weiterer Schwerpunkt der Ausrichtung ist die thematische Aktualität. Der diesbezilgliche Normenkonflikt kommt auf der vorbereitenden Versamnlung der Moskauer Sektion des Schriftstellerverbandes im Juni 1958 für den ersten SchriftstellerkongreB der RSFSR zum Ausdruck. ${ }^{3)}$ Das bei den Kolchosschriftstellern erwachende Interesse für die Vergangenheit des Dorfs - Troepol'skij veroffentlicht 1958 den ersten Teil seines historischen Romans "Cernozem" wird als "Theorie der Distanz" kritisiert; das Typische könne nicht aus der historischen Distanz, sondern nur "in seiner Bewegung" erfaBt werden. ") Als positives Beispiel einer gegenwartsorientierten Literatur werden die oderki Overkins gewürdigt, jedoch bereits als Erbe, das in Vergessenheit $z u$ geraten drohe. ${ }^{5)}$ Gleichzeitig wird aber die Beschränktheit einer $z$ engen Funktionalisierung der Literatur im Sinne eines sozialokonomischen und politischen Ratgebers erkannt und die durch sie entstandene Stereotypizität der Handlungen verworfen. ${ }^{6)}$

1) Vgl. Steininger, aao, $5.85 \mathrm{f}$ und $88 \mathrm{ff}$.

2) Tretij s-ezd pisatelej SSSR, 18-27 maja 1959 goda. StenografiCeskij otČet, Moskau 1959, S.220.

3) Die Materialien dieser Versammlung sind verbffentlicht

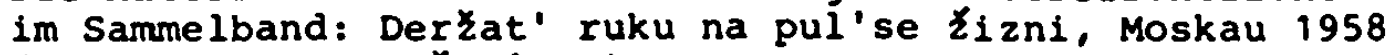
(im weiteren: Derzat'...).

4) G. Brovman, Bliže k nałemu segodnja, in: Deržt'..., aao, S. 10 .

5) Vgl. S. Surtakov, Bol'se chorosich knig o sovremennosti, in: Derzat'.... aao, S.102.

6) Vgl. F. Pevnev, Gluboko otrazat' Zizn' kolchoznoj derevni, in: DerŽat'..., aao, S.94ff. - Pevnev nennt die beiden Handlungsschemen a) des schlechten Vorsitzenden, der eine Kolchose zugrunderichtet und b) des neuen Vorsitzenden, der eine darniederliegende Kolchose wieder aufbaut. 
In der Heldendiskussion verschärft sich der Konflikt um die Auswahl der Figuren. Auf der einen seite fordert man die stärkere Orientierung auf Parteifiguren, was mit der Unzertrennbarkeit von "Parteilichkeit" und "Volkstümlichkeit" begründet wird; gerade die partei müsse als die für das Wohlergehen des Volkes entscheidende Kraft dargestellt werden. ') Diese Position wird von anderer Seite als Einschränkung des Begriffs der "Parteilichkeit" auf Parteifiguren abgelehnt. 2)

Als immer entscheidender erweist sich das Problem, wie gerade die Darstellung des "gewöhnlichen, kleinen Mannes" (obyknovennyj, malen'kij Celovek) ${ }^{3)}$ mit den Prinzipien eines positiven Leitbilds in Einklang gebracht werden kann. Als wichtigster Faktor gilt traditionell der Heroismus der Arbeit. Er wird nun gegen eine Privatisierung des Helden geltend gemacht, die G. Brovman als neue Tendenz, sich auf das "Hausinnere", die "familiaren streitigkeiten" der Helden $z u$ beschränken, konstatiert. ${ }^{4)}$ Daneben wird eine zweite Definition des Heldischen immer wichtiger, die eine stärkere Orientierung auf den Begriff des "Volks" (narod) beinhaltet. In scharfer Abgrenzung von einer "unerhabenen Darstellung grauer Alltagswesen und harmloser Gefühlchen" wird von V. Calmaev die Darstellung des Heldischen gefordert, welches in der Heimatverbundenheit und dem Patriotismus des "narodnyj charakter" begründet sei.5)

1) Vgl. Ozerov, aaO, S.220ff.

2) Vgl. V. Kardin, Iskatel' ili obyvatel'. Zametki o molodom geroe, in: Molodaja Gvardija, 1956, Nr.1, S.206.

3) V. Calmaev, Literatura sud'by narodnoj, in: Moskva, 1957, Nr.11, S.206.

4) Brovman (1958), aaO, S.12.

5) Calmaev (1957), aao, S.205. Wir verwenden im weiteren den russischen Begriff, da seine Ubersetzung ins Deutsche problematisch erscheint. Weder "volkstümlich" noch "volksverbunden" erfassen die volle Bedeutung von "narodnyj", das am ehesten mit dem vorbelasteten "volkisch" ubersetzt werden mübe. (Ebenso wird im weiteren mit "narodnost" verfahren.) 
IV.2. Sechziger Jahre

THESE: In Reaktion auf die literarische Entwicklung, welche immer stärker die Vergangenheitsthematik entfaltet und die individuelle bäuerliche Figur in den Mittelpunkt rückt, kommt es zu einer Umorientierung in der Literaturkritik. Der băuerliche Held steht im Mittelpunkt des Interesses. Hier kommt es $z u$ einem Normenkonflikt in der Frage der Aktivität des Helden. Gegen Ende der sechziger Jahre wird die auBerliterarische Funktionalisierung der Dorfprosa zum zentralen Gegenstand des Normenkonflikts, der sich in einer Konfrontation verschiedener literaturkritischer strömungen niederschlägt. Die Dorfprosa wird dabei zum streitobjekt eines tieferliegenden, auBerliterarischen Normenkonflikts un die primär zu organisierenden Werte des gesellschaftlichen Bewubtseins, der seinen spezifischen Charakter durch das Entstehen einer nationalistisch-ruralistischen Bewegung bekommt.

IV.2.1. Die Diskussion um den bäuerlichen Helden bis Mitte der sechifiger Jahre

In der Frage der Thematik und der Figurenauswahl findet Anfang der sechiger Jahre eine Umorientierung in der Literaturkritik statt. Dem liegt eine literarische Entwicklung zugrunde, die bereits Ende der fünfiger Jahre einsetzt:

- Das Dorf der zwanziger und dreibiger Jahre, besonders wätrend der Kollektivierungszeit, wird Themengegenstand einer Reihe von Werken. Den Hohepunkt dieser Entwicklung bilcet "Na Irtyse" (S. Zalygin, 1964), einer der meistdiskutierten Texte der sechziger Jahre. Dieses wachsende Interesse für die jüngere Vergangenhelt ist im zusammenhang mit der nach dem 22. Parteitag einsetzenden

"Entstalinisierungsliteratur" 24 sehen."

- Mit der lyrischen Prosa gewinnt das Individuum eine

1) Zur Bedeutung des 22. Parteitags sowie zur "Entstalinisierungsliteratur vgl. Steininger, aaO, S.164-185. 
Aufwertung gegenüber der Objektivität historischer und gesellschaftlicher Prozesse.

- Die bäuerliche Figur als eigenwertiger, von rein sozialokonomischen und politischen Charakterisierungsdimensionen zunehmend emanzipierter Mikrokosmos gewinnt an Bedeutung, am extremsten signalisiert mit "Matrenin dvor" (A. Solzenicyn, 1963).

Die bisher verpönte Vergangenheitsthematik wird nun anerkannt. Auf dem zweiten KongreB des Schriftstellerverbandes der RSFSR (1965) wird das Erscheinen vieler auf das Dorf der zwanziger und dreiBiger Jahre zurückblickenden Texte im Hauptreferat L.Sobolevs ausdrücklich gewürdigt. ${ }^{1)}$

Den Schwerpunkt der literaturkritischen Diskussion bis 1966 bildet die Heldenfrage. Die Diskussion um den Parteihelden wird fortgefürt, doch nicht mehr mit dem Anspruch seiner prinzipiellen Dominanz in der Figurenauswahl; Hauptstreitpunkt ist das Verhätnis des Parteihelden zu den bäuerlichen Helden. "Na Irtyłe" wird Gegenstand einer Kontroverse zwischen V. Calmaev ${ }^{3)}$ und I. Janovskij ${ }^{4}$ ). Calmaev kritisiert die einseitig negative Darstellung der Parteihelden im Verhälnis zu den Bauern und konstatiert eine allgemein verbreitete Tendenz zur Antagonisierung von Bauern und staat. ${ }^{5)}$ Janovskij weist demgegenuber auf die Notwendigkeit hin, schlechte ebenso wie gute Fuhrerfiguren zu zeigen. Er lehnt es $a b$, den Bauern nur unter

1) Vgl. L. Sobolev, Sovetskaja literatura i vospitanie novogo Keloveka. Doklad predsedatelja pravlenija Sojuza pisatelej RSFSR, in: Literaturnaja Gazeta, 4.3.1965, S.5.

2) Es wird allerdings auch auf die Gefahr einer vollständigen Vernachlässigung dieser Figuren hingewiesen. Vgl. L. Fomenko, Ne stoit selo bez truzenika, in: Moskva, 1964 , Nr.11, S.200.

3) V. Calmaev, Raspachannoe pole, in: Literatura i sovremennost' 6. Stat'i o literature 1964-1965 godov, loskau 1965 (zuerst in: Znamja, 1965, Nr.3 und Moskva, 1965, N.8.8).

4) I. Janovskij, Trudnyj put', in: Literatura i sovremennost' 6, aao, S.120-138 (zuerst in: Sibirskie ogni, 1965, Nr.10).

5) Vgl. Calmaev (1965), aaO, S.114: "V celom zascita krest'janina truzenika, vospevanie ego ne dolžny perechodit' $v$ svoju protivopolozennost': otdelenie 'pravdy' krest'janina ot pravdy gosudarstva." 
der Garantie einer positiven Führung als stutze für die Entwicklung des Dorfs anzuerkennen. 1)

Im Mittelpunkt des Interesses steht der bäuerliche Held. Das in den füfigiger Jahren bereits auftauchende Problem des Bauern als positiven Helden wird entscheidend. Schon 1962 stellt E. Starikova hinsichtlich der lyrischen Prosa V. Solouchins das Auftauchen eines "neuen Typs des Dorfbewohners" fest, der weniger durch soziale Ungerechtigkeit und Härte des Klassenkampfs wie zur zeit der zwanziger und dreibiger Jahre als durch einen "idyllischen" Lebensbereich geprägt sei. ${ }^{2)}$ Die zu ausschliebliche Beschränkung auf die Idylle aufkosten der "sozialen Kämpfe" wird zwar kritisiert, doch steht das "organische" Verhältnis zwischen Bauern und Kolchose positiv im vordergrund. ${ }^{3)}$ Der Normenkonflikt kommt erst voll zum Tragen mit dem Erscheinen băuerlicher Figuren, die weder dem Gebot des sozialkämpferischen Heroismus noch dem der gesellschaftlichen Integration gerecht werden. "Matrenin dvor" wird zum Negativparadigma einer nun einsetzenden Kampagne gegen die "Entheroisierun:" (degeroizacija). Exemplarisch sei aus A. Dymsic' Kritik im "Ogonek" zitiert:

"I nel'zja soglasit'sja s pisatelem, tto tip narodnogo pravednika, kotorogo on poétiziruet $v$ obraze Matreny, est' osnova $i$ opora vsej zemli nałej. Samyj tip étot, esli on $i$ dozil do pjatidesjatych godov, est' ne tto inoe, kak anachronizm. I sovetskaja derevnja, sovetskaja zemlja stoit $i$ deržitsja ne na pravednikach-stradal'cach, a na aktivnych tvorcach, na ljudjach, sposobnych, vozdelyvaja potvu, peredelyvat" mir." 4)

L. Jakimenko hält 1964 auf einer Leitungskonferenz des Schriftstellerverbands der RSFSR zu Fragen der Dorfprosa einen ausrichtenden Vortrag, in dem die Frage der "Entheroisierung" einen großen Raum einnimmt. ${ }^{5)}$ Die Grundopposition

1) Vgl. Janovskij, aaO, S.135ff.

2) E. Starikova, Rodnoe i blizkoe, in: Dies., Poézija prozy. Stat'i, Moskau 1962, S.169ff.

3) Ebd. , S.171f.

4) A. Dymsic, Rasskazy o rasskazach, zametki o povestjach, in: Ogonek, 1963, Nr.13, S.30.

5) L. Jakimenko, 0 chlebe, zemle i nasej literature, in: Literatura i sovremennost' 5, Moskau 1964, S.109-134. 
liegt zwischen Aktivitat und Passivität des Helden. "Aktivität, Unversöhnlichkeit und Tatkraft" (aktivnost', neprimirnost', dejstvennost') werden programmatisch als Charakterzüge des zeitgenössischen Helden formuliert im Gegensatz zu den "leidenden Personen" (stradatel'nye lica), die in vielen Texten zur normalen Erscheinung geworden seien. ${ }^{1)}$

1965 und 1966 wird das problem des positiven Helden intensiv in "Voprosy literatury" auf gesamtliterarischer Ebene diskutiert. Der Normenkonflikt betrifft hier bereits nicht mehr nur die inhaltliche Fullung des Begriffs, sondern implizit die Legitimitat des Schemas positiver vs. negativer Held überhaupt. Für die Dorfprosa konkretisiert sich der Konflikt in einer Kontroverse zwischen A. Janov" und A. Karaganov" (Janov lehnt das "voluntaristische Schema 'Held' und 'Antiheld'" ab und hält dem die Darstellung des "lebendigen Menschen" entgegen. ") Den Hintergrund des Konflikts bildet die alte Kontroverse um das Verhältnis zwischen "Charakter" und "Umständen". Janov wendet sich gegen eine von den realen Lebensumständen abstrahierende Charakterdarstellung, 5) wofür ihm von iaraganov der vorwurf des Objektivismus gemacht wird. ${ }^{6)}$ Klarer als in der "Typisierungs"-Diskussion von 1955 wird jetzt die Reichweite dieses konflikts erkannt. Es geht un die Frage der Wahrheitsfindung zwischen weltanschaulichem Dogma und Wirklichkeit. Janov weist deutlich auf den diesbezüglichen widerspruch hin mit seiner Kritik an der Gegenuberstellung verschiedener Wahrheitsbegriffe, - einer "Wahrheit des Jahrhunderts" (pravda veka) und einer "Wahrheit des Faktums" (pravda fakta). ?)

1) Jakimenko, aao, S.115 und 119.

2) A. Janov, Polozitel'nyj geroj ili Don Kichot?, in: Voprosy literatury, 1966, Nr.8, S.3-22.

3) A. Karaganov, Trubnikov snova pod ognem, in: Voprosy literatury, 1966, Nr.8, S.22-31.

4) Janov (1966), aaO, S.11.

5) Vgl. ebd.. S.11.

6) Vgl. Karaganov,aaO, 5.23 und 30.

7) Janov (1965), aaO, S.5 und $19 \mathrm{ff}$. 
IV.2.2. Die Diskussion um lyrische und analytische Prosa in den Jainren 1967 und 1968

Aufbrechen eines auBerliterarischen Normenkonflikts

In den Jahren 1967 und 1968 wird in der "Literaturnaja Gazeta" eine Diskussion uber "lyrische" und "analytische" Prosa gefuhrt. Diskussionscgegenstand sind ausschlieBlich Dorfprosa-Texte; V. Belov an erster Stelle, V. Lichonosov, v. Astaf'ev, S. Krutilin, S. Zalygin und V. Suksin sind die wichtigsten Autoren. Es stehen sich zwei Lager in relativ klarer Konfrontation gegenüber. Die Gegner der lyrischen Prosa (V. Kamjanov, V. Gusev, A. Janov, F. Levin) 1) werfen ihr eine Idealisierung der patriarchalischen Traditionen des Dorfs vor. Lyrische Prosa wird dabei im genreunspezifischen sinne verstanden (s.III.4.) und von einigen Diskutanten als Wertungskategorie abgelehnt. Gemeint ist ein Pathos der "Schwermut" und "Nostalgie", 2) des "Seufzens" ${ }^{3)}$ und der "Trauer"4), eine "pastorale Idylle"5), - während das Analytische als orientierung auf "schöpferische Arbeit", auf soziale Aktivität und das Pathos des "Denkens" 6 ) verstanden wird. Eine răumliche Komponente kommt hinzu: Levin stellt der orientierung auf die "eigenen vier Wände" die "ausgedehnte Weite der Untersuchung" gegenuber. ${ }^{7)}$

1) - v. Kamjanov, Ne dobrotoj edinoj.... in: Literaturnaja Gazeta, 22.11.1967, S.4.

- F. Levin, Obosnovana li trevoga?, in: Literaturnaja Gazeta, 17.1.1968, S.6.

- V. Gusev, 0 proze, derevne i cel'nych ljudjach, in: Literaturnaja Gazeta, 14.2.1968, S.6.

- A. Janov, Esli zagljanut' $v$ buduskee, in: Literaturnaja Gazeta, 28.2.1968, S.6.

2) Kanjanov, aao.

3) Ebd.

4) Gusev, aao.

5) Ebd.

6) Kamjanov, aao.

7) Levin, aao. Vgl. ebf. Kamjanov, aao. - Kamjanov stellt die Unbeweglichkeit der Figuren fest, die "nicht fortgehen". Vgl. auBerhalb der "Literaturnaja Gazeta"-Diskussion zur Kritik an der "Abgeschlossenheit" des dargestellten Dorflebens bes. G. Brovman, Talant i napravlenie, in: Don, 1967, Nr.7, S.168. 
Von den Verteidigern der lyrischen Prosa (V. Kozinov, I. Krjacko, S. Surtakov, Ju. Kazakov, V. Rosljakov) ') werden die Oppositionen anders akzentuiert. Die Orientierung auf den dörflichen "byt" wird einer Einengung auf rein ökonomische Thematik gegenübergestellt, - als notwendige Reaktion auf die diesbezügliche Einseitigkeit in der Kolchosprosa der funfziger Jahre. ${ }^{2)}$ Die unvermittelte, "leidende" Teilnahme an einer als eigenen verstandenen welt sei wichtiger als analytische "Distari". 3)

Kernpunkt der Auseinandersetzung ist die Bestimung der Funktion der Dorfprosa. Die Verteidiger der lyrischen Prosa bestimmen sie als eine "moralische"4); die Wiederentdeckung der moralischen "Quellen" (istoki) des Volks im uralt vererbten Charakter des russischen Bavern wird einem "abstrakten Humanismus" entgegengestellt. ${ }^{5)}$ Es gehe nicht nur undie dörfliche Thematik im sozialen Sinne, sondern um eine "Hinwendung $2 u$ den grundlegenden menschlichen Werten". 6) Die Gegner der lyrischen Prosa bezeichnen dies hingegen als eine Verabsolutierung der suellen, :velche einer Apologie des Rückständigen und der Unwissenheit im alten russischen Dorf sowie einer apokalyptischen Verteufelung der zivilisation gleichkomme. ${ }^{7)}$ Bedingung, um die neuen moralischen Werte erfassen $z$ u können, sei

1) - L. Krjaðko, Listy i korni, in: Literaturnaja Gazeta, 29.11 .1967$, S.5.

- S. Surtakov, o glavnom teloveke na zemle, in: Literaturnaja Gazeta, 5.12.1967, S.6.

- Ju. Kazakov, Ne dovol'no li?, in: Literaturnaja Gazeta, 27.12.1967, S.6.

- V. Rosljakov, Ironii ne podvlastno, in: Literaturnaja Gazeta, 17.1.1968, S.6.

- V. Kozinov, Cennosti istinnye i mnimye, in: Literaturnaja Gazeta, 31.1.1968, S.5.

2) Vgl. Surtakov (1967), aaO.

3) Ebd.

4) Kazakov, aao.

5) Krjałko, aao.

6) Kožinov, aaO.

7) Vgl. Janov (1968), aao und Kamjanov, aao. Zur Relativität moralischer Wertungskategorien vgl. ebf.

v. Voronov, Este raz o cennostjach istinnych $i$ mnimych, in: Literaturnaja Gazeta, 13.3.1968, S.4. - Voronov bezieht insgesamt eine mittlere Position zwischen den beiden Lagern. 
eine Orientierung auf den sozialökonomischen ProzeB, besonders auf die Entwicklung der Arbeit als Grundlage aller moralischen werte. ${ }^{1)}$ Anstelle einer idealisierten Darstellung der dörflichen welt sollen die sozialen Probleme des gegenwärtigen Dorfs, all das gerade, was den Bauern aus seiner Welt in die stadt vertreibe, gezeigt werden. 2)

Diese einseitig "soziologische" thematische Ausrichtung wird von der Mehrheit der Diskussionsteilnehmer zwar nicht gebilligt, ${ }^{3)}$ doch kann man das offizielle Ergebnis der Diskussion, wie es abschliebend von der Redaktion der "Literaturnaja Gazeta" formuliert wird, als eine entschärfte Fassung der "soziologischen" Linie betrachten. Die Hauptforderung an die Dorfprosaisten besteht in der Reaktualisierung der Themen, der "Erforschung der im Dorf vor sich gehenden sozialökonomischen Prozesse" anstelle eines "elegischen, sentimental-romantischen Blicks auf das alte Dorf". 4)

Die neue Qualität des Normenkonflikts, wie sie sich in der Konfrontation der Funktionsbestimmungen für die Dorfprosa ("moralisch" vs. "soziologisch") manifestiert, sprengt in ihren Dimensionen den Bereich der literarischen Norm. Hintergrund der differenten Funktionalisierungen ist ein auBerliterarischer Normenkonflikt, der die grundsätzliche Neuorientierung in der Wertorganisierung des gesellschaftlichen Bewubtseins betrifft. Es geht um die Frage, wo die identifikationsstiftenden krafte $z u$ finden sind angesichts des Verblassens der traditionellen heroischen Identifikationszusammenhänge (Revolution, Bürgerkrieg, Aufbau, Krieg, Wiederaufbau) und der zunehmenden Entfremdungserscheinungen im modernisierten zeitgenössischen Alltag.

Diese Dimension tritt in der Diskussion von 1967 und 1968 in der durchgängigen Polemik um die Bestimung der

1) Vgl. Janov (1968), aao.

2) Vgl. Gusev, aaO.

3) Den Vorwurf des Soziologismus erhebt Voronov, aao, gegen Janov.

4) Celovek na zemle, in: Literaturnaja Gazeta, 3.4.1968, S.7. 
Kräfte der gesellschaftlichen Erneuerung zutage. Zwei Konzeptionen stehen sich gegenüber:

a) eine moralische Erneverung durch die wiederentdeckung der im Revolutions- und Modernisierungspragmatismus verschütteten Werte ("Quellen") mit dem Bauern als ihrem sozialen Träger ${ }^{1)}$

b) eine pragmatische Fortschrittsideologie, die v.a. In okonomischen und sozialen Erfolgen sowie in der Faszinationskraft der "naturwissenschaftlich-technischen Revolution" gesellschaftliche Identifikationsmuster sieht mit dem technisch und intellektuell gebildeten Menschen als sozialem Träger ${ }^{2)}$.

Die Diskussion von 1967 und 1968 markiert die zeitliche Grenze $2 u$ einer neuen Phase literaturkritischer Normenbildung. Mit den beiden konkurrierenden Funktionalisierungskonzopten sind die Grundpole des Normenkonflikts, wie er sich in den siebziger Jahren entwickelt, konturiert, ohne sich bereits bis $z$ einer Dimension $z$ entfalten, in der die Daseinsberechtigung der Dorfprosa prinzipiell zur Debatte steht. Auch die Gegner der lyrischen Prosa wenden sich explizit nur gegen einige Autoren (besonders $v$. Lichonosov), wăhrend v.a. V. Belov ("Privycnoe delo") und S. Zalygin ("Na Irtyłe") von beiden Lagern für sich

1) Vgl. Koß̌inov, aao: "Krest'janstvo - éto ne 'ideal'naja', ne 'vysłaja' Cast' naroda; no ono neobchodimaja potva dija postojannogo "vozrozdenija ziznennoj sily nacil'."

2) Vgl. Janov (1968), aaO: "Esli mesto proizvoditelej material nych cennostej $v$ istoriCeskoj perspektive vse bol'se zanimaet nauka, esli ona stanovitsja glavnoj proizvoditel'noj siloj, glavnym dvigatelem processa, to oxevidno, tto buduskee prinadlezit l judjam tvorkeskogo truda, ljudjam obrazovannym i intellektual'nym, svjazannym ne stol'ko s material'nym, skol'ko s duchovnym proizvodstvom." 
vereinnahmt werden. ") Doch läBt der zugrundeliegende Konflikt um die Kräte der gesellschaftlichen Erneuerung diese Dimension bereits durchscheinen. Für die "soziologische" Richtung kann eine Literatur, deren dominanter Teil Figuren in den Mittelpunkt stellt, die zu Anachronismen erklärt werden, kaum noch legitimiert werden. ${ }^{2}$

IV.2.3. Fortsetzung der Heldendiskussion Das Problem des "narodnyj charakter"

In der Heldendiskussion bleibt die Frage des aktiven Helden Konfliktgegenstand. 1967/68 konkretisiert sich dieser Konflikt an der Hauptfigur aus "Privylnoe delo" (v. Belov, 1966), Ivan Afrikanovic Drynov. Die Kritiker der lyrischen Prosa versuchen die Figur im Sinne eines gesellschaftlichen Helden gegen die von der Gegenseite postulierte moralische Autonomie zu interpretieren. ${ }^{3}$ Gerade unter dem gesellschaftlichen Aspekt aber wird im Fortgang der Diskussion die Kritik an Ivan Afrikanovic immer deutlicher. Sie betrifft seine mangelnde soziologische Reprăsentativität, ${ }^{4)}$ v.a. aber seine "soziale Naivität und Passivităt".5)

1) Eine Polarisierung der Schriftsteller in zwei Lager analog zur situation in der Literaturkritik ist nicht möglich. Zwar gibt es seit Mitte der sechziger Jahre kontroverse Diskussionen mit ähnlichen Themenschwerpunkten, doch lassen sich nur wenige Schriftstellex eindeutig bestimmten Lagern zuordnen. Als Antipoden gelten seit ihrer Kontroverse in der "Literaturnaja Gazeta" im Jahre 1964 besonders V. Solouchin und B. Mozaev. Solouchin setzt den Schwerpunkt auf die "geistigen Traditionen" des Dorfs in Opposition zur Technisierung, Možaev auf die aktuellen "sozialen Verhaltnisse" des Dorfs. Vgl. v. Solouchin, Dialog, in: Literaturnaja Gazeta, 3.12.1964, S.2 und B. Moźaev, Prodolzim dialog, in: Literaturnaja Gazeta, 24.12.1964, S.2.

2) Vgl. Gusev, aaO: "Ne pristalo nam snova $I$ snova iskat" religiju $v$ 'muzicke' kak osoboj spasitel'noj sile/.../ Da i gde on - preźnij muzik? Gde Ivan Afrikanovic? Ich tak malo..."

3) Vgl. $2 u$ den konkurrierenden Interpretationen Ivan Afrikanovits bes. Kamjanov, aaO und Surtakov (1967), aao.

4) Vgl. Anm. 2 .

5) Voronov, aao. 
Auch auBerhalb der "Literaturnaja Gazeta" wird die Problematik des aktiven Helden besonders anhand Ivan Afrikanovics diskutiert. Eine orthodoxe Position hät am alten Aktivitätsideal des sozialkämpferischen, optimistischen Helden fest und kritisiert Ivan Afrikanovic in einer Linie mit Solzenicyns Matrena wegen seiner gesellschaftlichen Isolation und Passivitä. ${ }^{1)}$ Dem stehen verschiedene Versuche gegenüber, das alte, äußerlichsoziale Aktivitätsideal aufzugeben zugunsten einer inneren Aktivität, die sich im "aktiven Geist"2), "aktiver Humanität" 3 ) 0. a. ausdrücke.

Ein zweiter Aspekt der Heldendiskussion, der imner mehr in den Vordergrund ruckt, ist die Frage des "narodnyj charakter". Mit diesem Begriff versucht man in der Diskussion der Dorfprosa das Grundproblem des bäuerlichen "kleinen" Helden, namlich die Bestimung des Inhalts selner positiven Leitbildfunktion $2 u$ lösen. Der wichtigste und konsensuell mit dem Attribut "narodnyj" verbundene Aspekt ist die Integration des bäuerlichen Helden in das Schicksal des "Volks", wobei die primäre Lokalisierung des "narodnyj charakter" in der Dorfprosa mit den besonders schweren historischen Prüfungen des Dorfs und seiner Bewohner begründet wird. ") Als "narodnyj charakter" ist der bäuerliche Held folglich Träger von Geschichte. ${ }^{51}$

In der Diskussion von 1967 und 1968 sowie in einer weiteren von der "Iiteraturnaja Gazeta" $z$ diesem Thema gefuhrten Diskussion in den Jahren 1969 und 1970 wird der "narodnyj charakter" unter zwei Aspekten problematisiert. Erstens wird

1) Vgl. Brouman (1967), aaO, s.166f.

2) L. Fomenko, Charaktery, in: Zvezda, 1967, Nr.6, S.197.

3) I. Janovskij, Iz polemiCeskich zametok, in: Sibirskie ogni, 1968, Nr.4, S.171.

4) Vgl. bes. M.V. Minokin, Problema narodnogo charaktera $v$ sovremennoj sovetskoj proze, in: Zanry i stili literatury socialisticeskogo realizma. Sbornik trudov (Red. F. Vlasov u.a.), Moskau 1973, S.3. Vgl. ebf. A. Chvatov, Certy narodnosti, in: Nas sovremennik, 1973, Nr.1, S.180.

5) Zum "narodnyj charakter" als Träger von Geschichte vgl. bes. V. ProtEenko (1970), aao, S.78. 
die Frage nach seiner sozialen Trägerschaft akut vor dem Hintergrund des auBerliterarischen Normenkonflikts um die Kräfte der gesellschaftlichen Erneuerung. Ein (kleinerer) Teil der Kritiker erklärt die absterbende alte Bauerngeneration mit den traditionellen Eigenschaften "Bodenverbundenheit, Heimatliebe, Fleis und Lebensbeständigkeit"1) zum Trăger des "narodnyj charakter". Die Mehrheit greift dies als eine Enthistorisierung des Begriffs an, dessen Inhalt in Abhängigkeit vom historischen ProzeB wandelbar sei und heute nicht mehr mit den patriarchalischen Traditionen der alten Bauerngenerationen in Verbindung gebracht werden dürfe, sondern alle gesellschaftlichen Schichten der Sowjetunion einschlieblich der Intelligenz zum Trăger habe. In diesem zusammenhang wird besonders die Idealisierung alter Figuren in der Dorfprosa kritisiert. 2)

2weitens wird der nationale Aspekt des "narodnyj charakter" bzw. das Verhälnis zwischen nationalem und sozialem Aspekt zum Konfliktgegenstand, besonders in der Diskussion von 1969 und 1970. Die Mehrheit (V. Kulesov, F. Capčachov, v. Ivanov, Z. Kerdina, K. Volynskij und N. Dzusojti) 3) ordnet den nationalen Aspekt dem sozialen Aspekt unter. Die "sowjetische", ubernationale Qualität wird betont, als heutiger Inhalt der "narodnost" "wird die "weltanschaulichpolitische Einheit des sowjetischen Volkes" genannt. ${ }^{4)}$

Eine Minderheit (V. Koßinov, N. Vorob'eva/s. Chitarova,

1) Krjacko, aao.

2) Vgl. bes. Levin, aao und K. Volynskij, Narodnyj charakter: Model' i Kizn', in: Literaturnaja Gazeta, 16.6.1969, S.4.

3) - v. Kulesov, Narodnost': Istorija 1 sovremennost', in: Literaturnaja Gazeta, 3.6.1970, S.5.

- F. Capkachov, V ugodu koncepcii, in: Literaturnaja Gazeta, 25.6.1969, S.7.

- V. Ivanov, Nacional'nyj charakter i literatura, in: Literaturnaja Gazeta, 7.5.1969, S.3-4.

- 2 . Kerdina, obrascajas' $k$ istokam, in: Literaturnaja Gazeta, 18.6.1969, S.4.

- K. Volynskij, aao.

- N. DZusojti, Nacional'naja samobytnost' - svojstvo talanta, in: Literaturnaja Gazeta, 24.9.1969, S.4.

4) Kulesov, aao. 
G. Lomidze) ${ }^{1)}$ wendet sich gegen diese Unterordnung des nationalen unter den sozialen Aspekt bzw. deren Identifizierung. Die Vorstellung einer "synchronen" Veränderung des nationalen Bewubtseins mit den Veränderungen in der sozialen Sphäre wird abgelehnt. ${ }^{2)}$

Der Konflikt um den nationalen Aspekt des "narodnyj charakter" steht in zweierlei zusammenhang. Einmal wird er akut vor dem Hintergrund einer nationalistischruralistischen, russophilen strömung, die in der zweiten Hälfte der sechiiger Jahre entsteht und in der Literaturkritik ihren Niederschlag findet (s.IV.2.5.). Zweitens ist damit die Frage der Autonomie der nichtrussischen nationalen Literaturen verbunden. Dieser Aspekt kann in unserem zusammenhang nicht weiterverfolgt werden. Verwiesen sei besonders auf eine Diskussion uber die Dorfprosa in der Zeitschrift "Družba narodov" aus dem Jahr 1970, in der neben russischen kritikern und schriftstellern zahlreiche Vertreter nichtrussischer Literaturen teilnehmen und dieses Problem zur sprache bringen. ${ }^{3}$

IV.2.4. Angriffe der orthodoxen Kritik gegen die analytische Prosa

Neben den dargestellten Diskussionen entsteht eine literaturkritische strömung, die andere Akzente des Normenkonflikts setzt. Während sich die Kritik in "Literaturnaja Gazeta" und "Voprosy literatury" auf die Idealisierung des Dorfs bezieht und auch die schärfsten Kritiker gerade den sozialanalytisch-kritischen Aspekt eines Teils der Texte positiv hervorheben, dehnt diese - stark vom "Ogonek" repräsentierte - strömung die kritik

1) - V. Kožinov, Nacional'naja literatura: Prosloe ili buduscee?, in: Literaturnaja Gazeta, 23.6.1969, S.4.

- N. Vorob'eva/s. Chitarova, Nazad, k'istokam' ili ot 'istokov' $v$ budustee?, in: Literaturnaja Gazeta, 10.12.1969, S.4.

- G. Lomidze, Ne mif, a real'nost'!, in: Literaturnaja Gazeta, 3.6.1970, S.5.

2) Vgl. Vorob'eva/Chitarova, aao.

3) Zemija. Ljudi. Literatura., in: Družba narodov, 1970 , Nr.9, S.247-275. 
auf die "analytische" Prosa, v.a. die Texte F. Abramovs, v. Tenäjakovs und B. Mozaevs aus. " Der "Pessimismus" in der Darstellung der Dorfgegenwart und die "Umwertung der Werte" (pereocenka cennostej) in der Darstellung der historischen Vergangenheit - gemeint ist besonders die Darstellung der Kollektivierung und der Dorfsituation während des Kriegs - werden scharf von P. Strokov angegriffen. 2) Besonders "Iz Zizni Fedora Kuz'kina" (B. MoKaev, 1966) gilt als Negativparadigma einer übertreibenden und das Typische verleugnenden Anschwärzung der Kolchosordnung.

Diese Kritik wird von offizieller seite unterstützt. Sie richtet sich fast ausschlieBlich gegen "Novyj Mir" Autoren. Auf dem vierten KongreB des Schriftstellerverbands der UdSSR (1967) wird Mozaev wegen der positiven Darstellung einer gegen den Kolchos agierenden Figur scharf angegriffen. 3)

Neben Možaev wird besonders Abramov kritislert. Abramov hatte bereits 1963 nach dem Erscheinen seiner als schwarz-

1) Vgl. bes. den Grundsatzartikel von P. Strokov, Zemlja i ljudi, in: Ogonek, 1968, Nr.22, S.26: "K sozaleniju, nastojascego kritiðeskogo razgovora ob 'analiticeskoj', to est' problemnoj, 'derevenskoj proze' exte ne bylo." Als Repräsentanten dieser Prosa werden F. Abramov, B. MoZaev, v. Tendrjakov, V. Suksin und S. Zalygin - allesamt "Novyj Mir"-Autoren - genannt. Diesem Artikel wird von der "Ogonek"-Redaktion der Leserbrief eines Rajkom-Sekretärs vorangestellt, der sich - als Kenner der Situation und Betroffener - über die ausschliebliche Darstellung der "Schwierigkeiten" und "Schattenseiten" des Dorfs, über die Nichtbeachtung der "Verbundenheit des Dorfs mit den großen Ereignissen, die im Land und in der Welt stattfinden", sowie uber die Darstellung der Bauern als "Käuze" und "Menschen nicht von dieser Welt" beschwert. Namentlich genannt werden ebf. nur "Novyj Mir"Autoren (S.25). (Der Abdruck von Leserbriefen, die die Empörung der Betroffenen uber ihr eigenes Bild in der Literatur zum Ausdruck bringen und damit die Autoren gleichsam der Beleidigung des Volks und der Leser bezichtigen, ist ein auch in anderen zusammenhängen $z u$ beobachtendes Verfahren.)

2) Strokov, aaO, S.26.

3) Vgl. G.Markov, Sovremennost' i problemy prozy, in:Cetvertyj s-ezd pisatelej SSSR, 22-27 maja 1967 goda. Stenogratiðeskij otとet, Moskau 1968, S.14f. 
malerisch kritisierten Erzählung "Vokrug da okolo" seinen Platz in der Redaktion der zeitschrift "Neva" verloren. In der "Literaturnaja Rossija" wird 1968 eine Kontroverse zwischen P. Strokov und A. Michajlov um Abramovs Roman "Dve zimy i tri leta" (1968) veröffentlicht, in der strokovs scharfe Kritik am mangelnden "Optimismus" der Darstellung von der Redaktion der zeitschrift unterstutzt wird. ")

IV.2.5. Die nationalistisch-ruralistische strömung um die Zeitschrift "Molodaja Gvardija"

D. Brown ${ }^{2)}$ A. Yanov ${ }^{3)}$ und V. Pavlov ${ }^{4}$ stellen kenntnisreich die nationalistisch-ruralistische literaturkritische strömung am Ende der sechziger Jahre dar. Sie wird hauptsächlich von der Zeitschrift "Molodaja Gvardija" repräsentiert und mit dem Etikett "Čalmaevismus" (nach ihrem Hauptvertreter $v$. Calmaev) versehen. 5) pavlov und Yanov betonen die zumindest zeitweilige Protektion der Bewegung durch Teile der Parteiführung. Alle sehen die Ursache in der Krise des offiziellen sowjetischen Weltbilds und charakterisieren die Bewegung als einen Versuch, neue identifikationsstiftende Werte zu schaffen. Deren wichtigste sind:

- scharfe kulturelle Abgrenzung des Ostens vom Westen, v.a. vom "Amerikanismus" 6 )

1) P. Strokov, Prostet ili zadannost'?, in: Literaturnaja Rossija, 7.6.1968, S.8-9; Ot redakcil, ebd., S.9.

2) D. Brown (1972), aao.

3) A. Yanov, The Russian New Right. Right-wing Ideologies in the Contemporary USSR, Berkeley 1978. - Yanov untersucht v.a. die Beziehungen zwischen offiziellem und dissidentem Nationalismus.

4) V.N. Pavlov, Spory o slavjanofil'stve 1 russkom patriotizme $v$ sovetskoj nauknoj literature 1967 - $1970 \mathrm{gg}$. , in: Grani, 1971, Nr.82, S.183-211. - Pavlov untersucht v.a. die Neurezeption des russischen slawophilentums sowie die Beziehungen zwischen drei von ihm konstatierten weltanschaulichen Hauptströmungen: Nationalisten, orthodoxen Marxisten und liberaler Intelligenz.

5) Vgl. Yanov, aaO, S.48.

6) Vgl. bes. V. Kalmaev, Neizbeznost', in: Molodaja Gvardija, 1968, Nr.9, S.259-289 und Ders., Velikie iskanija, in: Molodaja Gvardija, 1968, Nr.3, S.270-295. 
- Diabolisierung des "Kosmopolitismus" im eigenen Land"

- Neubewertung der russischen National- und Kulturgeschichte, Rehabilitaion des slawophilentums und der zaristischen russischen GroBmachtpolitik ${ }^{2}$ )

- Absage an den "Materialismus" als Lebenseinstellung der "Ubersättigung" (sytost'), Beschwören der "Geistigkeit" (duchovnost') und der auserwählten Rolle des russischen volkes unter diesem Aspekt ${ }^{3)}$

- Antiurbanismus und Antiintellektualismus, Mystifizierung des russischen "Bodens" und seiner Bewohner"

Der uns interessierende Aspekt besteht im Versuch dieser strömung, die Dorfprosa im Sinne einer nationalistischruralistischen Erneuerungsbewegung $z u$ funktionalisieren.

Dies geschieht in erster Linie durch die Interpretation der Helden bzw. ihres "narodnyj charakter". Calmaev sieht in ihnen "die tiefen Ideale des Guten" im Gegensatz zum materiellen Pragmatismus verkörpert; an "Za dolami, za lesami" (E. Nosov, 1966) wird positiv die "märchenhafte Reinheit und Naivität" der Charaktere hervorgehoben. 5) Im Sinn der zentralen Opposition von "Masse" (tolpa = durch die Gier nach materiellen werten verbunden) und "Volk" (narod = durch moralische und nationale Ideale verbunden) ${ }^{6)}$ wird Abramovs Darstellung des Dorfs in der Kriegs- und Nachkriegszeit ("Brat'ja i sestry", 1959; "Dve zimy i tri leta", 1968) interpretiert als Darstellung einer durch Not und Entbehrung hervorgerufenen moralischen Stärke des volks. 7) Diese antimaterialistische, moralischideelle Interpretation des "narodnyj charakter" findet man auch bei P. Glinkin. Die "kämpferische Leidenschaft" und der "Optimismus" der Helden Belovs, Ajtmatovs u.a. wurzelten

1) Vgl, bes. P. Glinkin, Zemlja i asfal't, in: Molodaja Gvardija, 1967, Nr.9, S.240-255 und M. Lobanov, Prosvecennoe mestanstvo, in: Molodaja gvardija, 1968, $\mathrm{Nr} .4,5.294-306$.

2) Vgl. 'Calmaev, Neizbeźnost', aao. S.263ff.

3) Vgl. ebd., S.272ff.

4) Vgl. Glinkin (1967), aao.

5) Calmaev, Neizbeznost', aao, S.275.

6) Ebd., S.271.

7) Ebd., 5.283 . 
in der moralischen Sphăre; die Darstellung der alten Figuren als Bewahrer der Tradition wird besonders hervorgehoben, ausdrücklich werden leidende Helden wie SolZenicyns Matrena zu Trägern des russischen Nationalcharakters erklärt. ${ }^{1)}$

Die "Erde" ist die Quelle dieser Qualitäten. Die Nähe zum Boden und zur heimatlichen Natur (im Gegensatz zum städischen Asphalt) wird von Glinkin mit den moralischen Eigenschaften der Helden in Zusammenhang gebracht. ${ }^{2}$ ) Das Dorf wird als der eigentliche Raum des "narodnyj charakter" verteidigt gegen die Ausdehnung des "narodnost" "Begriffs auf die stadt bzw. die stätische Intelligenz. ${ }^{31}$

Mit der Erdverbundenheit in engem zusammenhang steht die an stärksten betonte Eigenschaft des "narodnyj charakter", - seine Heimatliebe und sein Patriotismus. v. Semenov nennt die Liebe zur "kleinen Heimat", d.h. zur "Erde der Vorfahren", die Basis für die Liebe zur "groben Heimat"; er wendet sich gegen die kritik an der dorflichen Abgeschlossenheit der Figuren und sieht ihre "soziale Reife" in ihren "Mühen zum wohl der Heimat" begrundet. 4)

1) Vgl. P. Glinkin, Pafos vremeni, in: Volga, 1968, Nr.8, S.132. - Diese Betonung der autonom-moralischen Qualitäten des "narodnyj charakter" impliziert eine Ablehnung der Identifikation von "narodnost" und "partijnost" bzw. eine Umkehrung der kanonisierten Dominanzverhältnisse. Glinkin interpretiert die "partijnost" " des Ajtmatovschen Helden Tanabaj ("ProsCaj Gul'sary", 1966) als das "Vermogen eines Menschen, seine Handlungen in Ubereinstimmung mit seinen Idealen zu bringen" (S.136). An anderer Stelle sagt er, daß die "stabilen Vorstellungen des Volks über die Gerechtigkeit" die Quelle für eine "Korrektur der Normen des Parteilebens" seien. Vgl. Glinkin (1967), aaO, S.252.

2) Vgl. Glinkin (1967), aaO, S.252ff.

3) Vgl. Calmaev, Neizbežnost', aaO, S.276.

4) V. Semenov, Rodniki b'jut iz glubin, in: Zit' strastjami i idejami vremeni. Sbornik statej o literature, Moskau 1970. - Dieser Sammelband wird von A. Lanstikov, einem dem "Calmaevismus" nahestehenden Kritiker (vgl. seinen Artikel: Ostorozno, koncepcija!, in: Molodaja gvardija, 1969, Nr.2, S.275-297) herausgegeben. Vgl. ebf. V. Semenov, o rodine 'maloj' i bol'కoj, in: Molodaja Gvardija, 1966, Nr.10, S.288-300. 
Die Sprache der Dorfprosa wird im Sinne eines antimodernistischen Sprachpurismus gewürdigt. Entsprechend der Gesamtkonzeption der Bewegung wird von Calmaev der medialen "Inflation des Wortes" bzw. dem "entgeistigten Wort" (bezduchovnoe slovo) das "geisterfullte Wort" (oduchotvorennoe slovo) entgegengesetzt. ${ }^{1)}$

Die Bedeutung dieser strömung in der Literaturkritik ist nicht zu unterschatzen. 2war werden ihre offenen Verstobe gegen die herrschende Weltanschauung, v.a. ihr verabsolutierter Nationalbegriff und ihre Revision des offiziellen Geschichtsbildes von orthodoxer Seite kritisiert. Ihre Interpretation der Dorfprosa stobt besonders am Punkt des Einschlusses passiver Helden in die Trägerschaft des "narodnyj charakter" auf widerstand. Strokov veroffentlicht in "Oktjabr" "eine Kritik an den "Molodaja Gvardija"Autoren, in der er gegen die Einbeziehung von "Duldern" und "hăuslich-primitiven Wahrheitssuchern" wie Matrena und Ivan Afrikanovic polemisiert. 2)

Der Hauptangriffspunkt der orthodoxen Kritik ist $z u$ jener Zeit jedoch die Zeitschrift "Novyj Mir". Diè seit 1967 einsetzende Kritik an der zeitschrift (die 1970 zum Rücktritt A. Tvardovskijs als Chefredakteur führt) steht in der ersten Halfte des Jahres 1969 im Zeichen einer Konfrontation zwischen "Novyj Mir" und "Molodaja Gvardija", in der sich die orthodoxen Kritiker und Schriftsteller eindeutig auf die Seite der "Molodaja Gvardija" stellen. Die zentrale Affinitat besteht in der antiwestlichen bzw. antikosmopolitischen Komponente. Das geht bereits deutlich aus einem gegen "Novyj Mir" gerichteten Artikel A. MetCenkos im Januarheft von "Moskva" hervor, in dem er unter dem Aspekt des sich verschärenden internationalen ideologischen

1) Vgl. Calmaev, Neizbežnost', aao, S.159ff. Vgl. ebf. Lanstikov, aao, S.281f. und zur folkloristischen Stiltradition der Dorfprosa als Ausdruck ihrer organischen Votksverbundenheit Glinkin (1968), aaO, S.129.

2) P. Strokov, O narode-"Savrasułke", o "zagadkach" russkogo charaktera i iskanijach "pri svete sovesti", in: Oktjabr", 968, Nr.12, S.197. 
Kampfes die Position Calmaevs gegen die Vorstellungen von einer Abschwächung der nationalen Traditionen zugunsten internationaler Integrationsprozesse verteidigt. " Intscheidend wirkt sich diese Affinität dann in einem vom "Ogonek" veröffentlichten Brief von elf Schriftstellern (darunter die Dorfprosaisten M. Alekseev, S. Voronin, I. Zakrutkin, P. Proskurin, N. Sundik) aus, der die in "Novyj Mir" gefuhrte Kritik an der "Molodaja Gvardija" (und konkret ihrer Interpretation der Dorfprosa ${ }^{2}$ ), zum Anlas niment, einen Generalangriff auf die "kosmopolitische" Tendenz in "Novyj Mir" zu starten. 3)

Die Kritiker von "Novyj Mir" vertreten in ihrer eigenes. Bewertung der Dorfprosa in der Heldenfrage eher orthodoxe Positionen. I. Dedkov differenziert zwischen "aktiven" und "hilflosen, schwachen, mitleiderregenden" Helden. ") Der Stein des AnstoBes liegt für die Autoren des Briefs jedoch besonders in A. Dement'evs' Ablehnung der moralischen Idealisierung der Bauernfiguren als Trägern nationaler Traditionen $^{5)}$ und in seiner prinzipiellen Kritik an der antikosmopolitischen Ausrichtung. "6) Gegen die westliche Infiltration von "Nihilismus" und "oberflächlichem Intellektualismus ohne moralische Normen" 7 ) wird der moralpädagogische Wert der Liebe zur "Erde" und zur

1) Vgl. A. MetČenko, Sovremennoe i veð̌noe, in: Moskva, 1967, Nr.1, S.204.

2) - I. Dedkov, Stranicy derevenskoj Zizni, in: Novyj Mir, 1969, Nr.3, S.231-246.

- A. Dement'ev, o tradicijach i narodnosti, in: Novyj Mir, $1969, . i x .4$, S.215-235.

3) Protiv ל̌ego vystupaet "Novyj Mir"? Pis'mo v redakciju, i..: Ogonek, 1969- Nr.30, S.26-29.

4) Deckov, aaO, S.241.

5) Kritisiert wird insbesondere Dement'evs Bezeichnung der Dorflyriker der "Molodaja Gvardija" als "muxestvujuscie". Vgl. Protiv Zego vystupaet "Novyj Mir"?, aaO, S.28.

6) Kritisiert wird insbesondere Dement'evs Auberung, man solle die Gefahren fremder Ideologien nicht übertreiben. vgl. Protiv Zego vystupaet "Novyj Mir"?, aao, S.27.

7) Protiv Čego vystupaet "Novyj Mir"?, aaO, S.26. 
"kleinen Heimat" betont." Das Verdienst der "Molodaja Gvardija"-Autoren im Kampf gegen die "Gefahr fremder ideologischer Einflüsse" und "kosmopolitische Integration" wird ausdrücklich hervorgehoben. ${ }^{2)}$

\section{IV.2.6. Exkurs: Zum Verhältnis von Junger Prosa und Dorfprosa}

Einen der wichtigsten normenevolutionären zusammenhänge zwischen der gesamtliterarischen Reihe und der Unterreihe Dorfprosa bildet das Verhältnis zwischen der "Jungen Prosa" (molodaja proza) und der Dorfprosa. Die Tatsache, das die Dorfprosa die Junge Prosa von der führenden Stelle in der literarischen Hierarchie verdrängt, darf jedoch nicht vorschnell auf ein gröberes innovatorisches potential der Dorfprosa zurückgefuhrt werden. Im folgenden soll einigen Aspekten des Verhältnisses zwischen diesen beiden Unterreihen Aufmerksamkeit geschenkt werden, die sich aus der Untersuchung der normenbildenden Instanz Literaturkritik ergeben. Die Hypothese ist, daB die Dorfprosa zeitweilig, nämlich Mitte bis Ende der sechziger Jahre, von einem groBen Teil der Literaturkritik - einschlieblich der offiziellen Ebene der Schriftstellerkongresse - als leitbildstiftende, moralpädagogisch funktionalisierbare Literatur u.a. aus dem Grund gefördert wird, weil man in ihr ein willkommenes Gegengewicht zur systemaffirmativ kaum funktionalisierbaren Jungen prosa und inrer Nachlaufer $2 u$ besitzen glaubt. Auch der seit 1967 aufbrechende Konflikt um die Funktionalisierung der Dorfprosa (s.o.) ist unter diesem - gesamtliterarischen Aspekt sekundär. Der streit um die Definition des "narodnyj charakter" ist dem prinzipiellen Konsens hinsichtlich seiner integrativen Leitbildfunktion gegenuber den desintegrierten Helden der Jungen Prosa untergeordnet. Die Koalition zwischen orthodoxer und nationalistisch-ruralistischer strömung erklärt sich nicht zuletzt aus diesem Verhältnis.

1) Protiv Cego vystupaet "Novyj Mir"?, aao, S.28.

2) Ebd., S.26. 
Die wesentlichen Aspekte der positiven Abgrenzung der Dorfprosa von der Jungen Prosa sind:

1) Die Helden der Dorfprosa werden als Träger moralischer Ideale den moralisch entwurzelten Helden der Jungen Prosa gegenubergestellt. Man entdeckt in den ersteren die Verkörperung eines neuen Heroismus gegenuber der nihilistischen Verweigerung der "jungen" Helden. Grundlage dieser neuen Heldenkonzeption ist die Integration in die wertstiftende Gemeinschaft des "Volks".

Auf dem zweiten KongreB des Schriftstellerverbands der RSFSR (1965) wird die Junge Prosa im Hauptreferat L. Sobolevs scharf kritisiert; ihre Helden seien durch "Skeptizismus", "MiBtrauen gegen jede Autoritat", "zynismus in Fragen der Moral", "Unruhe", "Unzufriedenheit mit der ordnung der Dinge", "Protesthaltung" charakterisiert. 1) Die Dorfprosa wird demgegenüber positiv gewurdigt; ihre Helden strahlten "innere Energie" und "seelischen Reichtum" aus."

F. Kuznecov veröffentlicht $1966 / 67$ in der zeitschrift "Junost" den Grundsatzartikel "K zrelosti" 3 ), in dem er die Deskription einer organischen Evolution von der "Bekenntnisprosa" (ispovedal'naja proza) zu einer "nüchtern-realistischen Prosa", in der die Dorfprosa einen wesentlichen Platz einnimmt, versucht. ${ }^{4)}$ Die Differenzen der Literaturkritik hinsichtlich der Bewertung der Jungen Prosa bzw. Bekenntnisprosa interessieren in diesem Zusammenhang nicht. ${ }^{5)}$ Entscheidend ist die auch von dem um Integration bemüten Kuznecov vorgenommene

1) Sobolev, aao, S.4.

2) Ebd.., S.5.

3) F. Kuznecov, K zrelosti. 1.Konec "Ketvertogo pokolenija", in: Junost', 1966, $\mathrm{Nr} .11, \mathrm{S.83-86.}$

2. Ot ispovedanija - $k$ issledovaniju, in: Junost', 1967, $\mathrm{Nr}$.3, S.59-64.

3. Sopričastnost' Zizni, in: Junost', 1967, Nr.5, S.83-88.

4) Kuznecov, K zrelosti (1. Teil), aaO, S.84.

5) Kuznecov erkennt die -zeitweilige - Legitimitat der Bekenntnisprosa an und wendet sich gegen die orthodoxe Kritik. Er rechnet auch die neue Dorfprosaistengeneration zu den Vertretern der Jungen Prosa. 
Abgrenzung: Die "imner stärkere Hinwendung zum Leben derer, durch deren Arbeit alles auf Erden aufrechterhalten wird", wird als Motivation fur eine Entwicklung der Literatur von "einer dem Leben des Volkes gegenüber gleichgultigen Oberflächlichkeit $z u$ den Urgründen (pervoosnovy) der geistigen, moralischen Verfassung des Lebens unserer Gesellschaft" bezeichnet. ") In der Uberwindung der "Infantilität" der Bekenntnisprosa wird besonders die neue Heldenkonzeption am Beispiel Tanabajs aus "Proscaj Gul'sary" gewirdigt; hier sei der "heroische Charakter" des Helden der Gegenwart, der in "staatsbürgerlicher Ehrenhaftigkeit" (grazdanskaja Kestnost'), "Prinzipientreue" und "Uberzeugtheit" bestehe, in vorbildlicher Weise dargestellt. 2)

Im dritten Teil des Artikels, in dem die Dorfprosa als Ganze von der Bekenntnisprosa abgegrenzt wird, kommt der Aspekt der "narodnost" als wertstiftende und integrative Basis der Heldengestaltung zur Geltung. ${ }^{3)}$

In der nationalistisch-ruralistischen Strömung betont besonders Glinkin diesen Aspekt der Abgrenzung:

"No est' dve tendencii $v$ sovremennoj nasej proze. Odna, predstavlennaja 'molodoj', ili, po novejsej terminologii, 'ispovedal'noj', 'intellektual'noj' prozoj, izzivaet sebja, obnaruziv besplodnost', otorvannost' ot narodnych istokov: drugaja, blizkaja zemnym interesam svoego naroda, vyrabatyvaet polozitel'nuju programmu nravstvennogo vospitanija sovremennika i uverenno nabiraet sily." 4)

Die Extegration aus dem wertstiftenden Zusammenhang des "Volks" wird als eigentliche Ursache der "Kleinheit", "Unbedeutendheit" der Helden der Jungen Prosa angesehen: sie litten am "Komplex der Minderwertigkeit, weil ein

1) Kuznecov, K zrelosti (2. Teil), aao, S.60.

2) Ebd. , S.63f.

3) Selbst die unterschiedlichsten Interpretationen der "narodnost" "bzw. des "narodnyj charakter" stimmen in der grundsätzlichen Betonung ihrer wertstiftenden und integrativen Funktion gegenuber den vom "Volk" isolierten Helden der Jungen Prosa uberein. Auf diesen Zusammenhang kommt es hier an: Kuznecov selbst vertritt eine deutlich "historische" bzw. "soziologische" Position in der Definition der "narodnost" . Vgl. Kuznecov, K zrelosti (3.Teil), aao, S.87.

4) Glinkin (1968), aao, S.131. 
Volk für sie nicht existiert": "1) ihr verhalten stehe "auBerhalb der Grenzen des Moralkodex des Volkes". 2)

2) Ein besonderer Aspekt der integrativen und wertstiftenden Funktion der "narodnost" ist das nationale Gemeinschaftsgefühl. Auch hier sind die unterschiedlichen Definitionen und Gewichtungen des nationalen Aspekts des "narodnyj charakter" (s.0.) kein Hindernis für den Konsens, wenn es um seine Aktivierung in der Abgrenzung der Dorfprosa von der Jungen Prosa geht.

Am schärfsten akzentuiert die nationalistisch-ruralistische Strobmung diesen Aspekt und wird hierin von der orthodoxen Gruppe um "Ogonek" unterstüzt. Besonders die Westorientierung der Jungen Prosa wird zum Abgrenzungspunkt. ${ }^{3)}$ (Ein Nebenaspekt ist der Versuch, anstelle der Entwicklungslinie Junge Prosa - Dorfprosa eine Traditionslinie zwischen der Kriegsprosa und der Dorfprosa unter patriotischem Aspekt herzustellen. ${ }^{4)}$ )

Auch Vertreter der antinationalistischen position grenzen die beiden Unterreihen unter dem nationalen Aspekt voneinander $a b .{ }^{5)}$ Selbst die Verfechter einer historischen Relativierung des Nationalitätsbegriffs in der Diskussion von 1969 und 1970 wenden sich scharf gegen die "nationslosen Helden" (beznacional 'nye geroi) bzw. "Sternenjungen" (zvezdnye mal'(tiki) der Jungen Prosa. ${ }^{6 \text { ) }}$

1) Glinkin (1967), aaO, S.245.

2) Ebd., S.248. Vgl. ebf. Semenov (1970), aaO, S.42f.

3) Vgl. Lobanov, aao und den bereits zitierten Brief im "Ogonek". Die Westorientlerung wird auch auBerhalb der "Molodaja Gvardija"-Diskussion zum Abgrenzungspunkt. Vgl. bes. im Zusammenhang der lyrischen Prosa Siskina, aao, S.181 f (s. Anm.2 auf S.56).

4) Vgl. Semenov (1966), aaO, s.298f (über die Kriegserzählungen V. Astaf'evs, E. Nosovs, P. Proskurins u.a.).

5) Vgl. bes. Kuznecov, $K$ zrelosti (3. Teil), aaO, S.83.

6) Vgl. Ivanov, aao, S.3. - Die "nihilistische Skepsis" der Helden der Jungen Prosa, ihr "kalter Egoismus" wird hier aus ihrer nationalen Entwurzelung abgeleitet. Vgl. ebf. Lomidze, aao. - Lomidze kritisiert die Gleichgultigkeit der Helden der Jungen Prosa gegenüber den werten und der Geschichte der eigenen Nation. 
3) Eine weitere Komponente des "narodnyj charakter", die zwar in der Bewertung der Dorfprosa selbst unstritten ist, in der Abgrenzung von der Jungen Prosa jedoch auch von einigen antiruralistischen kritikern aufgegriffen wird, ist der Antiintellektualismus. Hier wird wieder auf die integrative Funktion des "Volks" für die Helden der Dorfprosa im Gegensatz zu den individualistischen Intellektuelien der Jungen Prosa und ihrer Nachläufer Wert gelegt. Stellvertretend sei V. Protkenko zitiert:

"Predstavlennye $v$ sovremennoj derevenskoj povesti ljudi prostogo truda, casto ne imejustie daze snosnogo కkol'nogo obrazovanija, po glubine i soderzatel'nosti svoego nravstvennogo suకcestva okazyvajutsja vo mnogich otnoకenijach nesravnenno vyకe poludivకich neskol'ko let nazad chołdenie $v$ nasej literature predstavitelej poverchnostnogo intellektualizma, preispolnennych soznanija sobstvennoj 'elitnosti' i posemu splos' i rjadom predpotitavich ne obremenjat' sebja $v$ otnošenijach s okruzajuscimi, $v$ ponjatil vnutrennego dolga 'ustarevsimi uslovnostjami' etileskimi normami, vyrabotannymi v trudovom opyte naroda." 1 )

Für die nationalistisch-ruralistische strömung ist die antiintellektualistische Interpretation des "narodnyj charakter" von grundlegender Bedeutung (s.o.). V. Aksenov und A. Gladilin werden unter diesem Aspekt von Calmaev aus einer "echt volksverbundenen kunst" (podlinnoe narodnoe iskusstvol ausgeschlossen. 2)

4) Ein letzter mit der Heldengestaltung zusammenhängender Aspekt der Abgrenzung ist das Generationenverhältnis. Auch hier ist der Konsens nicht so weitgehend wie in den ersten beiden Punkten, was mit der Kritik an den alten Figuren in der Dorfprosa zusammenhängt (s.o.). Diese Kritik schließt jedoch eine integrative Funktionalisierung der Generationenharmonie in der Dorfprosa gegenüber dem Generationenkonflikt in der Jungen Prosa nicht aus. ${ }^{3)}$

1) Protð̌enko (1970), aao, s.77.

2) Calmaev, Neizbeznost', aao, S.261f.

3) Vgl. zur desintegrativen Funktion des Generationenkonflikts in der Jungen Prosa Sobolev, aao, S.3. 
Der MiBachtung für die WertmaBstäbe und Erfahrungen der der alteren Generationen bei den Helden der Jungen Prosa stellt Semenov - am Beispiel von "Rodnye" (V. Lichonosov, 1967) - das Interesse der Kinder für die Lebensschicksale ihrer Vorfahren in der Dorfprosa gegenüber. " ${ }^{1)}$ Auf dem dritten KongreB des Schriftstellerverbandes der RSFSR (1970) betont M. Alekseev das generationenvereinigende Band in der Dorfprosa besonders unter dem Aspekt der Sprache. 2)

5) Der sprachliche Aspekt spielt neben dem Figurenaspekt bei der Abgrenzung eine entscheidende Rolle. Der "narodnyj jazyk" der Dorfprosa wird dem "Jargon" der Jungen Prosa entgegengesetzt. Diesem Problem wird auf den Schriftstellerkongressen von 1965 und 1970 groBe Aufmerksamkeit geschenkt. Sobolev weist 1965 auf die Notwendigkeit hin, den "narodnyj jazyk" als das Medium, das die geistigen Qualitäten des "Volkes" zum Ausdruck bringe, zu verteidigen gegen den aus Vulgaritäten und geistigem Aristokratismus gemischten Jargon der Jungen prosa. 3) 1970 betont Alekseev neben der generationenvereinigenden Funktion die "patriotische" Funktion des "rodnoe slovo" der Dorfprosa. ")

In der literaturkritischen Publizistik besteht an diesem Punkt wieder weitgehend Konsens. Sowohl der Ruralist Semenov als auch der Antiruralist Ivanov grenzen den "Jargon" der Jungen Prosa unter dem Aspekt seiner Standardisierung und Erstarrung von der "Lebendigkeit" des "narodnyj jazyk", der sich aus dessen verbundenheit mit der volkssprachlichen Tradition speise, ab. ${ }^{5)}$

wir haben uns in diesem Exkurs auf den besonderen wert

1) Vgl. Semenov (1970), aao, S.43f.

2) Vgl. M. Alekseev, Nekotorye problemy sovremennoj prozy, in: Tretij s-ezd pisatelej RSFSR, 24-27 marta 1970 goda. StenografiCeskij otCet, Moskau 1972, S.39.

3) Vgl. Sobolev, aao, S.3.

4) Alekseev, aaO, S.38. Vgl. ebf. die Rede des Dorfprosaisten A. Anan'ev, in: Tretij s-ezd pistatelej RSFSR, aaO, S. 312 .

5) Vgl. Semenov (1966), aaO, S. 300 und Ivanov,aaO, S.3. 
konzentriert, welcher der Dorfprosa für die Kritik an der Jungen Prosa beigemessen wird. Der ungekehrte Aspekt - das Verhältnis einer der Jungen Prosa gegenüber positiv eingestellten Kritik (einer Minderheit) zur Dorfprosa muB hier unberücksichtigt bleiben. ${ }^{1)}$

IV.3. Siebziger Jahre

THESE: In den siebziger Jahren wird die Dorfprosa vom dominierenden Teil der Kritik prinzipiell abgelehnt. stattdessen wird eine neue Kolchosliteratur gefordert, welche den sozialökonomischen Umschwung auf dem Land, besonders den TechnisierungsprozeB darstellen soll. Der seit Ende der sechriger Jahre entstandene Konflikt um die auBerliterarische Funktionalisierung wird entscheidend modifiziert. Die "soziologische" strómung läBt jeglichen sozialanalytisch-kritischen Aspekt vermissen und befurwortet eine apologetische Darstellung der für gesetzmäBig erklärten gesellschaftlichen Prozesse. Die "moralische" Stromung wendet sich prinzipiell gegen eine utilitaristische Funktionalisierung der Literatur und betont die Notwendigkeit der sozialphilosophischen und ethischen Reflexion als Gegengewicht zum sich verselbständigenden Technisierungsproze $B$. Angesichts der Vertiefung der thematischen Dimensionen ist auch für diese Position das Ende einer nach primăr geosozialen thematischen Merkmalen definierten Dorfprosa gekommen. Vor dem Hintergrund der utilitaristischen Funktionalisierungsversuche vertieft sich die kluft zwischen Literaturkritik und Schriftstellern.

1) Dieses Verhältnis bestimmt sich nicht durch Abgrenzung. Hier ist besonders auf zwei Aufsätze von I. Antopol'skij zu verweisen, der un eine literaturhistorische Integration von Junger Prosa und Dorfprosa unter dem Aspekt der gesellschaftlichen BewuBtseinskrise bemüht ist. Vgl. I. Antopol'skij, Korni Celoveka, in: Junost', 1969, Nr.1, S.67-70; Ders., Puti i poiski, in: Novyj Mir, 1973, Nr.7, S.247-257. 
IV.3.1. Normenkonflikt um thematische Aktualitat

Dle soziologische Funktionalisierung der Literatur

Seit Anfang der siebziger Jahre wird die Frage der thematischen Aktualität mit bisher unbekannter Schärfe zum Gegenstand des Normenkonflikts. Als Markierungspunkte können die beiden Schriftstellerkongresse von 1970 und 1971 angesehen werden. Auf dem fünten KongreB des Schriftstellerverbandes der UdSSR (1971) wird unter diesem Aspekt die Dorfprosa als Ganze zum erstenmal hauptseitig negativ beurteilt. G. Markov macht ihr im Hauptreferat den Vorwurf, nicht auf die sozialökonomischen Umschwünge im Dorf zu reagieren und wirft ihren Autoren "Trägheit", "Gewöhnung an ein bestimmtes Schema" und "veraltete Vorstellungen über das Dorf" vor. " In den folgenden Jahren finden verschiedentlich Diskussionen uber die Dorfprosa statt, die ganz im zeichen der Ausrichtung auf eine aktuelle, am Vorblld der ocerk-literatur orientierte Berichterstattung uber landwirtschaftliche probleme stehen. ${ }^{2)}$ Im April 1971 wird auf einer Plenarsitzung der Leitung des Schriftstellerbandes ein Grundsatzreferat über die Entwicklung der Dorfprosa von $v$. Surganov vorgetragen, in dem eine prinzipielle Umorientierung der Dorfprosa in diesem Sinne

1) G. Markov, Sovetskaja literatura $v$ bor'be za kommunistiłeskoe stroitel'stvo i ee zadaci $v$ svete resenij XXIV s-ezda KPSS, in: Pjatyj s-ezd pisatelej SSSR, 29 ijunja - 2 ijulja 1971 goda. Stenograficeskij otłet, Moskau 1972, S.12f. Vgl. auf dem dritten KongreB des Schriftstellerverbandes der RSFSR (1970) bes. die Reden von $A$. Anan'ev und $V$. Lipatov, in: Tretij s-ezd pisatelej RSFSR, aaO, S.311-315 und 344-349.

2) Hier ist besonders aufschlubreich ein Rundtischgespräch der "Literaturnaja Gazeta" aus dem Jahr 1974, an dem Schriftsteller - vorwiegend Vertreter der neuen oterkistenGeneration - und ortliche Landwirtschaftsfunktionăre eines moldavischen Rajon teilnehmen. Die Diskussion mit dem programmatischen Titel "Novoe selo - novye geroi" trägt den Charakter einer Informationsveranstaltung uber die Situation der Kolchosen unter den Bedingungen der "naturwissenschaftlich-technischen Revolution", in der die Schriftsteller bei den Spezialisten in die Lehre gehen. Vgl. Novoe selo - novye geroi. Kruglyj stol, in: Literaturnaja gazeta, 23.10.1974, S.2 und 4 . 
gefordert wird. ${ }^{11}$

Der Gipfel dieses Normenkonflikts ist $1972 / 73$ mit einem in "Voprosy literatury" veröffentlichten Artikel E. Starikovas sowie der daran anschliebenden Diskussion erreicht. ${ }^{2}$ ) Starikova lehnt die gesamte Tradition der "derevenstiki" ab und stellt ihr als Alternative die neuen oxerkisten (L. Ivanov, I. CerniCenko u.a.) entgegen. Der Kern ihrer Kritik besteht in der Feststellung eines Widerspruchs zwischen den Themen und Problemen der Dorfprosa und den Erkenntnissen der Soziologie. ${ }^{3)}$ Die Helden der Dorfprosa werden als soziologisch irrelevant, "nicht existent" bzw. "ausgedacht" bezeichnet. ") In der anschlieBenden Diskussion stellt sich die Mehrheit der Teilnehmer hinter Starikova. Ju. Galkin radikalisiert ihre Position bezüglich der auBerliterarischen Funktionalisierung und befurwortet eine "Zusamenarbeit von Soziologie und Literatur". 5)

In sämtlichen genannten Artikeln und Diskussionen konzentriert sich die Forderung nach thematischer Aktualitat auf zwei Punkte:

- Konzentration auf die neuen, gebildeten, in technischen Berufen arbeitenden Helden

- Darstellung der engen Verbindung zwischen Dorf und stadt.

IV.3.2. Aufbrechen des nationalistisch-ruralistisch/ orthodoxen Konsens

Der Niedergang des Calmaevismus seit 1970 wird im Gesamtzusammenhang von A. Yanov dargestellt. 6) wir konzentrieren uns auf die für die Dorfprosa entscheidenden Punkte.

1) Vgl. Surganov (1971), aao, S.22ff.

2) - E. Starikova, Sociologiteskij aspekt sovremennoj "derevenskoj prozy", in: Voprosy literatury, 1972, $\mathrm{Nr} .7, \mathrm{~S} .11-35$.

- Sociologiלeskij aspekt sovremennoj "derevenskoj prozy". Vystupajut: $\zeta$. Galimov, Ju. Galkin, S. Surtakov, L. Ivanov, in: Voprosy literatury, 1973, Nr.3, S.45-78.

3) Vgl. Starikova (1972), aaO, S.27.

4) Ebd.. S.25.

5) Ju. Galkin, Derevnja - literaturnaja i podlinnaja, in: Voprosy literatury, 1973, Nr.3, S.58.

6) Vgl. Yanov, aaO, S.52ff. 
In L. Jakovlevs Artikel "Protiv antiistorizma" vom November $1972^{1)}$ - der als zentraler parteiautorisierter Schlag gegen den Calmaevismus gilt ${ }^{2}$ - wird die Abgrenzung von analytischer und lyrischer Prosa neu zum Programm

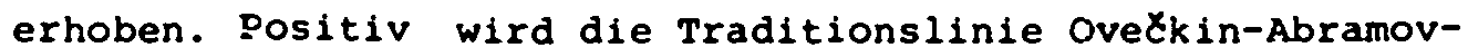
Doroł u.a.. die sich durch "ökonomische Analyse" auszeichne, von den "lyrischen Erzählungen" und "philosophischen Essays" der jüngeren Dorfprosaisten abgegrenzt. ${ }^{3)}$ Der Schwerpunkt des Artikels liegt auf der Kritik des ahistorischen "narodnost" "Verständnisses, besonders der damit verbundenen Idealisierung der rückständigen Elemente der alten Bauerngeneration und der Antagonisierung von Bauernschaft und Intelligenz.

In diesem Zusammenhang scheint die 1972 erlassene - nicht publizierte - Parteiverordnung lber die Literaturkritik von Bedeutung $z u$ sein, der als ein Schwerpunkt die Kritik des vergangenheitsorientierten "narodnost" "-Verstännisses zugeschrieben wird. ${ }^{4)}$ Dieses Problem wird seit 1973 in mehreren Artikeln linienkonform abgehandelt, wobei der schädiche EinfluB der nationalistisch-ruralistischen Kritik auf die Entwicklung der Dorfprosa festgestellt wird" ${ }^{5}$ und als zentrale Kritikpunkte an der Konzeption des "narodnyj charakter" in der Dorfprosa dessen Statik und Trăgheit sowie seine räumliche Isolierung festgemacht werden. ${ }^{6)}$

IV.3.3. Die neue Qualität des Funktionalisierungskonflikts: Soziologische Apologetik vs. philosophische Problematisierung

Die Position der "Soziologen" bleibt bis Ende der siebziger Jahre dominant. Die beiden in Kap.II. zitierten Monographien von Terakopjan und Surganov liegen auf dieser Linie. Auf dem

1) L. Jakovlev, Protiv antiistorizma, in: Literaturnaja Gazeta, 15.11.1972, S.4-5.

2) Vgl. Yanov, aaO, S.57.

3) Jakovlev, aao, S.5.

4) Vgl. A. Chvatov, Certy narodnosti, in: Nas sovremennik, 1973, Nr.1, S.179.

5) Vgl. F. Kuznecov, Sud'by derevni $v$ proze i kritike, in: Novyj Mir, 1973, Nr.6, S.247

6) Vgl. Chvatov, aao, S.180 und 185. 
sechsten Kongre $B$ des Schriftstellerverbandes der UdSSR (1976) wird bereits aus der Themenstellung der sitzung - "Arbeiterklasse in Stadt und Dorf und das Problem des wissenschaftlich-technischen Fortschritts" - die Diskussionsrichtung deutlich. V. Kozevnikov betont im Hauptreferat, die erforderlichen neuen Helden der Dorfprosa - als "ländlicher Teil der Arbeiterklasse" - liebten die Maschine gleichermaben wie die Erde. ${ }^{1)}$ N. Gribacev wendet sich prinzipiell gegen eine Uberbewertung der Moral als literarischem Moment. ${ }^{2)}$ Kulminationspunkt dieser Entwicklung ist eine erneute Diskussion uber die Dorfprosa in der "Literaturnaja Gazeta" in den Jahren 1979 und 1980, in der die "soziologische" Funktionalisierung der Literatur endgulltig jeglichen sozialkritischen Aspekt einbüBt und ausschlieblich im Sinne einer apologetischen Darstellung des "objektiven", soziologisch sanktionierten wissenschaftlich-technischen Entwicklungsprozesses und seiner Auswirkungen auf das Dorf verstanden wird. ${ }^{3)}$ Der materielle Wohlstand der Kolchosen und Familien, die für alle spürbaren Wohltaten der technischen Entwicklung werden in verschönernder Weise zum literarischen Gegenstand erhoben. ${ }^{4)}$ Der soziologische Objektivismus wird auf die Spitze getrieben mit der Abgrenzung von "Kasus" (kazus) und "GesetzmäBigkeit" (zakonomernost"), - wobei als ein solcher "Kasus" die Situation in "Proscanie s Materoj" (V. Rasputin, 1976) bezeichnet wird, deren Ausnahmecharakter hinter einem "dichten Nebel von Trauer" nicht sichtbar werde."

1) Sestoj s-ezd pisatelej SSSR, 21 ijunja - 25 ijunja $1976 \mathrm{~g}$. StenografiŁeskij otŁet, Moskau 1978, S.55.

2) Vgl. ebd., S.91.

3) Gleichzeitig findet eine Diskussion in "Voprosy literatury" mit identischer Thematik und StoBrichtung statt. Die Mehrheitsverhältnisse für die "soziologische Position" sind hier noch eindeutiger als in der "Literaturnaja Gazeta". Vgl. Novoe v kolchoznoj derevne 1 literature, in: voprosy literatury, 1979, Nr.1, S.3-38.

4) Vgl. N. Zalinskij, Složnosti mnimye i real'nye, in: Literaturnaja Gazeta, 14.11.1979, S.4 und V. Bondarenko, V novuju derevnju - na telege?, in: Literaturnaja Gazeta, 5.12.1979, S.4.

5) A. Ustinov, Kto "pervyj paren" na derevne"?, in: Literaturnaja Gazeta, 10.10.1979, S.4. 
Sozialkritische Elemente der Dorfprosa - wie die Kritik der Stadtmigration - werden als dem "objektiven ProzeB" im Wege stehend angegriffen. " Deutliche Parallelen zum Aufbaupathos der dreibiger Jahre und der Nachkriegszeit sind festzustellen in der häufigen Beschwörung des "epochalen" Charakters des gegenwärtigen sozialökonomischen Prozesses; die Umwălzungen seien "gigantischer" als zur zeit der Kollektivierung. "2) Ein neues "Podnjataja celina" sei gefordert ${ }^{3)}$ bzw. eine "Neuland-Epopöe" 4 ).

A. Prochanov, der radikalste Verfechter dieser Position ${ }^{5)}$, spricht jeglichen kulturellen Werten, die dem objektiven EntwicklungsprozeB im Wege stehen, die Existenzberechtigung ab. Man düfe "das Leben" nicht der Grobheit, Hărte und Aggressivitat bezichtigen, um die kultur davor zu retten:

"Pravda vsegda žizn'. Kultura ze inogda vinovata."

Eine philosophische oder ethische literarische Problematik wird gleichsam für gegenstandslos erklart, indem die Opposition von "Geist" (duch) und "Maschine" auf rigorose Weise aufgelost wird: Angesichts der Allgegenwart der Maschine sei für den traditionellen Geist kein Platz mehr. Damit verbunden ist eine neue Dimension in der Kritik der Dorfprosaisten, die sich mit solchen problemen beschätigen. Ihre schriftstellerische Integritat wird in zweifel gestellt mit dem Vorwurf des "Snobismus" bzw. der "elitaren schule".

Säntliche Vertreter dieser Position sprechen sich gegen eine Weiterverwendung der Bezeichnung "Dorfprosa" aus, da sie $z u$ sehr mit der schule der "derevenstiki" vorbelastet sei und die neuen okonomischen und geosozialen verhälnisse nicht erfasse. ${ }^{6}$ )

1) Vgl. D. Angel'ev, Na novoj derevenskoj ulice, in: Literaturnaja Gazeta, 19.12.1979, S.4.

2) Vgl. V. Michal'skij, Boj s ten'ju, in: Literaturnaja Gazeta, 7.11.1979, S.6.

3) Vgl. ebd..

4) Ustinov, aao.

5) A. Prochanov, Metafora sovremennosti, in: Literaturnaja Gazeta, 12.9.1979, S.4 (im weiteren zit. nach ebd.)

6) Vgl. V. Surganov, Pered zavtrasnim dnem, in: Literaturnaja Gazeta, 12.3.1980, S.5. 
Die Gegenposition ist seit Anfang der siebziger Jahre in der Minderheit. Surtakov formuliert 1973 (als einziger Kontrahent Starikovas) eine Kritik am soziologischen "Objektivismus", der sich besonders hinsichtlich der behaupteten klassen- und bewuBtseinsmäBigen Umstrukturierungen der Bauernschaft als Augenwischerei entpuppe. ") ProtCenko bringt 1977 in einem gegen die "soziologische" Kritik gerichteten Artikel ${ }^{2}$ ) den prinzipiellen Widerspruch zwischen der utilitaristischen Funktionalisierung der Literatur und deren "sozialphilosophischen" Aufgaben zum Ausdruck."

Die innere Welt des einfachen Menschen in ihrer Eigenständigkeit, ihrer nicht ausschlieblich von auberen $\mathrm{zwängen}$ determinierten Entscheidungskompetenz dargestellt $z u$ haben, wird als grundlegend innovatorisches verdienst der Dorfprosa gewurdigt. ${ }^{4)}$

Die Bemulhungen um eine philosophische orientierung der Literatur kulminieren ebenfalls 1979 und 1980. Die Opposition "Geist" vs. "Maschine" wird von den Gegnern der "Soziologen" aufgegriffen im sinne einer notwendigen Orientierung auf "philosophische" und "allgemeinmenschliche" Probleme als Gegengewicht zur drohenden Verselbständigung des technischen Prozesses und seiner Sachlogik. 5) Diese Probleme seien weit entfernt von der Dorfthematik im ursprünglichen Sinn, weshalb man von einer "Dorfprosa" nicht mehr sprechen könne. $\left.{ }^{6}\right)$

1) Vgl. S. Surtakov, Zivoj Zelovek, a ne obstie cifry, in: voprosy literatury, 1973, Nr.3, s.65 und 70.

2) V. ProtCenko, Sovremennaja "derevenskaja proza" v literaturnoj kritike. Real'nye dostizenija i spornye ocenki, in: Russkaja literatura, 1977, Nr.2, 5.54-66.

3) Vgl. ebd., S.62.

4) Vgl. ebd.., S.64.

5) Vgl. B. Anasenkov, ... kak zerkalo NTR, in: Literaturnaja Gazeta, 17.10.1979, S.4 und V. Konov, Pogoda na zavtra, in: Literaturnaja Gazeta, 13.2.1980, S.4.

6) Vgl. B. MoXaev, Gde dysit duch?, in: Literaturnaja Gazeta, 31.10.1979, S.4 und Ju. Seleznev, Novye puti neizbezny. No.... in: Literaturnaja Gazeta, 20.2.1980, S.5. AuBerhalb dieser Diskussion vgl. zur Terminuskritik bes. T. Napalova, Nacional 'naja samobytnost' pisatelja 1 duchovnyj oblik geroja, in: Volga, 1972, Nr.10, S.147f. und $V$. Lavrov, Rassirenie gorizonta. O derevenskoj proze, in: V seredine semidesjatych, Leningrad 1977, S.121-140. Lavrov zitiert hier auBerdem mehrere AuBerungen von Dorfprosaisten, die sich gleichfalls gegen eine Weiterverwendung des Terminus wenden. 
Ein Kulminationspunkt ist in der zweiten Hälfte der siebziger Jahre auch im Konflikt zwischen Literaturkritik und Schriftstellern erreicht. Auf dem sechsten KongreB des Schriftstellerbandes der UdSSR (1976) bringen S. Zalygin, v. Astaf'ev und F. Abramov deutlich ihren widerstand gegen die utilitaristische Funktionalisierung der Literatur zum Ausdruck und betonen die Notwendigkeit einer literarischen Aufarbeitung der mit den sozialökonomischen Umwälzungen erlittenen ethischen und kulturellen verluste. ") Abramov polemisiert gegen die Geringschätzung und Ironisierung der "derevenšciki" durch eine Kritik, die vom zauberwort der "naturwissenschaftlich-technischen Revolution" - dem "Turm von Babel unserer Zeit" - geblendet sei." 1979/80 ist der schärfste Kritiker der "Soziologen" der Schriftsteller Mozaev. ${ }^{3)}$ Er stellt eine Analogie der aktuellen Angriffe der "Soziologen" zu der Kritik des Orthodoxen Strokov gegen die analytische prosa im Jahre 1968 her und macht damit deutlich, wie sehr sich vor dem Hintergrund veränderter Funktionalisierungszusammenhänge die Positionen verschoben haben. In der zweiten Hälfe der sechziger Jahre war zumindest für einen Teil der Kritik mit der analytischen prosa ein iterarisch wie auBerliterarisch (sozialkritisch) innovatives Moment verbunden. Unter den Schriftstellern war Mozaev selbst einer der exponiertesten Verfechter dieser Prosa. ${ }^{4)}$ Jetzt aber wird die "sozialanalytische" Orientierung der Literatur zum Schlagwort ihrer systemapologetischen Funktionalisierung, während ihre Autonomisierung gegenüber der unmittelbar sozialen Sphäre als Bedingung ihres literarischen wie auBerliterarischen (bewubtseinskritischen) Innovationspotentials verstanden wird.

1) Vgl. Sestoj s-ezd pisatelej SSSR, aaO, S.115-118 (Astaf'ev), 122-123 (Zalygin) und 574-575 (Abramov).

2) Ebd.. S.574.

3) MoZaev (1979), aao.

4) Vgl. Anm. 1 auf 5.75 . 


\section{v. Źanov-Ära}

Das Modell des unfassend integrierten Makrokosmos (M.1)

Das in der Kolchosliteratur der Zdanov-Ära entwickelte Normensystem bildet den Ausgangspunkt bzw. die Folie für die Normenevolution in der Tauwetterperiode. Der extrem hohe Verbindlichkeitsgrad dieses Normensystems bringt es mit sich, daB die modellkonstitutiven Merkmale auf den verschiedenen strukturebenen stereotyp wiederkehren. Deshalb scheint die exemplarische Darstellung anhand eines Textes sinnvoll. Aus verschiedenen in der RasskazAnthologie von $1952^{1)}$ veroffentlichten Kolchoserzählungen dient im folgenden "Vesna" (s. Antonov, 1947) 2) als Beispieltext. Begrenzte Varianten auf einzelnen Ebenen werden anhand weiterer Texte aus der Anthologie dargestellt.

THESE: Die Welt des Modells des unfassend integrierten Makrokosmos (M.1) ist eine storungsfreie, in all ihren Dimensionen harmonisierende Einheit. Vom Makro- bis zum Mikrokosmos erstrecken sich in sämtlichen Dimensionen homologe Hierarchien abgestufter Integrationsgrade. Alle Figuren sind gesellschaftlich integriert, Unterschiede betreffen den Grad ihrer Integration auf der von den privaten $z u$ den offentlichen gesellschaftlichen zonen aufsteigenden Skala. Desintegrierte Figuren sind Ausnahmen ohne störende Kraft. Die Naturwüchsigkeit dieser Integrationsstruktur basiert auf der Aquivalenz von naturlichen, moralischen und gesellschaftlichen Charaktermerkmalen der Figuren. Gesellschaftliche Verhältnisse werden naturalisiert.

Die Handlungen bestehen vornehmlich in der (wieder-) Herstellung kurzfristig gestörter harmonischer strukturen:

1) S. Anm. 1 auf S. 50 .

2) Zur Zitierweise der Texte: Die Quellen säntlicher in der Arbeit behandelten primartexte werden ausschlieblich im Literaturverzeichnis angegeben. Im darstellenden Teil der Arbeit beschränken wir uns - was verfahrensund lesetechnisch aufgrund der Anzahl der Texte sinnvoller erscheint - auf die Angabe von Titel, Autor und Erscheinungsjahr bei der ersten Nennung eines Texts. Die eingeklammerten Seitenangaben werden mit den im Literaturverzeichnis nachzuschlagenden Abkürzungen für die jeweiligen Texte versehen. 
im gesellschaftlich-öffentlichen Bereich in Form von Bewăhrungsmotiven, im privaten Bereich in Form von Liebesmotiven, wobei sich das Integrationsprinzip auf das Verhältnis $2 w i s c h e n$ diesen beiden Handlungsmotiven erstreckt.

Die räumliche Dimension dieser Welt umfaBt ein - homolog zur gesellschaftlichen Dimension - abgestuftes. bis in extrem weite ('sowjetische') Bereiche integriertes Feld. Die zeitliche Dimension wird von der Homologie zweier Zeitsysteme - Naturzeit und historische zeit geprăgt. Indem das raumliche substrat der Naturzeit (Räume des Wachsens, Blühens, Reifens) beide Zeitsysteme zugleich verkorpert, entsteht eine Chronotopizität, in welcher die historische zukunft sichtbar anwesend ist.

Es gibt nur ein Wertesystem in dieser Welt, welches von allen sie bevollkernden Figuren sowie vom Erzählsubjekt getelit wird. Dies findet seinen Niederschlag in der Standpunktkomposition, welche standpunktvielfalt allenfalls aus den der iertungsebene funktional untergeordneten Ebenen kennt. Die Wertungsebene selbst ist monologisch organisiert.

\section{V.1. Konfigurationsstruktur}

V.1.1. Dominanz der positiven Figuren

Nebenfiguren als Charakterisierungsfolie

In der Konfigurationstruktur isteine Basisnorm die Dominanz der positiven über die negativen Figuren. Oft existieren uberhaupt keine negativen Figuren; die Hauptfiguren bilden den hierarchischen Gipfel innerhalb einer graduell abgestuften Gemeinschaft positiver Figuren. Die Nebenfiguren dienen als Vergleichsfolie für die herausragenden Charaktereigenschaften der Hauptfiguren. Ein Beispiel für diese Variante ist "Bibliotekarsa" (S. Antonov, 1950): Besonders deutliche Vergleichsbeziehungen bestehen $\mathrm{zwischen}$ der Haupteigur Nadja und ihrer Freundin Klava. 
Beide sind jung, beide arbeiten in der viehzuchtbrigade, beide interessieren sich für Bücher. Die Unterschiede bestehen im Maß des weltanschaulichen Durchdringens ihrer sozialen und privaten Beziehungen. Nadja ist Rekordmelkerin und arbeitet zusätzlich in ihrer Freizeit als Bibliothekarin. Ihr gesellschaftliches Engagement prägt die Qualität ihrer zwischenmenschlichen Beziehungen, - zu den Bibliotheksbesuchern, denen sie als Erzieherin und Ratgeberin bzw. als Vermittlerin der entsprechenden Funktion der Bücher gegenübertritt, und zu Leonid Michajlovic, dem ebf. jungen Klubverantwortlichen, den sie in erster Linie als ihren Vorgesetzten begreift $(A B 145)$. Klava hingegen sieht ihre Arbeit in der Viehzuchtbrigade noch nicht als ihre von der Gesellschaft auferlegte Bestimmung, sie ist bereit, ihrem Bräutigam Pavel zuliebe in dessen Beruf als Fahrer überzuwechsein. Ihr lobenswertes Interesse für die Lektüre sozialistisch-realistischer Romane beschrainkt sich auf die private Liebesthematik ( $A B$ 148).

Die dominant als 'privat' charakterisierte Liebesbeziehung zwischen Klava und Pavel wird durch ein zusätzliches sujetstrukturelles verfahren zur charakterisierungsfolie fur das Verhältnis zwischen Nadja und Leonid Michajlovic. Der hohe strukturelle stellenwert dieses Verhaltnisses ist durch dessen Rahmenposition markiert (Anfang: von Nadja erwartete Ankunft Leonid Michajlovils, Betonung des 'offiziellen' Verhaltnisses 2 wischen beiden; Ende: verspätete Ankunft Leonid Michajlovids, Uberreichen eines 'persönlichen' Gratulationsgeschenks). Das Ende steht in kausalem Zusammenhang mit dem Verhaltnis Klava - Pavel. Leonid Michajlovil verspätet sich, da Pavel wegen Klava vergessen hat, ihn in seinem Auto mitzunehmen. Unmittelbar nach dieser Information folgt die Uberreichung des personlichen Gratulationsgeschenks an Nadja, welches im Dienst der gemeinsamen gesellschaftlichen Verpflichtung steht (Bücher für die Bibliothek) (AB 151). Vor dem Hintergrund einer nur 'privaten' Beziehung zwischen zwei Nebenfiguren wird in dieser Situation die gegenüber der 'offiziellen' Anfangssituation verănderte Qualităt der Beziehung Nadja Leonid Michajlovic als Einheit von gesellschaftlichem und persönlichem Interesse charakterisiert, die innerhalb des umgebenden Konnotationsfeldes als das Aufkeimen einer vorbildichen Liebe verstanden werden kann. 
In einer zweiten Variante bestehen deutlich markierte Oppositionen zwischen positiven und negativen Figuren. Doch haben auch in diesem Fall die negativen figuren lediglich die Funktion einer Charakterisierungsfolie. Die figurencharakteristischen Oppositionen werden nicht handlungskonstitutiv.

In "Vesna" besteht eine solche Opposition zwischen den Hauptfiguren Njusa und Vasilij Karpovic auf der einen Seite und ihren vatern auf der anderen Seite.

Die Väter werden als 'rückschrittlich', 'patriarchalisch', 'besitzgierig' charakterisiert. Njusas Vater ist Trinker. sie stehen jedoch auBerhalb der verschiedenen Handlungsstränge der Erzählung (s.v.2.). So steht etwa die für die beiden vaterfiguren zentrale Charakterisierungsstelle, ein Gesprăch zwischen beiden uber Heirat und Ehefrauen, in keinem handlungsstrukturellen Funktionszusammenhang mit dem Strang einer aufkeimenden Liebe zwischen NjuSa und Vasilij Karpovic, folgt aber unmittelbar nach der ersten Aktivierung des Merkmals 'verliebt' für die Beziehung zwischen den belden Hauptfiguren (Anrede Njusas durch Vasilij Karpovic: "krasnostekaja", anschlieBende Verwirrung Njusas) (AV 136). Die im Gespräch der Văter zutagetretende patriarchalische Einstellung wird somit zur Abgrenzungsfolie für die sich andeutende positive, im gemeinsamen gesellschaftlichen Engagement gründenden Liebe zwischen Njusa und Vasilij Karpoviz.

V.1.2. Aquivalenzbeziehungen der figurencharakteristischen Dimensionen

Die gesellschaftlich-öfentlichen Funktionstrăger

Die figurencharakteristischen Merkmale können drei hauptsăchlichen Dimensionen zugeordnet werden:

- einer gesellschaftlichen Dimension, wozu u.a. die Bereiche Arbeit, Politik, Weltanschauung, Familie als soziale Institution gehören und die durch die Pole 'öffentlich' vs. 'privat' bzw. 'kollektiv' vs.

'individuell' konturiert wird

- einer moralischen Dimension, die von sittlichen Grundoppositionen wie 'Liebe' vs. 'HaB', 'Egoismus' vs.

'Altruismus' konturiert wird

- einer naturlichen Dimension, die die Merkmalkomplexe Alter, Gesundheitszustand, Schönheit sowie generell die körperliche Verfassung der Figuren beinhaltet. 
Uber eine naturliche Dimension verfügt - neben der gesellschaftichen Dimension - besonders die Familie (Blutsverwandtschaft, Erbe, Generationenverhältnis).

Die Aquivalenzbeziehungen zwischen diesen drei Dimensionen liegen darin begründet, daB die Plusund Minus-Wertpole der Merkmaloppositionen aller Dimensionen in den jeweils gleichen Trägern zusammenfallen.

Die gesellschaftliche Pluswertigkeit (politisches und soziales Engagement, Arbeitsheroismus) ist wiederum äquivalent zum Grad der gesellschaftlichen Integration der jeweiligen Figur, markiert durch die Trägerschaft gesellschaftlich-offentlicher Funktionen. Der Grad der gesellschaftlichen Integration bemibt sich geradezu an der Lokalisierung der Figuren innerhalb des Spektrums zwischen den Polen 'privat' und 'offentlich'. '1)

Die höchsten Pluswerte in allen Dimensionen vereinigen in "Vesna" die beiden hauptfiguren Njusa und Vasilij Karpovix auf sich. Beide sind jung, gesund, emotional begeisterungsfähig, von natürlicher schönheit, beide haben eine hohe moralische und gesellschaftliche Auffassung von der Liebe, beide sind in inrer gesellschaftlichen Charakterisierungsdimension dynamisch konzipiert, lernen, entwickeln sich. Vasilj Karpovižs gesellschaftliche Qualitäten sind besonders sein anspornender, vorbildlicher Führunsstil, sein solidarisches Verhalten, sein Bildungshunger. Njusa zeichnet sich durch ihren Arbeitsheroismus aus (sie ist Rekordarbeiterin). Beide Figuren befinden sich auf einer hohen Stufe gesellschaftlicher Integration: Sie sind Funktionsträger (Njusa als Brigadeleiterin, Vasilij Karpovic als Kolchosvorsitzender) und Mitglieder im Komsomol. Vasilij Karpovil wird am Ende befördert, Njusa nimmt an einer Konferenz von Stachanov-Arbeitern teil.

1) Zur Aquivalenz von gesellschaftlich-bffentlicher Funktionsträgerschaft und hoher figurencharakteristischer Pluswertigkeit vgl. auch "BibliotekarSa", wo Nadja und Leonid Michajlovit als Bibliothekarin bzw. Klubvorsitzender Funktionsträger im kulturell-padagogischen Bereich sind. Vgl. ebf, "Cumaki" (S. Babaevskij, 1946): Die jugendliche Hauptfigur Vas'ka Tutarinov ubernimmt hier als Leiter eines Getreidefuhrwerk-Trecks die erste begrenzte gesellschaftlich-offentliche Funktion. Vas'ka Tutarinov vereinigt die hochsten figurencharakteristischen Pluswerte in allen Dimensionen auf sich und wird in Ubereinstimmung der eigenen und fremder Charakterisierungsperspektiven als zuküntiger Vorsitzender der Kolchose gesehen. 
Die Nebenfiguren aus der Komsomol-Brigade sind ebenfalls in allen Dimensionen pluswertig, jedoch abgestuft: sie sind fleiBig, aber nicht vom Arbeitsheroismus der beiden Hauptfiguren erfullt, sie sind gesellschaftlich integriert, aber keine Funktionsträger. Dasselbe gilt für Djadja Ivan, den Leiter einer zweiten Brigade. Diese Figuren können auch - vereinzelt - Mängel in ihren moralischen und gesellschaftlichen Charakterisierungsdimensionen aufweisen, die jedoch absorbiert werden vom positiven Gesamtcharakter des sie ungebenden Kollektivs. Ein zur Bequemlichkeit neigender Fahrer etwa andert nichts daran, daB sein vermeintlich fahruntuchtiger LKW in Schwung gebracht wird.

Die Tierärztin Lel'ka ist als einzige junge Figur hauptseitig negativ charakterisiert. Ihre Schönheit ist küstich ("kak artistka") (AV 139), sie ist eitel, intrigant, hat eine niedrige gesellschaftliche und moralische Auffassung von der Liebe. Sie ist zwar als Tierärztin nicht gesellschaftlich extegriert, steht jedoch abseits vom Komsomolkollektiv und vom Landleben ("baryకnja", "gorodskij platok") (AV 141). Im Gegensatz zum Bildungshunger Vasilij Karpovics ist ihre Intellektualität primär mit dem Merkmal 'privat' behaftet (Funktionalisierung klassischer Literatur für Liebesbriefe).

Der Vater Vasilj Karpovils, Karp Savel'it, moralisch und weltanschaulich eindeutig minuswertig (s.0.), ist zwar in den Arbeitszusammenhang der Brigade integriert, stellt jedoch im Verhältnis zu Vasilij Karpovic seine familiären Beziehungen (Vater - Sohn) über die gesellschaftlichoffentlichen Beziehungen (Untergebener - Vorgesetzter) und stort damit die Arbeitsorganisation. Der Vater NjuSas schlieblich ist vollends extegriert, - signalisiert durch seine Amtsenthebung als Kolchosvorsitzender und seine ausschlieBliche Lokalisierung im häuslich-privaten Lebenszusammenhang.

\section{V.1.3. Die Figurengemeinschaft der umfassenden Integration}

\section{Beide bisher behandelten Aspekte - die Dominanz der}

positiven Figuren sowie die Aquivalenz der gesellschaftlichen, moralischen und natürlichen Charakterisierungsdimensionen haben zum Resultat die umfassend integrierte Figurengemeinschaft. Gemeint ist die Integration aller loder fast aller) Figuren in die dargestellte Welt als einer Einheit naturlicher, moralischer und gesellschaftlicher Dimensionen. Diese Einheit kann bis zur Homologie familiarer (im Sinne natürlicher, blutsverwandtschaftlicher) und gesellschaftlich-öffentlicher strukturen gehen. Ein deutliches Beispiel ist "Cumaki", wo sich die harmonische Gemeinschaft des Fuhrwerktrecks reproduziert 
in den deutlich als familiär charakterisierten (und z.T. reell familiären) Beziehungen zwischen Vas'ka Tutarinov, dessen kleinem Bruder Mitja, Zinuša, die wăhrend der Fahrt die Mutter ersetzt und dem alten Ded Kornej. Auch in "Vesna" und "Bibliotekarsa" signalisiert die Integration von Kindern und Greisen in die dargestellten gesellschaftlichen $\mathrm{z}$ usammenhänge deren quasifamiliären Charakter.

Die wenigen nicht integrierten Nebenfiguren sind erstens deutlich als Ausnahmen charakterisiert - in "Vesna" durch das breite Spektrum integrierter Nebenfiguren, auch alter Figuren wie Djadja Ivan, dessen Frau und die Mutter Njusas - und stellen zweitens kein gesellschaftliches konfliktpotential dar. Sie desintegrieren nicht ihrerseits die integrierte Gemeinschaft, sondern sind als Extegrierte, Ausgeschlossene zur gesellschaftlichen Irrelevanz verurteilt.

\section{V.2. Handlungsstruktur}

Integration privater und gesellschaftlich-bffentlicher Handlungsstränge

Die umfassende Integration setzt sich auf der Ebene der Handlungsstruktur fort mit der Integration privater und gesellschaftlich-bffentlicher Handlungsstränge. Zwischen diesen bestehen Komplementär- und Interdependenzbeziehungen bei eindeutiger Dominanz der gesellschaftlich- $6 f$ fentlichen Stränge.

In "Vesna" laufen vier stränge parallel. Beide Hauptfiguren agieren in je einem gesellschaftlich-öffentlichen Strang, der durch das Motiv der Bewăhrung oder Prüfung gekennzeichnet ist. Vasilij Karpovic muB sich in seiner Eignung als Kolchosvorsitzender beweisen, NjuSa muB kritisierte Mißstände in ihrer Brigade beseitigen. Daneben verlaufen zwei private Stränge, die durch das Liebesmotiv gekennzeichnet sind. Der erste betrifft die Beziehungen zwischen Njusa und Vasilij Karpovit, der zweite die zwischen Lel'ka und Vasilij Karpovic. Zwischen allen vier Strängen bestehen temporale und kausale Abhängigkeitsbeziehungen, die man 
verdeutlichen kann anhand eines Schemas mit den

Koordinaten a) der textuellen Abfolge der situationen

(Senkrechte) und b) der Parallelordnung der vier Stränge (horizontale). (Dabei werden die Situationen jeweils dem Strang zugeordnet, für den sie - figural, räumlich etc. eine direkte situative Markierung darstelien. Indirekte - konnotative, symbolische, im BewuBtsein der Ich-Erzählerin vollzogene etc. - Auswirkungen auf andere stränge werden in Klammern auf der jeweiligen Vertikalachse eingetragen. Minus- und pluszeichen stellen den wert der situationen im Hinblick auf die positive oder negative Lösung der jeweiligen stränge dar.)

(S. Schema auf der nächsten seite.)

\section{Erlauternder Kommentar}

Der Anfang ist deutlich von den beiden gesellschaftlichoffentlichen Strängen besetzt, die minuswertig beginnen und ihre ersten Interdependenzen entfalten (zuspitzung der jeweiligen Bewăhrungsmotive auf die figuralen Beziehungen zwischen Njusa und Vasilij K. in Sit.1 und Sit.2: Uberkreuzung beider Stränge in Sit.4 und Sit.5: das Bewährungsmotiv Vasilij K.s entfaltet sich im situativen Rahmen von Strang 2, zunăchst negativ - ungerechte Kritik - , dann positiv - solidarisches Verhalten).

Erst nachdem auf diesen beiden strängen die ersten pluswertigen situationen vollzogen sind, folgt die erste situation auf Strang 3, ebenfalls pluswertig (sit.6) (nachdem die vorhergehenden indirekten Auswirkungen auf diesen strang komplementär zu den dominanten Strängen minuswertig waren) und von vornherein eng verknüpt mit den gesellschaftlichoffentlichen Strängen (Angebot Njusas, die während der Arbeit zerrissenen Handschuhe Vasilij K.s zu stopfen). Das Merkmal 'Familie' wird aktiviert (Anwesenheit des Kindes Garajska, Nachdenken Njusas über häusliche Situation Vasilij K.s). Die Interdependenzen zwischen diesen drei Strängen sind also bereits in ihren Grundlagen entwickelt, als strang 4 einsetzt (Sit.7), - von vornherein in deutlicher Isolierung von den ersten beiden Strängen (Abendgesellschaft nach Feierabend, innerhalb dieser situation zusatzlich markierte räumliche Trennung von der als familiär charakterisierten dörflichen Abendgesellschaft: der Dialog zwischen Lel'ka und Vasilij $\mathrm{K}$. findet drauBen statt und ist von der Erzählerin/ Njusa nur durch das Fenster zu hören). Dieser Strang gerät nun in einen begrenzten Konflikt zu strang 3, die Pluswertigkeit des einen hat die Minuswertigkeit des anderen zur Folge. 


\begin{tabular}{|c|c|c|c|}
\hline & 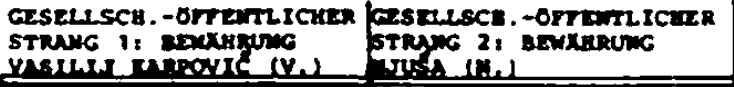 & $\begin{array}{l}\text { PRIVATER STRNeG 3i } \\
\text { MUSA - VASILIS }\end{array}$ & 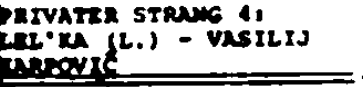 \\
\hline 1 & 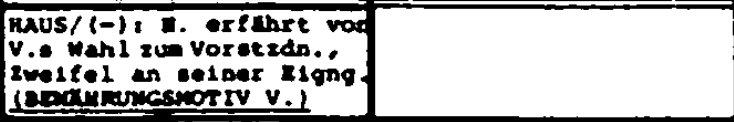 & 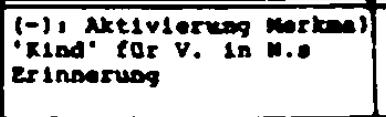 & \\
\hline 2 & 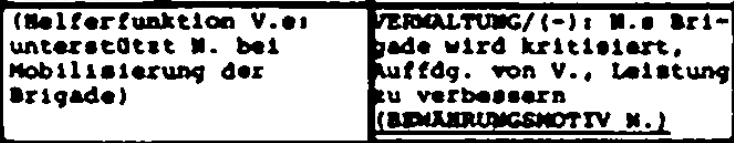 & & \\
\hline 3 & 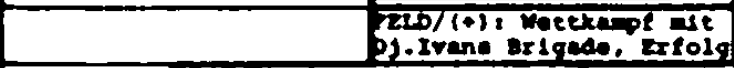 & & \\
\hline 4 & 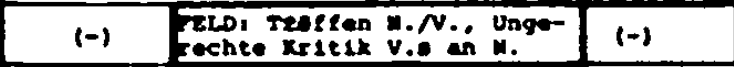 & 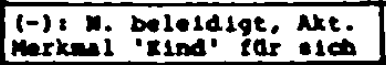 & \\
\hline 3 & 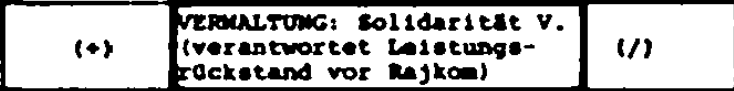 & & \\
\hline 6 & & 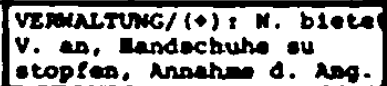 & \\
\hline 7 & & 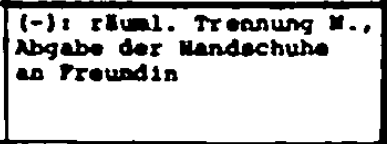 & 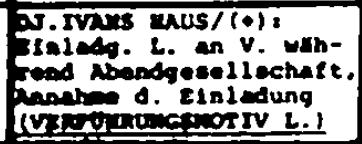 \\
\hline 8 & 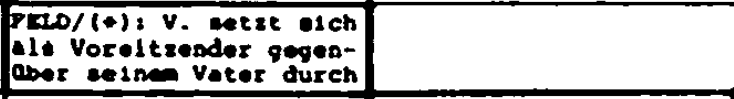 & & \\
\hline 9 & 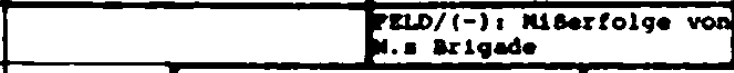 & & \\
\hline 10 & 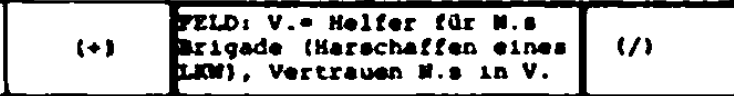 & & \\
\hline 11 & $\begin{array}{l}\text { ReLD: V. alse seatelefe, } \\
\text { vergrabe Glesecherbe in } \\
\text { reid }\end{array}$ & 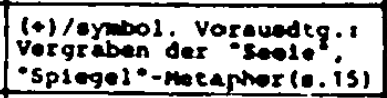 & 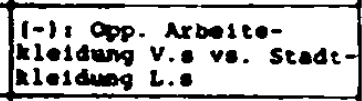 \\
\hline 12 & 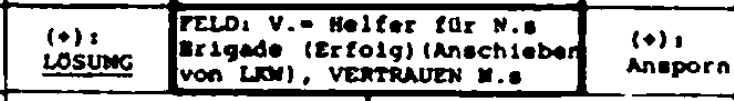 & & $\begin{array}{l}(-): \text { M. denke bolusetgt } \\
\text { an vartende } 2 \text {. }\end{array}$ \\
\hline 13 & & 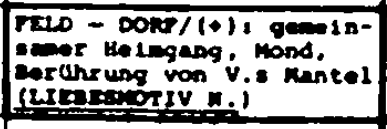 & \\
\hline 14 & & & 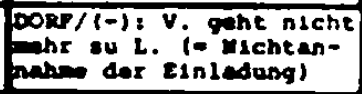 \\
\hline 15 & 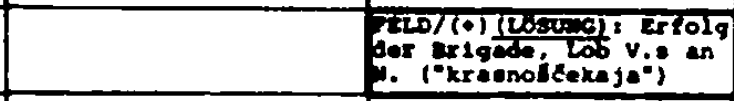 & $\begin{array}{l}\text { (t): Vervirrune M.: vor } \\
\text { splegel. "verlebe" } \\
\text { lenechl. Dislog d. vuter }\end{array}$ & \\
\hline 16 & 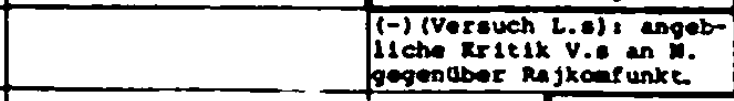 & 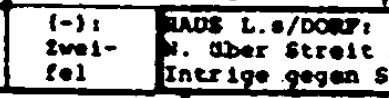 & 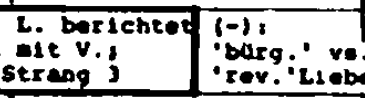 \\
\hline 17 & 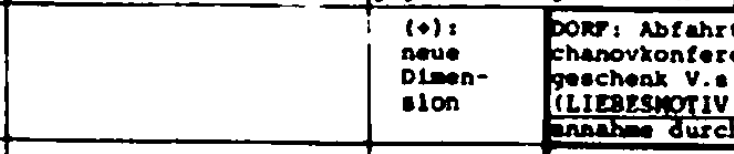 & 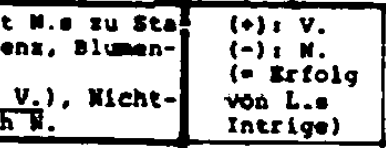 & \\
\hline 18 & $\begin{array}{l}\text { (+): } \\
\text { Detat 1- tolocon, Tre } \\
\text { gung }\end{array}$ & 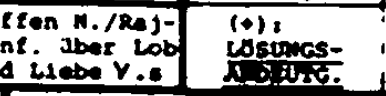 & 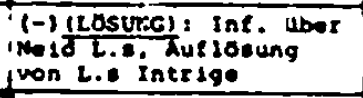 \\
\hline 19 & $\begin{array}{l}(+1) \text { new diseneson/ } \\
\text { Patsrderung }\end{array}$ & 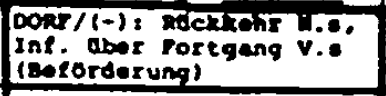 & \\
\hline 20 & & $\begin{array}{l}\text { Mucs V.s/(-), Ver zwedl- } \\
\text { lung M.s }\end{array}$ & \\
\hline 21 & 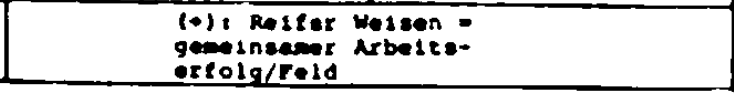 & 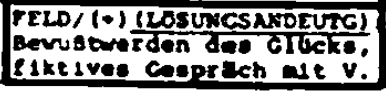 & \\
\hline
\end{tabular}


Nach dieser ersten Stufe (Sit.1 - sit.7), in der alle vier Stränge in ihren gegenseitigen Relationen einsetzen, folgt die zweite Stufe (Sit.8 - Sit.15), welche wiederum eine klare Dominanz der ersten beiden stränge aufweist und die positive Lösung dieser beiden Stränge beinhaltet. In der Interdependenz beider stränge erweist sich dabei das temporale und kausale Primat von Strang 1: Seine Lösung ist die Bedingung für die Lösung von Strang 2. Der bereits das Vertrauen Njusas besitzende Vasilij $\mathrm{K}$. Wird zum Helfer für deren Brigade (Sit.10) und ermöglicht erst durch sein vorbild und die damit verbundene Bewährung die Uberwindung der Arbeitsschwierigkeiten in der Brigade (val. bes. in sit. 12 seine Anspornfunktion für Njusa:

"Vasilij Karpovic podnjal obelmi rukami vedro i stal pit', zaprokinuv golovu, i kapli, kak businki, skatyvalis' na zemlju po ego Sineli, ne ostavijaja sleda, i mne stalo zavidno, tto on tak p'et, i samoj zachotelos' tak ze oteret' pot so lba $i$ priniknut' $k$ vode, ot kotoroj pachnet mokrym Zelezom. "(AV 135) und in Sit. 15 die einem zirkelschluB gleichkommende Begründung der bestandenen Bewährung Njusas gegenüber Vasilij K. Tit dessen eigener Bewăhrung als Vorsitzendem:

"Vasilij Karpovic kazdyj den' byval na moem utastke, no bol'se ne komandoval, da i nełego ne bylo komandovat': ljudi stojali na toj rabote, na kotoruju on postavil, lozadi vozill zerno tak, kak on velel, 'gazik' rabotal. Menja on bol'se ne rugal, a odin raz, poslusav, kak ja ucila Tamarku, skazal: - Pravil'no delo vedes', krasnoscekaja." (AV 136)).

Auf neuer stufe wiederholen sich die temporalen und kausalen Beziehungen zwischen den exsten beiden Strängen und Strang 3: Nach der positiven Lösung der gesellschaftlichoffentlichen stränge folgt die erste Aktivierung des Merkmals 'verliebt' im Strang 3 (Sit.15), wobei über das Spiegelmotiv eine zusatzliche metaphorische Verklammerung der Stränge entsteht (Sit.15: Verwirrung Njußas vor dem Spiegel, Sit.11: Vergleich einer von Vasilij $\mathrm{K}$. ins Feld vergrabenen Glasscherbe mit einem Spiegel). Mit dem Vergraben der Glasscherbe im Feld ist daruberhinaus eine symbolische Vorausdeutung verbunden, die über das Motiv der "Seele" in Verbindung zum Liebesstrang steht:

"- Ne zerno ty. paren', a dusu svoju v zemlju klades', zasmejalsja Lesa, kogda my poravnjalis', a ja uvidela to, tto blestelo izdali, kak zerkalo: stekljasku velicinoj s nogot'." (AV 134)

In Abhängigkeit von Strang 1 und 2 vollzieht sich schlieblich auch die Umwertung und erste Lösungsandeutung im Verhältnis der beiden privaten Stränge (vgl. besonders die Minusaktivierungen für Strang 4 im Bewubtsein der Erzählerin/ Njusas in Sit.11 und Sit.12: Oppositionsbildung zwischen der durch Arbeit verschmutzten Kleidung Vasilij K.s und der städischen kleidung Lel'kas, sowie in Sit.13 und Sit.14, welche in kausaler Abhängigkeit von Strang 1 und 2 - gemeinsame Arbeit auf dem Feld bis in den späten Abend - positiv für NjuSa und negativ für Lel'ka ausfallen). Die Situationsveränderung in diesen beiden strängen erfolgt also nicht durch die Austragung eines Konflikts zwischen den Agenten. 
Erst auf der dritten Stufe (Sit.16 - sit.21) folgt dann die konzentrierte Entwicklung und Lbsung der beiden privaten Stränge, wobei eine neue stufe in der Verklammerung der beiden gesellschaftlich-bffentlichen Stränge und des ersten privaten Strangs erreicht wird, während strang 4 nun gänzlich isoliert ist. Die begrenzte Anbahnung eines Konflikts zwischen Lel'ka und Njuša auf der Ebene der Stränge 3 und 4 in Sit. 16 wird bereits dort auf strang 2 zurückverwiesen: Lel'kas Intrige gegenuber Njusa basiert auf einer erneuten Minusaktivierung für den Bewährungsstrang Njušas (angeblich verächtliche Außerungen Vasilij K.s über NjuSa gegenüber einem Rajkom-Funktionär). In den folgenden Situationen ist es gerade die erneute und endgulltige plusaktivierung auf diesem Strang, welche eine positive Losung von Strang 3 sichert und Strang 4 damit gegenstandslos macht. Hier ist besonders auf die erste situative Uberkreuzung von Strang 2 und Strang 3 in Sit. 17 hinzuweisen: In dieser Situation wird eine neue Dimension im Bewährungsmotiv Njusas eröffnet (Stachanovkonferenz) und gleichzeitig die erste Markierung von Vasilijs Verliebtheit (Blumengeschenk) gegeben. Die endgultige positive Auflosung von Strang 3 erfolgt nun innerhalb dieser neuen Dimension des gesellschaftlichen Bewährungsstrangs (Sit.18: Mitteilung des Rajkomsekretärs während der Konferenz in Vologda uber Vasilij K.s Lob für Njusa als bester Arbeiterin und uber seine Verliebtheit in Njusa, gleichzeitig Auflösung der Intrige Lel'kas). Das von Sit. 17 bis zum Ende verlaufende Wechselspiel zwischen Minus- und Plusaktivierungen auf dem nun situativ dominierenden Strang 3 gewinnt seine besondere Qualität durch die erneute Verklammerung mit den ersten beiden Strängen in ihren neuen Dimensionen: Die zunächst (mit Vasilij K.s Fortgang aus dem Dorf) vermeintliche Negativiousung schlägt um in die GewiBheit von der positiven Lösung in der letzten Situation, welche durch einen extrem markierten Raumwechsel von Haus und Dorf zum Weizenfeld die mit dem Weizenfeld durchgaingig verbundene Konnotierung von Strang 1 und Strang 2 intensiviert und sogar um die neue Dimension der gesellschaftlichen Integration beider Figuren erweitert. (Dies wird ausfuhrlicher unter dem Abschnitt Raum/zeit-Struktur zu begründen sein.)

Wir können zusammenfassen:

1) Es besteht eine eindeutige funktionale Dominanz der gesellschaftlich-offentlichen uber die privaten stränge.

2) Innerhalb der beiden ersten stränge besteht ein weiteres Dominanzgefäle von Strang 1 zu Strang 2 .

3) Strang 3 und seine Lösung sind integriert in strang 1 und Strang 2 sowie deren Lösungen.

4) Strang 4 ist extegriert, er wird nicht zum Konfliktgegenstand, sondern wird in Abhängigkeit von der Entwicklung der anderen Stränge gegenstandlos und irrelevant. 
Dieses Ergebnis steht mit weiteren modellkonstitutiven Merkmalen für die Handlungstruktur der umfassenden Integration in engem zusammenhang. Aus der Dominanz der gesellschaftlichöffentlichen Stränge und der ausschließlichen Teilnahme positiver Figuren an diesen folgt das Monopol der positiven Figuren auf Agentenfunktionen (bzw. die Einschränkung der Agentenfunktionen negativer Figuren auf gesamthandlungsirrelevante Nebenstränge "). Innerhalb dieses Agentenmonopols positiver Figuren entsteht wiederum eine Funktionenhierarchie homolog zur Hierarchie der gesellschaftlichen Integrationsgrade (die gleichbedeutend ist mit einer Hierarchie der handlungsentscheidenden Kompetenzen in der gesellschaftlich-öffentlichen Strängen). In unserem Beispiel wird das besonders durch die agentenfunktionale Dominanz Vasilij K.s gegenüber Njusa (Verhältnis von Strang 1 und strang 2) sowie durch die Einschaltung des RajkomFunktionärs für die endgültige Auflösung von Strang 2, 3 und 4 signalisiert.

Das Agentenmonopol positiver Figuren prägt den Charakter der dargestellten Handlungen. Figurencharakteristische Oppositionen werden nicht konstitutiv für die Handlungsstruktur ("Konfliktlosigkeit"), Situationsveränderungen bestehen nur darin, das die kurzfristig gestörte, jedoch von vornherein erwartete Harmonie zwischen zwei Figuren (Vas'ka Tutarinov und sein kleiner Bruder in "Cumaki", Nadja und Leontij Michajlovic in "Bibliotekarša", Njuša und Vasilij Karpovit in "Vesna") sich am Ende herstellt. Ereignisse, die diesen vorbestimr.ten Ablauf aufhalten oder ur.ukehren könnten, gibt es nicht, da nur ein semantisches Feld existiert, in dem sich die Figuren bewegen ${ }^{2}$, in dem nichts Unwahrscheinliches, Fremdes existiert,

1) Eine Ausnahme bildet lediglich in Sit. 8 der Nebenkonflikt zwischen Vasilij $K$. und seinem Vater Karp Savel'it im ersten Hauptstrang. Karp Savel'it will sich als Vater den Anweisungen des Sohnes während der Feldarbeit nicht unterordnen, dieser setzt jedoch das Primat seiner gesellschaftlich-öffentlichen Funktion vor den familiären Beziehungen durch und behauptet sich als Vorsitzender gegenitber dem Vater.

2) Zum Ereignis als Versetzung einer Figur über die Grenzen eines semantischen Feldes vgl. Lotman (1972), aao, S.332ff. 
und das kleinere MiBverständnisse durch seinen integrativen Gesamtcharakter absorbiert.

\section{3. Raum/Zeit-Struktur}

v.3.1. Homologie răumlicher und gesellschaftlicher Integration

Die Raumstruktur setzt die Beziehungen der umfassenden Integration fort. Der dargestellte Raum ist harmonisch in einen ungebenden Makrokosmos integriert, er ist durchschreitbar, und sein Durchschreiten kann zur sujetgrundlage werden, wie in "Cumaki", wo besonders mit der Figur des kleinen Bruders, der zum erstenmal auf den Treck mitgenommen wird, das Erlebnis der Integration von Stanica, Steppe und stadt thematisiert wird. Einzelne mit dieser in sich geschlossenen, integrierten Raumstruktur verbundene modellkonstitutive Eigenschaften sollen wiederum anhand "Vesna" dargestellt werden.

Es existieren verschiedene Raumweitengrade, die ein geschlossenes Ganzes bilden. Das Dorf ist in die unliegenden Felder, diese sind in das ungebende Universum integriert. Alles ist uberblickbar:

"My vyšli na verłinu cholma, i stali vidny daleko vo vse storony prostornye polja, bol'saja doroga, derevnja. Za lesom, prjamo na zemle, leżali gustye oblaka, a nad golovoj nebo bylo cistoe, bez pjatnyłka, i svetilos' takim sinim svetom, $x_{t o}$ na nego bol 'no bylo gljadet', 1 graci $v$ étom lučistom nebe kazalis' Cernymi, kak ugol'." (AV 126)

Das Dorf selbst ist ein einheitlicher, uberblickbarer Raum:

"My vošli v derevnju. Vse - 1 doroga, i stupen'ki, i izgorodi, i krysi - bylo pokryto rovnym lunnym svetom, slovno na derevnju vypal goluboj sneg." (AV 136)

Diese allumfassende Integration schliebt das Verhälnis Natur - Technik ein, welches interaktionsahnlichen Charakter hat:

"Izdali donessja dolgij dvojnoj gudok parovoza. Za stenoj zakrical petuch, i vse zasmejalis', potomu tto ponjali, tto petuch sproson'ja sputal gudok s kukarekan'em." (Av 125)

Für die Technik wird besonders das Merkmal der Beweglichkeit und damit ihre raumintegrierende Funktion aktiviert (Loko- 
motive - "izdali"; Traktor; LKW - wiederum in interaktiver Beziehung zur Natur: Spiegelung des Scheinwerferlichts in einem Pferdeauge (AV 132)).

Im Rahmen dieses in sich geschlossenen Kosmos existieren unterschiedliche räumliche Integrationsgrade für die einzelnen Figuren. Es stellt sich heraus, daB diese Grade in exakten Homologiebeziehungen zu den unterschiedilichen Graden der gesellschaftlichen Integration der Figuren stehen.

Wir kommen hier zurück auf das handlungsstrukturelle Schema. Daraus geht hervor, daB für bestimmte Figuren und bestimmte Handlungsstränge festgelegte Răume bestehen.

1) Die gesellschaftlich extegrierten Figuren sind auch räumlich extegriert, am extremsten Njusas Vater, dessen Haus als einziger Raum mit einer markierten Grenze vom ungebenden Raun abgetrennt ist (Fenster). Allerdings wird für die Hauptfigur Njusa, die ebenfalls hier wohnt, gerade die offenheit dieser Grenze hervorgehoben, gleich mit dem Anfangssatz:

"EšCe $v$ detstve ja ljubila sidet' u otkrytogo okna 1 slušat", kak zasypaet ulica." (AV 122)

Ihr Eintritt in den gesellschaftlich-offentlichen Handlungsstrang ist mit einem markierten Grenzubbertritt verbunden (Klopfen an die Fensterläden als Aufforderung, zur Versammlung zu kommen) (AV 124).

Auch Lel'ka wird vornehmlich in häuslichem Zusammenhang dargestellt, bei sich zuhause oder in Djadja Ivans Haus während der Abendgesellschaft, hier wiederum räumlich getrennt von der Abendgesellschaft (s.0.). Das Feld hingegen ist für Lel'ka beinahe ein feindlicher Raum, hier endet ihre Verführungskunst gegenüber Vasilij Karpovic (dieser beendet einen gemeinsamen Abendspaziergang, nachdem er Torf gefunden hat) (AV 139).

2) Alle anderen Figuren sind auch räumlich integriert, allerdings verschiedengradig: Haus und Dorf sind die räumliche Integrationsstufe für alle Dorfbewohner, besonders markiert während der Abendgesellschaft in Djadja Ivans Haus ("nasi derevenskie") (AV 129). 1)

3) Für die Arbeitsbrigaden und/oder Komsomolmitglieder existiert mit dem Feld ein noch höherer Grad räumlicher Integration. Die Funktion des Felds als dominantem Handlungsraum für die beiden ersten stränge geht deutlich aus dem Schema hervor. Das Weizenfeld hat daruberhinaus die Funktion des spezifischen Raums für die Integration des Liebesstrangs 3 in die beiden Hauptstränge. Es tritt bereits

1) Ein geschlossener, warmer, heller Raum als Integrationsfeld für die Dorfbewohner, für alle offenstehend, ist auch die Bibliothek in "Bibliotekarš". 
in den Sit.8 - Sit.15 in symolischen Bezug zu Strang 3 ("Seelen"-Motiv, metaphorische Verklammerung "Spiegel", s.o.), auch die ersten situativen und im BewuBtsein der Erzählerin/ Njusas vollzogenen Aktivierungen von 'verliebt' geschehen hier (Sit.13, Sit.15). Nachdem an Ende der gesellschaftliche Integrationsgrad der Hauptfiguren eine neue Dimension erreicht hat und beide entsprechend neuen Raumdimensionen zugeordnet werden (Fortgang Vasilij K.s aus dem Dorf, Fahrt Njušas zur Konferenz nach Vologda), bleibt das Weizenfeld der symbolische Raum für die positive Lösung von Strang 3 dank dessen Integration in die gesellschaftlich-öffentlichen Stränge: Erst mit dem Hinausgehen aus dem Dorf legt Njusa ihre momentane Verzweiflung ab und wird sich ihres Glücks bewuBt.1) Das Feld wird uber diese symbolische Funktion hinaus sogar $z u$ einem imaginierten situativen Handlungsraum für diese Lösung, wenn Njusa trotz der Abwesenheit Vasilij K.S diesen - der ja in dieses Feld mit der Saat seine "Seele" vergrub - anspricht und dabei räumlich-körperlich mit dem Feld verschmilzt:

"A po pక̌nice s mjagkim svistom poßla uprugaja volna, zavorałivajas' bokom $i$ nabegaja $v$ moju storonu, $i$ kolos'ja, tolpjas' $i$ protiskivajas', potjanulis' $k$ moim rukam." (Av 143)

\section{V.3.2. Zeitliches Kontinuum und Homologie von Naturzeit und historischer zeit \\ Chronotopizität der unfassenden Integration}

Der integrative Charakter der zeitstruktur manifestiert sich unter zwei hauptsächlichen Aspekten:

a) der Existenz eines zeitkontinuums zwischen Vergangenheit, Gegenwart und zukunft

b) einer der Homologie räumlicher und gesellschaftlicher Integration entsprechenden Homologie verschiedener Zeitsysteme, der Naturzeit und der historischen bzw. gesellschaftlichen zeit.

Das zeitliche Kontinuum wird bereits durch die Einbettung des dargestellten situationsablaufs in einen durativen zeitfluB markiert. Aufschlubreich sind hier besonders die strukturellen Rahmenstellen. Exemplarisch sei der Anfang von "Vesna" betrachtet:

Der erste Satz ("Esce v detstve/.../", s.o.) ist eine Markierung des zeitlichen Kontinuums. Das iterative Präsens

1) Das Feld wird jetzt besonders mit dem Merkmal räumlicher Weite versehen: "So vsech storon, uchodja vdal" $k$ samomu lesu, slabo Sevelilas' nalitaja psenica." (AV 143) 
im folgenden Satz, welches sich auf dieses Gesamtkontinuum bezieht ("V izbe gorit svet, mama chodit /.../") wird ubergeleitet in das durative Präsens der Situation ("Vot i sejtas ja sizu $\left./ \ldots /^{n}\right)$, welches nach drei kurzen Absätzen abgelöst wird vom momentanen Präteritum als im folgenden dominierendem Erzähltempus. (AV 122)

Weitere Markierungen des zeitlichen Kontinums sind die Bekanntschaften der Hauptfiguren seit ihrer kindheit (in "Vesna" und in "Novyj sekretar" (E. Doros, 1947)) sowie der EinschluB von Kindern und Greisen in die gesellschaftichen und räumlichen Integrationsfelder. In "Vesna" gilt das besonders für die Anwesenheit des Kindes Garajs'ka auf dem Feld und in der kolchosverwaltung. In "Kumaki" bekommt die Integration des kleinen Bruders in die gesellschaftichen und raumlichen Felder zentralen thematischen stellenwert; der alte Ded Kornej bildet den anderen Pol des generationenubergreifenden Bands. Die Bibliothek in "Bibliotekarsa" bietet von den kreuzworträtsellösenden Kindern bis 24 den weltpolitisch debattierenden Alten allen Platz.

Dieser Harmonie der Generationen ist der Gegensatz zwischen ihnen untergeordnet. Falls er auftritt - wie in "Vesna" - , so wird mit ihm v.a. die Homologiebeziehung zwischen Naturzeit und historischer zeit wirksam. Die Opposition

'alt' vs. 'jung' entspricht der Opposition 'alt' vs. 'neu' bzw. 'rückschrittlich' vs. 'fortschrittlich'.

Die Homologie der beiden Zeitsysteme wird in "Vesna" besonders in der Relation zwischen der Jahreszeitenfolge und der Entwicklung der gesellschaftlichen Handlungsstränge deutlich. Hier gewinnt wiederum das Weizenfeld eine zentrale Funktion, da es nicht nur die räumliche Integration, sondern ebenfalls die zeitliche Integration von Handlungssträngen und Jahreszeitenfolge verkörpert. In dieser Einheit aus răumlicher und zeitverkörpernder Funktion wird es zu einem Chronotopen der umfassenden Integration. 1) Es verkörpert

1) Von einem Chronotopen der umfassenden Integration kann man auch im Fall von Djadja Ivans Haus sprechen, da hier ebenfalls zeitliche Integration - die Generationenharmonie răumlich-körperlich wird: "Ran'se vsech $v$ izbu ponabilis' rebjatiski, కkol'niki." (AV 129, Hvh. G.W.) Ahnliches gilt für die Bibliothek in "Bibliotekarsa". 
einerseits den Wechsel vom Frühling zum Sommer in Homologie zu den gesellschaftlichen Strängen (Feldarbeit, erste Marklerung von "vesna" während der Saatzeit auf dem Feld, Sommer und reifender Weizen am Ende) und wird gleichzeitig in dieser Eigenschaft zum Chronotopen der Entwicklung von Njusas und Vasilij Karpovids Liebe, besonders signalisiert durch die im Feld vergrabene Glasscherbe in Konnotation mit "Seele" und "Spiegel" (s.o.).

Man kann verallgemeinernd von der Chronotopizität der unfassenden Integration sprechen. Die historische zeit wird, indem sie dem naturzeitlichen Kontinuum (Generationenfolge, Jahreszeiten, Wachstum) homolog gesetzt wird, von dessen Substraten verkörpert und damit räumlich. Die historischgesellschaftliche Zukunft wird sichtbar. In "Novyj sekretar"n wird dieser Zusammenhang - wieder mit dem Chronotopen des Weizenfelds - explizit:

"I zemlja, gljadite, kakaja ona stala, zemlja - maslo. Milliony millionov semjan prinimaet ona sejtas $v$ sebja, kormit' budet každoe zernyško, poit'... I vojdut oni $v$ silu, $v$ bogatyj rost, a s nimi ves' nas rajon, vsja oblast'. vsja beskrajnaja derzava sovetskaja. Kak podumaes', tto i tvoja tut rabota, i vasa, tovarise, i von togo traktorista, kotoryj, badite, za temi chatami krajnyj gon so svoimi sejalkami prochodit, 1 Davidenkova, - kak podumaes' pro èto, tak $x i s t o ~ i z$ dal'nej dali kommunizm $k$ tebe progljanul." (DN 696)

\section{V.4. Standpunktkomposition \\ Monologische Wertung}

In der Standpunktkomposition wird nur die Ebene der Wertung modellkonstitutiv. Die Dominanz dieser Ebene erweist sich in der funktionalen Unterordnung der Variationsvielfalt auf den anderen Ebenen unter eine möglichst monologische Wertung, v.a. in figurencharakteristischer Hinsicht. Anhand zweier Texte, die auf psychologischer, raum/zeitlicher und 2.T. phraseologischer Ebene über eine betont 'entautorisierte' Kompositionsstruktur verfügen, was sich besonders in der Existenz figuraler Erzähler niederschlägt, soll dieses Dominanzverhältnis verdeutlicht werden. 
In "Vesna" ist die Ich-Erzählerin als Hauptfigur 'subjektiv' bzw. 'parteilich' in die Handlung verstrickt, was zunăchst ihre objektivität in Frage stellen könnte. Auch auf raum/zeitlicher Ebene wird ihre Erzăhlkompetenz relativiert. Sie ist stellenweise räumlich getrennt vom Geschehen. Wenn sie auch die Gesamthandlung aus der zeitlichen Distanz der Erzählsituation uberblicken kann, wird dennoch ihre mangelnde Erinnerung thematisiert ("i daze, kažtsja, ne poprošcalas" (AV 140, Hvh. G.W.); "skazala ja i, kazetsja, zaplakala" (AV 143, Hvh. G.W.)). Auch die subjektive Betroffenheit wird aus der zeitlichen Distanz heraus nicht beseitigt:

"On mne otvetil. No mne neochota $i$ govorit', tto on mne otvetil." (AV 127)

Trotz dieser Relativierungen ihrer Erzăhlautorität ist sie im Besitz einer unbezweifelbaren Wertungskompetenz hinsichtlich aller Figuren einschlieblich ihrer selbst. Grundlage dieser Kompetenz ist ihre Weltanschauung, die sie beispielsweise die Mängel ihres Vaters sowie Lel'kas klar erkennen labt. In der gemeinsamen Weltanschauung ist auch die Identität ihrer Wertungsperspektive mit der der anderen Funktionsträger begründet, wie sich besonders an der Abwertung Lel'kas durch den Rajkom-Funktionär am Ende zeigt. Nur gegenuber Vasilij Karpovit ist diese Wertungskompetenz anfangs kurzfristig gestört, da sie ihn nur aus der zeit der Kinderstreiche erinnert, entwickelt sich aber schnell $\mathrm{zu}$ einer Wertungskompetenz, die auch in scheinbar ausweglosen Situationen die Fähigkeiten Vasilij Karpovits im vorhinein erkennen läbt:

"No Vasilij Karpovie, podavsis' vpered, ǔe Sagal v derevnju, i ja smotrela, kak raspachivajutsja na obe storony poly ego కineli, $i$ mne poxemu-to podumalos', $t_{t o}$ 'gazik' vse-taki proedet, chotja i doroga ne prosochla i nechvataet akkulumatora." (AV 134)

In "Novyj sekretar"" wird das Verfahren eines Binnenerzählers angewandt, der phraseologisch deutlich perspektiviert ist durch verschiedene Idiolektismen und eine skaz-ähnliche Erzählweise. Entscheidend ist aber die trotz 
dieser (phraseologischen) Vielstimmigkeit zwischen

Rahmenerzähler und Binnenerzähler vorhandene Monologizität auf der Wertungsebene. Hier wird der integrative Charakter, welcher der Wertungsmonologizität prinzipiell anhaftet nämlich die Integration der bewertenden Mikroinstanz einer Figur oder eines Erzählsubjekts in die Makroinstanz des umgebenden ideologischen Milieus - anschaulich im Verhältnis zwischen Rahmen- und Binnenerzähler.

Die kommunikative Dialogsituation zwischen beiden Erzählern ist eine rein äuBerliche, wertungsmäBig handelt es sich um eine monologische situation. Der Rahmenerzähler beschränkt sich auf Informationsfragen und formuliert keinen widerspruch. Als Resultat entsteht die Erzählung über den Parteisekretär Davidenko - die eigentlich der Rahmenerzähler/Journalist schreiben sollte und wegen der er sich mit Davidenko treffen will - bereits auf der Fahrt zu letzterem aus dem Mund dessen Chauffeurs als Binnenerzăhler. Durch verschiedene Verfahren, welche die Wertungskompetenz dieses Binnenerzăhlers signalisieren, erweist sich am Ende, dab eine weitere Erzählung des Rahmenerzählers uberflüssig geworden ist. Der Text bricht ab mit der Begegnung zwischen Davidenko und dem Rahmenerzähler, kommentiert vom Binnenerzähler:

"Tovarisc Davidenko, éto 12 redakcil predstavitel' sledom za nami priechal, tak ja uz im vse rasskazal. Da net, zatem brechat', vse ob-jasnil iz Zizni, kak ono bylo i kak ono est'... poechali?" (DN 697)

Die Wertungskompetenz des Binnenerzählers wird durch folgende Verfahren signalisiert:

1) durch die explizite Thematisierung der Bewertungskompetenz. Der Binnenerzăhler thematisiert die Bewertung, er formuliert explizit die Bewertungsmasstabe für einen Parteifunktionär:

"Partijnyj rabotnik, on kak? on vsegda mez ljudej, i ljudi opjat' $\mathrm{Ke}$ vsegda partijnogo rabotnika vidjat /.../". (DN 688)

"V tom $i$ est', tovarist, partijnaja rabota, ttob Eeloveka ponimat' $/ \ldots / /^{n}$. (DN 691)

Gleichzeitig thematisiert er die potentiellen zweifel des Rahmenerzählers an seiner Wertungskompetenz, die sich aus 
seiner eingeschränkten, 'privaten' Perspektive als Chauffeur Davidenkos ergeben könnten, indem er sich selbst als Parteimitglied ausweist und damit die eigentliche Grundlage der Wertungsmonologizität herstellt:

"Eto ja vam ne kak sekretarnyj కofer govorju, a kak દ̌len partii." (DN 696)

Er macht auBerdem auf sein Alter und seine Erfahrung aufmerksam ("glaz u menja na sekretarej opytnyj") (DN 691) und unterstreicht damit die Lebensnähe, Echtheit seiner Aussagen. 2) Neben dieser expliziten Thematisierung wird die Wertungskompetenz implizit abgesichert, besonders durch die räumliche und zeitliche Kompetenz des Binnenerzahlers, der als Chauffeur weit herumgekommen ist, und dessen Erzählung einen umfassenden zeitlichen Komplex von der Kollektivierung uber den Weltkrieg bis zur Gegenwart bzw. zum sichtbaren Kommunismus (s.o.) abdeckt. Das Alter des Binnenerzählers gibt ihm sogar eine gewisse Autorität gegenuber Davidenko, den er schon als Jungen kannte und der damals von ihm den Fahrerberuf erlernen wollte. Diese enge Bekanntschaft drückt sich auch im familiaren Ungangston zwischen den beiden sowie in der Nichtexistenz sozialer Barrieren (Freundschaft zwischen den Ehefrauen, verschiedentlich Anrede mit "du") aus. 
VI. Fünfziger Jahre

Das Modell des reduziert integrierten Makrokosmos (M.2)

Das Modell des reduziert integrierten Makrokosmos (M.2) bildet sich seit Ende 1952 (V. Oveckin, "Rajonnye budni") heraus und erreicht 1956 in verschiedenen Texten (E. Doros, "Derevenskij dnevnik"; Ju. Nagibin, "Chazarskij ornament" u.a.) seine Grenzen. 1956 entstehen andererseits Texte, welche die modellkonstitutiven Normen endgultig durchbrechen und anstelle einer - wenn auch reduzierten Integration die Desintegration der dargestellten Welt zeigen (A. Jašin, "Rycagi", N. Źdanov, "Poezdka na rodinu"). Die folgenden Jahre sind unter dem Gesichtspunkt der Modellbildung von geringer Bedeutung, da sich im Zusammenhang mit der gesamtliterarischen Restaurationstendenz seit Ende 1956 (s. IV.1.2) keine über die radikale Negationsstufe von 1956 hinausgehende, für ein neues Modell konstitutive Normenevolution vollzieht.

THESE: Die Reduktion gegenüber dem M. 1 betrifft in erster Linie die interfiguralen Beziehungen. Der gesellschaftliche Makrokosmos büBt seine naturwilchsige Integrationskraft ein, signalisiert v.a. durch den Konflikt der gesellschaftlichoffentlichen Funktionsträger. Die gesellschaftliche Integration der Bauern ist verschiedengradig gestorrt, ihre Interessen und die des Makrokosmos sind nicht von vornherein identisch. Die Herstellung dieser Integration wird zum eigentlichen Thema der Texte.

Gleichzeitig aber bleiben die Grundstrukturen der Integration erhalten. Der gesellschaftliche Makrokosmos bleibt der wenn auch nicht selbstverständliche, so doch einzig mögliche Integrationsrahmen. Er ausschlieblich prägt die Dimensionen des Mikrokosmos dex bäuerlichen Figuren. Diese Grundstrukturen behaupten sich auch auf den Ebenen der Handlungs-, Raum/Zeitund Kompositionsstruktur. Die Gegensätze zwischen gesellschaftlichem Makrokosmos und bäuerlichem Mikrokosmos reifen nicht zu handlungskonstitutiven Oppositionen, ihre Lösung obliegt allein den Funktionsträgern des Makrokosmos. Der geselischaftlichen Integrationskraft des Makrokosmos 
entspricht nach wie vor eine räumliche Integration, die zwar reduziert sein kann (Betonung lokaler Besonderheiten), jedoch durch die raumverbindenden Eigenschaften der gesellschaftlich-öffentlichen Funktionsträger ihre Wirksamkeit behauptet. Die Standpunktkomposition wird nach wie vor von einer monologisch am Normensystem des Makrokosmos ausgerichteten Wertungsebene beherrscht.

Auf den letzten drei Ebenen ist das normeninnovatorische Potential der Texte entsprechend gering.

Unterschiedliche Varianten des Modells betreffen v.a. den Reduktionsgrad der Integrationsstruktur. Dem Extrempol einer sehr weitgehenden Reduktion in den bereits erwähnten Grenztexten des Jahres 1956 steht der Pol einer starken Normenverwandtschaft mit dem M.1 - etwa in Texten wie "Povest' o direktore MTS i glavnom agronome" (G. Nikoaeva, 1954), "Teša" (G. Radov, 1958), "Sef" (G. Redov, 1956) gegenubber. In der Analyse soll das Schwergewicht auf die Hauptstromtexte des Modells gelegt werden, während die Grenztexte unter dem Aspekt der Dehnbarkeit bzw. des Toleranzbereichs der modellkonstitutiven Normen Erwähnung finden.

VI. 1. Konfigurationsstruktur

VI.1.1. Die Opposition zwischen negativem und positivem Funktionsträger

(V. Ove飞kin, "Rajonnye budni")

Das entscheidende innovatorische Moment gegenüber dem M. 1 ist die Ansiedlung antagonistischer figurencharakteristischer Oppositionen auf der Ebene der gesellschaftlich-öffentlichen Funktionsträger. Es ist gleichzeitig die modellkonstitutive Norm mit dem höchsten Verbindlichkeitsgrad und wird fast ausnahmslos von den Texten realisiert. In den meisten Fällen ist damit eine einseitige konzentration in der Auswahl der Figuren aus dem sozialen Spektrum der dargestellten Welt verbunden: Parteisekretäre auf Kolchos-, Kreis-(Rajon-) und Gebiets-(Oblast'-) Ebene, Kolchosvorsitzende, Brigadiere und Agronomen - meist ebenfalls Parteimitglieder - bestimmen weitgehend die Figurenkonstellation. Hier treffen sich Texte. 
die ansonsten extrem gegensäzliche Grenzpositionen innerhalb des Modells einnehmen, wie etwa G. Nikolaevas "Povest" " und E. Dorołs "Derevenskij dnevnik". Diese invarianteste Modellkonstituente steht in einem Kausalzusammenhang mit der auBerliterarischen Funktionalisierung im Dienst der Landwirtschaftsreform, in der ja die "Kaderfrage" (s.IV.1.1.) zentrale Bedeutung besitzt.

Die Dominanz der positiven Figuren im M.1. war - selbst bel Anwesenheit negativer Abgrenzungsfolien - in der analog zum gesellschaftlichen Integrationsgrad steigenden Positivwertigkeit der Charaktere garantiert. Diese Garantie entfälit nun.

Mit dem Rajkom-Sekretär Borzov und selnem Stellvertreter Martynov aus "Rajonnye buani" sind zwei Paradigmafiguren eines negativen und eines positiven Funktionsträgers geschaffen, deren figurencharakteristische Merkmale in nur geringfugiger Variation in den meisten Texten des Modells wiederkehren ${ }^{1)}$ :

Der Konflikt zwischen den beiden geht äuBerlich um die richtige Methode, das wirtschaftliche Leistungsniveau des Rajon zu erhöhen. Borzov vertritt die pragmatische Linie der Ausbeutung der leistungsstarken Kolchosen, Martynov hingegen sieht gerade in dem krassen sozialen Gefälle zwischen den Kolchosen die Ursache fur die MiBstände und vertritt die Linie, mit der Politik des materiellen Anreizes Erhöhung der Arbeitstagsvergutung (trudoden') - das Niveau der rückständigen Kolchosen zu heben und die sozialen Ungerechtigkeiten $2 u$ beseitigen.

Borzovs Handlungen und Reden sind autoritär; er zwingt die Kolchosen mit strengen Befehlen zu unsinnigen Produktionsschlachten. Er redet nicht mit den Bauern und Kolchosvorsitzenden. Der einzige kommunikative Kontakt mit unteren Ebenen ist eine mit Strafmaßnahmen drohende briefliche Verordnung an die Kolchos- und MTS-Leitungen. Borzov rechtfertigt seine Handlungsweise mit dem Druck, den er selber von oben bekommt, und reproduziert diesen Druck mithilfe seiner institutionellen Macht nach unten. Das BewuBtsein institutioneller Macht kennzeichnet auch den Stil seiner Auseinandersetzung mit Martynov:

"Razlagaes' partijnuju organizaciju." (OR 211) Borzov ist auch moralisch negativwertig. Sein Verhalten gegenüber Martynov ist von MiBtrauen, Konkurrenzdenken und Neid geprägt. Seiner Frau - einer ehemaligen Rekordarbeiterin gegenüber entwickelt er bürgerliches Besitzdenken (er heiratete

1) Zum Paradigmacharakter von "Rajonnye budni" vgl. bes. Lapsin, aaO, S.56ff. 
sie nur wegen ihres 'Images', verlangte aber anschliebend von ihr, ihren Beruf aufzugeben).

Martynov stüzt sich dagegen nicht auf die Macht seiner Position, sondern einzig und allein auf die Uberzeugungskraft seiner Argumente:

"I plan rajonnyj my objazany vypolnit'. No možno po-raznomu vypolnit'. Mozno tak vypolnit', $\iota_{t o}$ chot' $i$ tugo budet potom koe-gde s chlebom, no ljudi pojmut, soglasjatsja /.../". (OR 210)

Er steht in ständigem Kontakt mit den unteren Ebenen, gleich zu Anfang wird er im Gespräch mit dem Kolchosvorsitzenden Openkin vorgestellt. Hier zeigt sich, daB auch Martynov seinerseits bereit ist, sich von den Argumenten des an Erfahrung reicheren Vorsitzenden der besten Kolchose überzeugen $z u$ lassen. Martynov hat nicht seine Karriere, sondern nur die Lebensinteressen der ihm anvertrauten Kolchosbauern im Sinn. Obwohl ihm von Borzov nahegelegt wird, in einen anderen Rajon zu gehen, wo er erster Parteisekretär werden könnte, führt er seinen Kampf fort.

Die dominante Charakterisierungsdimension ist die gesellschaftliche. Hier erweist sich die Interaktion der Figuren als zentrales Charakterisierungsfeld. Die Basisopposition ist vom unterschiedlichen Interaktionsverhalten der beiden Hauptfiguren bestimmt: 'Autorität der institutionellen Macht' steht gegen 'Autorität der Argumente'.'

1) Zum zentralen Charakterisierungsfeld wird die Interaktion auch in "Odin den" (G. Troepol'skij, 1954). Die Hauptfigur, der Brigadier Katkov, wird in einer Serie von Dialogen mit U.stergebenen dargestellt. Dabei erweist sich seine Făhigkeit, menschliche Anteilnahme mit den Sorgen der Bauern $z u$ verbinden mit politischer Uberzeugungsarbeit ('Autoritat der Argumente'). Gleiches gilt für die Kolchosvorsitzenden Ivan Fedosseevid aus "Derevenskij dnevnik" und Rusakov aus "Novyj predsedatel'" (Ju. Nagibin, 1955). In S. Zalygins oxerkzyklus "Vesnoj nynešnego goda" (1954) wird der stellenwert der Interaktion besonders deutlich im "Razgovor s Pisleginym", der ausschlieblich aus einem vom Erzähler belauschten Dialog zwischen dem MTS-Direktor Baslakov und dem gestrauchelten Funktionär Pislegin besteht.

In diesen späteren Texten wird die Opposition 'Autorität der institutionellen Macht' vs. 'Autoritat der Argumente' erweitert um den Aspekt der 'Offenheit', der Freiheit der interaktiven Situation von institutionellem 2 wang. In "Odin Den'" sagt Katkov zum Erzähler: "Éto ty, vladimir Akimyt, po objazannosti govoris'. Davaj po dusam govorit'." (TO 111, Hvh.G.W.) In "Vesnoj nynešnego goda" betont der Erzähler den "offenen" Charakter des Gesprächs lotkrovennyj razgovor) (2R 60). In "Na srednem urovne" (A. Kalinin, 1955) entspricht dem die Opposition 'kazennyj razgovor' vs. 'dusevnyj, serdecnyj, otkrovennyj razgovor' (KN 10). 
In engem Zusammenhang mit der gesellschaftlichen Dimension steht die moralische Charakterisierungsdimension, die von der Basisopposition 'Egoismus' vs. 'Altruismus' konturiert wird. Die Aquivalenzbeziehungen zwischen diesen beiden Dimensionen werden beibehalten. In der Charakterisierung Borzovs durch Martynov wird die ungebrochene Tradition dieser Dimensionenăquivalenz deutlich ${ }^{1)}$ :

" /.../ vot on volnuetsja, chlopotet, nazimaet, ttob zjab" pachali, chleb vezli, vsjakie plany vypolnjali, a blizko li $k$ serdcu prinimaet on vse éto? ¿to strane nuzen chleb, 1 nužno ego oten' mnogo. Cto chleb nam ponadobitsja i $v$ buduskem godu - ne odnim dnem zivem. Cto esli v kakom-to kolchoze ne podnimut zjab' - trudno pridetsja tam ljudjam vesnoj. Cto za vsemi našimi svodkami i ciframi - chorosaja ili plochaja $Z_{i z n}$ ljudej. A moket, on tol'ko o sebe dumaet? Ne vypolnit to-to i to-to - na durnom stetu $v$ obkome budet rajon 1 on, sekretar'. Pjatno ljazet na ego sluzebnuju reputaciju." (OR $216 \mathrm{f}$ )

VI.1.2. Aufhebung charakterlicher Naturwüchsigkeit

Wăhrend die Äquivalenzbeziehungen zwischen gesellschaftlicher und moralischer Charakterisierungsdimension als weitgehend ungebrochene Norm vom M.1 übernommen wird, gerăt die natürliche Dimension aus diesem zusammenhang und wird für die Figurencharakterisierung zunehmend irrelevant. Die mit ihrer Aquivalentisierung konnotierte Naturwlichsigkeit positiver und negativer Charaktereigenschaften, die Naturalisierung der gesellschaftlichen und moralischen Dimensionen - basierend auf einer mit biologischen bzw. familiären Erbgesetzen vergleichbaren Entwicklung der Figurencharaktere - wird überwunden. Stattdessen werden die

1) Damit verbunden ist eine Tendenz zur Personifizierung der gesellschaftlichen MiBstände, wenn etwa von Martynov die mangelnde Bereitschaft höherer Funktionăre, eine Stelle als Kolchosvorsitzender anzunehmen, lediglich in deren Angst vor Borzov begrundet wird: "Est' i zdes' takie, cto s udovol'stviem promenjali by svoju kanceljariju na zivuju rabotu v kolchoze, s narodom, no - ego bojatsja." (OR 220) Vgl. ebf. I. Vinogradov, Derevenskie ocerki Valentina oveckina, in: Literatura i sovremennost' 6 (zuerst in: Novyj Mir, 1964, Nr.6), S.156: "Vnimanie pisatelja v

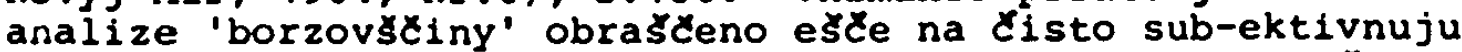
storonu dela - na stil' rukovodstva, ponimaemyj kak necto zavisjastee prežde vsego imenno ot lidnych kakestv rukovoditelja /.../." 
oft schwierigen Lernprozesse der Figuren, die Veränderlichkeit ihrer Charaktereigenschaften in Abhängigkeit von den gesellschaftlichen Umstănden dargestellt.

Im bereits 1952 veröffentlichten "Rajonnye budni" ist zwar ein Fortwirken der alten Normen unter diesem Gesichtspunkt erkenntlich, wenn etwa die Gegenuberstellung der positiven und negativen Figuren durch die Merkmalopposition 'gesund' (Martynov) vs. 'krank' (Borzov) ergänzt wird. Doch haben wir es hier bereits mit einem begrenzten Normbruch zu tun: Borzov wird gerade nicht als naturwilchsig negativer Held dargestellt, sein Bürokratismus steht nicht im Widerspruch $\mathrm{zu}$ einem unermudilichen Arbeitseinsatz, auf den auch die Krankheit zurückzuführen ist. Borzovs erstes Erscheinen ist mit seiner vorzeitigen Rückkehr aus der Kur - aus Sorge un den Ernteerfolg des Rajon - verbunden.

Für den positiven Helden Martynov wird die Veränderlichkeit des Charakters deutlich markiert: Er war früher zeitungsredakteur und hat dort in seinen Kritiken an den Kolchosen genau die despotischen Methoden praktiziert, die er heute Borzov vorwirft. 1)

Die Entsprechung zwischen familiärer und gesellschaftlicher Integration existiert nicht mehr, allerdings stehen sich die beiden Dimensionen auch nicht konfrontativ gegenüber. In der Regel fehlt die familiäre Dimension. ${ }^{2)}$

1) Der Charakterwandel der Funktionsträger kann in späteren Texten des M.2 zum thematischen Schwerpunkt werden. Markantestes Beispiel für eine negative Entwicklung ist "Padenie Ivana Cuprova" ( $V$. Tendrjakov, 1954), in dem der geselischaftiche und moralische Fall eines ehemals verantwortungsbewuBten Kolchosvorsitzendendargestellt wird. Eine positive Entwicklung wird deutlich in "Novyj predsedatel'", wo mit der Figur des Kolchosvorsitzenden Rusakov der wandel von einem bürokratischen städtischen Parteifunktionär zu einem unbürokratischen, flexiblen und verantwortungsbewubten Kolchosvorsitzenden als ein LernprozeB aus der tagtäglichen Konfrontation mit der ländichen Lebensrealität thematisiert wird. Wir kommen auf beide Texte im Abschnitt VI.2. zuruck.

2) Ein Beispiel für die Trennung beider Dimensionen ist "Derevenskij dnevnik". Hier wird die familiäre desintegrierte Situation der Hauptfigur (Ivan Fedosseevid lebt getrennt von seiner Frau) konfrontiert mit der gesellschaftlich integrierten Situation als positiver Funktionsträger. Ein Gegenbeispiel ist "Tesca". Die für M. 1 konstitutiven Normen werden weitgehend reproduziert in der Darstellung der Beziehungen zwischen der Hauptfigur - einem Kolchosfahrer - und seiner Schwiegermutter. Unter dem erzieherischen Einflub der Schwiegermutter entwickelt sich die Hauptfigur von einem ehemaligen Kolchosschäding zu einem verantwortungsbewuBten Kolchosmitglied. Analog zu diesem gesellschaftichen IntegrationsprozeB (und in Abhängigkeit von (hm) entwickeln sich die familiären Beziehungen zwischen beiden Figuren von Feindschaft und Нав $2 u$ Freundschaft und verehrung. 
VI.1.3. Darstellung băuerlicher Nebenfiguren

Bauern sind mit Ausnahme einiger Texte G. Troepol'skijs Nebenfiguren. Di.e Dimensionen ihrer Charakterisierung beschrănken sich auf ihre materielle situation (Lohnverhältnisse, Steuern, bäuerliche Privatwirtschaft), ihre Arbeit und ihre Einstellung zur Kollektivwirtschaft. Autonome Dimensionen des bäuerlichen Mikrokosmos (Individualpsyche, Familie) existieren nicht. In Ansätzen werden autonome Dimensionen in der Darstellung bauerlich-ländlicher Kulturtraditionen entwickelt (folkloristische Szenen in "Odin den'", Beschreibung von dörflicher Architektur und Religion in "Derevenskij dnevnik"), doch nicht anhand komplexer Figuren als Trägern dieser Traditionen, sondern in der Form von Erzählerkommentaren oder kurzen Nebenepisoden.

Die wichtigste bäuerliche Tradition, die auch in unterschiedlichem Grad in ihrer Autonomie respektiert wird, ist die Landarbeit. Der zentrale Aspekt ihrer Darstellung ist allerdings gerade die Notwendigkeit, ihre Erfahrungen in die modernen Arbeitsmethoden $z u$ integrieren.

In "Derevenskij dnevnik" werden dem Erzähler diese Traditionen von der alten Băuerin Natal'ja Kuz'minicna vermittelt, ohne daB diese selber $z u$ einer komplexen Figur dimensionisiert wird. Sie fungiert nur als sprachrohr ihrer Erinnerungen, die in indirekter Rede vom Erzăhler wiedergegeben und kommentiert werden:

"Vo vsech étich rasskazach ugadyvaetsja drevnaja, očen' drevnaja kul'tura zdesnego ovoscevodstva, s ego vyrabotannymi $v$ texenie mnogich stoletij priemami. Vse èto sozdal narod, sozdal $v$ rezul'tate opyta, nabljudenij, bez pomosti so storony $/ \ldots / . "$ (DD 568)

Als lebendige Träger dieser Traditionen sind in Ansätzen der Vater des Brigadiers Katkov und der alte Prokofij in "Odin den'" charakterisert. Sie verkörpern die jahrhundertealten Erfahrungen băuerlicher Arbeit, deren Wert von Katkov erkannt wird. Er kommentiert die Bauernweisheiten seines Vaters: 
"Gromadnyj opyt u papasi /.../ Interesno, pocemu ucenye metereologi ne dadut nauxnych ob-jasnenij narodnym primetam? Ljudi tysjaci let primectali: ne moßem že my vybrosit' èti nabljudenija." (TO 103)

Dominantes Charakterisierungsmerkmal in der Darstellung băuerlicher Figuren ist jedoch ihr gesellschaftliches Bewubtsein, konkret: ihre Arbeitsmoral und ihre Einstellung zur Kollektivwirtschaft. Dies ist gleichzeitig der dominante Aspekt in der zuordnung von (funktionstragenden) Hauptfiguren und (bäuerlichen) Nebenfiguren. Es besteht ein spezifisches Oppositionen- und Aquivalenzengefüge, welches die Grundstrukturen der Integration aufrechterhält, wenn diese auch ihres familiär-naturwichsigen Gewandes entkleidet sind. Es stellt sich nämlich heraus, dab Oppositionen nur im Verhältnis zwischen Bauern und negativen Funktionstrăgern Gewicht erlangen, während im Verhältnis zu den positiven Funktionstrăgern Aquivalenzen vorherrschen bzw. vorhandene Oppositionen uberlagern.

Dem Verhältnis zwischen Bauern und negativen Funktionsträgern wird auch quantitativein wesentlich geringerer stellenwert beigemessen. Zwar werden die Auswirkungen der bürokratischen und sozial ungerechten Leitungspolitik auf die Lebenssituation der Bauern in verschiedenen Texten thematisiert, doch verdichtet sich dieser Interessengegensatz nicht in markierten interfiguralen Oppositionen. Er wird stattdessen transformiert auf interfigurale Oppositionen innerhalb der Ebene der Funktionsträger und nur in dieser transformierten Form handlungskonstitutiv (s.VI.2.3.).

Positive Funktionsträger und Bauern treten relativ hăufig in interfigurale Beziehungen. Die Oppositionen beschränken sich auf untergeordnete Merkmalreihen und betreffen nicht die grundsätzliche Einstellung zum Kolchos als gemeinsamem Integrationsfeld aller Figuren. Meistens werden in Form kurzer Dialoge - wie etwa zwischen Katkov und seine Brigademitgliedern ("Odin den"), Ivan Fedosseevil und seinen Kolchosbauern ("Derevenskij dnevnik"), Rusakov und seinen Sprechstundenbesuchern ("Novyj predsedatel"") - das grobere gesamtgesellschaftliche Verantwortungsbewustsein und die 
gröBere Sachkompetenz der Funktionsträger dem mangelnden Verantwortungsbewubtsein (mangelnden FleiB) und der mangelnden wirtschaftlichen Ubersicht der Bauern gegenübergestellt. Diese Oppositionen sind nicht antagonistisch urd bilden kein Potential für Handlungskonflikte. Sie werden überlagert von Aquivalenzen auf ubergeordneter Merkmalebene. Die Aquivalenzen bestehen neben der gemeinsamen Kolchosmitgliedschaft in der grundsatzlichen Identität der sozialen Interessen der Bauern und der Reforminteressen der Funktionsträger. ${ }^{1)}$

Diese gesellschaftliche Interessenidentität findet eine besondere Entsprechung in den markierten Aquivalenzen zwischen den Charaktereigenschaften der besten Bauern und Funktionsträger.

Die Frau Borzovs, Mar'ja Sergeevnja, wird in dem Moment, wo sie sich Martynov gegenüber als ehemalige bäuerliche Rekordarbeiterin Mała Gromova zu erkennen gibt, von diesem als Interessenpartnerin erkannt:

"Esli b ne byla ty byvsej Mašej Gromovoj, mǒ̌et, ne stal by tebe govorit' vsego, ¿to skazu. No ty ne iz tech dam, u kotorych vse znakomstvo s derevnej cerez molotnic. Sama 12 kolchoza vysla." (OR 216)

Auch ungekehrt ist es gerade die Erinnerung Mar'ja Sergeevnjas an ihre băuerliche Herkunft, die sie im Konflikt zwischen Martynov und ihrem Mann auf die Seite Martynovs rückt.

1) Der am häufigsten genannte Faktor der Interessenidentităt ist die mit Chrustevs Landwirtschaftsreform verbundene Politik des materiellen Anreizes (s.IV.1.1.).

Erst in den Grenztexten von 1956 erscheinen Figuren, die auBerhalb des Integrationsfelds Kolchos stehen. In "Derevenskij dnevnik" werden bäuerliche Figuren, die keine Kolchosmitglieder sind, vom Erzähler registriert etwa der Fischer Paska, der sich vom privaten Fischhandel ernăhrt (DD 612f) - , doch nux mit marginalem Stellenwert versehen. Ihnen werden Figuren gegenubergestellt, die sich von der Notwendigkeit des Kolchos uberzeugen lassen, wie der Traktorist viktor, der zunächst nur unter Zwangseinwirkung Kolchosmitglied wurde, durch die guten Verdienst- und Ausbildungsmöglichkeiten die Richtigkeit seines Schritts jedoch im nachhinein erkennt (DD 587ff). Eine weitere dem Kolchosleben sehr fernstehende Figur erscheint in "Chazarskij ornament", doch dominiert auch hier am Ende die integrative Potenz des Makrokosmos (s.VI.3.1.). 
Die Aquivalenzen zwischen positiven Eigenschaften bäuerlicher und funktionstragender figuren finden darüberhinaus Ausdruck in der Darstellung von Funktionsträgern, deren Qualitäten aus ihrer bäuerlichen Vergangenheit erklärt werden. ${ }^{1)}$

VI.1.4. Modellvariante: Bauern als Hauptfiguren (G. Troepol'skij, "Sosedi")

Anhand eines Textes von G. Troepol'skij, eines Autors, der der Darstellung bäuerlicher Figuren mehr Aufmerksamkeit schenkt als die anderen Schriftsteller, kann verdeutlicht werden, welche Verbindlichkeit den bisher für das M. 2 entwickelten konstitutiven Normen der Konfigurationsstruktur zukommt. Sie wirken selbst in einem Text mit zwei alten Bauern als Hauptfiguren fort, indem eine autonome Dimensiosierung der bäuerlichen Figuren unterbleibt und als entscheidende Instanz für die Integration der Bauern in den gesellschaftlichen Makrokosmos die gesellschaftlichoffentlichen Funktionsträger aus ihrer Nebenfigurenposition heraus fungieren. Hier liegt gleichsam die Grenze des Mcdelis, die auch in der Variante einer stärkeren Orientierung auf die bäuerlichen figuren nicht uberschritten wird.

In der Erzăhlung "Sosedi" (1954) wird die Entwicklung eines Streits zwischen zwei alten Eauern, Makar Petrovic Luckov und Pavel Ef imyc Ptachin, dargestellt. Das gewohnte friedlich-nachbarliche zusammenleben der beiden wird gestort durch wachsende Meinungsverschiedenheiten über die Einstellung zur Kolchoswirtschaft, besonders zum Vorsitzenden Cerepkov, der von Makar für die Notsituation des Kolchos verantwortlich gemacht wird. Diese Streitigkeiten spitzen sich zu, als Makar infolge der ungerechten Besteuerung gezwungen ist, seine Kuh zu verkaufen. Er trifft auf dem Basar einen jungen Bauern aus einer florierenden Kolchose, der ihn in seiner Uberzeugung bestärkt, daB nur eine intakte Kolchoswirtschaft die Notsituation der Bauern im eigenen Dorf beheben kann. Nach seiner Rückkehr ins Dorf spitzen sich sowohl der Konflikt mit dem Vorsitzenden Cerepkov als auch mit dem Nachbarn

1) Vgl. etwa die Figuren der Kolchosvorsitzenden Stepan Gorsikov in "Rajonnye budni" und Ivan Fedosseevit in "Derevenskij dnevnik", dessen "Bauernschläue" (krest'janskaja chitrinka) sowie das "Gefühl der eigenen würde, das Gefühl, Herr (chozjain) zu sein im Land" als Erklärung für seine Funktionärsfähigkeiten dienen (DD 615). 
Pavel zu. Zum Höhepunkt kommt es nach Bekanntwerden der Reformbeschlüsse des Septemberplenums, auf das pavel mit dem Plan reagiert, eine private Viehwirtschaft in groBem Stil aufzubauen, während Makar für die Stärkung des Kolchos eintritt. Während einer Kolchosversammlung, auf der der Vorsitzende Cerepkov abgewăhlt wird, stelien die beiden Nachbarn ihre Meinungsverschiedenheiten über das Septemberplenum dem neu gewählten Vorsitzenden Telegin zur Entscheidung, welcher Makars position unterstüzt.

\section{Zum Verhältnis der Charakterisierungsdimensionen}

Dominante Charakterisierungsdimension für die beiden Hauptfiguren ist die gesellschaftliche. Hier läBt sich eine Oppositionsreihe festmachen, die an das Merkmal

'gesellschaftliche Integration' gekettet ist, wobei die Plus- und Minuswerte eindeutig auf die beiden Figuren verteilt sind.

(S. Schema auf der nächsten Seite) 
MAKAR $=(+)$ INTEGRATION

Arbeit im Kolchos als

Pferdewärter, arbeitserfahren

("/..) pjatnadcat let rabo-

taju konjuchom.") (TS 84)

("Ja den' i not' rabotaju

$\checkmark$ kolchoze.") (TS 84)

um Kolchoswirtschaft besorgt

(Einsatz für neues zaumzeug)

(Interpretation des Septem-

berplenums im Sinne der

stärkung des Kolchos)

Primat des Kollektiveigentums

(Kauf neuen zaumzeugs vom

eigenen Geld)

Integration der Familie

in Kolchos

(Makar zu seiner Frau:

"Koren'-to u nas s toboj

v kolchoze.") (TS 89)

Kontakte mit Obkom- und

Rajkomfunktionären

("Makar i sekretarju obkoma skazet, ¿to zachoket.") (TS 84)

("A esce byl sluch - eto uz tokno, - $\boldsymbol{z}_{\text {to }}$ Makar Petrovic samolicno chodil k sekretarju rajkoma partii i polcasa razgovarival s nim o predsedatele kolchoza /.../" (TS 96)

Vertrauen in Interessenidentitát Bauern - Funktions$\left.\frac{\text { träger }}{\left({ }^{*} \text { my }\right.} 1\right)$

Ausweitung der Interessenidentität auf gesamten Makrokosmos

("/... napisu v centr /../" ) (TS 81)

(Interessenidentität "narod" und "Verchovnyj Sovet") 2)
PAVEL $=(-)$ INTEGRATION

wenig Arbeit im Kolchos

"No ty Ze, Pal Efimyc, daže ot ezdovoj dolznosti otkazalsja - bez konej na rabotu chodis..") (TS 83)

nicht um Kolchoswirtschaft

besorgt

TInterpretation des Septemberplenums im Sinne der Schwächung des Kolchos)

Primat des Privateigentums (Plan einer privaten viehzucht) (Makar: "U tebja kurs $v$ liknoe delo.") (TS 83)

\section{Extegration der Familie aus} Kolchos

Makar: "U tebja koren' vo dvore, a suchie suc'ja $v$ kolchoze.") (TS 95)

- (Kontakte nur zum Kolchosvorsitzenden Cerepkov)

Trennung bäuerlicher Interessen und Funktionsträgerinteressen

("oni")"

Trennung vom Makrokosmos

(Nichtidentität Bauern -

"Verchovnyj Sovet") 2)

1) " - Kto - oni?

- Nu, pravlenie, $t_{t o}$ li... Tot Ze predsedatel'.

- Dak éto ze my i est'!" (TS 83)

2) " - /../ Ono, naverno, nepravil'no. No ty i ne Verchovnyj Sovet?

- Kak tak - ne Verchovnyj? Ja - narod. My eto ponimaem.

I tam ponimajut." (TS 84) 
Neben diesen Oppositionen in der gesellschaftlichen Dimension, die das Verhältnis der Figuren zum Makrokosmos betreffen, existiert eine zweite Oppositionsreihe,

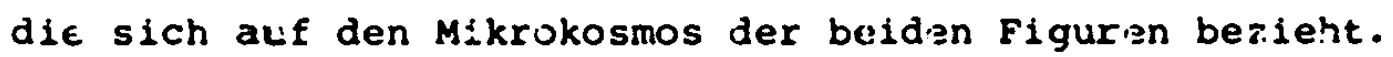
Aufschlubreich ist nun besonders die Entwicklung dieser Oppositionsreihe in ihrem Verhaltnis zur dominanten Reihe.

Beide Figuren werden zunächst in ihren äuBeren Erscheinungen charakterisiert, denen Spitznamen als sprechende Namen zugeordnet werden.

MAKAR

Sprechender Name:

"Goreica" (Senf)

AuBeres:

lang, hager, gekrümmt,

"knöchern" (kosistyj) (TS 81) haltbar ("kost' u nego procnaja") (TS 81)

Merkmal:

'scharf', 'spitz'

\section{PAVEL}

Sprechender Name:

"Pomidor" (Tomate)

AuBeres:

runa, dick ("Ves" on kakoj-to

kruglyj so vsech storon.") (TS 82)

"rundes Gesicht" (lico krugloe)

(TS 82)

Merkma 1:

'weich' ' (-) scharf'

(sdobnyj = aus Milch/Butter)

(TS 82)

wahrend die beiden Nachbarn so in betont auberen Merkmaloppositionen einander zugeordnet werden, stehen in grotesker Umkehrung ihre beiden kühe ("oken' i oten' raznye zivotnye") (TS 82) in markiert 'innerer' ("charakterlicher") Opposition zueinander:

\section{MAKARS KUH}

ungehorsam, storrisch, "nervors" (nervnaja) (TS 82), nicht melkbar

"auBergewöhnlich" ("Ne po moloku osobennaja, a po charakteru. " (TS 82 , Hvh.G.W.)

\section{PAVELS KUH}

gehorsam, melkbar

("/...) a po charakteru byla

takaja, cto daze ot ružejnogo vystrela ne vil'net chvostom.") (TS 82, Hvh.G.W.)

"gewbhnlich"

(obyknovennaja) (TS 82) 
Diese groteske Oppositionsreihe zwischen Makar und Pavel sowie ihren jeweiligen Tieren wird in einem Zusammenhang entwickelt, der in deutlicher Isolierung vom gesellschaftlichen Integrationsfeld beider Figuren steht und für den gerade die Existenz der Oppositionen aus der dominanten Reihe nicht zu gelten scheint. Der extegrierte Charakter der Situation wird zeitlich (Feiertage), räumlich (zunächst teilnahmslose Anwesenhelt beider Figuren an den Festtagsversammlungen, dann zur eigenen Feier ins eigene haus) und v.a. bezüglich des Verhaltens der beiden (wiederholte Feststellung, daß sie sich während dieser zeit, aber nur während dieser zeit gründlich betrinken) markiert. Die Nichtexistenz der dominanten Oppositionsreihe erklärt sich gerade aus der Isolierung dieser Situation aus dem gesellschaftlichen Lebenszusamenhang: Beide Bauern haben es sich zur Regel gemacht, an den Feiertagen nicht iber Politik zu sprechen (TS $80 f$ ).

Diese Ausgangssituation wird im folgenden immer deutlicher als trügerische und durch die Einwirkung der gesellschaftlichen. Realität aufbrechende dargestellt. " Es stellt sich heraus, daB sich die inneren, charakterlichen Oppositionen zwischen den beiden Figuren nur in ihren Beziehungen zum gesellschaftlichen Makrokosmos entfalten können, während die Dimensionen eines eigenen, abgetrennten Mikrokosmos auf aubere Merkmale beschränkt bleiben. In diesem Zusammenhang ist das Fehlen von Dialogen im Bereich der Extegration von Bedeutung. Es wird geradezu die Unmöglichkeit eines vom gesellschaftlichen Makrokosmos isolierten kommunikativen zusamenhangs demonstriert, indem bereits die Sprache einer solchen Isolation nicht standhält. Ein Dialog über Alltagsthemen (Rauchgewohnheiten) schlägt aus diesem Grund 'von

1) Vgl. den vorbereitenden Kommentar: "Odnim slovom, v prazdnienye dni nikakich raznoglasij $v$ nich ne bylo." (TS 81). Vgl. ebf. die wiedergabe der 'bffentlichen Meinung': "Dobrye sosedi - Makar-Gorcica i Paska-Pomidor. Dobrye!" (TS 81) 
selbst' in eine gesellschaftspolitische Diskussion um ${ }^{1)}$ : "- Nu, kuri, - soglasilsja pavel Efimyc. - Kuri, raz dusa trebuet. Samo soboj: komu tto idet. Vot finagent nas toße trubku kurit.

Slovo 'finagent' srazu navelo sobesednikov na razmyslenija. Makar Petrovic priglotnul iz trubki 1 zagovoril, budto prodolzaja kogda-to nacatyj razgovor:

- Dak vot ja - o korovam. Eto $z$ poluCaetsja nepravil 'no..." (TS $82 f$ ).

Der einzige im Kontext der Privatfeiern wiedergegebene Dialog betrifft gegen die Ubereinkunft der beiden Nachbarn (s.o.) die Beurteilung des Kolchosvorsitzenden Cerepkov. Der Abbruch dieses Dialogs gemäB dem Ubereinkommen wird demgegenüber als Minuskomunikation (betrunkenes singen) charakterisiert.

Aufgrund dieser Unmöglichkeit kommunikativer Interaktion bleibt für die gesellschaftliche Extegrationssphäre nur die äuBere Charakterisierungsdimension übrig. Ihr grotesker Charakter hat die hauptsächliche Funktion der Signalisierung dieses zusammenhangs.

Mit der Entwicklung der gesellschaftlichen Dimensionierung der Figuren bekommt die äuBere Charakterisierungsdimension einen immer geringeren stellenwert. Sie wird, falls sie weiter verwendet wird, umfunktioniert zu einer metaphorischen Ebene für die dominante Oppositionsreihe. Deutlich wird dies v.a. an der Entwicklung der sprechenden Namen. Nachdem das Erzählsubjekt anfangs die unbekannte Herkunft der Namen betont ("Potemu takoe prozvisce emu dano, ne srazu soobrazis' /.../") (TS 80) und zunächst Bezüge zur äuBeren Erscheinung herstellt, wird mit zuspitzung des Konflikts die metaphorische Funktion der Namen deutlich. Der Name "Gortica" wird von

1) Vgl. auch die leitmotivisch wiederkehrenden Idiolektismen, die von der Sprache des gesellschaftlichen Makrokosmos (politischer Stil) geprägt sind: "Ne sootvetstvuet dejstvitel'nosti" und "v korne nepravil'no". Die anfangs hierin mitschwingende ironische Brechung der uneigentlichen Sprachverwendung wird im weiteren Verlauf sekundär gegenuber der dominanten Funktion, die sprachliche Integration zu signalisieren. Bezeichnenderweise werden nur dem integrierten Makar diese Idiolektismen in den Mund gelegt: Makar weiB sie mit zuspitzung des politischen Konflikts immer 'korrekter' in ihrem eigentlichen Kontext zu verwenden. 
Cerepkov nach Makars scharfer Kritik an diesem thematisiert ("Dali tebe prozviše 'Gorłica' - ty i est' Gortica!")(TS 90). Beide Nachbarn thematisieren ihre gegenseitigen Namen zweimal zu fortgeschrittenen zeitpunkten ihres streits, diesmal in eindeutiger Bezugnahme auf die unterschiedlichen gesellschaftlichen Einstellungen:

"A Ptachin stojal v osemlomlenii i tol'ko proiznes:

- Gorlica i est' Gorlica. - Pomoltal, połesalsja i dobavil:

- Kaplju ee $v$ rot poloßi, a ona tebe $i v$ nos $\xi i b a e t i v$ glaza b'et. -

No skazal on vse eto ticho, pro sebja, - Makar Petrovic ne slysal.

Tot sel i tože pro sebja burčal:

- Pomidor $i$ est' pomidor. Sidit, okrugljaetsja, nalivaetsja, zreet, sukin kot. Tri vychodnych $v$ nedelju - dva dnja na rabote, odin den' doma." (TS 93)

" - Gde Ze tvoja sovest' kolchoznaja, Zertov Pomidor!

- Gortica! - skazal Ptachin.

- Gniloj Pomidor! - skazal Makar Petrovic." (TS 95)

(Vgl. Makar über Pavel: "gniloj kolchoznik") (TS 95)

Die äuBere Charakterisierungsebene wird andererseits in ihrer grotesken Funktion nur dann weiterverwendet, wenn sich die Figuren in der gesellschaftlichen Extegrationssphäre bewegen. Für Makar wird sie beispielsweise während des Kuhverkaufs aktiviert, der in markierter Extegration vom Integrationsfeld kolchos vonstatten geht (Makar bleibt fünf Tage von der Kolchosarbeit fern und wird zu privathändlerischen Betrügereien gezwungen, un einen Käufer für seine Kuh zu finden). 1)

Demgegenüber wird dann, wenn Makar einen besonders hohen Grad gesellschaftlicher Integration erreicht, eine neue, nicht-groteske äußere Charakterisierung vorgenommen, die in

1) Entsprechend wird wieder die Ebene der grotesken "Charakter"-Beschreibung von Makars Kuh aktiviert

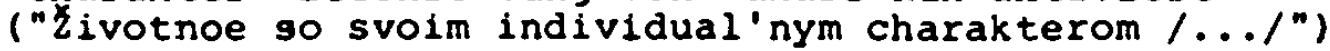
(TS 85), - zum zeitpunkt eines sehr groBen Individualitä:sverlustes Makars: "On videl gromadnuju tolpu, $v$ kotoroj smesalis' ljudi, lošadi, korovy, avtomasiny ... Komu kakoe delo do togo, Eto Makar Petrovie prodal korovu? Nikomu." (TS 87) Gleichzeitig wird hier jedoch die metaphorische Funktion der Kuh bzw. ihres Charakters für Makars gesellschaftliche Charakterisierungsmerkmale deutlich. Die Kuh läßt sich nur melken, wenn ihr die FüBe gefesselt werden. Makar läBt sich nur 'melken', wenn er unterdrückt wird. 
ihrer Konzentration auf die Augen den Zusammenhang zur inneren Charakterisierung herstellt: in unmittelbar an den Kuhverkauf anschlieBenden Dialog mit dem Bavern aus der Nachbarkolchose ("On posmotrel svoimi svetlymi i dobrymi glazami na parnja /.../") (TS 87) und im Dialog mit seiner Frau, in dem Makar seine faniliäre situation in den Kolchos integriert ("Ona ljubila èti prjamo-dusnye glaza svoego Makara, $v$ kotorych vidna vsja ego dusa.") (TS 88 ).

\section{Haupt- und Nebenfiguren}

Ein weiterer Aspekt, unter dem sich die ungebrochene wirksamkeit des makrokosmischen Integrationspotentials erweist, ist das Verhältnis zwischen den băuerlichen Hauptfiguren und den Nebenfiguren der Kolchosvorsitzenden. Hier ergibt sich das gleiche Aquivalenzen- und Oppositionengefüge wie in den Texten, in denen Bauern nur als Nebenfiguren vorkommen. Negativer Bauer und negativer Funktionsträger sowie positiver Bauer und positiver Funktionsträger stehen jeweils in Aquivalenzbeziehungen. Die Basis der Aquivalenzen ist die Identität der băuerlichen Interessen und der Kolchosinteressen bei den positiven Figuren und die Schädigung der Kolchosinteressen bei den negativen Figuren. Entsprechend sind die Oppositionen zwischen negativem Bauer und positivem Funktionsträger sowie zwischen positivem Bauern und negativem Funktionsträger verteilt.

Innerhalb dieses Aquivalenzen-/Oppositionengefüges bestehen bzw. entwickeln sich Dominanzverhältnisse, welche die prinzipielle Aquivalenz zwischen positivem Funktionsträger und băuerlichen Interessen als vorherrschende Relation (und letztlich entscheidenden Faktor fulr die Integration beider bauerlicher Figuren) manifestieren.

In der folgenden schematischen Darstellung dieser Relationen sind auf der horizontalen Koordinate die beiden bäuerlichen Hauptfiguren und auf der vertikalen Koordinate die beiden Kolchosvorsitzenden als Nebenfiguren eingetragen. In den Quadraten als Schnittpunkten dieser Figurenreihen sind die jeweiligen Áquivalenz- und Oppositionsbeziehungen sowie ihre unterschiedlichen Auswirkungen auf die Integration bzw. Desintegration der beiden Hauptfiguren verzeichnet: 
MAKAR

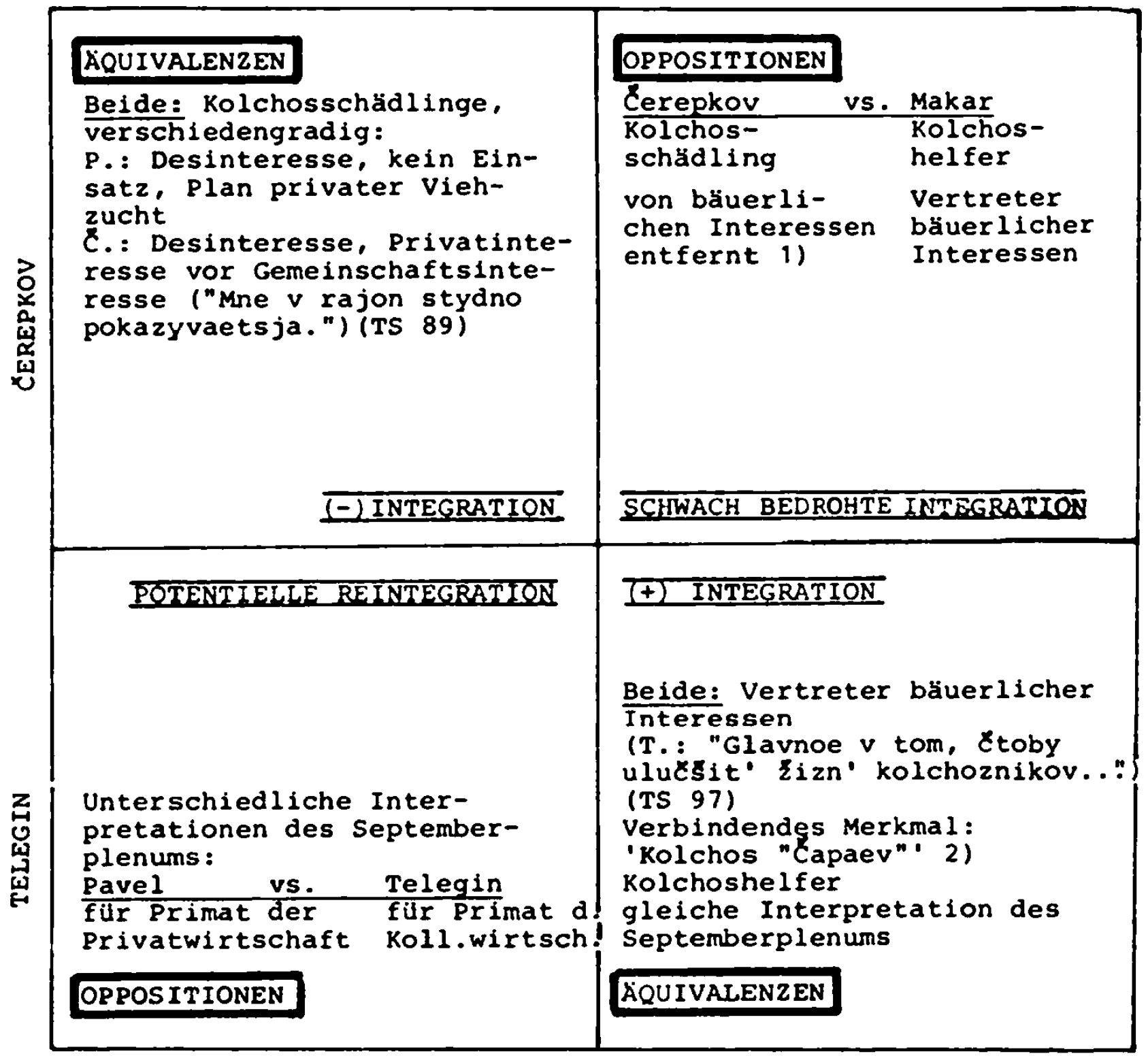

1) "Cerepkov Euvstvoval sebja javno nelouko. On nakonec ponjal, ¿to chot' 1 predsedatel'stvuet bol'se goda, a Makara Luckova ne zametil. Torcit Celovek celymi dnjami $v$ konjusne, suet vsem k nosu osokovye puty - 1 vse. A Cert ego znaet, kakoj on! Cto u nego doma? Cem on dysit? Do vsego étogo Cerepkov ne dosel." (TS 90)

2) Telegin stamnt aus dem Kolchos "Capaev", eben dem Kolchos, der für Makar nach seinem Gespräch mit dem jungen Bauern auf dem Basar zum Symbol für eine gesunde Kolchoswirtschaft wird. 


\section{Erläuternder Komentar}

Es erweist sich, daß auch die scharf markierte Opposition zwischen Makar und Cerepkov (eine solche Opposition nahm in den Texten mit bäuerlichen Nebenfiguren keine interfigurale Gestalt an, s.IV.1.3.) die Integration Makars nur vorübergehend und schwach bedroht. Makar ist gezwungen, seine Kuh zu verkaufen und bleibt deswegen fün Tage von der Kolchosarbeit fern. Zerepkov versucht nach Makars Rückkehr, diesen von seiner Arbeit als Pferdewärter zu entlassen, was aber scheitert und mit Cerepkovs Isolierung auf der Kolchosversammlung endet. Makars Konflikt mit Cerepkov beeinträchtigt nie die grundsätzlich integrative Einstellung des ersteren zum kolchos und $z u$ den Funktionsträgern. Seine Kritik an Cerepkov betont gerade die zentrale Funktion des Kolchosvorsitzenden ("A predsedatel' - vsemu golova.")(TS 92), ("Nam golova nuzna dlja kolchoza, a ne pivnoj kotel.") (TS 92). Entsprechend erreicht Makars Integration den höchsten Grad mit der Wahl des neuen Kolchosvorsitzenden Telegin, der diesen Anforderungen eines Funktionstrăgers entspricht; Makar hält auf der Wahlversammlung "unter stürmischem Applaus" (pod burnye aplodismenty) eine Einführungsrede für den neuen Vorsitzenden (TS 98).

Umgekehrt ist die Opposition zwischen Pavel und Telegin nur schwach entwickelt und hat keinen antagonistischen Charakter. Sie betrifft die unterschiedliche Interpretation des Septemberplenums und erscheint v.a. durch die von Telegin ausgehende Uberzeugungskraft (Identität von bäuerlichen und Kolchosinteressen, 'Autorität der Argumente') auflobsbar. Die mit dem Septemberplenum ermöglichte Reintegration Pavels war bereits unmittelbar nach Bekanntwerden der Beschlüsse angedeutet worden (gemeinsames Lesen der Zeitung, vorubergehende Beendigung des Streits der beiden Nachbarn). Erst mit dem Erscheinen Telegins wird diese Möglichkeit konkret, wahrend Makar allein die zunächst fortgesetzte Extegrationstendenz pavels nach dem Septemberplenum nicht verhindern konnte (zuspitzung des streits um private viehzucht). Pavels Extegration wiederum war $2 u$ wesentlichen Teilen durch die Figur des negativen Funktionstrăgers לerepkov bedingt. Dieser ermöglichte erst Pavels privatisierende Tendenzen, indem er persönliche Beziehungswirtschaft betrieb und kolchosschädigende Tendenzen deckte. Entsprechend war Pavels nicht-kritisches, opportunistisches Verhalten ihm gegenüber nicht Ausdruck seiner positiven Einstellung $z u$ den gesellschaftlich-öffentlichen Funktionsträgern, sondern seines Interesses an einer Schwächung ihrer Funktionen ("Potraf" emu $i$ - porjadok!") (TS 92), (Charakterisierung Cerepkovs als "ungänglich" (obchoditel'nyj) (TS 92)).

Als Resultat dieser Beziehungen zwischen Haupt- und Nebenfiguren erweist sich wiederum die dominierende Rolle der Funktionsträger, welche hier nur indirekt, aus einer Nebenfigurenposition heraus wirksam wird. Der gesamte Verlauf des Streits zwischen den beiden Nachbarn 
ist zum groBen Teil durch diese Nebenfiguren geprägt. Er entsteht aufgrund der ungerechten Behandlung Makars unter Čerepkovs Leitung und spitzt sich auf das Verhältnis zu Cerepkov zu. Beide Nachbarn tragen ihren streit am Ende offentlich in ihrer Befragung Telegins aus, der dort zwar nicht endgultig gelöst, jedoch durch Telegin entschärft wird und in der Schlubszene, dem gemeinsamen Heimgang der beiden Nachbarn, in seiner Absurditat angesichts der neuen Situation deutlich wird (getrennter Heimgang auf gegenuberliegenden StraBenseiten, nachdem vorher das "Zusammenstoben" beider in der Tür des Versammlungsraums dargestellt wird) (TS 98).

VI.2. Handlungsstruktur

VI.2.1. Die beiden dominanten Handlungsschemata

Für das M.2 lassen sich zwei dominante Handlungsschemata feststellen:

a) die Leitungsarbeit eines Funktionsträgers mit dem $z i e l$ der Reformierung einer Kolchoswirtschaft (bzw. einer MTS)

b) der Konflikt zwischen zwei (oder mehreren) Funktionsträgern um die richtigen Leitungsmethoden eines Kolchos bzw. Rajon.

In beiden Fällen liegen Handlungen vor im Sinne des dreigliedrigen Schemas Ausgangsituation - Veränderung neue Situation. Im Schema a ist - unabhängig vom Erfolg die Veranderung einer Ausgangsituation des Kolchos Grundmotiv für die als Norm ungebrochen gültige Aktivität der Hauptfigur. Handlungsschema $b$ muB zwar nicht mit eindeutigem sieg bzw. Niederlage eines der beiden Agenten enden, doch haben wir es auch hier immer mit aktiven Versuchen der Veränderung einer Ausgangsituation, die in der Regel von den positiven Funktionsträgern ausgehen, zu tun. Beide Handlungsschemata können sich in den Einzeltexten uberlagern.

In dieser Dominanz des Handlungsprinzips uber das Geschehensprinzip ist eine modellkonstitutive literarische Norm festzumachen, nicht jedoch in der Frage der fabelmäBigen Geschlossenheit der Handlungsstruktur. Die beiden 
Handlungsschemata können entweder nur einzelne Fabelsegmente bzw. gröbere Fabelsequenzen oder aber die gesamte Fabel umfassen. Im ersten Fall sind die Segmente lediglich chronologisch, im zweiten Fall zusätzlich kausal (bezogen auf den Gesamtverlauf) miteinander verkettet. So wird man in einem "Tagebuch" ("Derevenskij dnevnik") vergeblich nach einem einheitlichen Handlungsschema suchen, welches die einzelnen Segmente, die in sich sehr wohl eine Handlungsstruktur aufweisen, organisiert. In "Padenie Ivana Cuprova" hingegen prägt der Kampf zwischen einem Parteischädling und seinen Kontrahenten die gesamte Fabel. Entscheidend ist, das beide Grundschemata in jedem Fall die wesentlichen Elemente für die Konstitution der Geschichte sind. ${ }^{1)}$

Die integrativen strukturen schlagen sich nicht wie in der Zdanov-Ara in der Integration von gesellschaftlichöffentlichen und privaten Handlungssträngen - wobel nur letztere Konfliktansätze aufwiesen - nieder. Es existieren ausschlieblich gesellschaftlicb-öffentliche stränge, die zumindest im Schema b scharfen Konfliktcharakter besitzen können. Reduzierte Integrationsstrukturen lassen sich jedoch im Agentenverhältnis zwischen Funktionsträgern und Bauern sowie in der Agentenhierarchie innerhalb der Ebene der Funktionsträger wiederfinden.

VI.2.2. Die einseitige Handlungsfunktion der 'Erziehung' im Schema a (Ju. Nagibin, "Novyj predsedatel'")

Im Agentenverhältnis zwischen Funktionsträgern und Bauern sind die Subjektagenten generell die gesellschaftlich-öffentlichen Funktionsträger. Ihre dominante Handlungsfunktion ist entweder die der 'Erziehung' (entsprechend dem figurencharakteristischen Merkmal 'Autorität der Argumente') oder die der 'Unterdrückung' (figurencharakteristisches Merkmal: 'Autorität der institutionellen Macht').

1) Zum Begriff der Geschichte als sinntragende Abstraktion und Organisation von Geschehen vgl. K.H. Stierle, Geschehen, Geschichte, Text der Geschichte, in: Ders., Text als Handlung, München 1975, S.49ff. 
Die Handlungsfunktion der 'Erziehung' dominiert im Handlungsschema a. Zur exemplarischen Verdeutlichung eignet sich ein Text, der nur aus chronologisch geketteten Fabelsegmenten besteht, die allesamt dem Schema a zuzurechnen sind. In "Novyj predsedatel'" wird ein Tag in der Leitungsarbeit des Kolchosvorsitzenden Rusakov dargestellt. Er ist in folgende situationen segmentiert:

1) Sprechstunde. Rusakov empfängt einen Alten, der sich uber ungerechte Lohnabrechnung beschwert. - Lösung offen.

2) Sprechstunde. Rusakov empfängt einen Jungen aus dem Nachbardorf, der als Fahrer angestellt werden will. Lösung: Rusakov macht zur Bedingung, daB auch die Frau des Jungen in die Kolchose eintritt und uberfunrt den Jungen egoistischer Motive.

3) Rusakov macht eine studentische Praktikantin auf Fehler beim Melken aufmerksam.

4) Eine Melkerin wendet sich an Rusakov. Sie ist gegen die künstliche Hochzüchtung von Rekordergebnissen. - Lösung: Rusakov ist einverstanden.

5) Rusakov versucht eine Schullerin zu überzeugen, ein Fernstudium $z u$ beginnen, anstatt die Kolchose $z u$ verlassen. Lösung offen.

6) Parteiversammlung. Meinungsverschiedenheiten zwischen Rusakov und Gor'kom-Sekretär bezüglich des Maisanbaus. Lösung offen (Erzählerkommentar gibt dem Sekretär recht).

7) Inspektion der Felder. Rusakov rügt streng einen Traktoristen wegen unachtsamer Arbeit.

s) Entladung eines Transportflugzeugs mit Kunstdünger. Streit unter den Ladearbeiterinnen. - Lösung: Rusakov schlichtet.

9) Ein betrunkener Alter fühlt sich miBachtet. - Lösung: Rusakov gibt ihm eine Aufgabe (Bewachung des Flugzeugs).

10) Streit in der Traktoristenbrigade. - Losung: Rusakov schlichtet.

11) Rusakov rügt die schlechte Arbeit der Mechanisatoren und erklärt den Fehler (Schädigung des Gemeinwohls) (= Lösungsandeutung).

12) Zwei Fahrer bedrängen Rusakov wegen Benzinmangels. Lösung: Rusakov telefoniert mit der Benzinstation.

Es gibt nur eine Situation, in der Rusakov sich der Ausgangssituation nicht gewachsen zeigt (6). Immer, wenn er hingegen mit Bauern zusamentrifft, ist er derjenige, der die Situation entweder löst $(2,3,4,8,9,10,12)$ oder zumindest cen richtigen Lösungsweg angibt bzw. falsches Verhalten kritzsiert $(5,7,11)$. Nur in einem Fall verhält er sich unentschieden (1). Nur in einem Fall muB er von den Bauern zur iösung einer situat:on erst gedrärgt werden 112 ; in sit. 
4 ist Rusakov von vornherein einer Meinung mit der Melkerin ${ }^{1}$ ), Die verschiedenen Funktionen, die Rusakov dabei wahrnimmt, lassen sich unter 'Erziehung' - in politischer $(2,4,5,8)$, wirtschaftlicher $(3,7)$ oder menschlicher $(8,9,10)$ Hinsicht-zusamenfassen, wobei Strenge und weltanschauliche Uberzeugungsarbeit sich nicht ausschlieBen, das Hauptgewicht aber auf der Uberzeugungsarbeit liegt.

Die Funktion der 'Erziehung' wird also nur in einer Richtung wirksam (vom Funktionstrăger zum Bauern), sie setzt auf der Seite der băuerlichen Figuren keine Subjektagenten, sondern lediglich objektagenten voraus. Die Funktion der 'Unterdrückung' ware hingegen, um handlungskonstitutiv werden zu können, auf bauerliche subjektagenten mit entsprechenden Antagonisten-Funktionen ('widerstand', 'kritik') angewiesen. Diese bäuerlichen Subjektagenten existieren jedoch nicht. Der potentielle Konflikt zwischen Funktionstrăgern und Bauern wird stattdessen auf der Ebene der Funktionstrăger ausgetragen, wobei sich die stellvertreterfunktion des positiven Funktionstrăgers aus der Identitat von băuerlichen und Reforminteressen legitimiert. Dies wird im Schema b $z u$ sehen sein.

VI.2.3. Agentenhierarchie im Schema b (V. Tendrjakov, "Padenie Ivana Xuprova")

Die dominanten Handlungsfunktionen im Schema b sind entweder die des 'Schădigers' oder die des 'Retters' bzw. 'Helfers' der integrativen Institutionen des gesellschaftlichen Makrokosmos. In der Verteilung dieser Funktionen auf eine Agentenhierarchie, die der Hierarchie der gesellschaftichen Funktionen entspricht, erweist sich die Fahigkeit des Makrokosmos zur Reaktivierung seines vorübergehend gestorten integrativen Potentials.

1) Hier haben wir einen weiteren Fall der in VI.1.3. beschriebenen Aquivalenz von positiver funktionstragender und positiver bauerlicher Figur. Nicht zufälig handelt es sich bei der Melkerin um die beste Melkerin der Kolchose. 
In "Padenie Ivana Cuprova" ist die Hauptfigur ein bestechlicher und trinkender Kolchosvorsitzender. Der Handlungsverlauf ist von den immer tieferen Verstrickungen des ehemals verantwortungsbewubten Cuprov in betrügerische Geschäfte sowie vom Kampf um seine Rettung, geführt von dem jungen Parteisekretär der Kolchose Aleksej Bykov, dem ehemaligen Freund Cuprovs Bessonov (damals Parteisekretär der Kolchose, jetzt Vorsitzender einer Nachbarkolchose), Xuprovs Tochter Raja und dem Rajkom-Sekretar Sutulov, bestimmt. Die wichtigsten Situationen im Kampf dieser Figurenreihe sind:

1) Besuch Bessonovs. Bessonov äuBert gegenüber Aleksej sein Unbehagen über Cuprovs verändertes Benehmen.

2) Der von Cuprov protegierte Aleksej bekommt Zweifel, kann aber nicht aus seinen Verpflichtungen Kuprov gegenüber heraus.

3) Auf einer Leitungsversammlung tritt Aleksej offen gegen Kuprov auf ("Partijnoj sovesti u tebja net!") (TP 112). Er wird unterstutzt von der warterin Glafira, die nicht Leitungsmitglied ist und vor die Tur gesetzt wird.

4) Auf einer zweiten Versammlung spielt Cuprov seine Autorität gegenuber Aleksej aus (Vortauschung einer Krankheit etc.) und isoliert ihn.

5) Raja als einzige Vertraute Aleksejs schlägt vor, das Rajkom zu benachrichtigen. Zweifel Aleksejs (Cuprov genieBe dort mehr Vertrauen).

5) Neues Treffen Bessonov - Xuprov. Bessonov wird miBtrauisch.

7) Aleksej und Raja erkennen ihre Unfăhigkeit, zu handeln. BeschluB, sich an Bessonov zu wenden.

8) Bessonov schaltet nach Informierung durch Aleksej und Raja Sutulov (Rajkom) ein.

9) Ankunft Bessonovs, Rajas und Aleksejs bei Cuprov. Ein klärendes Gespräch kann nicht mehr stattfinden.

Auf der untersten Ebene in der Agentenhierarchie stehen Raja und Aleksej. Ihnen ist eigenständiges Handeln nicht möglich (der einzige Versuch schlägt in Isolation um, sit. 3,4), sondern sie sind dazu auf Bessonov angewiesen. Bessonov steht auf einer mittleren Position zwischen Aleksej/Raja und Sutulov. Er macht als erster Aleksej auf Cuprovs Veränderung aufmerksam (1), er ist die Bezugsperson, an die sich Raja und Aleksej am Ende ihrer Handlungsmöglichkeiten wenden (7). Er stellt schlieblich die Verbindung zum Rajkom her und kann dann erst die abschließende (vergebliche) Rettungsaktion starten. Dabei ist besonders diese letzte Kausal- 
beziehung (8) von der handlungslogik her redundant, da das von Bessonov angestrebte persönliche Gespräch mit Xuprov als altem Freund dieser Verknüpfungsinstanz nicht bedurfte. Ihre Funktion ist eher in der positiven zerstreuung von Aleksejs Zweifeln gegenüber dem Rajkom (5) zu sehen.

Es ergibt sich, daB die Partei in ihrer Gesamtstruktur in der Lage ist, sich von Schädigungserscheinungen, wie Cuprov sie repräsentiert, rein zu halten. Gerade das mangelnde Vertrauen Aleksejs in die Partei als integrative Institution des gesellschaftlichen Makrokosmos ist ja ein Grund dafür, das die Rettung für Cuprov zu spät kommt. Häte er gleich das Rajkom verständigt, wăre eine positive Lösung noch möglich gewesen.

Bäuerliche Figuren mit Agentenfunktionen existieren nicht. Sie als die eigentlichen Leidtragenden unter der Leitungspolitik Čuprovs und als informierte zeugen seines moralischen und gesellschaftlichen Verfalls sind zur Tatenlosigkeit verurteilt. Ihre Funktion beschränkt sich darauf, durch Gerüchte den Niedergang Cuprovs publik zu machen. 'Des Volkes Stimme' kommt nur einmal zu wort, aber auch hier nur in unterstüzender Funktion für den Parteifunktionär Aleksej (Glafira in der Versammlung, Sit.3). Die positiven Funktionsträger übernehmen mit ihrem Kampf gegen Kuprov gleichzeitig stellvertreterfunktionen für die handlungsunfähigen Bauern. ${ }^{1)}$

1) $\mathrm{Zu}$ dieser Transformierung des potentiellen Konflikts zwischen negativem Funktionsträger und Bauern auf die Ebene des Konflikts zwischen den Funktionsträgern vgl. ebf. "Rajonnye budni". - Obwohl noch krasser als in "Padenie Ivana Cuprova" das Leid der Bauern unter dem despotischen Borzov dargestellt wird, finden deren Interessen keinen elgenen Ausdruck, sondern sind auf Martynov als Delegierten bzw. Vermittler angewiesen. zur Agentenhierarchie im Handlungsschema b vgl. ebf. "Na srednem urovne". - Hier wird zunächst die Entwicklung des ehemals selbstbewuBten und tatkräftigen kolchosvorsitzenden Stepan Tichonovic $z u$ einem desengagierten Funktionär dargestellt. Es folgt auf einer zweiten Ebene die Darstellung des unterdrückerischen Verhälnisses der Rajkomparteisekretäre Neverov und Moltanov zu Stepan Tichonovic als Ursache für dessen Entwicklung. Der auf dieser Ebene sich entwickelnde Konflikt zwischen Neverov/ Moléanov ('Autorität der institutionellen Macht') und 
VI.2.3. Die transfigurale Handlungsinstanz des offentlichen Mediums

Das Integrationspotential des gesellschaftlichen Makrokosmos beschränkt sich nicht auf die führende stellung 'helfender' bzw. 'rettender' Funktionsträger in der figuralen Agentenhierarchie. Diese wird gleichsam perpetuiert in der transfiguralen Handlungsinstanz des offentlichen Mediums (Zeitung und Radio), welches den gesamten ('sowjetischen') Makrokosmos als Integrationssphäre markiert. Wir haben es hier mit einem für das M.2 besonders typischen und kennzeichnenden Verfahren $z u$ tun.

Das offentliche Medium hat in der Regel eine positiv handlungsentscheidende Funktion.

In "Sosedi" wird diese Funktion deutlich markiert. Das gemeinsame Lesen der zeitung mit den Beschlüssen des Septemberplenums führt zur ersten Beilegung des streits zwischen den Nachbarn.

Nach dem Erhalt der zeitung besucht Makar zum erstenmal wieder seinen Nachbarn, der zunächst ablehnend reagiert. Nach dem Vorlesen der ersten Satze durch Makar wird die Zeitung jedoch zum beinahe körperlich verbindenden Gegenstand:

dem Rajkom-Instrukteur Eremin ('Autorität der Argumente', Verbundenheit mit den Bauern) wird wiederum erst nach der Einschaltung einer dritten Ebene (Parteizentrale, Septemberplenum) zugunsten Eremins gelöst. Jetzt erst findet auch stepan Tichonovic sein altes selbstbewuBtsein zurück, wobei sein kritisches Auftreten auf einer Parteikonferenz gegen Neverov erst durch die Unterstützung Eremins zum Erfolg führt.

In Form eines Minusverfahrens wird die Agentenhierarchie auch in "Razgovor S Pisleginym" ("Vesnoj nynešneg̣o goda") markiert. Pislegin erbittet von Baslakov die Einstellung in dessen MTS. Die Uberzeugungsleistung Baslakovs besteht nun gerade darin, daB nicht er, sondern der zustandige Rajkom-Sekretär die Kompetenzen für die Reintegration Pislegins besitzt. Der Oxerk endet mit der Abfahrt Pislegins zum Rajkom.

In G. Nikolaevas "Povest" manifestiert sich die Agentenhierachie in der Funktion des Obkom-Sekretärs Sokolov. Er greift immer dann handlungsentscheidend ein, wenn eine Lösung des Konflikts zwischen den MTS-Funktionären von diesen selbst nicht mehr herbeigefuhrt werden kann; er verhindert die drohende Entlassung Nastjas aus der MTS und er löst den Streit um die richtige Saatmethode. 
"Ptachin ot udivlenija vstal. Makar Petrovid toze vstal, ne otryvajas" ot gazety.

- A nu, daj-ka - ja sam potitaju, - neozidanno skazal

Ptachin.

Oni seli teper' uže na brevno, prjamo sredi dvora. Ptachin tital toze ne oxen' bojko. On vremja ot vremeni ostanavilvalsja, podnimaja palec vverch, davaja sebe porazmyslit'. Potom snova $\ell_{i t a l}$ Makar Petroviz. Potom - opjat' Ze Pavel Efimyd. $V$ texenie trech posledujustich dnej oni neskol'ko raz schodilis' uže pozdno vekerom i snova titali. Gazeta uze razlezlas' po skladkam, no ee skleili i znali tolno, tto tam napisano, pod sklejkoj. I snova i snova prinimal is' citat' i obsuzdat'." (TS 94)

Exponiert wird die handlungsentscheidende Funktion des Offentlichen Mediums auch in "Na srednem urovne". Auf der Parteiversammlung, während der Neverov abgewählt und Eremin zum neuen Rajkomsekretăr gewählt wird ${ }^{1)}$, wird die Zeitung mit den Beschlussen des Septemberplenums zur - ahnlich wie in "Sosedi" sich korrperlich auswirkenden Triebkraft.

Der erste Auftritt des Kolchosvorsitzenden Stepan Tichonovit nach der langen zeit seines politischen Schweigens wird so eingeleitet:

"Kogda emu popala gazeta, on vdrug ves' tak i vstrepenulsja, tak i vpilsja v gazetnyj list glazami, ravnodusie s nego kak rukoj snjalo. Stepan Tichonovid cital, namorsciv lob i Sevelja gubami, v lice u nego vystupilo tto-to detskoe. posle ètogo on poprosil slova." (KN 22)

Die zeitung wird hier auch in inrer transfiguralen, die einzelnen figuralen Agenten verbindenden und leitenden Eigenschaft veranschaulicht ${ }^{2)}$ :

"I u každogo vychodivšego na tribunu byla $v$ rukach gazeta." (KN 24)

1) S. Anm.1 auf S.143(144).

2) Diese Funktion des offentlichen Mediums beschränkt sich nicht auf die zeitungs- und Radioberichte uber das

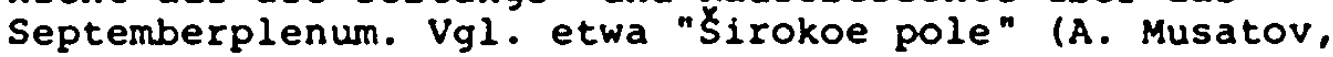
1955). - Hier wird der Konflikt zwischen einer Agrarwissenschaftlerin, die als Agronomin in einer Kolchose arbeiten will und dazu auch ihre Kollegen anspornt, und dem Direktor des Forschungsinstituts, der dies verhindern will, in letzter Instanz durch die zeitung gelost: "No bylo uze pozdno. EłCe Zerez dva dnja v gazetach pojavilas' zametka o tom, $t_{t o} v$ Institute zernovogo chozjajstva naćalos' dviženie za perechod specialistov sel'skogo chozjajstva na nizovuju rabotu." (MS 477).

Vgl. ebf. "Povest" : Ein Mitglied der Nastja zugeordne- 
VI. 3. Raum/Zeit-Struktur

VI.3.1. Entsprechung räumlicher und gesellschaftlicher Integration

(Ju. Nagibin, "Chazarskij ornament")

Auf der Ebene der Raum/Zeit-Struktur besteht eine relativ ungebrochene Kontinuitat der alten Normen. Die räumliche Integration des Handlungsorts (Kolchos) in den Makrokosmos (Rajon, Oblast') entspricht der gesellschaftlichen Integration. Der Topos des positiven Nachbarkolchos als Alternative $z u$ den MiBständen im Handlungsort ist weit verbreitet. In "Sosedi" wird er in verbindung der răumlichen Trennung vom heimischen Kolchos zum entscheidenden Motiv für das Kolchos-Engagement Makars (Treffen auf dem Basar, s.VI.1.4.).

Die Technik besitzt nach wie vor raumintegrierende Funktion. Der Anfang von "Vesnoj nynesnego goda" markiert die räumliche Integration des Handlungsorts durch die Technik in Uberwindung der natürlichen Grenzziehung (FluB) und der historischen räumlichen Extegration (Wachturm): "Celovek na kalance vsegda smotrit tol'ko v odnu storonu na jug - i vidit pered soboj ves' gorod; s drugoj storony ploscad' obryvaetsja vysokim jarom, pod kotorym letom izredka proplyvajut parochody, storonjas' krutogo berega, a zimoj po gladkoj sinevatoj poverchnosti skovannoj l'dom reki

ten Figurenreihe, der Komsomolze Goła, wird offentlich für sein Rekordergebnis in der von Nastja durchgesetzten neuen Saatmethode ausgezeichnet. Dieses Eingreifen der Medien hat einen stürmischen Aufschwung der gesamten MTS-Arbeit und damit den endgültigen sieg Nastjas zur Folge.

Eine negative Funktion wird dem offentlichen Medium nur selten - und erst in der Auflösungsphase des Modells zugeschrieben. In "Derevenskij dnevnik" wird die Presse als ein Instrument dargestellt, das die Flexibilitat der Kolchosen fesselt. Beispielsweise wird von der Presse eine Spekulationsaffäre gegen Ivan Fedosseevid inszeniert. Ihm wird ein betrügerisches Geschäft mit einer Konservenfabrik vorgeworfen. In der Auflosung der Affäre durch den Erzähler stellt sich heraus, daB der von Ivan Fedosseevit verkaufte Rübenabfall sich zum groBen Teil als frische vare erwies, woraufhin der Kolchos legitimerweise den frischen Teil aussonderte und auf dem Markt in Moskau verkaufte. (DD $595 \mathrm{ff}$ ) 
toroplivo begut $v$ lesa avtomasiny, medlenno polzut traktory s tjaŽlymi vozami. Lesa nacinajutsja srazu za rekoj. podnimajutsja po vzgor'ju i uchodjat vdal', naskol'ko chvataet glaz..." (2V 55).

"Odin den" wird eingeleitet mit einer Beschreibung der der morgendlichen StraBe als Chronotopen der interaktiven Begegnung zwischen Natur und Technik:

"No vot gružennaja meskami semjan avtomasina vypolzla iz-za ugla zernochranilista, vybralas' na dorogu, nabrala skorost. i zasignalila telenku. Tot povernul mordocku, stal poprocnee posredi dorogi, nabljudaja, tto budet dal'se. Konecno, masine dorogu on ne ustupil: videli, deskat', my tebja na ferme - ne udivitel'no! Prílos' soferu akkuratno ob-echat' uprjanca." (TO 99)

Die gesellschaftich integrierenden Agenten zeichnen sich durch einen entsprechend hohen Grad an räumlicher Beweglichkeit aus. Am extremsten wird sie in "Šef" markiert. Die Hauptfigur stellt hier eine Merkmalkombination aus den räumlichen Feldern Dorf und Stadt dar. Gleich zu Anfang wird sie als stadtischer, aus Leningrad stamender Industriearbeiter beschrieben, dessen Haar in einem ausgefuhrten Vergleich mit Feldweizen verglichen wird (RS 160). Dieser Nikanor Ivanovic Serikov wird von seinem Betrieb als Monteur ins Vologdaer Gebiet geschickt, wo er die Absetzung eines bürokratischen und bestechlichen Kolchosvorsitzenden bewirkt. " Ein Verfahren, das die răumliche Integrationskraft Serikovs zusätzlich unterstreicht, ist die Darstellung dieses Ereignisses vom räumlichen Standpunkt des städischen Betriebes in Form eines Beschwerdebriefes des abgesetzten Kolchosvorsitzenden, den der Betriebsdirektor erhält.

Diese raumliche Integrationskraft der gesellschaftlich integrierenden Funktionsträger bleibt modellkonstitutive Norm auch in der späteren Phase des Modells, als im Rahmen einer schärfer sozialkritischen Tendenz der Literatur u.a. die Mängel der Iăndlichen Infrastruktur, besonders die Unpassierbarkeit der Wege, dargestellt werden. Ein Text,

1) Diese Absetzung steht wiederum in engem Zusammenhang mit dem Topos der positiven Nachbarkolchose. Sie erfolgt nach der Rückkehr einer Delegation, die sich in den Nachbarkolchosen ein Bild uber die Arbeit positiver Kolchosvorsitzender gemacht hat. 
in dem diese Kritik in scharfer Form manifest wird und $z u$ einer extremen Markierung der räumlichen Grenzen zwischen Dorf und Stadt führt, ist "Chazarskij ornament". Gerade dieser Text aber, der auch unter anderen Aspekten an die Grenzen des Modells stöBt - indem z.B. einer bäuerlichen Figur ein auBergewöhnlich breiter Handlungs- und Rederaum mit sehr kritischer Intention gewährt wird - offenbart vor dem Hintergrund der räumlichen Grenzmarkierungen besonders deutlich die räumliche Integrationskraft des dominierenden Agenten in Verbindung mit dessen gesellschaftlich integrierender, 'erzieherıscher' Funktion.

Zwei Moskauer verirren sich auf dem Weg $z u$ ihrem Jagdgebiet, treffen unterwegs mehrmals einen Unbekannten, der ihnen aus der Klemme hilft. Der Unbekannte erweist sich als sehr streitbarer Kritiker am zerrüteten zustand der Infrastruktur (Wege), zum groBen Argernis des Wissenschaftlers Leontij Sergeevit, der sich die Erforschung des "chasarischen Ornaments" zur Lebensaufgabe gemacht hat. Beim letzten Treffen in einer Hütte im Fischerdorf Mescera kommt es zum Disput zwischen einem alten Fischer und dem Unbekannten über Wilddieberei und Raubfischfang, an dessen Ende sich der Unbekannte als neuer Parteisekretär des Rajon zu erkennen gibt.

zur Darstellung eignet sich wieder ein Schema, dessen Vertikale die Abfolge von Situationen bildet. Auf der Horizontalen soll das Verhältnis zwischen den jeweiligen Agenten unter besonderer Berücksichtigung des zusammenhangs ihrer Handlungsfunktionen mit ihren räumlichen Funktionen abgebildet werden."

(S. Schema auf der nächsten Seite)

1) Der figurale (Ich-)Erzähler, raumzeitlich dem Wissenschaftler Leontij Sergeevid/Agent 2 zugeordnet (gemeinsamer Jagdausflug), kann bei dieser Darstellung unberücksichtigt bleiben, da er keine Handlungsfunktionen ubernimnt.

Bei der Segmentierung des Texts in Situationen ist die zum Ende hin zunehmende Verlagerung der Handlung auf dialogische Interaktion $2 u$ berücksichtigen. Hier volizieht sich ein wesentlich dichterer (und nicht an figurale oder răumliche Veränderungen gebundener) situationswechsel. 


\begin{tabular}{|c|c|c|c|c|c|c|}
\hline & 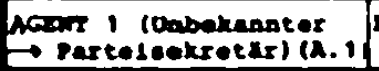 & ruake1on & 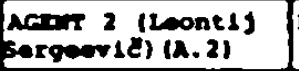 & runkelon & 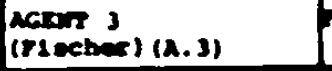 & punke $10 n$ \\
\hline 1 & & & rarlrit $1 \mathrm{ch}$ & Nom & & \\
\hline$\overline{2}$ & $\begin{array}{l}\text { welet In der Dunkel- } \\
\text { hele den weg }\end{array}$ & Rinn, & & & & \\
\hline 3 & $\begin{array}{l}\text { echlople auf echlech- } \\
\text { tee mogesyeten }\end{array}$ & 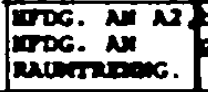 & 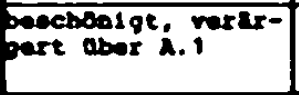 & 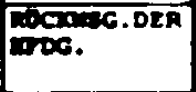 & & \\
\hline 4 & getrennter Weltergang & 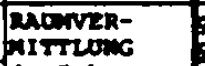 & petrennter wolter- & 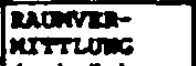 & & \\
\hline s & $\begin{array}{l}\text { echlife berolte to } \\
\text { eurte bel nakunle A.2 }\end{array}$ & $\begin{array}{l}\text { letarker } \\
\text { ele } \lambda .21\end{array}$ & $\begin{array}{l}\text { rerepstate Ankunft } \\
\text { in wetes }\end{array}$ & $\begin{array}{l}\text { lectrichar } \\
\text { ale A.1) }\end{array}$ & & \\
\hline - & & & & & 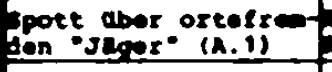 & 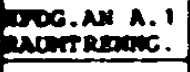 \\
\hline 7 & & & & & 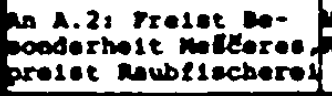 & 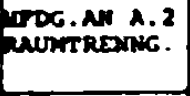 \\
\hline$\bullet$ & & & $\begin{array}{l}\text { Feaglert we phre- } \\
\text { peolnto raselest }\end{array}$ & $\begin{array}{l}\text { AUTORITKT D } \\
\text { INST. MAKUT }\end{array}$ & & \\
\hline 9 & 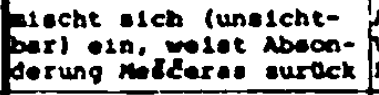 & 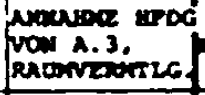 & perwelgt vertrgert & nucar & & \\
\hline 10 & $\begin{array}{l}\text { Eregt a.3 nach der } \\
\text { situation dee Dorfe }\end{array}$ & 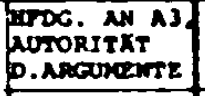 & & & 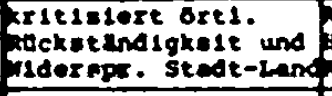 & 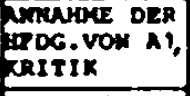 \\
\hline 11 & 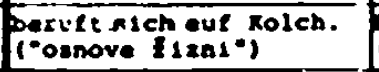 & $\begin{array}{l}\text { Rereanini } \\
\text { (Vereuch) }\end{array}$ & & & $\begin{array}{l}\text { informiert aber } \\
\text { perreteg. d. Tolch. }\end{array}$ & Ax. Geger \\
\hline 12 & $\begin{array}{l}\text { lragt nach ylled der } \\
\text { pertes }\end{array}$ & 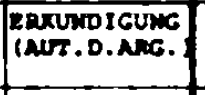 & & & 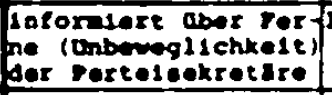 & ITPORuTIOX \\
\hline 13 & & & 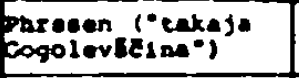 & (-IADCuntent & & \\
\hline T19 & 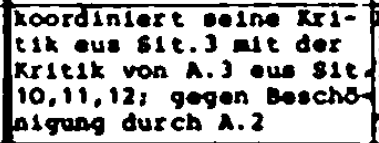 & 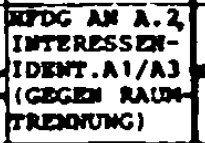 & cenvelge & rwacts & & \\
\hline is & $\begin{array}{l}\text { infornlert aber verbot } \\
\text { der paubli echerel }\end{array}$ & 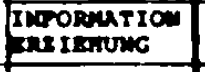 & & & 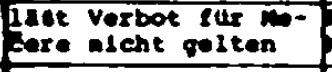 & 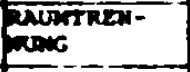 \\
\hline 16 & 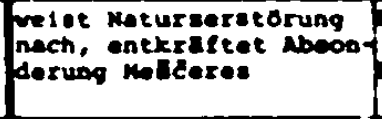 & 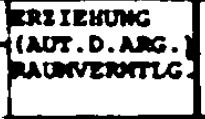 & & & $\begin{array}{l}\text { pabe bleb aborzeu- } \\
\text { jea, bole andere } \\
\text { porfowehner her }\end{array}$ & 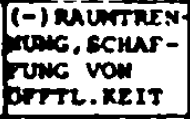 \\
\hline 17 & $\begin{array}{l}\text { Plbe elch ale nower } \\
\text { Parteiseokretsi su } \\
\text { erkennen }\end{array}$ & 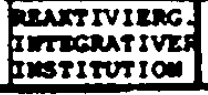 & & & & \\
\hline
\end{tabular}




\section{Erläuternder Kommentar}

Nur zwei Agenten (A.1 und A.3) übernehmen handlungsinitiierende Funktionen. Ihre jeweilige Herausforderungsfunktion verbindet sich mit einer raumtrennenden (A.3, Sit.6) oder einer raumerbindenden (A.1, Sit.2,3,5) Funktion. A.2 hingegen als Vertreter der 'Autorität der institutionellen Macht' ubernimmt nur passive Reaktionsfunktionen (Sit.3,8, 9,13). Er wird von beiden anderen Agenten, d.h. sowohl vom Vertreter der 'Autorität der Argumente' als auch vom Vertreter der bauerlichen Interessen herausgefordert und nimmt diese Herausforderung nicht an. Sein endgulltiges Ausscheiden aus der Handlung (Sit.14) folgt nach der Koordinierung dieser beiden gegen ihn gerichteten Herausforderungen: als namlich $A .1$ seine anfängliche Kritik am schlechten Wegesystem (Sit.3) mit der Kritik von A.3 an der Lebenssituation im Dorf verbindet und A.2 damit erneut herausfordert:

"A est' este ljudi, - Xelovek ocen' pristal'no pogljadel na Leontija Sergeeviča, slovno na musku vzjal, - kotorye tak srodnilis' s bedoj, s pamjat'ju o bede, nu kak bol'noj svykaetsja s bolezn'ju." (NC 393).

So bleiben nur der vertreter der băuerlichen Interessen und der Vertreter der gesellschaftlichen Integration als hand lungsrelevante Agenten Ubrig. Die raumverbindende Funktion des Vertreters der gesellschaftichen Integration (A.1), die sich anfangs besonders gegenüber A.2 manifestierte (Sit.2, 4/5), wird nun gegenuber dem Vertreter der băuerlichen Interessen (A.3) wirksam (ab Sit.9, signalisiert durch die abermalige Uberwindung der răumlichen Trennung von A. 1 innerhalb der lutte - er ist unsichtbar, schlaft vermeintlich auf dem Ofen - in Kombination mit seinem Angriff auf die Raumtrennung durch A.3:

" - Cto u vas za prikazka takaja. Mescera da Mesceral poslyłalsja s peci iz-za sitcevoj zanaveski prostuzennyj golos./...l

- Mescera!.. Mescera!.. - skvoz' kasel' progovoril לelovek na perke. - Budto vy i vprjam' iz osobogo testa slepleny." (NC 389)

Die Herausforderung A.3s in Sit.6 - als dieser den "Unbekannten" (A.1) gerade als raumfremden, unerfahrenen Jäger verspottete (NC 387) - annehmend, durchbricht A.1 nun wiederholt die von A. 3 vorgenommene Abgrenzung des Dorfs Meskera, indem er den Raum erweitert. In seiner Argumentation gegen A. 3 weist er nach, daB der Naturhaushalt des gesamten Rajon, nicht nur der Mesceras, vom Raubfischfang betroffen ist. In Verbindung mit diesem Sieg der răumlichen Integrationskraft ist auch der gesellschaftliche Integrationsversuch (Erziehung zum KolchosbewuBtsein) erfolgreich und endet mit der Enthüllung des "Unbekannten" als neuem Parteisekretăr sowie dessen Anerkennung durch die Dorfbewohner. 
VI.3.2. Der modellspezifische Chronotop der Versammlung

Die Chronotopizität der umfassenden Integration, in der die historisch-gesellschaftliche zeit dem naturzeitlichen Kontinuum homolog gesetzt wurde und in den Substraten des letzteren räumlich-körperliche Gestalt annahm, existiert nicht fort. Stattdessen entsteht nun eine Chronotopizitä. welche der auf die gesellschaftliche Dimension reduzierten Integration entspricht. Die raum/zeitlichen Dimensionen des Makrokosmos beschränken sich auf dessen Eigenschaft als gesellschaftliche offentlichkeit. In dieser reduzierten Form aber prägen sie weiterhin die gesamte dargestellte Welt, eine andere Chronotopizitat als die des gesellschaftlichen Makrokosmos existiert nicht.

Ihren spezifischen Ausdruck findet sie im Chronotopen der Versammlung (sovešanie, zasedanie, partsobranie etc.), der mit fast ausnahmsloser Regelmäigkeit in den Texten erscheint. Die Versammlung ist der spezifische raumliche und zeitliche Realisationspunkt der integrativen offentlichkeit des Makrokosmos, konkret: seiner integrierenden Institutionen. Hier finden die handlungsentscheidenden Konfrontationen zwischen den Funktionsträger-Agenten statt, hier werden die Interessen der Bauern zwischen den 'Erziehern' und den 'Unterdruckern' verhandelt, hier kann es auch zur unmittelbaren Interaktion zwischen Bauern und Funktionsträgern kommen (Kolchosversammlung).

Die chronotopische Qualitat der Versammlung wird in "Sosedi" anschaulich, als die beiden Nachbarn bei Eröffnung der Kolchosversammlung nebeneinander auf ihren "gewohnten Plätzen" zu sitzen bekommen und damit die Trennung zwischen beiden răumlich und zeitlich aufgehoben wird:

"Kogda otkryli sobranie, to Ptachin posmotrel, kto sel s nim rjadom. Okazalos' - Makar Petrovic! On prisel pered samym otkrytiem, potomu $t_{\text {to }}$ zaderialsja na vecernej uborke $v$ konjusne. Oni oba tak privykli k svoim mestam, ¿to nezavisimo drug ot druga okazalis' rjadom." (TS 96)

Die integrierende Funktion des Chronotopen wird am Ende der Versammlung noch deutlicher: 
"No opjat' Ke - vot ved' Stuka! - v dverjach oni stolknulis" vmeste." (TS 98)

Der Chronotop der Versammlung bekommt "darstellende Bedeutung" bzw. "Sujetbedeutung" im Sinne Bachtins (s.I.3.3.). Das markanteste Beispiel ist "Na srednem urovne". Dieser Text besteht zum gröBten Teil aus einer weniger darstellenden als berichtenden ${ }^{1}$ ), von Kommentaren dominierten Beschreibung der Situation im Rajon ${ }^{2}$. Es wird weniger die Entwicklung eines Konflikts dargestellt als vielmehr eine wertendsystematisierende Bilanz aus journalistischem Anspruch gezogen. Entsprechend dominiert das iterative und durative Präsens. Einzelne eingefügte szenische Episoden (Dialoge) sind zeitlich nicht definiert und haben lediglich exemplifizierenden Charakter. Im letzten Abschnitt, der eine Parteiversammlung nach dem Septemberplenum darstellt, verändert sich der Charakter des Texts. In szenischer Anschaulichkeit, zeitlich definiert und in momentaner Aktionsart - der erste Satz lautet: "V sentjabre v rajone otkrylas' partijnaja konferencija." (KN 20) - , wird die (positive) Lösung des Konflikts zwischen Neverov/ Molkanov ('Autoritat der institutionellen Macht') und Eremin/Stepan Tichonovid ('Autorität der Argumente') im darstellenden Modus erzählt (KN 20ff). Es wird hier gleichsam szenisch wiederholt, was das Erzahlsubjekt in seinen vorhergehenden Betrachtungen bereits entwickelt hat.

1) Zur Unterscheidung der beiden Erzählmodi Darstellung und Bericht vgl. Todorov, aaO, S. $284 \mathrm{ff}$. - Wichtig scheint der Hinweis auf Drama (Darstellung) und Chronik (Bericht) als historische Quellen der Modi. Der Modus der Darstellung besitzt demnach szenische Eigenschaften. Dies entspricht weitgehend der Bachtinschen "darstellenden Bedeutung" des Chronotopen. Bachtin spricht in diesem Zusammenhang ebenfalls vom Chronotopen als entscheidendem Punkt für die Entwicklung von "Szenen". Vgl. Bachtin, aao, S. $398 \mathrm{f}$.

Eine terminologisch differente, in der Sache jedoch ahnliche Unterscheidung ist die 2 wischen Narration und Deskription. Vgl. Schmid, aaO, S.60.

2) S. Anm.1. auf S. 143(144). 
Vor der zentralen Anklagerede Eremins gegen Neverov heibt es:

"I svoim negromkim tenorkom on rasskazal konferencii to, - Eem uže znajut titateli." (KN 23) 1)

VI.4. Standpunktkomposition

VI.4.1. Der Erzähler als "Schatten des Vorsitzenden"

Auch für das M.2 läBt sich eine konstitutive Norm nur für die Wertungsebene festmachen. Es gibt allerdings eine, wenn auch nicht für das gesamte Modell, so doch für die Herausbildung einer spezifischen Variante typische raum/zeitliche zuordnung des Erzählers zu den funktionstragenden Hauptfiguren. Das ist in den meisten okerki der Fall, in denen sich ein figuraler Erzähler/Journalist in einen Kolchos oder Rajon begibt und dort die Leitungsarbeit eines Funktionars beobachtet. In "Novyj predsedatel'" formuliert der Erzähler seinen raum/zeitlichen Standpunkt:

1) Vgl. zur "darstellenden" bzw. "Sujetbedeutung" des Chronotopen der Versammlung auch "Sirokoe pole". - Der darstellende Teil des Texts - nach einer ausfühlichen berichtenden Exposition uber die Vorgeschichte der Ich-Erzählerin - beginnt mit einer Gebietsversammlung von Ernte-Rekordarbeitern. Hier fast die Erzählerin den BeschluB, als Agronomin in einer Kolchose $z u$ arbeiten (nach einer szenisch-dramatischen Darstellung der diesbezüglichen Aufforderung durch die Kolchosbrigadierin Varvara Kivałeva). Die Versammlung ist damit gleichzeitig der Chronotop des ersten zusammentreffens der beiden Hauptfiguren in der nun einsetzenden Handlung. Als Chronotop der entscheidenden Handlungsperipetien fungiert die Versammlung in "Povest" ".

Selbst im Grenztext "Chazarskij ornament", der in einer răumlich stark isolierten Welt spielt, wird am Ende mit den erfolgreichen Integrationsbemühungen des "Unbekannten" und dessen Enthüllung als Parteisekretär eine dieser Funktion entsprechende versammlungsähnliche రffentlichkeit hergestellt: Der Fischer ruft die anderen Dorfbewohner in seine Hilte, welche damit auch das Merkmal räumlicher offentlichkeit erhält.

Eine weitere Funktion des Chronotopen der Versammlung ergibt sich aus der Bedeutung der Interaktion fur die Figurencharakterisierung. Die Versammlung als offentliche Interaktion ist der zentrale raum/zeitliche Punkt des Aufeinandertreffens der unterschiedlichen Interaktionsweisen. 
"I ja rešil na nekotoroe vremja stat' ten'ju Alekseja Nikolaevica." (NN 6)

Als "Schatten" von funktionstragenden Figuren beziehen auch der Erzähler in "Derevenskij dnevnik" - ein Zeitungskorrespondent, der von Kolchose zu Kolchose reist, um dort hauptsächlich mit den Kolchosvorsitzenden zusammenzutreffen und sie auf ihren Expeditionen $z u$ begleiten - und der Erzahler in "Odin den"" - ein Agronom, der als Helfer und Begleiter des Kolchosbrigadiers auftritt - ihre raum/zeitlichen Standpunkte.

Diese raum/zeitliche Perspektivierung des Erzăhlers steht in doppeltem Funktionszusammenhang. Einerseits signalisiert sie uber die raum/zeitliche Ebene hinaus die Zuordnung des Erzählers innerhalb der Konfigurationspole 'Bauer' und 'Funktionsträger', was sich in der Wertungsebene niederschlägt (s.VI.4.2.). Andererseits wird der dokumentarischauthentische Charakter des Texts unterstrichen, besonders dann, wenn sich der Erzähler als 'weibes Blatt', fremd, ohne Vorinformationen, vorstellt.

Unter dem letzten Aspekt ist das einleitende Kapitel von "Vesnoj nynesnego goda" exemplarisch. Bereits die Auswahl das Reportageorts ist mehr oder weniger dem zufall uberlassen. Im Dialog zwischen dem Rajkomsekretär und dem Erzähler heiBt es:

"Dlja menja interesno ljubaja MTS." (Erzăhler) "Tak i poezzajte $v$ ljubuju! $v$ kakuju MTS budet poputcik, $\checkmark$ tu i poezzajte!" (Sekretăr) (NV 56)

Auch im folgenden wird der Erzähler als durch Vorinformationen und Gespräche unbelasteter "Zeuge" (svidetel") (NV 60) der Dinge charakterisiert. Seine kunftige Hauptfigur, der MTSDirektor Baslakov, verlangt wăhrend des ersten zusammentreffens selbst dokumentarische Aufrichtigkeit:

"Da $\ell_{t o}$ govorit"! - neozidanno zakoncil on. - $t_{t o}$ o dele govorit'? Ego nuzno videt' svoimi glazami, v rukach poderzat'! /.../ Rabotaem! Pogljadite sami!" (NV 60) 
VI.4.2. Kontinuităt der Wertungsmonologizität

Die strikte Monologizität auf der Wertungsebene wird vom M. 2 bruchlos übernommen. Sie beruht wiederum auf der Integration aller Wertungsinstanzen in ein geschlossenes ideologisches Milieu, dessen Wertesystem als uneingeschränkt herrschend vorausgesetzt wird. Die Variabilitat der Standpunktkomposition auf den anderen Ebenen ist dieser Wertungsmonologizität funktional untergeordnet. Selbst relativ desintegrierte Standpunkte auf den anderen Ebenen - vgl. bes. die dokumentaristische stilisierung - führen nicht zu einer dem herrschenden Wertesystem fremden sicht der Dinge.

Aus dem breiten Spektrum der psychologischen, raum/ zeitlichen und phraseologischen standpunktvariationen seien einige der am meisten verbreiteten herausgegriffen, um ihre gemeinsame Funktionalisierung für die monologische Wertung zu verdeutlichen.

\section{1) Das Erzählsubjekt mit psychologischem Innenstandpunkt}

Dieses Erzăhlsubjekt, das z.B. in "Na srednem urovne" erscheint, nimnt eine unfassende Wertungskompetenz für sich in Anspruch. Sie gründet sich auf seine zeitliche Distanzposition, d.h. auf sein Vorherwissen des Handlungsablaufs, der lediglich nachtrăglich für den Leser aufbereitet werden muB. Dieses Vorherwissen wird mit hăufigen rhetorischen Fragen demonstriert:

"Cto oni znali? Dlja étogo nado poznakomit'sjas rukovoditelJami rajkoma." (KN 5$)$

Die Wertungskompetenz gründet sich weiterhin auf die ökonomische, politische und historische Kompetenz des Erzăhlsubjekts. In mehreren Kommentaren erweist es sich als in der Landwirtschaft erfahren, es kennt die politische und wirtschaftiche Geschichte des Rajon und seiner Leitungsfunktionäre genau (KN $6,12 f, 14 f)$. V.a. aber besitzt es eine unhinterfragte figurencharakterisierende Kompetenz. sie wird markiert durch mehrere verallgemeinernde Kommentare, 
die sich - eingeleitet durch das rhetorische Leitmotiv "ljudi"1) - durch den Text ziehen. Hier werden die Charaktereigenschaften der Figuren eindeutigen Wertungen unterzogen:

"Est' ljudi, kotorym kak by dostavljaet udovol'stvie podrezyvat' ostromu, dumajušemu Celoveku kryl'ja." (KN 12,

über Neverovs Verhältnis zu Stepan Tichonovi丈)

Das Erzahlsubjekt thematisiert auBerdem mehrmals selbst die Wertmabstabe für Parteifunktionare:

"Ne bylo $v$ nich smelosti, bez kotoroj novozmožno sebe predstavit' partijnogo rukovoditelja." (KN 21)

Der spezifisch monologische Charakter dieser figurencharakterisierenden Wertungskompeten 2 wird - abgesehen vom Monopol des Erzählsubjekts auf solche generalisierenden Wertungen - durch die Identifizierung seiner Wertungsperspektive mit der einer anonymen Allgemeinheit aller an der dargestellten Welt Teilhabenden ("der Kolchosbauern", "der Parteimitglieder" etc.) hergestellt. Hier wird gleichzeitig das integrative Wesen der Wertungsmonologizität deutlich, da die Interessenidentitat zwischen Bauern und positivem Funktionsträger die Basis der gemeinsamen Wertungsperspektive bildet:

"O Moldanove govorjat $v$ rajone, ¿to on ne stoit, a lezit na zakone." (KN 9)

"U kolchoznikov, u partijnych rabotnikov krov'ju oblivalos' serdce." (KN 7)

"Vot 1 na étot raz to, tto davno nazrevalo 1 tto nabolelo u ljudej, somknulos' s tem, o Cem dumali vverchu, $v$ rukovodstue partil." (KN 21)

\section{2) Dex Elqurale Erzähler/Journalist (Variante a)}

Auch dieser Erzăhler - 2.B. In "Derevenskij dnevnik" besitzt aufgrund seines wissens als bkonomischer und politischer Fachmann in Landwirtschaftsfragen die notwendige Kompetenz, um das Verhalten der Figuren zu bewerten. Hier

1) "Est" raznye ljudi." (KN 3); "Est' ljudi, kotorye /.../" (KN 5): "Charaktery u ljudej byvajut raznye." (KN 20) 
wird die Funktion der raum/zeitlichen Perspektivierung als "Schatten des Vorsitzenden" für die Wertungsperspektive des Erzahlers gegenüber den băuerlichen Figuren deutlich. Diese ist identisch mit der des positiven Funktionstrăgers:

"Ivan Fedosseevil dejstvitel'no vspyl'civ, ljuto nenavidit lodyrej i raschitelej kolchoznogo dobra. S takogo roda ljud'mi on byvaet grub, a kestnych kolchoznikov uvazaet, chotja pri nekotoroj Zestkosti charaktera svoego ne vsegda najdet dobroe slovo." (DD 590) 1)

Kritik nicht-prinzipieller Natur bezieht sich lediglich auf Fragen des pädagogischen Geschicks in der festeren Integration der Kolchosbauern. ${ }^{21}$

\section{3) Der fiqurale Erzähler/Journalist (Variante b)}

Eine zweite Variante dieses Erzăhlers ist der fragende, staunende, fremde Erzăhler, dessen fachmännische Kompetenz nicht so stark entwickelt ist wie im Fall a. Dieser Erzahler erscheint 2.B. in "Vesnoj nynesnego goda". Durch wiederholte Fragen nach der situation im Rajon wird seine Ortsfremdheit und Nichtinformiertheit markiert:

"A est' u vas sil'nye kolchozy?" (zV 56)

"/.../ i ja sprosil łofera, poxemu mašina eše chodit, kogda ee davno pora sdat' $v$ metallolom." (2V 57)

"Ja sprosil Baslakova, kakie peremeny proischodjat $v$ rabote MTS za poslednee vremja." (2V 59)

Er ist hăufig auf Vermutungen angewiesen:

1) Vgl. ebf. verschiedene Kommentare zu Erscheinungen schlechter Arbeitsmoral unter den Bauern, wie etwa das Fernbleiben von der Arbeit an kirchlichen Feiertagen, das vom Erzahler unter dem Aspekt wirtschaftlicher Verluste und der Nicht-Echtheit der religiobsen Motive bei den Bauern kritisiert wird.

2) Vgl. ebf.: "Vse mysli i mecty ego - v kolchoze. Odet on $v$ deseven'skij sinij ševiotovyj kostjum, kerzovye sapogi, staren'kij plast. Na golove - Zernaja kepka. Eto $1 \mathrm{v}$ prazdnik $i \mathrm{v}$ budni. A zarabatyvaet nemalo. Byt' možet, éta ego nevzyskatel'nost', èta oderímost' rabotoj 1 , ja by skazal, umstvennymi zanjatijami mesajut emu inoj raz ponimat' material 'nye 1 bytovye nuzdy kolchoznikov, kotorye, chotja i uvazajut ego, no, kak mne kažetsja, ljubvi k nemu ne Euvstvujut." (DD 591) 
"Esli by on ne sobiralsja pogovorit' o Xem-to ser'ezno $s$ Baslakovym, togda zacem by ego zaneslo v Bujanovku? /.../ inatit, u Pislegina est' pritina 1 , nado dumat', ser'eznaja. Mozno bylo daze predpolozit': Pislegina snjali s rabotoj." (2V 62)

Er staunt über unerwartete zusammenhänge, wie etwa die Krankheit Pislegins:

"Ja smotrju na Pislegina s udivleniem /.../ Ja.gotov prostit" emu mnogoe." (2V 67)

Trotz dieser Relativierungen der Wertungskompetenz des Erzăhlers ist die Wertungsmonologizitat jedoch nie ernsthaft in Frage gestellt. Der entscheidende Grund ist die Anwesenheit positiver Funktionstrăger des Makrokosmos, deren figurencharakterisierende Wertungskompetenz - gleichsam als Ersatz für die des Erzählers, der ihnen nicht etwa widerspricht - deutlich markiert wird. In "Vesnoj nynešnego goda" ibernimnt MTS-Direktor Baslakov diese Funktion. Er ist erstens in der Lage, selber die Gefahren fur die Leitungsarbeit zu formulieren:

"Kanceljariju, baten'ka moj, ne tak-to prosto povernut' naoborot." (2V 58)

Zweitens beweist er seine auf eindeutigen Wertungskriterien und Menschenkenntnis beruhenden figurencharakterisierenden Făhigkeiten gegenuber Pislegin:

"Gosudarstvennogo uma ne chvatilo. Svoj est', a gosudarstvennogo malovato." (2V 72)

Die Wertungskompetenz Baslakovs wird auf der Ebene der Phraseologie unterstutzt durch seinen elaborierten politischen Code und die Länge seiner Monologe. ${ }^{1)}$

Ein anderes Beispiel für diese Variante ist "Novyj predsedatel"". Hier wird besonders die Wertungskompetenz

1) Auch in den anderen Varianten zeichnen sich wertungskompetente Figuren häufig durch eine entsprechende phraseologische Kompetenz aus. Vql. bes. für die Variante des psychologischen Innenstandpunkts die sich oft in mehrere Seiten langen Monologen manifestierende Kompetenz Martynovs ("Rajonnye budni") und begrenzt auch Eremins ("Na srednem urovne"). 
des positiven Funktionstrăgers gegenuber den băuerlichen Figuren deutlich.

Ein junger Mann aus einem Nachbardorf bewirbt sich um eine Stellung als Fahrer in Rusakovs Kolchose. Obwohl die Kolchose dringend Arbeitskräte benötigt, erkennt der Vorsitzende nach einem kurzen Gespräch die wahren, egoistischen Motive des Mannes, und zwar daran, daß er nicht bereit ist, auch seine Frau zum Eintritt in die Kolchose zu bewegen. Die Frage des Erzählers, warum Rusakov den Mann nicht eingestellt habe angesichts des groBen Bedarfs der Kolchose an Menschen, wird von Rusakov befriedigend beantwortet: "Tol'ko lju-di, a ne otsevki. Ved' étot dlja ¿ego na mašinu prositsja? $K$ iene $v$ stupino ezdit'. Na grésovskoj masine on ne risknet, a kolchoz vse sterpit. Net, nam takie chalturšliki ne nuźny. Koli ides' $k$ nam, tak uz vser'ez, so vsemi potrochami." (NN 7)

Zwei weitere Varianten, deren Verfahren zur Herstellung der Wertungsmonologizität bereits anhand des M. 1 dargestellt wurden, seien nur noch erwähnt:

\section{4) Der Binnenerzähler}

Er erscheint in "Teša". Die Wertungskompetenz dieses Erzăhlers - wieder eines Chauffeurs ${ }^{1}$ - gegenüber seiner eigenen Person und seiner Schwiegermutter ergibt sich v.a. aus der Fahigkeit, seine eigene Umerziehung zum verantwortungsbewuBten Kolchosmitglied und die damit zusammenhängende positive Veränderung im zunächst feindlichen Verhältnis zu seiner Schwiegermutter ${ }^{2}$ in klaren Wertungskategorien zu formulieren, sodab der Rahmenerzahler sich wiederum

1) Vgl. zum vom M.1 ubernommenen Topos des Chauffeurs als Binnenerzähler auch "Derevenskij dnevnik". In der Schlubsituation erscheint hier ein Chauffeur als Charakterisierungsinstanz fur einen Funktionsträger: wahrend einer gemeinsamen Fahrt des Erzahlers mit dem Rajkom-Chauffeur Petr Nikolaevit - die mit der Ankunft in Moskau endet (räumliche Integration) -schildert Petr Nikolaevid die positiven Eigenschaften des RajkomSekretărs Aleksej Petrovid Koßuchov. (DD 624ff)

2) Vgl. Anm.2 auf S.124. 
mit bloBen Informationsfragen begnügen kann. 1)

\section{5) Der figurale Erzähler als Agent}

Dieser Erzähler erscheint in "Širokoe pole". Ahnlich wie in "Vesna" wird die Wertungsmonologizität hier durch die Identitat der Wertungsperspektiven aller positiven Figuren hergestellt. ${ }^{2}$ ) Die figuralen Wertungen erfolgen auf kompetentem sprachlichem Niveau, das dem politischen Niveau der Figuren, bewuBten Aktivisten für die Kolchoswirtschaft, angemessen ist:

\footnotetext{
"Opytnoe pole u vas tesnoe, razvernut'sja negde." (MS 475 , Varvara Kivatevas Aufforderung an die Erzahlerin, im Kolchos zu arbeiten)

"Skrepljaete, tak skazat', sojuz truda 1 nauki. Dobroe delo." (MS 475, Kommentar des Brigadiers Usov nach dem EntschluB der Erzählerin, in den Kolchos zu gehen).
}

1) Zum Binnenerzähler, der aus zeitlicher Distanz den ProzeB seiner eigenen Umerziehung darstellt, vgl. ebf. "Povest" " - Wahrend einer gemeinsamen zugfahrt erzăhlt der MTS-Direktor Calikov der Rahmenerzählerin die Vorgeschichte zu seinem Auftritt auf einer landwirtschaftlichen Bestarbeiterkonferenz im Moskauer Kreml. welche die Rahmenerzahhlerin einleitend dargestelit hat.

2) In diese Wertungsidentitat ist die zeitung als wertformullerende Instanz des Makrokosmos eingeschlossen (vgl. Anm. 2 auf S.145). Hier liegt eine weitere Funktion des offentlichen Mediums neben seiner Rolle als transfigurale Handlungsinstanz. Dies gilt für alle Varianten. 
VII. Von der Integration zur Desintegration

Negation der modellkonstitutiven Normen

(A. Jašin, "Ryðagi")

Anhand einer exemplarischen Textanalyse soll in diesem Kapitel das Verhaltnis zwischen Normenreproduktion und Normenbruch entwickelt werden, wie es in einigen seit 1956 erschienenen Texten sichtbar wird. Im Unterschied 24 den Grenztexten des M.2, welche die Grundelemente eines wenn auch stark reduzierten Integrationspotentials des Makrokosmos nicht in Frage stellten, werden nun die modellkonstitutiven Normen nur noch als Folie für ihre eigene Negation reproduziert. Der Text "Rycagi" bietet sich als Beispiel an, da hier in einer mehrschichtigen struktur sowohl ein eindeutiger Normenbruch als auch die Reaktivierung der der alten Normen - in modifizierter Form - realisiert werden. Es entsteht eine Gesamtstruktur, deren dominante Funktion in der Negation der alten Normen besteht, ohne das jedoch. bereits neue, positive Normen entwickelt werden. ${ }^{1)}$

Vier Kolchosbauern und Parteimitglieder - Cipysev, stukin, Konoplev und Petr Kuz'mic - sitzen in der Kolchosverwaltung und schimpfen auf den Bürokratismus der oberen Parteiebenen. Die Situation andert sich mit Beginn der Parteiversammlung, die eben diese vier sowie eine junge Lehrerin abhalten. Das zuvor kritisierte Verhalten der Parteibürokraten wird zu ihrem eigenen. Nach Beendigung der Versammlung kommen Jugendliche in den Raum, um Radio zu hören. Die Situation entkrampft sich, der Druck, der auf den Versammlungsteilnehmern lastete, weicht.

1) Ein Text, in dem ebenfalls ehemalige strukturen der Integration von Strukturen der Desintegration uberlagert werden, ist "Poezdka na rodinu". Die Erzăhlung schildert die kurzfristige Reise eines hochgestellten städtischen Burokraten in sein Heimatdorf zur Beerdigung der Mutter. Im AufeinanderstoBen der vergangenen und der gegenwartigen Welt der Hauptfigur werden antagonistische Oppositionen aktiviert. Es gibt nichts Verbindendes mehr zwischen beiden Welten (Signalisierungen: Nichtwiedererkennen; Vergessen; metaphorische Radikalisierung der Oppositionen zu 'Tod' vs. 'Leben': das Totenhaus der Mutter als Gaststatte des Fremden vs. die Hebammenstation als Geburtstatte eines neuen Kindes; groteske Verfahren in ahnlicher Funktion: lebendiges Inventar im Haus während der Kindheitserinnerungen der Hauptfigur). 
VII.1. Die Folie der alten Normen

Das gesamte Inventar des M.2 ist in diesem Text konzentriert:

Die Hauptfiguren sind Funktionsträger des gesellschaft- lichen Makrokosmos. In ihrer gleichzeitigen Charakterisierung als Kolchosbauern wird die Interessenidentität zwischen den beiden Figurengruppen - im M.2 markiert in figuralen Aquivalenzen, die bis zur Verkörperung von bäuerlichen und Funktionsträger-Eigenschaften in ein und derselben Figur führen konnten - als Folie reproduziert.

Auch die beiden Handlungsschemata sind als Folie erkennbar: Der Konflikt zwischen den positiven, die büuerlichen Interessen vertretenden und den negativen, unterdruckerischen Funktionsträgern wird reproduziert in der kritik der vier Parteimitglieder am Rajon-Parteisekretär, den sie "sam" nennen. Die Leitungsarbeit schlieblich ist der eigentliche Gegenstand der Versammlung.

Die Versammlung als Chronotop der integrativen రffentlichkeit des gesellschaftlichen Makrokosmos steht im zentrum des Texts, auch unter raum/zeitlichem Aspekt. Die gesamte Geschichte spielt ausschlieblich in der Kolchosverwaltung als spezifischem Raum der Versammlung und unfaBt zeitlich nur die Versammlung und ihren einleitenden bzw. abschlieBenden Rahmen.

Auch die Wertungskompetenz der Funktionsträger wird reproduziert, und zwar dann, wenn es um die Formulierung der Oppositionen $2 w i s c h e n$ positiven und negativen Funktionsträgern ('Autorität der Argumente' vs. 'Autorität der institutionellen Macht') geht. Diese Kompetenz wird besonders gegenüber dem "sam" aktiviert.

Abgesichert durch die politische Lehre und ihre Sprache wird die 'Autorität der Argumente' expliziert:

"Ljudej ubezdat' nado. Lenin ukazyval: aktivno ubezdat' nado." (JR 504)

Das Grundübel wird beim Namen genannt, gleichzeitig erweist sich der Redner als kompetent, die im Titel signalisierte Basisopposition selber zu formulieren: "Ljudi dlja nego - tol'ko rycagi. A ja tak ponimaju, rebjata, tto eto i est' bjurokratizm." (JR 505)

Die durch den Bürokratismus lediglich gestörte, prinzipiell 
jedoch existente Interessenidentität zwischen Bauern und Funktionsträgern - die Basis der reduzierten Integration wird thematisiert:

"Razve my ne za odno delo boleem, razve u nas interesy raznye?" (JR 507)

Die desintegrativen Funktionstrăger werden in Opposition zur integrativen Institution als qanzer gestellt:

"/.../ ne ponimaet on, Kego choket partija, boitsja ponjat'." (JR 505)

Diese Modellelemente aller vier Ebenen werden von einer Textstruktur uberlagert, die sie in verschieden starkem MaBe verfremdet und in neue Funktionszusamenhänge bringt. Das Resultat ist eine Umwertung der im M.2 mit innen verbundenen Werte: Alles ehemals Integrative wird desintegrativ. Diese Umwertung vollzieht sich prozeBhaft; in ihrer ProzeBhaftigkeit wird sie als Bruch des alten Systems erfahrbar.

VII.2. Konfigurationstruktur

VII.2.1. Von interfiguralen zu intrafiguralen Oppositionen

Auf der Ebene der Konfigurationsstruktur wird das Verfahren der figuralen Personalunion zwischen Bauern und Funktionsträgern zum zentralen Motiv der verfremdung. An die Stelle der Aquivalenzen, die diese Personalunion Im M.2 ermöglichten (s.VI.1.3.), treten Oppositionen, die zudem antagonistischen Charakter annehmen. Indem die Oppositionen nicht mehr interfigural, sondern intrafigural, d.h. in den einzelnen Figuren verkörpert sind, wird das Grundschema positiver vs. negativer Held gegenstandslos. Gerade der ProzeB von einer zunächst interfiguralen zu einer intrafiguralen Oppositionsblldung signalisiert diese Umwertung.

Die Oppositionen konzentrieren sich auf das Interaktionsverhalten. Die Anfangssituation hat folgende Oppositionsbasis: 
HAUPTF IGUREN

(plus parteisekretär

des Nachbarrajon)
"SAM"

(plus Junge aus der Radio-

ubertragung)

(+) Gespräch

("sobesedniki", wiederholt markiert)

(t) Vertrauen

("doveritel'no") (JR 504)

(-) Vertrauen

("Ne verjat nam.") (JR 504)

(+) persönlich

Twiederholte Anreden

"muziki", "brat",

"rebjata")

$(-)$ persönlich, $(+)$ offiziell

("Rede" (rec") des Jungen in

der Radiosendung) 1)

(-) Furcht

(Lachen uber Furcht

der Kühe) (JR 502)

(Kritik am "sam") (JR 503f)

(t) Furcht (furchtverbreitend und fürchtend)

("boitsja") (JR 505)

Autorität der Argumente/

offene Interaktion

(")...Trazgovarivaet $s$

ljud'mi ne po bumazke.")

(JR 507)

("po dusam") (JR 505)

("prjamoe slovo") (JR 505)

Autorität der institutionellen Macht / nicht of fene Interaktion ("strogost") (JR 505)

("On dumaet, \&to partija avtoritet poterjaet, esli on $s$ narodom budet razgovarivat' kak Celovek, po-prostomu.") (JR 505)

(")...) skazat" ob ètom vsluch ne chotjat.") (JR 505)

Der nun einsetzende ProzeB der intrafiguralen Oppositionsbildung gipfelt mit dem Beginn der Parteiversammlung, markiert im ausgeführten Vergleich mit einem "wundertätigen Mechanismus" (Eudodejstvennyj mechanizm), der "alles bis zur Unkenntlichkeit verändert" $(" / \ldots /$ vse $v$ izbe nacalo preobrazat'sja do neuznavaemosti") (JR 510). Die Personalunion von Bauern und Funktionsträgern stellt sich erst jetzt heraus, nicht jedoch in Form aquivalenter, sondern verschiedenen semantischen Feldern zugehöriger - oppositiver Merkmale:

"Vse zemnoe, estestvennoe istezlo, dejstvie pereneslos" $v$ drugoj mir, $v$ obstanovku sloznuju i ne sovsem ponjatnuju dlja etich prostych, serdexnych ljudej /.../

Zivotnovod stepan Cipysev okazalsja sekretarem partorganizacii /.../ Petr Kuz'mic Kućrjavcev, odnorukij, okazalsja predsedatelem kolchoza." (JR 510, Hvh.G.W.) 2)

1) "Parenek obrastalsja k svoej dorogoj mame, no tak, budto nikogda ran'se ne proiznosil étogo imeni." (JR 507)

2) Zur Nichtverständlichkeit der beiden welten vgl. auch den Kommentar der Putzfrau Marfa zur Verscimmlung:

" - Govorite, govorite. Razve ja ne ponimaju." (JR 510) 
Sämtliche bisher dem "sam" bzw. der Radioübertragung zugeordneten Merkmale prägen jetzt das Interaktionsverhalten der der vier Hauptfiguren:

(-) Gesprăch ("vse promolcali") (JR 509)

$(+)$ offiziell (Anrede "tovaristi")

(+) Furcht (Furchtverbreitung gegenüber der Lehrerin)

(+) Autoritat der institutionellen Macht ("strogo, po-nalal'niCeski") (JR 509).

Die Oppositivität zur anfänglichen Interaktionssituation wird - in ihrer nun intrafiguralen Dimension - unterstrichen durch einen Dialog zwischen Scukin und Konoplev uber den Wahrheitsbegriff, der deutlich auBerhalb des offiziellen Interaktionsrahmens der Versammlung situiert ist (Flustern) und die Merkmale ' (+)Gespräch' und ' (+)Vertrauen' trăgt (Vertrauen auf baldiges Erscheinen der "Wahrheit") (JR 511 , s.u.).

VII.2.2. Nonverbale Interaktion als Indikator der sozialen Kommunikationssituation

In der Darstellung des Prozesses dieser Verwandlung und seiner Triebkräte ist eine zusätzliche umwertende Komponente enthalten, die sich mit Fortentwicklung der intrafiguralen oppositionsbildung auch ruckwirkend auf die Anfangssituation erstreckt.

Ein wichtiger Faktor ist hier die mit dem VerwandlungsprozeB interdependierende soziale Kommunikationssituation unter dem Aspekt der bffentlichkeit. Mit dem Erscheinen der Putzfrau Marfa wird klar, daB die vorhergehende 'offene' Interaktion der Hauptfiguren unter der vermeintlichen Voraussetzung der Nichtoffentlichkeit stattfand, und zwar sowohl der Nichtöffentlichkeit von 'unten' (die Figuren sprechen uber die Ausnutzung ihrer Posten für Privilegien) als auch der Nichtoffentlichkeit von 'oben' (die Kritik am "sam" wird unter Voraussetzung seiner Nichtanwesenheit geführt, die mit Marfas Erscheinen verbundene Furcht der Figuren beruht auf der momentanen Schreckvorstellung, ein höherer Funktionăr könne ihr Gespräch belauscht haben). 
Der nun einsetzende Proze $B$ bis zur Eröffnung der Parteiversammlung besteht in der wiederherstellung der Nichtöffentlichkeit (nach 'unten': Abweisung zweier Jungen, die Radio horren wollen; Hinausweisen Marfas; nach 'oben': Ausschalten des Radios).

Ein zweiter Faktor ist die Bewegung der Figuren innerhalb des Oppositionsfeldes der gesellschaftlichen Hierarchie ('oben' vs. 'unten') im Zusammenhang mit ihrer Furcht bzw. Furchtlosigkeit. Dieser zusammenhang wird v.a. durch das nonverbale Interaktionsverhalten der Figuren signalisiert.

1) In der ersten Situation, in der das Gesprăch um die Ausnutzung der Parteiposten geht (Merkmal 'oben'), herrscht keine Furcht. Die nonverbale Interaktion ist durch das Fehlen von Blicken ("bez vsjakich ogljadok") (JR 502) und durch Lachen (gelacht wird uber die Furcht der Kühe vor Cipysevs Bart) (JR 502) gekennzeichnet.

2) In der zweiten Situation, in der das Gesprăch um das despotische Verhalten des "sam" gegenuber den vier Hauptfiguren geht (Merkmal 'unten'), wird die eigene Furcht thematisiert, wenn es etwa vom Nachbarrajon heiBt: "Tam net etogo stracha." (JR 507)

Die Furcht prägt aber noch nicht das eigene Interaktionsverhalten. Nonverbale Interaktion ist nicht markiert.

3) In der dritten Situation wird mit dem Erscheinen Marfas zunächst das Merkmal 'unten' aktiviert (Verwechslung Marfas mit dem "sam"). Die Folge ist das Einsetzen von Furcht, deren nonverbaler Ausdruck das Beenden des Lachens ("ne ulybalsja") (JR 508) und die intensive Aktivierung der Blicke ist ("vzdrognuli i peregljanulis"") (JR 507) ("to $i$ delo ogljadyvajas' po storonam") (JR 508).

4) Nach der ersten Schrecksituation wird jedoch das Lachen umso intensiver reaktiviert und sogar von den Figuren thematisiert (Streit zwischen Cipysev und den anderen um die Angemessenheit des Lachens). Es ist jetzt unmittelbar mit Furcht verbunden, was sich in der Kombination von Blicken und Lachen ausdrückt ("peregljanulis" i toze zachochotali") (JR 508). Gleichzeitig aber ist es mit einer Reaktivierung des Merkmals 'oben' verbunden. Es entsteht, als die Verwechslung Marfas mit dem "sam" und damit die eigene 'oben'-Position gegenuber Marfa bewuBt wird: "- Och, i napugala そe nas prokljataja baba! - chochota, govoril Stukin." (JR 508) (Vgl. entsprechend das nun folgende Einsetzen des Lachens bei Petr Kuz'mic und Konoplev unter Hinweis auf diese Verwechslung.) (JR 508) In dieser Kombination wird nun das Lachen zum Verbindungsmerkmal zur ersten situation:

"Smech razrjadil naprjazennost" i vernul ljudjam ich normal'noe samoCuvstvie." (JR 508, Hvh.G.W.) Das Lachen wird zum Ausdruck der Verdrängung von Furcht durch das BewuBtsein der eigenen Macht. Die im Lachen vermutete Furchtlosigkeit der ersten situation erscheint im 
Licht dieser Rückblende bereits als Transmission der eigenen Furcht auf die Furcht anderer. Der "immer selbe Witz" (odna i ta ze stuka) (JR 502) iber die Furcht der Kühe gewinnt in diesem zusammenhang eine neue Bedeutungsdimension.

5) Diese furchttransmittierende Funktion des Lachens erreicht bei der nächsten Markierung - wăhrend der Parteiversammlung - ihren Hohepunkt. Hier ist der Gipfel in der 'oben'-Position der vier Hauptfiguren erreicht (Ubernahme der Rolle des "sam") (JR 511), das Lachen ist unmittelbar mit dieser Position verbunden:

"A Scukin opjat" zaulybalsja. On dostal iz karmana večnoe pero, povertel ego $v$ rukach, zatem vynul raskesku $/ . . /$." (JR 511) 1)

Gleichzeitig ist nun die Furcht der Hauptfiguren endgültig transformiert in ihre Furchtverbreitung gegenüber der Lehrerin, deren Angst und Eingeschulchter theit bis zur Unfahigkeit $2 u$ jeglicher Interaktion (Sprachlosigkeit plus Verweigerung nonverbaler Interaktion: verdecktes Gesicht) gesteigert wird.

Als einigendes Band sämtlicher situationen erweist sich die Furcht in ihrer Funktion als Transmissionsfaktor gesellschaftlicher Macht. Der dargestellte gesellschaftliche Kosmos exscheint als vielfach gestaffelte Hierarchie, deren ehemals integrativer Zusammenhang (M.2) durch eine Perpetuierung der Opposition 'oben' vs. 'unten' mit der Furcht als Transmissionsfaktor ersetzt ist.

UNTEN $\quad$ OBEN

Kuhe 4_- Furchtverbreitung/Lachen___ Hauptfiguren

Marfa 4_Furchtverbreitung/Lachen_Hauptfiguren

Lehrex in $\longrightarrow$ Furchtverbreitung/Lachen $\longrightarrow$ Hauptfiguren

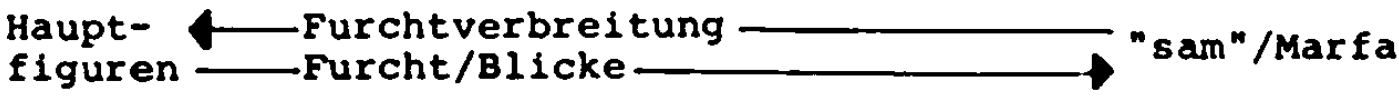

"saj"/ Pajkom Furchtverbreitung___ hohere Ebenen

1) Die auBeren Insignien Kugelschreiber und Kamm werden bereits $z u$ Anfang als mit der Ubernahme des Parteipostens von SCukin erworbene statussymbole beschrieben (JR 503).

Die Umwertung des Lachens wird vom Erzahlsubjekt thematisiert: "Konoplev toze ulybnulsja, no krivo, nedobro." (JR 511, Hvh.G.W.) 
Es stellt sich im Resultat heraus, daß der gesamte dargestellte ProzeB von Anfang an in einem einzigen gesellschaftlichen Feld situiert ist, das von den beiden Faktoren der Nichtöffentlichkeit und der oppositionsdominierten gesellschaftlichen Hierarchisierung geprägt ist. Beides sind Faktoren der Desintegration.

Erst mit der letzten Situation wird ein gänzlich neues gesellschaftliches Feld, das ausschlieblich durch Faktoren der Integration bestimmt ist, eröffnet. Hier wird die రffentlichkeit hergestellt, - von 'oben' wie von 'unten' (Rückkehr Marfas, Hereinstürmen der Jugendlichen, Anschalten des Radios) (JR 511). Die gesellschaftliche Reintegration der Figuren drückt sich besonders im Verhalten der Lehrerin und Scukins aus (Hinweis auf Altersgleichheit der Lehrerin mit den Jugendlichen und EntblöBung des Gesichts, Hofierung der Mädchen durch Sxukin) (JR 512f). Die desintegrative wirkung der gesellschaftlichen Hierarchisierung besteht nicht mehr. Alle Figuren hören gemeinsam die Radionachricht von der Vorbereitung des 20. Parteitages, Ihre Reaktion auf diese Manifestation der höchsten Position in der gesellschaftlichen Hierarchie ist nicht Furcht, sondern Hof fnung:

" - Teper' tto dvadcatyj s-ezd skazetl - to i delo povtorjali oni." (JR 513)

VII. 3. Handlungsstruktur

Entmündigung der Agenten

Die Umwertung auf der Ebene der Handlungsstruktur hängt eng mit dem dargestellten Verwandlungsproze $B$ und der Furcht als seiner Triebkraft zusammen: Die Figuren handeln reaktiv auf die Einbruche der రffentlichkeit, ihre Handlungen entbehren jeglicher autonomen Intention und Planung. Die Titelmetapher der "Hebel" (rycagi) findet hier eine Entsprechung, Die Figuren bewegen sich nicht, sie werden bewegt von fremden Kräften, - auch äußerlich:

"/.../ tjazelyj astmaticeskij kasel' vdrug schvatil ego $i$ vyvel iz-za stola." (JR 505) 
Die entscheidenden Situationsveränderungen - der Anfang und das Ende der Versammlung - sind nicht von den Hauptfiguren herbeigefuhrt,., sondern vom Eindringen fremder Figuren diktiert. Mit Marfas Erscheinen setzt der ProzeB der Umwandlung ein, mit dem Erscheinen der Jungen und der Lehrerin wird er vollendet. Der vom willen der Figuren unabhängige Automatismus dieses Prozesses aubert sich in einer Verselbständigung der verbalen Interaktion und ihrer Instrumente gegenuber den Blicken.

Zunächst werden Cipysevs entschuldigende Blicke dargestellt (mit Cipysev als syntaktischem Subjekt):

"/.../ i robko ogljanulsja vokrug, budto prosil izvinenija za svoi slova."

Dann heibt es:

"Togda golos Cipyseva okoncatel 'no priobrel tverdost' $i$ vlastnost'." (JR 509)

Dem korrespondiert die anschliebende Darstellung der auberen Verwandlung und der Vergleich mit einem "Mechanismus". Hier werden wieder syntaktische konstruktionen verwendet, welche die Körperteile, nicht aber ihre Besitzer zu den subjekten der Verwandlung machen:

"Boroda ego raspravilas', udlinilas', glaza posurovell /.../." (JR 509)

"Lica u vsech stali sosredotolennymi /.../." (JR 510)

Das Ende der Versammlung wird wiederum von der zurückkehrenden Marfa diktiert, die damit verbundene Handlungsunfahigkeit der Figuren offenbart sich:

"Ni odnoj rezoljucii napisat' ne mogli, - vernulas' Marfa, 'ctoby pribrat' i zaperet' kontoru." (JR 512)

Die Handlungen wăhrend der Versammlung selbst - im M.2 fanden hier oft die entscheidenden Peripetien statt - sind vollends vom willen der Figuren unabhängig. Die einzige Handlung, die dem Schema a (Leitungsarbeit) entspricht, besteht darin, eine bestimmte Anzahl von Kolchosmitgliedern zur Bestrafung, eine bestimnte Anzahl zur Belohnung festzusetzen, weil es von 'oben' so verlangt wird. Man weib allerdings nicht, wofur die Bestrafungen und Belobigungen erteilt werden sollen. 
VII.4. Raum/Zeit-Struktur

VII.4.1. Räumliche Extegration der Versammiung

Eine extreme Umwertung erfährt die Versammlung in ihrer chronotopischen Funktion. Sie wird vom Chronotopen der integrativen offentlichkeit (im M.2) zum Chronotopen der extegrierten Nichtoffentlichkeit der Institutionen des Makrokosmos. Raum/zeitliche Extegration und gesellschaftliche Extegration bedingen einander.

Die räumliche Extegration der Versammlung wird durch die häufigen Grenzmarkierungen zwischen Verwaltungsraum ('innen') und StraBe ('auBen') signalisiert (Fenster, Tür, Schwelle). Die vier Hauptfiguren uberschreiten als einzige nicht diese Grenze, deutlich im Falle Ivan Konoplevs, dessen Hustenanfälle ihn genau bis zur schwelle treiben, ohne das er diese überschreitet:

"U poroga Konoplev podnjal venik i dolgo pleval $v$ ugol." (JR 505)

"Cipysev vstal iz-za stola 1 połel k porogu, k Konoplevu." (JR 505)

Das Nichtüberschreiten wird zusätzlich unterstrichen durch den anschlieBenden Dialog uber "Luft", "Urlaub am Meer" etc. in Opposition zur stickigen Luft im Innenraum."

1) Hier ist eine uber die räumliche Extegration der Versammlung hinausgehende, generelle Verfremaung des integrierten Raums in M. 1 und M.2 erkennbar. Die dort mit der räumlichen Integration verbundene gesellschaftliche Integration wird durch die Kombination von gesellschaftlichem LernprozeB und privilegiertem Urlaub am Meer ironisiert:

"s-ezdis' $k$ morju za vozduchom, zaodno posmotris', kak ljudi tam zivut, poutis'sja i nam rasskazes'. Smelosti vsem dobavis'." (JR 505)

Dieser Dialog ist auf der Schwelle lokalisiert, deren Uberschreiten Luft genug verschaffen würde, - sowohl für den hustenden Konoplev als auch für den gesellschaftlichen LernprozeB (Schauen, wie die Leute in der eigenen Kolchose leben).

Diese verfremdung des integrierten Raums wird noch deutlicher bei einer weiteren Markierung der Schwelle, diesmal im Zusammenhang mit der Radioübertragung vom Neuland:

" - Ne vsem Ze na Altaj echat'! - burknul Konoplev 1 , zakasljavsis' snova, podnjalsja iz-za stola, vzjal obeimi rukami gorకłok s okurkami, poß̌el k porogu." (JR 507) 
Die räumliche Grenzmarkierung erfährt ihren Höhepunkt und zugleich die deutlichste Signalisierung ihres Zusammenhangs mit der gesellschaftlichen Nichtoffentlichkeit zu Beginn der Versammlung:

"Kogda za pritichక̌j Marfoj ticho zakrylas' dver', Cipysev vstal $i$ proiznes te samye slova, kotorye $v$ podobnych slucajach proiznes sekretar' rajkoma partii/.../." (JR 510)

Alle anderen Figuren uberschreiten die Grenze. Dieses Uberschreiten ist jedesmal mit einer Aktivierung der రffentlichkeit verbunden. Der zusamenhang zwischen beiden Dimensionen wird offensichtlich mit dem ersten Einbrechen der gesellschaftlichen Offentlichkeit in Gestalt Marfas. Obwohl diese selbst keinen räumlichen Grenzübertritt vollzieht - sie befand sich schon im Verwaltungsraum - , durchbricht hier zum erstenmal die raumliche AuBenwelt die Grenze:

"Na mgnovenie stala slyšna ulica, కum vetra, dalekaja devit'ja pesnja." (JR 508)

Am Ende der Versammlung ist mit der wiederherstellung der రffentlichkeit durch Marfa und die Jugendlichen ein răumlicher Grenzübertritt verbunden:

"A na kryl'ce uze zastuxali sapogi, $v$ dverjach pojavilas" molodez'." (JR 512).

Das anschliebende Hereinsturmen der Jugendlichen wird wieder mit einer Markierung der răumlichen AuBenwelt (Luft, Lărm, Straße) sowie einer zusätzlichen räumlichen Grenzöffnung (రffnen des Fensters) kombiniert (JR 511).

Im Zusammenwirken von räumlicher und gesellschaftlicher Dimension entsteht so eine Dichotomie zwischen zwei semantischen Feldern, die in sich jeweils durch eine vielzahl direkter oder metaphorischer verschränkungen organisiert sind. Dabei unfaBt ein semantisches Feld die gesante Vorgeschichte der Versammlung sowle diese selbst, während das zweite auf die letzte situation beschränkt bleibt: 
LET2TE SITUATION

(t) öffentlich

(Anwesenheit aller Figuren) ("ljudi")

lautes Radio, von allen gehörtes Radio

("Vkljukennyj priemnik neozidanno zagovoril gromko i Eisto.") (JR 513)

(Verschränkung mit "ljudi": "Eistye ljudi") (JR 513)

("proslusali vse") (JR 513)

(Verschränkung mit ' bffentlich': Jugendliche wollen Radio hören, Einschalten des Radios an Ende der Versammlung)

laut

("sum vetra") (JR 508)

(Verschränkuna mit 'öffentlich' und 'Luft': "Sumeli devuski: Nu i dymu u vas!") (JR 512)

(Verschränkung mit 'offentlich': "povelitel'nyj starusecij okrik") (JR 507, beim Erscheinen Marfas)

\section{auben, offene Grenze}

(StraBe)

(Verschränkung mit 'Luft', 'hell': "V izbu vorvalsja prochladnyj vozduch s ulicy. Ogonek $v$ lampe okil, zadvigalis" taburetki."(JK 512)

(t) Luft

(Verschrănkung mit 'auBen':

"Luft/Meer", "Luft/Wald",

"Luft/Heilung" (JR 506)

(Verschränkung mit 'hell': "Lampe tože vozduch nuzen." (JR 506)

hell

(Verschränkung mit 'auBen' und 'Luft': $s$. dort)
VERSAMMLUNG + VORGESCHICHTE

(-) offentlich

(Anwesenheit nur der Funktionsträger)

("rytagi")

leises Radio, knisterndes Radio, nicht gehörtes Radio

("potreskival batarejnyj radiopriemnik") (JR 502)

'Verschränkung mit ' $(-)$ Luft' :

"Kazalos', cto i radiopriemnik potreskivaet potomu, tto dymu $v$ i zbe mnogo." (JR 502)

("potreskival i sipel") (JR 507) (Verschränkung mit 'dunkel' und '(-) Luft': "slovno vydychajuskijsja pennyj ognetusitel'") (JR 507) (Verschränkung mit '(-)öffentl.': Abschalten des Radios vor Versammlung)

leise

("priglusenno, ticho") (JR 508)

(Verschränkung mit '(-)öffentl.' :

"Kogda za pritichక̌j Marfoj

ticho zakrylas' dver/.../n)

(JR 510)

innen, geschlossene Grenze

(Tür, Fenster, Schwelle)

(Verschränkung mit ' $(-)$ Luft' : hustender Konoplev zur Schwelle, Dialog uber Luft und Urlaub am Meer auf der Schwelle)

(-) Luft

TVerschrankung mit 'leises Radio': s. dort)

(Verschränkung mit 'dunkel' und

'Versammlung": "/.../ tabacnogo

dymu bylo stol'ko, tto ogonek

$v$ lampe ele-ele dyకal, kak $v$

casy bol' Sogo sobranija." (JR 502)

dunkel

("A lampa u nas eovsem

gasnet $\left./ \ldots / /^{n}\right)$ (JR 506)

(Verschränkung mit 'Versammlung' und ' $(-)$ Luft': s. dort) 
VII.4.2. Zeitliche Extegration der Versammlung

In diametralem Gegensatz zum M.2 trägt die Versamilung, - in der die historisch-gesellschaftliche zeit oft ihre höchste Verdichtung und ihren Kulminationspunkt fand -, nun die Merkmale zeitlicher Extegration. Sie stellt gleichsam eine Unterbrechung des gesellschaftlichen Lebens und seines Zeitverlaufs dar.

Die zeitliche Grenze wird besonders in zusammenhang mit den Jugendlichen markiert. Bei deren erstem Erscheinen wird die zeit der Versammlung zum Extegrationsmotiv: "U nas sejæas partsobranie budet." (JR 509, Hvh.G.W.)

"My tut provernem partsobranie, pogovorim, a potom uz vy zanimajte pozicii." (JR 509, Hvh.G.W.) 1)

Beim zweiten Erscheinen der Jugendlichen am Ende der Versammlung wird der räumliche Grenzubertritt erneut mit einer Markierung der zeitlichen Grenze und ihrer Uberwindung verbunden:

" - Vo-vremja my podošli? - sprosil odin iz tech dvuch paren'kov, kotorye uke zachodili $v$ kontoru. - Vo-vremja! - otvetil Petr Kuz'mil. - Samoe vremja. zachodite, rebjata, vse." (JR 512)

Besonders mit dem Nachsatz Petr Kuz'mics ("Samoe vremja.") wird die wiederherstellung des zeitkontinuums signalisiert.

zeitlich abgegrenzt wird die Versammlung ein weiteres mal im Dialog Cipysevs mit der Lehrerin. Die Bitte der Lehrerin, die Frage der Brennholzbeschaffung für die Schule zu klären - von der Lehrerin bereits auBerhalb des zeitlichen Rahmens der Versammlung angesiedelt ("/..) ja by chotela do nacala sobranija resit' vopros /.../") (JR 509, Hvh.G.W.) - wird von Cipysev unter Intensivierung dieser zeitlichen Abgrenzung abgelehnt:

" - O delach potom, - oborval ee cipyšev, - sejとas sobranie provodit' nado." (JR 509, Hvh.G.W.)

1) Der chronotopische Charakter wird hier in der engen Kombination von zeitlicher und räumlicher Dimension ("tut"/"potom", "zanimajte pozicil") deutlich. 
Hier wird die Entsprechung von zeitlicher und gesellschaftlicher Extegration offensichtlich. Die zeit des gesellschaftichen Lebens und seiner Reproduktion ("dela") befindet sich auBerhalb der Versammlungszeit. Erst nach dem Ende der Versammlung wird - entsprechend dem Sonderstatus der letzten Situation - die Bitte der Lehrerin erfullt:

" - Drova budut, ty ne bespokojsja, rasporjazus'." (JR 513)")

Der zeitlichen Extegration der Versammlung korrespondiert der Sujet-Aufbau. Der zeit vor und nach der Versammlung - vom Fabelaufbau her betrachtet eine Rahmenzeit - wird im Sujet die Dominanz über das fabelstrukturelle zentrum (die Versammlung) zugemessen. Der Rahmen dehnt sich nach innen, wird zum sujetkonstitutiven Kontinuum, welches durch die Versammlung lediglich unterbrochen wird. Neben der Lănge der einzelnen Teile (acht Seiten vor der Versammlung, zweieinhalb Seiten Versammlung, eine Seite nach der Versammlung) wird die sujetstrukturelle Umwertung von Rahmen und Zentrum durch den am Ende erfolgenden AnschluB an die Ar.fangssituation deutlich:

"/.../ vozobnovilsja razgovor o zizni, o byte, o rabote, - tot samyj, kotoryj కel do sobranija." (JR 513, Hvh.G.W.)

"I snova éto byl1 tistye, serdetnye, prjanye ljudi /../" (JR 513, Hvh.G.W.)

Weder der Anfang noch das Ende sind abgegrenzt von der Zeit auBerhalb des dargestellten Ausschnitts ("kak vsegda" im ersten Satz; Verweis auf demnächst stattfindenden Parteitag im letzten Satz), während die zeitliche Abgrenzung

1) Eine Entsprechung finden zeitliche und gesellschaftliche Extegration bereits im vorhergehenden Gespräch der Hauptfiguren. Hier werden "Feiertag" und "Versamilung" aquivalent gesetzt:

" - Pravda nuźna tol'ko dlja sobranija, po prazdnikam, kak kritika i samokritika." (JR 504)

Im Vergleich mit "Sosedi", in dem der Feiertag gerade zur zeitlichen Sphäre der privaten Extegration der beiden Nachbarn, die Versammlung hingegen $z$ um Chronotopen ihrer gesellschaftlichen Integration wurde, wird die hier vollzogene Umwertung der chronotopischen Funktion der Versammlung besonders deutlich. 
nach innen gegenüber der Versammlung markiert wird. ${ }^{1)}$

Im selben Funktionszusammenhang ist schlieblich der mit Beginn der Versammlung einsetzende Wechsel im Erzahlmodus zu verstehen. Hatte sich im M.2 die "darstellende Bedeutung" des Chronotopen der Versammlung u.a. im Wechsel des Erzählmodus zur szenischen Darstellung niedergeschlagen, wird jetzt die Versammlung in sehr geraffter Form und - im Unterschied zu den dialogdominierten Rahmenteilen in indirekter Rede wiedergegeben. ${ }^{2)}$ Im Gegensatz zu "Na srednem urovne", wo dem Leser das bereits Bekannte bewust noch einmal in szenischer Darstellung auf der Versammlung vorgefuhrt wird (s.VI.3.2.), kommentiert das Erzählsubjekt nun den Ablauf der Versammlung als bekannte GesetzmäBigkeit, die eine Darstellung erübrigt:

'S etim soglasilis' vse vystupavilie $v$ prenijach. Inałe bylo nel'zja." (JR 512)

\section{VII.5. Standpunktkomposition}

VII.5.1. Verfremdete Wertungskompetenz der Figuren

Ein markierter Normenbruch auf der Ebene der Standpunktkomposition liegt v.a. hinsichtlich der Wertungskompetenz der Figuren als Funktionsträger vor. Die Reproduktion dieses für M.2 konstitutiven Elements wurde in VII.1. dargestellt. Einige Verfahren der Verfremaung dieser Folie

1) Neben den bereits erwähnten Markierungen ist hier die Funktion des Zeitdeiktikums "vdrug" im Anfangsteil zu verstehen. Es erscheint zweimal in unmittelbarer Folge des im Dialog auftauchenden Stichworts "sobranie" und leitet eine vorübergehende Unterbrechung der Anfangssituation ein: " - Pravda nuźna tol'ko dlja sobranij /.../. Na lice Cipyseva vdrug promel'knula nastorožnnost' i kakoeto Euvstvo nelovkosti /.../." (JR 504)

" - Eto éto uxitel'nica zameskalas'? Nacinat' by nado partijnoe sobranie.

Odin Scukin varug povel sebja neskol'ko stranno /.../" (JR508) (JR 508)

Ein drittes "vdrug" erscheint im zusammenhang mit dem Hustenanfall Konoplevs (s.o.) und steht ebenfalls in engem (symbolischen) Zusammenhang mit der Versanmlung (Husten, stickige Luft, vorhergehende Beschreibung des "sam") (JR 505).

2) Bis auf die Einführungs- und Schlubreden wird nur ein Dialog in direkter Rede wiedergegeben, welcher bezeichnenderweise auBerhalb des Kommunikationsrahmens der Versammlung lokalisiert ist, nämlich Konoplevs und Scukins gefliustertes Gespräch über die "Wahrheit" (JR 511). 
sollen im folgenden aufgezeigt werden.

Die Mehrdeutigkeit der verwendeten Sprache ist im Figurendialog z.T. thematisiert. Sie konzentriert sich bezeichnenderweise im Begriff der "Wahrheit". Indem die Bedeutungsgarantie gerade dieses Begriffs in Frage gestellt wird, gerät die Legitimität einer auf alleinigen Wahrheitsanspruch pochenden Welterklärung in Frage.

Die erste Diskussion um den Begriff "Wahrheit" entsteht, nachdem $S$ Xukin von der zuckerlieferung durch einen bestochenen Dorfkonsum-Angestellten berichtet. SCukin rechtfertigt sein Verhalten mit der allgemeinen Nichtexistenz der "Wahrheit":

"Vzjal-to ja vzjal. /.../ no gde Ze vse-taki pravda?" (JR 503) Petr Kuz'mil greift diesen Wahrheitsbegriff (im Sinne von 'Ehrlichkeit', 'Gerechtigkeit') auf, um ihn - mit zynischlegitimierender Intention - in Opposition zur Funktionärstätigkeit zu stellen:

"Zakem tebe pravda, ty sejlas - kladovstik?" (JR 503)

Die zweite Bedeutung des Begriffs wird im anschlieBenden Dialog entwickelt. Sie steht nicht in Opposition zur Funktionsträgerschaft, sondern wird mit der Aktivierung des Merkmals 'offiziell' an diese gebunden. Sie ist durch '(-)Vertrauen', '(-)Ehrlichkeit', '(-)Gerechtigkeit' gekennzeichnet:

" - /... Vot tebe $i$ pravda! Ne verjat nam!

- Pravau u nas $v$ rajon sazajut tol'ko $v$ pocetnye prezidiumy. ttoby ne obizalas' da pomalkivala /.../" (JR 504)

" - Pravda nuzna tol'ko dlja sobranij/.../" (JR 504)

Diese von den Figuren selbst erkannte und kritisierte Mehrdeutigkeit des Begriffs prägt jedoch gleichzeitig ihr eigenes Sprachverhalten. Deutlich wird das v.a. an der Ubergangstelle zwischen den Thematisierungen der beiden Bedeutungen.

Dieser Ubergang wird von einer längen Replik Petr Kuz'mils im AnschluB an die Rechtfertigung des 'nicht ehrlichen', 'nicht gerechten' Verhaltens mit der Uberflussigkeit der "Wahrheit" für die Tätigkeit des Lagerverwalters (s.o.) qebildet:

"- Nu, pravda - ona nužna. Na nej vse deržimsja." (JR 504)

Die pluralische Verallgemeinerung des Nachsatzes steht in offensichtlichem widerspruch zur vorher erörterten Realitat. In ihrer an den offiziellen politischen stil anknüpfenden anonym-hortativen syntaktik aktiviert sie das 'offizielle' Bedeutungsmerkmal des Begriffs.

Das schwankende, unentschiedene Verhalten der Figuren gegenüber der Bedeutungsvielfalt des Begriffs prägt auch den diskussionsbeschlieBenden Satz Cipysevs: 
"Pravda, brat, ona est' pravda." (JR 504)

Die im Fall des "Wahrheits"-Begriffs von den Figuren selbst thematisierte Bedeutungsvielfalt ist auch in anderen Zusammenhängen zu beobachten. Sie wird v.a. durch die Verwendung identischer sätze und Begriffe entweder durch verschiedene Figuren oder durch dieselben Figuren in verschiedenen Stadien ihres Wandlungsprozesses signalisiert. Die Zerstörung der Bedeutungseinheit ist hier wiederum mit der Auflösung des monologischen Anspruchs des gesellschaftlichen Wertesystems verbunden:

" - /.../ Ljudej ubezdat' nado. Lenin ukazyval - aktivno ubezdat" nado." (JR 504)

Die zunächst durch die Autorität der politischen Lehre ("Lenin") abgesicherte Eindeutigkeit des von Petr Kuz'mic gegen den Rajkom-Sekretăr verwendeten Arguments wird durch dessen Replik zerstört:

"Vot ty ubezdaj. My tebja ran'se ubezdali, kogda kolchozy organizovyvali, a sejkas ty ubezdaj drugich, provodi partijnuju liniju." (JR 504)

Das "ubezdat'" - von Petr Kuz'mil im Sinne der 'Autorität der Argumente' verstanden - wird vom Rajkomsekretär im entgegengesetzten Sinn der 'Autorität der institutionellen Macht' ("provodi partijnuju liniju") aufgegriffen.

Auf der Versammlung schlieblich verwendet Petr Kuz'mil selbst sein ursprüngliches Argument im Sinne des Rajkomsekretärs (JR 511).

Neben dieser auf der Wertungsebene selbst entstehenden Polyphonie wird die Wertungskompetenz der Figuren durch eine zusätzliche ironische schicht gebrochen, welche sich aus der widersprüchlichkeit zwischen phraseologischer/wertungsmäBiger Kompetenz (manifestiert in monologischer Sprechweise) und auberer, physischer Kommunikationssituation ergibt.

Ivan Konoplev, der anfangs als der schweigsamste der vier "sobesedniki" charakterisiert wird, hält eine unverhăltnismäßig lange Rede über die Zustände im Rajon, deren monologähnlicher Charakter durch den programmatischen Einfuhrungssatz (" - Ja tak ponimaju nasi dela /.../") (JR 506) unterstrichen wird. Diese Rede folgt unmittelbar nach einem Hustenanfall, der ihm seine physische Sprechfähigkeit raubte ("/.../ no skazat" iz-za kaslja nitego ne smog.") (JR 506) und wird gleichsam keuchend ("dychanie tjazeloe") (JR 506) vorgetragen.

Die ironisierende Funktion der physischen situation gegenüber der monologischen Kommunikationsform wird durch eine Unterbrechung von Konoplevs Monolog durch Petr Kuz'mit verstärkt: 
"Konoplev peredochnul, i Petr Kuz'mit vospol'zovalsja ètim, vstavil slovo: /.../" (JR 506)

AnschlieBend wird die ironisierende Funktion der physischen situation unmittelbar auf die Wertungsebene ausgedehnt. Eine der markantesten Reproduktionen des M. 2 - die Verteidigung der Interessenidentität zwischen Funktionsträgern und Bauern - wird kontrastiert mit der extrem desintegrierten physischen Kommunikationssituation (Schreien): " A pocemu - proval?! - potti kriknul Konoplev. - Razve my ne za odno delo boleem, razve u nas interesy raznye?" (JR 507)

VII.5.2. Normenkonkurrenz im Verhältnis des Erzählsubjekts zu den Figuren

Dem Normenbruch hinsichtlich des Wertungsstandpunkts der Figuren entspricht kein gleichermaßen eindeutiger Normenbruch hinsichtlich der Standpunkte des Erzählsubjekts auf den verschiedenen Ebenen. Zwar existieren auch hier unterschiedliche Normen nebeneinander; doch handelt es sich weniger um einen markierten Bruch der alten Normen als vielmehr um eine tatsachliche Konkurrenz, in der es zwar auf den untergeordneten Ebenen der Psychologie und der Phraseologie zu Verfremdungen kommt, insgesamt sich jedoch - und besonders auf der Wertungsebene - die Dominanz der alten Normen behauptet.

Die Normenkonkurrenz manifestiert sich zunächst auf der Ebene der Psychologie. Das Erzählsubjekt nimmt einen AuBenstandpunkt ein (haufige Modalkonstruktionen im Zusammenhang mit dem Innenleben der Figuren wie "slovno", "kazalos"", "budto"). Es scheint das Innenleben der Figuren nicht zu kennen. Hier ist zunächst eine Umwertung dieses auch im M.2 geläufigen Verfahrens festzustellen. Das Innenleben der Figuren verschliebt sich dem Erzählsubjekt nämlich in analog zur Ubernahme ihrer Funktionsträgerrollen wachsendem MaB. Der extremste Rückwurf auf eine rein aubere Charakterisierungsdimension ist mit Beginn der Parteiversamlung gegeben und äuBert sich hier in $2 . T$. grotesken Formen ("Boroda ego raspravilas', udlinilas' /...", Mechanismus, s.o.). In "Soseci" wurde die äuBere Darstellung (und ihr grotesker Ausdruck) ungekehrt an die private Extegrationssphäre gebunden. 
Fur die Figur der Lehrerin wird die Unmöglichkeit der Einnahme eines Innenstandpunkts durch das Erzählsubjekt während der Parteiversammlung thematisiert:

"/.../ lica ee ne stalo vidno, 1 o Kem ona sejkas dumala, nikto by skazat' ne smog." (JR 511)

In der letzten situation jedoch tritt in markierter Opposition - nämlich wieder im zusammenhang mit der Lehrerin und der Entblobung ihres Gesichts - der einzige Fall der Einnahme eines Innenstandpunkts durch das Erzăhlsubjekt ein, kombiniert mit einem höchst wertungsintensiven Charakterisierungsmerkmal:

"Akulina Semenova s pojavleniem molodezi vyprjamilas", sbrosila s golovy platok. Ėto byli ljudi ee vozrasta, s nimi ona Euvstvovala sebja svobodnee." (JR 512f, Hvh.G.W.)

Hier vollzieht sich eine unverhoffte Annäherung von Erzăhl- und Figurenstandpunkt sowohl auf der psychologischen Ebene (Innenstandpunkt) als auch auf der Wertungsebene (wertungsintensives Merkmal 'frei' ohne Bedeutungsvielfalt), die - wiederum dem integrativen Sonderstatus der letzten Situation entsprechend - die monologische Integration von Erzahlsubjekt und integrierten Figuren im M.2 reproduziert.

Auf der Ebene der Phraseologie ist ebenfalls auf der einen Seite eine extreme zuruckhaltung des Erzählsubjekts festzustellen. Eindeutige Dominanz besitzt die direkte Figurenrede, stellenweise ist der Erzähltext auf die Einleitung der Figurenrepliken durch Verba dicendi reduziert. Die Repliken können auch wie in einem Dramendialog unmittelbar aufeinanderfolgen.

Es gibt nur zwei Stellen, in denen die Figurenrede indirekt wiedergegeben wird: die Parteiversamulung sowie die rückblickende Darstellung der Ubernahme des Lagerverwalterpostens durch Scukin in Verbindung mit seinem Parteieintritt. Beidesmal wird die Rede des Erzählsubjekts dabei deutlich von der Figurenrede beeinflust, die indirekte Rede besteht aus der lexikalisch identischen Reproduktion der im jeweiligen parteioffiziellen Rahmen verwendeten 
Sprache:

"6../ on nacal pogovarivat" 0 tom, $x_{\text {to }}$ vse komandnye vysoty $v$ kolchoze dolzny zanimat' kommunisty /.../." (JR 503)

Die Beeinflussung kann auch über die indirekte Rede hinaus im einfachen Satz des Erzählsubjekts wirksam werden:

"Cipyšev byl udovletvoren splokennost'ju kommunistov /.../." (JR 512)

Dieses Verfahren hat verfremdende Funktion sowohl gegenüber der Figurenrede als auch gegenüber der Rede des Erzählsubjekts. Erstens wird den Figuren genau an der Stelle die eigene Textzone 'entzogen', wo sie inre eigene Sprache endgültig verlieren. Zweitens wird jedoch dem Erzählsubjekt mit dieser Einschränkung der figuralen Textzone nicht etwa eine eigene Rede, welche sich in phraseologischer Autonomie gegenüber den Figuren ausdrückte, zugestanden. Die Redeinterferenz entsteht hier also in der Beeinflussung des Erzählworts nicht durch das Figurenwort, sondern durch das dem Erzählsubjekt wie den Figuren gleichermaben fremde 'offizielle' Wort. Das Erzählsubjekt erweist sich gleichsam als genauso durch dieses wort domestiziert wie seine Figuren. Hier handelt es sich um einen Normenbruch. Indem phraseologische Monologizitat auf der Basis gemeinsamfremder Rede entsteht, wird der vermeintlich damit verbundenen Wertungsmonologizität (gemeinsame Sprache eines gemeinsamen Wertungssystems) die Grundlage entzogen.

In Konkurrenz zu dieser indirekten Beschränkung der Wertungskompetenz des Erzählsubjekts gegenüber den Figuren stehen allerdings auf der Wertungsebene selbst einige wenige, strukturell jedoch umso exponiertere Kommentare, die den starken Wertungsanspruch des Erzählsubjekts sowie seine relativ ungebrochene Kompetenz in dieser Hinsicht behaupten. 1) Die beiden wertungsintensivsten Kommentare

1) Das konkurrierende Nebeneinander dieser beiden unterschiedlichen Erzăhlpositionen wird deutlich im unmittelbaren Aufeinanderfolgen eines sehr wertungsbewuBten Komentars des Erzählsubjekts und einer extremen Form von Beeinflussung des Erzählworts durch das Figurenwort:

"/.../sejças soglasovannost' i edinodusie projavilis' neskol'ko $v$ inom, mozno skazat', v obratnom znatenii. Cipysev byl udovletvoren splokennost'ju kommunistov /...." (JR 512) 
stehen in textueller Rahmenposition. Im AnschluB an

den ersten Abschnitt heibt es:

"Sideli dolgo, razgovarivali netoroplivo - obo vsem ponemnogu i doveritel'no, bez vsjakich ogljadok, kak starye dobrye tovarisci." (JR 502)

Am Ende bildet der wertende Kommentar den Schlußsatz:

"I snova èto byli listye, serdelnye, prjanye ljudi, ljudi, a ne rycagi." (JR 513) 1)

\section{VII.6. Zusammenfassung}

Wir können in der Zusammenfassung der Analyseergebnisse für eine Definition der normenevolutionären Funktion des Texts drei Schichten unterscheiden.

Die erste Schicht wird gebildet von der Reproduktion der für das M.2 konstitutiven Normen, wobei der Schwerpunkt auf der besonderen Rolle liegt, die den integrativen

1) Bei der ersten Wertung kann allerdings im Zusammenhang mit dem situativen Kontext eine ironische Schicht in Rechnung gestellt werden. Einen Hinweis bildet v.a. die Benennung "tovaristi". Die ihr attribuierten positiven Werte ("dobrye", "doveritel 'no") werden mit dem situativen kontext konfrontiert und verfremdet (eingeschränkte offentlichkeit, Parteiposten. Privilegien). Die Benennung "tovaristi" wird im weiteren Verlauf nur noch im Kontext der Parteiversammlung (in der Figurenrede) verwendet. (Das gleiche gilt dann entsprechend für die in der letzten wertung vom Erzählsubjekt hergestellte zeitliche Anknüpfung an die Anfangssituation mit "snova". Die sujetstrukturelie Exponierung der Anfangssituation gegenuber der Versammlung - als Verfahren der zeitlichen Extegration letzterer, s.o. - war ja nicht gleichbedeutend mit einer Einordnung von Anfangs- und Endsituation in dasselbe semantische Feld. Vielmehr erwies sich die Anfangssituation bereits als schrittweise konstituierung des semantischen Felds der Desintegration, welches in der Versammlung seine Kulmination erreichte.)

Im Schlubsatz hingegen entspricht die Benennung "ljudi" dem Sonderstatus der letzten siturtion. Nachdem die Opposition 'ljudi' vs. 'rytagi' zunachst nicht vom Erzahlsubjekt, sondern von den Figuren, von diesen jedoch in mangelnder Kompetenz entwickelt wurde (polyphone Verwendung der Opposition im ersten Teil und wahrend der Versammlung), sind jetzt die Bedingungen für eine eindeutige Verwendung der Opposition durch das Erzählsubjekt geschaffen. Jetzt erst, mit der endgültigen Auflösung der desintegrierten Situation, sind die Figuren tatsächlich zu "Menschen" geworden. 
Instanzen des gesellschaftlichen Makrokosmos (Funktionsträger, Parteiversammlung) im M.2 beigemessen wird.

Die zweite Schicht wird gebildet von der Negation dieser Normen durch die Umwertung der mit ihr im M.2 verbundenen Werte. Die Figuren in ihrer Rolle als Funktionsträger sind desintegriert, desgleichen die institutionalisierte Offentlichkeit der Versammlung, die zur Nichtöffentlichkeit wird. Die Umwertung vollzieht sich prozeBhaft, sie wird erreicht durch die sämtliche Ebenen einschlieBende Zuordnung der vermeintlich oppositiven Phasen dieses Prozesses $z u$ einem semantischen Feld der Desintegration (Nichtöfentlichkeit, Furcht, raum/zeitliche Extegration, Nichteinheitlichkeit der Sprache und des in ihr materialierten gesellschaftlichen Wertesystems).

Eine dritte Schicht schlieblich reproduziert Elemente des M.2, die jedoch nicht negiert werden, sondern in Konkurrenz zum desintegrierten Feld der zweiten Schicht treten. Diese Schicht ist hauptsächlich mit der letzten situation verbunden und entsteht durch die Bildung eines ebenfalls sämtliche Ebenen einschließenden semantischen Felds der Integration (రffentlichkeit, Auflösung der Opposition 'oben' vs. 'unten', Hoffnung statt Furcht, raum/zeitliche Integration, Standpunktannäherung FigurenErzählsubjekt).

Als primäre Funktion des Texts läBt sich die aus dem Verhältnis zwischen den ersten beiden schichten resultierende Normennegation bestimmen. Sie ergibt sich neben der textquantitativen Dominanz, die diesen beiden Schichten zukommt, daraus, daB mit der ersten, negierten Schicht die zentralen Elemente des M.2 in ihren typischen Erscheinungsformen reproduziert werden, während mit der dritten, nicht negierten Schicht bereits Modifikationen verbunden sind, die auf die erschwerten Bedingungen der Integration verweisen. Das dargestellte Integrationsfeld wird vom institutionalisierten gesellschaftlich-öffentlichen Feld getrennt, bzw. die wiederherstellung von dessen integrativem Potential wird nur möglich durch seine Ausdehnung auf Dimensionen, die auBerhalb der dargestellten 
Welt liegen (räumlich: Radionachricht aus Moskau; zeitlich: Hoffnung auf die zukunft). Der vielfach markierte Sonderstatus der letzten Situation läBt sich darüberhinaus als primăr genrebedingtes Phänomen vermuten. 1)

1) Zum normenevolutionär hemmenden, der klassischen Genretradition verpflichteten Rasskaz-Ende vgl. Cudakova/ Cudakov, aaO (s.III.2.3.). 


\section{Sechziger Jahre}

Das Modell des autonom integrierten Mikrokosmos (M.3)

THESE: Die normennegierenden Texte der fünfiger Jahre erwiesen sich als unfähig, den dargestellten destruierten Integrationsstrukturen des Makrokosmos autonome Integrationsstrukturen des Mikrokosmos gegenüberzustellen. Die Reaktivierung integrativer makrokosmischer Strukturen auf höherer Ebene in der Schlubsituation von "Ryłagi" war Ausdruck dieser Schwierigkeit.

Mit Beginn der sechziger Jahre setzt ein ProzeB der autonomen Dimensionierung des Mikrokosmos auf allen Ebenen ein. Es entstehen neue Strukturen der Integration.

In der Konfigurationsstruktur schlägt sich dies in der Dominanz bäuerlicher Figuren, welche eigene Charakterisierungsdimensionen entwickeln, sowie besonders in der zentralen Rolle der Familie als autonomem gesellschaftlichem Integrationsfeld nieder.

In der Handlungsstruktur sind die Agenten meist passiv in Bewegungsgesetze integriert, die unabhängig von den Bewegungsgesetzen des gesellschaftlichen Makrokosmos verlaufen (Naturzyklik, Schicksal).

Die Raum/Zeit-Struktur besitzt einen besonders hohen modellkonstitutiven Stellenwert. Samtliche Texte organisieren ein dichtes Chronotopensystem, dessen zentrale Elemente das Bavernhaus, das Dorf und der Naturraum als raumliche Substrate einer iterativen und kontinuinen zeitbewegung sind, in der die Vergangenheit mit der Gegenwart verschmilzt.

In der standpunktkomposition vollzieht sich ein wechsel des Erzählstandpunkts von der Seite der Funktionsträger auf die Seite der bäuerlichen Figuren, primär auf der Wertungsebene.

Dieses Modell, das wir als "Modell des autonom integrierten Mikrokosmos" (M.3) bezeichnen, besitzt eine stärkere Variabilität als M.1 und M.2. Es lassen sich zwei Grundtendenzen feststellen, die sich auf die unterschiedliche Darstellung des Verhältnisses zwischen Mikro- und Makrokosmos beziehen. Der Hauptstrom der Modelltexte stellt die Konfron- 
tation zwischen Mikro- und Makrokosmos, konkret: die Bedrohung der autonomen Integrationsstrukturen des Mikrokosmos durch die desintegrativen Einwirkungen des Makrokosmos dar. Diese Tendenz wird von allen gröBeren seit Mitte der sechziger Jahre erschienenen Paradigmatexten - "Privyenoe delo" (V. Belov, 1966), "Na Irtyక̌e" (S. Zalygin, 1964), "ProłXaj Gul'sary" (C. Ajtmatov, 1966), "Iz Zizni Fedora Kuz'kina" (B. Možaev, 1966), "Den'gi dlja Marii" (V. Rasputin, 1967) u.a. - vertreten. Die Konfrontation kann allerdings unterschiedlich scharf verlaufen. Im Extremfall können die ehemals autonomen strukturen des Mikrokosmos als bereits weitgehend zerstört dargestellt werden, etwa in "Matrenin dvor" (A. Solzenicyn, 1963). Eine zweite Textgruppe stellt einen von Fremdeinflüssen weitgehend unberührten Mikrokosmos dar. Potentlelle Konfrontationen mit dem Makrokosmos werden uberlagert durch die Integration makrokosmischer Elemente in den Mikrokosmos. Diese Tendenz wird besonders von Texten V. Lichonosovs ("Brjanskie", 1963; "Rodnye", 1967) und Z.T. E. Nosovs ("Za dolami, za lesami", 1967) repräsentiert.

VIII.1. Konfigurationsstruktur

VIII.1.1. Konfrontation der figurencharakteristischen Wertmaßstäbe von Makro- und Mikrokosmos

(v. Sukకin, "Kosmos, nervnaja sistema i Kmat sala")

Die Entwicklung eines autonom dimensionierten Mikrokosmos schlägt sich auf der Ebene der Konfigurationsstruktur bereits in der Figurenauswahl, konkret: in einer Umkehrung des Dominanzverhältnisses zwischen Funktionsträgern des Makrokosmos und Bauern nieder. Fast alle Texte der sechziger Jahre haben bäuerliche Figuren als Hauptfiguren. Funktionsträger sind entweder gar nicht vorhanden oder bekommen in ihrer Nebenfigurenposition einen aus der Welt der Hauptfiguren extegrierten Statusisie bedrohen diese Welt entweder mit Desintegration oder sind zu marginaler Irrelevanz verurteilt.

Entscheidend ist, daB für die bäuerlichen Hauptfiguren nach der Auflösung des ehemaligen Integrationsfelds Makro- 
kosmos ein eigenes Integrationsfeld entsteht, in dem sich neue, autonome figurencharakteristische Wertmaßstäbe eröffnen, die sich häufig in scharfem Gegensatz zu den Wertmaßstäben des Makrokosmos befinden.

Ein Text, in dem die Opposition dieser Wertmaßstäbe in extremer Weise manifest wird, ist "Kosmos, nervnaja sistema i smat sala" (V. SukSin, 1966, im folgenden: "Kosmos"). Die alte Norm wird als deutlich erkennbare Folie reproduziert und gebrochen. Der Bruch beschränkt sich nun jedoch nicht mehr auf die Negation, sondern entwickelt sich zur Uberwindung der alten durch eine positive neue Norm.

In der Erzählung wird das zusammenleben des alten Bavern Naum Evstigneit und des Schulers Jurka, Naums Mieter. dargestellt. Sie besteht zum größten Teil aus Dialogen zwischen den beiden Figuren, in denen die 'rückschrittliche' Gesinnung Naums mit der 'fortschrittlichen' Gesinnung Jurkas zusammenstöbt. Die Gesinnung Naums ist dabei in jeder Hinsicht durch eine Extegration aus dem Makrokosmos (räumlich, zeitlich, gesellschaftlich), die Gesinnung Jurkas durch eine Integration in diesen gekennzeichnet. Auf dieser ersten Ebene entstehen folgende Oppositionen:

NAUM/EXTEGRATION JURKA/INTEGRATION

\begin{tabular}{|c|c|}
\hline GESELLSCHAFTLICHE DIMENSION & \\
\hline Primat des individuellen & Primat des Gemeinwohls \\
\hline $\begin{array}{l}\text { Reichtums } \\
\text { (Vorschlag an Jurka; Chauf- } \\
\text { feur zu werden: "Oni von } \\
\text { po skol'ko zasibajut.") } \\
\text { (Sk 18) }\end{array}$ & $\begin{array}{l}\text { (Wunsch, Arzt zu werden, um der } \\
\text { Menschheit einen Dienst zu leisten) } \\
\left(S_{K} 18\right)\end{array}$ \\
\hline reich $(S K 16)$ & arm (sk 17) \\
\hline 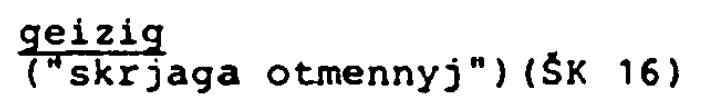 & - \\
\hline $\begin{array}{l}\text { gegen Kollektivwirtschaft } \\
\text { (für Betrügerein gegenüber } \\
\text { dem Sovchoz) (Sk 18) } \\
\text { ("No rabotat" - eto znatit } \\
\text { tol'ko dlja sebja, na svoej } \\
\text { pasne, na svoem ogorode. } \\
\text { Kak ran'se. kolchoze on } \\
\text { davno ne rabotal.")(Sk 18) }\end{array}$ & $\begin{array}{l}\text { für kollektivwirtschaft } \\
\text { TVorwurf gegenüber Naum: } \\
\text { "U tebja kakoj-to kulackij } \\
\text { uklon } / \ldots / \text { ") (sk 18) }\end{array}$ \\
\hline
\end{tabular}


Interessentrennung gegenüber Funktionsträgern 1)

Nichtwissen, ungebildet

(Ressentiments.gegen

Wissen, lernbegierig

Bildung: "Tam titat"

(technische Kenntnisse)

nexego - vran'e odno." (Šk 21)

ZEITLICHE DIMENSION

Ablehnung der Gegenwart, wiederholtes Beschwören der Vergangenheit

("ran'se")
Ablehnung der Vergangenheit ("Rassuzdenija, kak pri krepostnom prave.") (ŠK 16)

("U vas tol'ko odno na ume: ran'se!" (SK 18)

für Gegenwart und zukunft

(").../ispytyvaet udovletvorenie ottogo, Xto vstupaetsja za Novoe /.../"n) (కK 18)

für Technik und Wissenschaft

(Flugzeug $^{2)},\left(\right.$ Radio) ${ }^{3)}$

für moderne Medizin

T"Cuma ran'se byla? /.../

Gde ona sejtas?") (šk 21)

"A babka, byvalo, posepcet /..." ) (Sk 22)

\section{RAUMLICHE DIMENSION}

Extegration des mikrokosm. Raums: Haus, Ofen, Dorf (unbeweglich, Ofen: "Lezal na pełke, stonal." ) (SK 15) (gegen Stadt: "Co ét vas tak šibko $v$ gorod-to tjanet?") (SK 17) ("HaB" auf die Kinder, weil sie in die stadt gezogen sind) (SK 17)
Integration in makrokosm. Raum (beweglich, Kosmonauten)

(Antagonisierung von ofen und Kosmonauten: "A $t$ to oni, budut lư̌se na pecke ležat'?") ( $K K$ 19) (Uber Paviov: "I ne valjalsja potom na pecke $\left./ \ldots /^{n}\right)($ (SK 23)

(Verschränkung von 'kosmischer' und gesellschaftlicher Integration: Utopie der "Weltmenschheit"/mirovoe Celovecestvo) (SK 20)

1) " - Nascet uklona-to... smotri ne vjakni gde. A to pridut, ogorod urezut." (Sk 19)

"- Ty by, naverno, komissarom u nich byl." (SKK 19, Hvh.G.W.)

2) " - A to... iraplanov ponadelali-der'ma-to.

- A tebe bol' 5 e gljanetsja na telege?"

- A Cem plocho na telege?" (కkK 18)

3) " /.../ 'Ran'se bylo! Ran'కe bylo!..' Vot tak bylo ran'కe?! - Jurka podosel $k$ rozetke, vkljutil radio. Pela pevica. Gde ona? Ee ze net zdes'!" (=verschränkung mit räumlicher Dimension) ( $\left.\mathrm{S}_{\mathrm{K}} 22\right)$

4) Verschränkung mit zeitlicher Dimension ('Alter'):

"- Sto ty privjazalsja s étoj pexkoj? - obidelsja starik. Dozivi do moich godov /.../" (SK 2O) 
Neben dieser Charakterisierungsebene, die sich im Dialog der beiden Figuren - 2.T. durch Kommentare des Erzählsubjekts ergänzt - entwickelt, existiert eine Ebene, die sich aus zwei eng miteinander zusammenhängenden Faktoren zusammensetzt. Erstens verläuft parallel zu den Dialogen, besser: in ihrem Hintergrund, ein nichtsprachlicher Handlungsstrang, der in seiner Alltäglichkeit sowie seiner zeitlichen und räumlichen Reduktion zunächst als bedeutungslos gegenüber der extrem makrokosmischen Dialogthematik erscheint, sich jedoch immer mehr in den vordergrund schiebt. Vor dem Hintergrund dieses Strangs (= praktische Schicht) wird zweitens eine zusätzliche Schicht innerhalb des Dialogs aktiviert (= zweite Dialogschicht), die sich aus der Konfrontation der makrokosmischen Thematik mit dem Mikrokosmos der alltäglichen Lebenswelt konstituiert und die in der ersten Dialogschicht geltenden Wertmasstabe verfremdet.

Die nichtsprachliche Miniaturhandlung wird besonders am Anfang und am Ende markiert. Sie besteht aus folgenden Situationen:

1) Der alte Naum liegt auf dem ofen und hat "Katzenjammer" (pochmel'e) (Anfang).

2) Jurka macht den Vorschlag, ein Glas Wodka zur Ausnüchterung zu trinken (Anfang).

3) Jurka will mit den Schularbeiten beginnen (Anfang $\rightarrow$ Mitte).

4) Naum geht hinaus, holt ein stück speck und schenkt es Jurka (Ende).

5) Jurka iBt den Speck (Ende).

6) Das Befinden Naums bessert sich (Ende).

7) Jurka macht das Angebot, eine Flasche Wodka zu holen (Ende).

8) Jurka beginnt mit den Schularbeiten (Ende).

Der Stellenwert dieser Schicht wird - neben ihrer Rahmenposition - bereits im Titel signalisiert. Hier werden die extremste makrokosmische Dimensionierung der Dialogthematik ("Kosmos") und das zentrale Motiv der praktischen Schicht ("Imat sala") miteinander konfrontiert.

Als Resultat der Konfrontation dieser beiden Schichten im Text ergibt sich v.a. die Unvereinbarkeit der mit beiden verbundenen WertmaBstäbe. Der 'rückschrittliche' und 'geizige' Naum der ersten Dialogschicht ist innerhalb der praktischen schicht 'grobzügig' und 'hilfsbereit'. Der auf weltanschau- 
licher Ebene gegen das Trinken polemisierende Jurka ist im alltäglichen, praktischen Zusammenleben mit Naum von weniger starker Prinzipienfestigkeit. Eine weitere Konfrontation dieser beiden Schichten ist mit der zentralen Funktion des ofens in der praktischen schicht verbunden. Der ofen ist hier - im Gegensatz zur 'kosmischen' Dimension des Dialogs und der damit verbundenen Abwertung des ofens zum Chronotopen der 'Rückschrittlichkeit' durch Jurka sowohl der Ort der Dialoge ("Po utram besedujut u pecki.") (SK 17) als auch der ort, an dem sich das zusammenleben beider Figuren mit Entwicklung der praktischen Schicht konzentriert. Er rückt sowohl für Jurka als auch für Naum im zusammenhang mit der Speckschenkung ins zentrum:

" - EX'. Tam Cajnik v peðke - 1 కo gorjadij, naverno... Poes'.

Jurka dostal cajntk iz pecki, nalil v kruzku teplogo esce Caja, narezal chleba, vetciny i stal est'. Starik s trudom zalez opjat' na pec' i smotrel ottuda na Jurku." (SK 24)

Auch die zeitlichen Dimensionen beider Schichten werden konfrontiert. Der 'unendlichen' Dimension der ersten Dialogschicht - von der Leibeigenschaft bis zur eschatologischen ZukunftsverheiBung ("raj", "perspektiva Celovecestva") (SKK 20) - steht die Miniaturzeit der praktischen Schicht - ein Morgen - gegenuber.

So entsteht ein neues Dimensionierungsfeld fur die Charakterisierung der beiden Figuren. Es ist das Feld des alltăglichen zusammenlebens an gleichen ort und zur gleichen zeit, der gemeinsamen Sorgen um die materiellen, körperlichen, psychischen Befindlichkeiten des jeweils anderen. Die Wertdichotomie der ersten Dialogschicht ('fortschrittlich' = integriert in den Makrokosmos vs. 'rückschrittlich' = extegriert aus dem Makrokosmos) wird gegenstandslos angesichts der gemeinsamen Integration beider Figuren in denselben Mikrokosmos.

Die Uberlegenheit der praktischen Schicht gegenuber der ersten Dialogschicht erweist sich in den Auswirkungen auf der Dialogebene selbst (zweite Dialogschicht). Die vielfache Verschränkung des Dialogs mit dem mikrokosmischen Lebensbereich der beiden Kommunikationspartner wird offenbar. Das 
Resultat ist eine ironisierende Verfremdung der von Jurka vertretenen makrokosmischen Dimension und ihrer Wertmaßstäbe.

Es stellt sich erstens heraus, daB Jurkas vermeintlich überlegenes Denken und Reden immer wieder auf die mikrokosmische Dimension zurückgeworfen wird, in der auch Naum denkt, und die häufig sogar von diesem diktiert wird. Dies äubert sich während der "Kosmos"-Diskussion. Die unmittelbar praktischen, an den eigenen menschlichen Lebensbereich gebundenen Vorstellungen, mit der Naum diese Thematik erfaBt, prägen letztlich auch Jurkas Vorstellungskraft. Naum projiziert die Formen menschlichen zusammenlebens auf die von Jurka eingebrachte Imagination fremder Lebewesen im Kosmos und der Moglichkeit einer Kontaktaufnahme mit diesen:

"ISo drat'sja kinutsja." (SKK 20)

"Neprosennyj gost" chuze tatarina." (5K 20)

"Ženit'sja, కto li, drug na druzke budete?" (Šk 20)

Jurka stützt sich in seiner Gegenargumentation auf die gleichen Vorstellungskategorien:

"Ne kinutsja. Oni toze obradujutsja." (SKK 20)

"My tol'ko ne raspolagaem dannymi. No my voz'mem $1 \mathrm{ch} u$ sosedej po Galaktike." (SKK 20)

Auch in seinen Prophezeiungen der technischen Weiterentwicklung erweist sich Jurkas Vorstellungskraft beständig auf eben die Dimensionen zurückgeworfen, die er dem Alten zum vorwurf macht. Ein Hubschrauber soll vom Dach des Bauernhauses fliegen ( $\left.\xi_{K} 20\right)$, Videokontakt mit der Umwelt entsteht "direkt vom ofen aus" (prjamo s pełki) ( $\aleph_{K}$ 20). Zur schärfsten Konfrontation der beiden Vorstellungsbereiche kommt es, als Jurka versucht, die dargestellte praktische situation unmittelbar mit seiner zentralen Argumentationsbasis auf der Díalogebene - der Lehre Pavlovs - $z$ verbinden:

"A u tebja uz uslovnyj refleks vyrabotalsja: kak pensija, tak objazatel'no pol-1itra." (Sk 23)

Dieser Kombinationsversuch signalisiert im naiven, laienhaften Verständnis der Lehre Pavlovs die Unangemessenheit der verschiedenen Dimensionen.

Zweitens labt sich eine spezifische Reaktionsweise Jurkas auf die wiederholten Konfrontationen beider Schichten 
feststellen. Sie besteht in einem 'ideologischen' 1)

Interaktionsverhalten, das besonders dann aktiviert wird, wenn Jurka sich nicht in der Lage sieht, die von Naum provozierte Verbindung zwischen beiden Vorstellungsbereichen herzustellen. Es äuBert sich in einer Tabuisierung des eigenen Wertesystems vor systemfremden Fragen, im Ausweichen auf tautologisierende Antworten, in einem quasireligiósen Verehrungs - und Glaubensverhältnis zu Medium (Buch) und Schopfer (Pavlov) der wissenschaftlichen Lehre. Dies soll anhand eines Textbeispiels verdeutlicht werden, in dem verschiedene Varianten dieses Verhaltens einander ablösen:

Auf Naums Frage, warum die Menschen in den Kosmos fliegen, reagiert Jurka zunachst mit der Ablehnung dex Frage als solcher:

"No sprašivat': załem ljudi v kosmos letajut? - èto ja tebe skazu..."

Dann folgt eine auf das eigene Wertsystem zurückverweisende, tautologisierende Antwort:

"Nu, vo-pervych: osvoenie kosmosa - éto ... nado."

Schlieblich folgt als letzter Ausweg das Umkippen in den praktischen, vom zwischenmenschlichen zusammenleben bestimuten Vorstellungsbreich:

"A na Venere, mozet, toze ljudi Zivut. Razve ne interesno pogljadet" na nich?.." (SK 20)

1) Mit 'ideologischem' Interaktionsverhalten wird hier und im weiteren jedes Interaktionsverhalten bezeichnet, welches vom widerspruch zwischen vorgeblich globalen werten (die als allgemeingültige, objektive, uberhistorische ausgegeben werden) und den tatsächlich partialen (zeit- und situationsbedingten, subjektiven, durch eine soziale Trägergruppe vertretenen) Werten bestimmt ist. (Mangels eines geeigneteren Terminus soll hier auf die für die Bezeichnung dieses Interaktionsverhaltens allgemein üblich gewordene Verwendung des Ideologiebegriffs in seiner eingeschrănkten Bedeutung - "falsches Bewubtse in" (s.Anm.2 auf S.11) - zurückgegriffen werden.) Die AuBerungsformen 'ideologischer' Interaktion sind unterschiedlich (Tabuisierungen des Wertesystems, Anthropomorphisierungen und Naturalisierungen sozialer bzw. wissenschaftlicher Faktoren, Enthistorisierungen etc.). Der Begriff der Interaktion verweist zusätzlich auf die unmittelbar sozialen Implikationen 'ideologischer' Wertformulierung: Sie reproduziert als kommunikatives Handeln bereits elementare gesellschaftliche Strukturen wie 'Herrschaft' (Machtausübung, Beeinflussung, Uberlegenheit durch verbale Strategien) und 'Entfremdung' (Ubernahme bzw. Verinnerlichung fremder Partialinteressen). 
Der zentrale Berührungspunkt beider Vorstellungsbereiche und der mit ihnen verbundenen Wertesysteme ist das Dialogthema "Pavlov". Seine besondere Funktion besteht darin, daB hier das endgültige Umschlagen des ersten in das zweite System innerhalb der Dialogebene und damit die Dominanz des zweiten prozeBhaft vollzogen wird. Die Markierung des Themas im Titel ("nervnaja sistema") - und zwar in mittlerer Position zwischen den jeweiligen Extremmotiven der beiden Systeme - signalisiert zusätzlich diese zentrale und transformatorische Funktion.

Für Jurka ist Pavlov der entscheidende Bezugspunkt seines Wertesystems. Hier gipfelt sein 'ideologisches' Verhätnis $\mathrm{zu}$ diesem System. Er idolisiert Pavlov $\mathrm{zu}$ einer übermenschlichen Autoritat, was sich besonders in der ausschlieblichen Benennung "akademik Pavlov" und in der romantisierenden Beschreibung seines Todes niederschläagt. Das Thema führt zunächst zu einer Uberlegenheit Jurkas uber Naum, auf den die Beschreibung von Pavlovs Tod einen "starken Eindruck" (sil'noe dejstvie) macht ( $\mathrm{SK}_{K} 22$ ). Pavlov wird von Jurka im folgenden als pädagogisches Vorbild gegenüber Naum verwendet ("I ne valjalsja potom na pecke /.../") (క̌K 23). Mit der Argumentation gegen Naums Trinkerei auf der Basis der "Lehre vom Nervensystem" (s.o.) scheint Jurkas pädagogische Autorität zunächst abgesichert:

"Jurka oscutil vdrug nekoe prijatnoe cuvstvo, tto on mozet spoknjno $i$ ubeditel'no dokazyvat' stariku ves' vred i vse posledstrija ego vypivok. Starik slušal." (SKK 23)

Unmittelbar anschliebend folgt die Speckschenkung Naums, in deren Folge sich die Interaktionsrollen der beiden Figuren umkehren. Naum ist jetzt der Belehrende, als er Jurka die Methoden der Schweinezucht erklärt ("Jurka slusal") (Sk 24). Naum greift nun - unverhofft im mittlerweile dominierenden Alltagskontext - das Thema "Pavlov" wieder auf, allerdings in einer neuen Dimension. Er fragt, ob auch Verwandte beim Tod Pavlovs anwesend waren und versetzt pavlov damit vom Feld des Makrokosmos in das Feld des alltäglichen menschlichen zusammenlebens. Jurka seinerseits schwenkt auf diese Dimension ein (er will sich in der Schule nach den Verwandten Pavlovs erkundigen). 
Das Thema "Pavlov" wird durch die Frage nach der Familie darüberhinaus zum spiegelbild der alltäglichen Lebenssituation beider Figuren. Beide sind aus dem familiăren Zusammenhang gelöst - Naum, weil seine Kinder in der Stadt wohnen, Jurka, weil die Familie im Nachbardorf wohnt. Es ist diese gemeinsame situation beider Figuren im mikrokosmischen Bereich, die uber das Thema "Pavlov" in parallelen AuBerungen beider - exponiert am Ende des Texts - endgülig ins zentrum rückt und damit ihre Dominanz uber die Oppositivităt beider Figuren in der makrokosmischen Dimension beweist:

"Odnomu-to plocho." (Naum)

"Odnomu plocho." (Jurka) (SK 25)

VIII.1.2. Die Familie als gesellschaftliches Integrationsfeld

Die gesellschaftliche Dimension des figuralen Mikrokosmos, die in "Kosmos" als das alltăgliche zusammenleben mit den nächsten, am selben ort (im selben Haus) zusammenlebenden Menschen erkenntlich wurde, konzentriert sich in der Familie. In "Kosmos" wird sie mittels eines Minusverfahrens

- der markierten Isolation beider Figuren aus ihrem famliaren Zusammenhang - thematisiert. In sämtlichen groberen Paradigmatexten des M. 3 wird sie zum autonom dimensionierten (d.h. autonome Labensinhalte, Lebensformen, WertmaBstabe gegenüber dem makrokosmischen Integrationsfeld entwickelnden), dominierenden Integrationsfeld der bäuerlichen Hauptfiguren. Modellkonstitutiv ist das konkurrierende Nebeneinander beider Welten, die Darstellung der Figuren innerhalb des - meist konfliktgeladenen - Kräftemessens der unterschiedlichen Wertesysteme. Die Varianten dieses Nebeneinander reichen - analog den beiden eingangs erwahnten Grundtendenzen von einer weitgehenden zerstörung des Integrationsfelds Familie durch die desintegrative Kraft des umgebenden Makrokosmos bis hin zu einer von störenden Fremdeinwirkungen unberührten, harmonisch in sich geschlossenen Familie.

Ein Beispiel für die erste Variante ist "Matrenin dvor". Hier ist es die Gier nach materiellen Werten, welche die 
familiären Bande auflöst. Die Zerstörung des Hofs, auf dem Matrena lebt, im zuge eines noch zu ihren Lebzeiten ausgetragenen Erbstreits der Familienangehörigen wird zum Symbol für die zerstörung des gemeinsamen familiären Integrationsfeldes.

Die zweite Variante wird in einigen Erzählungen V. Lichonosovs realisiert. In "Brjanskie" wird das harmonische Zusammenleben eines alten Ehepaars und ihres Gastes (des Erzählers) dargestellt, wobei sich die familiăre Integrationskraft auf das Verhältnis zwischen den Alten und dem Gast auswirkt:

"Dva goda chodil k nim, privecali kak syna, govorili: napominaju im Cem-to ich mladšego, Mišu /.../." (LB 8)

In den Hauptstromtexten des Modells ist die Familie zwar als autonomes Integrationsfeld noch nicht zerstort, existiert allerdings auch nicht in inselhafter Abgeschlossenheit, sondern wird gerade in ihren vielfältigen Beziehungen mit der umgebenden Welt dargestellt. Diese Beziehungen lassen sich auf der einen Seite als Bedrohung der Familie durch den umgebenden Makrokosmos charakterisieren. Die Familie ist der ort, auf den sich die desintegrativen Auswirkungen des Makrokosmos konzentrieren. In "Den'gi dlja Marii" wird dieser Zusammenhang bereits im Titel manifest. Das handlungsauslösende Ereignis - eine Finanzrevision im Dorfkonsum und die anschlieBende Beschuldigung der Konsumleiterin Marija, tausend Rubel unterschlagen $z$ u haben - wird von Anfang an in seinen Auswirkungen auf die Familie, dem drohenden finanziellen Ruin, der drohenden Gefängnisstrafe für die kinderreiche Mutter und Ehefrau dargestellt. Die anschlieBende Handlung ist von den Bemühungen des Ehemanns Kuz'ma bestimmt, das fehlende Geld "für Marija" (nicht: für den Dorfkonsum) zu beschaffen, um die drohende Gefängnisstrafe abzuwenden. Die Projektion des ursprünglich makrokosmischen Ereignisses auf die familiăre Dimension wird durch ein sujetstrukturelles Verfahren abgesichert: Der gesamte Verlauf wird dargestellt aus der erinnernden Perspektive Kuz'mas während einer zugfahrt $z$ um in der stadt lebenden Bruder. 
Die materiell ruinierenden Auswirkungen des Makrokosmos (und ihre desintegrativen Konsequenzen) auf die Familie werden ebenfalls in "Iz zizni Fedora Kuz'kina" und "Privylnoe delo" dargestellt. Fedor Kuz'kin ist aufgrund seiner materiellen Notlage und der Schikanen, die ihm von den Kolchosfunktionären bereitet werden, gezwungen, Arbeit auBerhalb des Dorfs zu suchen und getrennt von seiner Familie zu leben. Katerina, die Ehefrau Ivan Afrikanovid Drynovs (der hauptfigur in "Privycnoe delo"), Mutter von neun Kindern, stirbt an den Folgen einer ihre Kräfe ubersteigenden Arbeit, zu der sie aufgrund ihrer materiellen Notlage unmittelbar nach der Geburt ihres neunten Kindes gezwungen ist.

Auf der anderen Seite ist die Familie die Basis für den materiellen und moralischen Uberlebenskampf der Figuren in ihrer Umwelt; sie in erster Linie und nicht der Makrokosmos ist die wertbildende Instanz fur die charakterlichen (moralischen, gesellschaftlichen) Eigenschaften der Figuren, an ihren MaBstäben werden diese Eigenschaften gemessen.

In "Privycnoe delo" wird das in der wiederholten Konfrontation von Ivan Afrikanovils Verhalten im gesellschaftlichen Makrokosmos mit der familiären situation signalisiert. wir konzentrieren uns auf drei sujetstrukturell exponierte Stellen: Anfangs wird der Trinkerei Ivans und einer daraus resultierenden Fahrlassigkeit im Dienst als Kolchosfuhrmann die Geburt des neunten Kindes durch Katerina gegenubbergestellt, von der Ivan erst erfährt, als er von seiner nächtlichen Trinkerei zurückkehrt. In der Mitte wird Ivans Auswanderung in die stadt mit dem Tod Katerinas konfrontiert. Umgekehrt ist es die Familie, besonders Katerina, die Ivan in seinem sozialen und moralischen Uberlebenskampf hilft. Anfangs unterstüzt Katerina Ivan in einer Strafsache wegen des DienstverstoBes, am Ende ist es Ivans Reue am Grab Katerinas, die ihm seine eigene Verantwortungslosigkeit bewubt macht und einen neuen Lebenssinn eroffnet.

Der Konflikt 2 wischen beiden gesellschaftlichen Integrationsfeldern wird am schărsten in "Na Irtyse" thematisiert. 
Die Hauptfigur, der Bauer Stepan Kausov, befindet sich in einer extremen Konfliktsituation im makrokosmischen Bereich. Im Kontext scharfer sozialer Kämpfe wăhrend der Kollektivierung tritt er aktiv fur die Kolchoswirtschaft ein. Er beteiligt sich als Mutigster an der Lobschung eines Scheunenbrands, den der Kolchosschädling Udarcev gelegt hat, und er ist ebenfalls an der anschliebenden spontanen strafexpedition gegen den geflüchteten Udarcev beteiligt, in deren verlauf dessen Haus zerstört wird. Im folgenden aber wird er durch die ungerechten Maßnahmen der Kollektivierungspolitik in eine immer distanziertere position gedrängt und schlieblich als angeblicher Kulakenfreund verbannt.

Dem steht ein familiärer Bereich gegenüber, der sich als uberlegene wertbildende Instanz für Causovs Verhalten

- auch im makrokosmischen Bereich - erweist.

"Vse zaboty, i trevogi, i zavist', kakaja byla, i zlost', i koryst" - vse-vse pereskazyval on Klaske dlinnymi zimnimi nozami. Vse slova, kotorye byli otpułzeny emu, $\boldsymbol{C}_{\text {toby }}$ on skazal ich ljudjam, govoril on tol'ko ej odnoj. Na ljudjach slusal i, slusaja, dumal, cto $i$ kak sleduet skazat' $v$ otvet na reti Chromogo Netaja, kak nuzno s Fofanom pobesedovat' ob pasne $i$ ob jagodnikach, no vse, tto sobiralsja, vse, tto mog on skazat' im, opjat' Ze govoril Klaske." (2N 22)

Seine aus ärmlichen Verhältnissen stammende Frau Klavdija hat ihn zum sozialen Bewubtsein erzogen. Die Sorge um sie und die Kinder ist es ungekehrt, welche ihn von seinen Gedanken, als Privatbauer Reichtum zu erringen, abbringt:

"A sej¿as, poka rebjata malye, kupit' konja - éto znatit Klasku na drugoj ze god $v$ staruchi zagnat'. Eto tak i est' ej by uže doma s rebjatiłkami ne sidet', a na pašne $v$ izbuske zit', muzickuju rabotu rabotat' vrode vdovy kakoj." (2N 49) 1)

Der Konflikt zwischen den beiden Bereichen und ihren Wertesystemen entsteht, als die Frau des geflüchteten Brandstifters mitsamt den Kindern von Klavdija bei sich zuhause aufgenommen wird. ${ }^{2)}$ Das familiăre Wertesystem verlangt, daB Causov die Udarceva bei sich zuhause wohnen läBt. Es wird von Klavdija formuliert - unter expliziter Abgrenzung vom "fremden" makrokosmischen Wertesystem:

1) Zu den patriarchalischen vorstellungen Causovs, die hier bereits deutlich zum Ausdruck kommen, vgl. VIII.4.2. Die ausgesprochen frauenfeindichen Implikationen fast aller Dorfprosatexte mübten den Gegenstand einer eigenen Untersuchung bilden.

2) Ein sujetstruktureller Hinweis auf diesen Konflikt ist der unmittelbare AnschluB eines retrospektiven Kapitels uber Causovs Ehe an dieses Ereignis. 
"Udarcev Leksandra zerno poß̌eg - tak èto Že razboj i est', on, kak varnak, posle togo skrylsja, a rebjatiški? Neuźeli i ty rebjatiskam vrag, dom ichnij razoril i so svoego zimoj vygonis'?! Ty he ne Kuzoj kakoj nacal'nik - sdelal, i net tebja! Tebe rebjatiski èti vsjakij den' na puti budut, vsjakij den' im $v$ glaza gljadet'! Nel'zja nam ich $s$ izby gnat', nel'zja mne bylo ich $i v$ izbu ne privesti. Pover' ty mne, Stepa, ne obmanyvaj menja: ja ved' za Keloveka vzamuz sla..." (ZN 27)

Das makrokosmische Wertesystem hingegen verlangt, daB Causov die Udarceva als Frau eines Kolchosschädings des Hauses verweist. Wiederholt verlangen das die Funktionsträger des Makrokosmos - der Untersuchungsrichter, der Kolchosvorsitzende Pecura - von Causov.

Im Kern geht es in diesem Konflikt um die Anerkennung oder Nichtanerkennung autonomer Normen zwischenmenschlichen Zusammenlebens im familiären Bereich. Die zerstörerische Funktion des Makrokosmos gegenuber diesen autonomen Normen kulminiert am Ende: Causovs Weigerung, die Udarceva $z u$ verstoBen, wird $z u$ einem der Hauptanschuldigungspunkte gegen ihn und dient $z$ um $A n l a B$ seiner Verbannung wegen angeblicher Kulakenfreundschaft.

Im letzten Kapitel, das die Abfahrt von Causovs Familie in die Verbannung darstellt, prallen die beiden systeme erneut aufeinander. Diesmal ist Causovs eigene Familie der Angriffspunkt der desintegrierenden Kräte des Makrokosmos. Der Parteibevollmächtigte Mitja macht Klavdija den Vorschlag, sich von ihrem Mann loszusagen, womit sie ihrer Verbannung entgehen könne. Indem Klavdija diesen Vorschlag zuruckweist, bestätigt sich die Uberlegenheit des familiàren Integrationspotentials uber das desintegrative Potential des Makrokosmos zum zeitpunkt von dessen extremster Agressivität.

VIII.1.3. Modellvariante: Der Funktionsträger als Hauptfigur (F. Abramov, "Vokrug da okolo")

Eine Minderheitenvariante bilden Texte, in denen geselischaftlich-öffentliche Funktionsträger Hauptfiguren sind. Unter ungekehrtem Vorzeichen entspricht das Verhältnis dieser Variante zum M. 3 dem Verhältnis der entsprechenden Minderheitenvariante zum M.2 ("Sosedi", s.VI.1.4.): 
Die Wirksamkeit der modellkonstitutiven Normen setzt sich indirekt, in der Uberlegenheit der von den Nebenfiguren repräsentierten Dimensionen des jeweils modelldominierenden Kosmos fort.

Dieses Verhältnis soll anhand eines Texts mit deutlichen Traditionsbezügen zum M.2 - "Vokrug da okolo" (F. Abramov, 1963) - verdeutlicht werden. Hier zeigt sich, wie unter dem EinfluB der neuen modellkonstitutiven Normen das literarische Erbe des alten Nodelis gleichsam mutiert. Dies geschieht in Form eines Prozesses, dem die Hauptfigur unterliegt.

Den Rahmen dieses Prozesses (Prolog, erstes und letztes Kapitel) bildet die Leitungstätigkeit des Kolchosvorsitzenden Ananij Egorovit Mysovskij, konkret: seine Bemühungen um das Einbringen der von Unwetter bedrohten Heuernte. In scharfer Form ist die Opposition 'oben' vs. 'unten' innerhalb der Ebene der Funktionsträger ausgeprägt: Der Kolchosvorsitzende wird durch die bürokratischen Anforderungen der oberen Ebenen in seiner Tätigkeit behindert. Die höheren Instanzen zwingen Ananij Egorovit $z u$ wirtschaftlich unvertretbaren Maßnahmen (Einbringung von silofutter während der Heumahd-Zeit; Prolog). Auf der anderen Seite besteht eine scharfe Opposition zwischen Bauern und Kolchosvorsitzendem. Die Bauern arbeiten nachlässig, trinken, bleiben der Arbeit fern. Am Ende des ersten Kapitels steht der BeschluB des Vorsitzenden, jeden Bauern persönlich aufusuchen und $z u$ einem freiwilligen Sonntagseinsatz zur Rettung der Heuernte $z u$ bewegen. Im letzten Kapitel wird der Erfolg seiner Bemühungen dargestellt: Der sonntägliche Ernteeinsatz findet statt, nachdem Ananij Egorovit jedem Bauern dreibig prozent des geernteten Heus fur den eigenen Gebrauch zugestanden hat. Gleichzeitig deutet sich im letzten Kapitel ein prinzipieller Wandel in den Beziehungen zwischen Bauern und Vorsitzendem an, der jedoch erst durch den im Textzentrum vollzogenen ProzeB verständlich wird. Wir werden abschließend darauf zurückkomen.

Das Textzentrum wird von einer Serie kapitelmäBig unterteilter Begegnungen zwischen Vorsitzendem und Bauern gebildet, die durch den Beschluß des Vorsitzenden am Ende des ersten 
Kapitels mit dem Rahmen in handlungsstrukturellem zusammenhang stehen. Im Verlauf dieser Begegnungen aber wird der Funktionsträger in die Dimensionen einer anderen Welt, der des bäuerlichen Mikrokosmos, förmlich hineingezogen.

Die Begegnungen bekommen eine selbständige Funktion, sie werden zum Konfrontationsort der beiden Welten, in denen sich prozessual die Autonomie, am Ende sogar die Uberlegenheit des Wertesystems der 'kleinen', bäuerlichen Welt im Bewubtsein des Funktionsträgers vollzieht. Die selbständige Funktion der Begegnungen wird durch ihre zunehmende Ablosung von der ursprünglichen Handlungsintention der Hauptfigur unterstrichen.

1) Die erste Signalisierung der Unvereinbarkeit beider Welten erfolgt unmittelbar nach dem BeschluB. In den ersten drei Hăusern, auf die Ananij Egorovit trifft, wohnen sehr alte Menschen, die nicht mehr in Kolchos arbeiten. Der Besitzer des einen ist vor kurzem gestorben. Diese Hăuser gehoren einer dem eigenen Wirkungsbereich derart fremden Welt an ("Zivaja 111 justracija $1 z$ dorevol jucionnogo Zurnala.") (AO 114), daB Ananij Egorovit an ihnen vorbeigeht. (Kapitel 2)

2) Nach dieser fremden Welt betritt er als erstes Haus das der "Hauptstutze" (glavnaja opora) des Kolchos, des Baubrigadiers Voronicyn. Auch hier aber kommt es zu einer Konfrontation beider Welten: Der Baubrigadier ist nicht anwesend, entgegen seiner Handlungsintention wird Ananij Egorovid mit den Sorgen der Familie Voronicyns konfrontiert. (Kapitel 3)

3) In den zwei folgenden Begegnungen mit drei Frauen, die während der Arbeitszeit im Wald Pilze sammelten (Kapitel 4) und mit einem Kolchosbauern, der krank feiert (Kapitel 5), werden die Erwartungen an Ananij Egorovit als Funktionsträger mit seinem erwachenden Verständnis für die situation der Bauern konfrontiert:

"Da, let vosem' nazad Ananij Egorovid nagnal by stracha na etich gribnic. A sejcas..." (AO 117)

"Tut nado prinimat' mery. 'A kakie mery? - dumal Ananij Egorovit /.../" (AO 118)

4) Die mittlerweile vollzogene Bewegung des Funktionsträgers im Spannungsfeld der beiden Welten wird in der folgenden

1) Sein BeschluB, "in jedes Haus zu gehen" ("vojdet $v$ kałdyj dom") (AO 113), stelit bereits eine deutliche intertextuelle Verbindung zum M. 3 her: Das "Hineingehen in jedes Haus" ist ein Grundtopos der Texte aus der Anfangsphase des Modells. Vgl. "Kaplja rosy", wo sich die Erinnerungen des Erzählers an den einzelnen Häusern und ihren Bewohnern festmachen. Vgl. später ebf. "Lipjagi" (S. Krutilin, 1965). Zum genrespezifischen Topos des "obchod sela" bzw. des "vojti v kazdyj dom" in der "Povest" in Novellen" vgl. Sakun, Nekotorye Zanrovye Kerty..., aaO, S.239. 
Begegnung mit dem alten Bauern Ignat Pozdeev und seinem Sohn Kir'ka deutlich (Kapitel 7). Ananij Egorovit, der auch dieses Haus wie die drei ersten meiden will, "kommt nicht vorbe1" :

"Odnako minovat' Pozdeevych ne udalos'. Starik kak nazlo podnjal golovu i zakrical vysokim petusinym golosom:

- Cego nos vorotis'? Ne vory." (AO 119)

Hier setzt der ProzeB ein, der oben als 'Hineinziehen' des Funktionstrăgers in die bäuerliche Welt bezeichnet wurde.1) Das betrifft bereits das Verhältnis zwischen den unterschiedlichen Interaktionsformen beider Welten:

" - Uvaz' starika, tovariš predsedatel'.

Delat' nexego - prílos' 'uvazit' '." (AO 119)

Im anschließenden Dialog erweist sich die Dominanz der von den Pozdeevs repräsentierten Welt besonders darin, daB ihre räumlichen und gesellschaftlichen Dimensionen von den Nebenfiguren auf die Hauptfigur projiziert werden, als der alte Pozdeev sich nach Haus und Familie Ananij Egorovits erkundigt. 2 Am Ende des Kapitels wird erneut die Ablösung dieser Begegnung von der ursprünglichen Handlungsintention deutlich: "Ananij Egorovic kivnul golovoj i vstal: prilicie sobljudeno, a tocit. ljasy emu sejkas nekogda." (AO 120)

5) Eine neue Stufe der Konfrontation stellt die Begegnung mit der alten Bäuerin Agaf'ja Tichonovna dar. Die Zugehörigkeit dieser Nebenfigur $z u$ einer vom Standpunkt des Makrokosmos fremden Welt wird bereits durch ihren Spitznamen "perezitok" (in der leninistischen Terminologie gebräuchliche Bezeichnung für fortbestehende Einflüsse der alten

Gesellschaftsformationen) signalisiert. In nun schon bewuBter Lösung von der eigenen Handlungsintention nimmt Ananij Egorovil die Einladung in dieses Haus an:

"A $v$ samom dele, potemu by emu ne perechvatit' Kego-nibud'? Kogda eše on doberetsja do svoego doma?" (AO 123)

Die damit verbundene Projektion der familiären Dimension dieser Welt auf die eigene Situation wird durch eine zusätz-

1) Die beiden Pozdeevs werden in verschiedener Hinsicht als Reprasentanten einer dem gesellschaftlichen Makrokosmos fromden Welt charakterisiert. Sie reprasentieren eine andere Sprache, die bis zur Unverständlichkeit von der des Makrokosmos entfernt ist:

(Ignat Pozdeev auf einer Versammlung:) " - Ne Euju! Kak bubnit kak d'jacok." (AO 119).

Kir'ka Pozdeev wird im Dorf als "Ubersetzer" (perevoddik) der Sprache der Funktionsträger bezeichnet. (AO 120)

Sie repräsentieren auBerdem die Dominanz der familiăren über die offentlichen gesellschaftlichen Beziehungen (Opposition 'tovaristi' vs. 'otec'):

(Kirka kommentiert die Aufforderung des Dorfsowjets, das provokante Auftreten seines Vaters auf Versammlungen $2 u$ verhindern:) "- Nu tol'ki ja perelit' otcu ne mogu. Ne tak vospitan. Ėto vy tože poimejte v vidu, tovariši." (AO 120)

2) Diese familiäre Dimension wird später für Ananij Egorovic in einem eigenen Kapitel entwickelt (Kapitel 13). 
liche Aktivierung des Merkmals 'Familie' unterstrichen: "Ananij Egorovic po-domasnemu - vse tut bylo znakomo snjal namoktij plast /.../" (AO 123)

6) Die letzten Begegnungen, die mit einer Reaktivierung der urspringlichen Handlungsintention verbunden sind, signalisieren die mittlerweile vollzogene Veränderung. Im Gespräch mit dem alten Petunja Devjatyj, der sich für die Kolchosarbeit hat arbeitsunfähig schreiben lassen, stattdessen aber eine private Gemüsezucht betreibt, wird die Konfrontation beider Welten unter sprachlichem Aspekt deutlich. Der Begriff des "Gewissens" (sovest"), den Ananij Egorovit in seiner Argumentation gegen Petunjas Weigerung, am Ernteeinsatz teilzunehmen, verwendet, wird von Petunja im Kontext des eigenen Wertesystems hinterfragt. In Form eines "Gleichnisses" (pritCa), in dem die Menschen statt Geldes das "Gewissen" in Säcken auf dem Rücken tragen, weist Petunja auf die apologetische Funktion des Begriffs angesichts des materiellen Elends der Bauern hin. Ananij Egorovic ist dem bäuerlichen Wertesystem mittlerweile so nahe gekommen, dab er nicht nur die Unterlegenheit seiner eigenen Argumentationsbasis erkennt, sondern sich selber in die Rolle der Bauern hineinzusetzen versucht:

"Ananiju Egorovicu nicego ne ostavalos' kak molca proglotit' Petuninu pritcu. A $t_{t o}$ on mog vozrazit'? $t_{t o}$ by on sam delal na meste ètogo starika?" (AO 129) 1)

Wăhrend sich im ProzeB dieser Begegnungen das ehemalige Oppositionsverhälnis zwischen Hauptfigur und bauerlichen Nebenfiguren immer mehr zu einem Aquivalenzverhältnis entwickelt, wird das Verhältnis zu den funktionstragenden Nebenfiguren von einer zunehmenden Schärfe der Oppositionen bestimnt.

Im Textzentrum gibt es nur eine Begegnung mit einem Funktionsträger - dem Parteifunktionăr Serafim Ivanovic Jakovlev (Kapitel 10) - - was bereits als ein sujetstruktureller Hinweis auf die Irrelevanz dieser Figurenreihe zu verstehen ist. In dieser Begegnung wird der Hauptfigur durch das Verhalten Jakovlevs (der die Notsituation Ananij Egorovics ausnutzen will, um Privilegien für seinen Sohn zu erpressen) die Distanz bewubt, mit der sie der gesamten ortlichen welt der Funktionsträger gegenübersteht. Dies zeigt sich v.a. in einem anschlieBenden inneren Monolog Ananij Egorovids, der die extegrierte Position der gesamten Parteiorganisation vom ortlichen gesellschaftlichen Leben anklagt (AO 126f).

1) Es gibt nur eine Begegnung, die diesem ProzeB nicht entspricht: Einer Gruppe von alten Frauen, die ihre Rente abholen, wirft Ananij Egorovic - allerdings auch hier nicht offen, sondern insgeheim - mangelndes KlassenbewuBtsein vor, ohne daB wie in den anderen Kapiteln sein Verständnis für ihre Situation Erwähnung findet. Diese Begegnung ist jedoch schon wegen der Kurze des Kapitels (Kapitel 6, eine halbe Seite) als Ausnahme anzusehen. 
Eine Grenzfigur zwischen den beiden welten ist die Brigadeleiterin Klavdija. Sie wird sowohl in den Dimensionen des gesellschaftlich-öfentlichen Bereichs (als Funktionsträgerin) als auch in denen des privaten Bereichs charakterisiert, und zwar in deutlicher Nicht-Aquivalenz beider Dimensionen:

"Pervaja rabotnica po kolchozu, i ona ke pervaja rasputnica." (AO 113)

Während anfangs ihre Charakterisierung auf die Dimensionen des gesellschaftlich-öffentlichen Bereichs beschränkt bleibt, tritt am Ende die private Dimension in den Vordergrund. Entsprechend andert sich die Einstellung Ananij Egorovits. Anfangs wird sie vom gemeinsamen Funktionars-Interesse bestimnt (Absprache über Arbeitsorganisation, Kapitel 1), am Ende - nach Klavdijas betrunkenem Erscheinen auf einer Tanzveranstaltung - wird ihm die private Dimension zum erstenmal bewubt:

" /.../ i emu kak-to srazu stala ponjatna vsja nesuraznaja, izlomannaja Zizn' Klavdii. Perestarok - postoronis'! A Cto $^{\prime}$ ze étomu perestarku-to delat'?" (AO 134)

Der Grenzposition dieser Figur zwischen den beiden Welten entspricht ihr Erscheinen an den sujetstrukturellen Grenzen zwischen Rahmen und zentrum. Sie erscheint zum erstenmal in Kapitel 1. Nach einem langen inneren Monolog uber Klavdija folgt Ananij Egorovits BeschluB, $i u$ den Bauern zu gehen. Ihr zweites Erscheinen im Klub fallt in das letzte zentrumskapitel (Kapitel 14). Unmittelbar nachdem sich für Ananij Egorovic die private Dimension Klavdijas eroffnet hat, folgt eine Verallgemeinerung des vollzogenen Bewustseinswandels ("Cto Ze ja segodnja vsech Kaleju? - varug razozlilsja na sebja Ananij Egoroviz.") (AO 135) und mit dem Gang in die Dorfwirtschaft der endgültige Grenzübertritt in die bauerliche Welt (AO 135).

In der Grenzfigur Klavdija spiegelt sich somit die Grenzposition der Hauptfigur.

Im Ubergang 2 wischen der letzten Information des Zentrums (dem Eintritt in die Dorfwirtschaft) und dem letzten Kapitel kulminiert die Ablösung des zentrums vom Rahmen. Es stellt 
sich im letzten Kapitel nachträglich heraus, daB der schliebliche Erfolg von Ananij Egorovils anfangs geäuBerter Handlungsintention in dem ausgesparten zeitausschnitt zwischen den beiden Kapiteln errungen wurde. Ananij Egorovic hat in betrunkenem zustand den Bauern in der Wirtschaft das dreiBigprozentige Beteiligungsversprechen gegeben. Er hat sich damit zugleich auBerhalb des Wertesystems seiner eigenen Welt gestellt. Am Ende des letzten Kapitels wird die zerrissenheit der Figur zwischen beiden Welten in einer scharfen räumlichen Grenzmarkierung deutlich. Vor dem Haus des Parteisekretärs, in dem nun auch der Rajkomsekretär (wie in "Rycagi" "sam" genannt) anwesend ist, kommt es $2 u$ einer neuen Begegnung Ananij Egorovits mit den Bauern, die von ihm die Erlaubnis für die Fortsetzung der Mahd verlangen.

"Ananij Egorovit oblizal vdrug peresochsie guby, posmotrel na dom Isakova. $V$ oknach - nikogo. Radio smolklo. Slovno i tam, za zanaveskami, zataiv dychanie, sidjat i zdut, na ¿to on resitsja sejCas." (AO 137)

Indem er die verlangte Erlaubnis gibt, bekräftigt er - gleichsam vor den Augen seiner 'eigenen' Welt - seine Parteinahme für die Welt der Bauern.

VIII.2. Handlungsstruktur

VIII.2.1. Autonomes Bewegungsgesetz: Naturzyklus (v. Belov, "Privycnoe delo")

Auf der Ebene der Handlungsstruktur lassen sich verallgemeinernde Feststellungen uber modellkonstitutive Normen nur bedingt treffen. Der These von der Dominanz der inneren Handlung (BewuBtseinshandlung, Retrospektive) ${ }^{1}$ ) ist nur begrenzt zuzustimmen. Zwar gewinnt die Darstellung des inneren Lebens der Helden und die Retrospektive ein groberes

1) Vgl. Schmid, aao, S.60: "Für die neue Prosa ist charakteristisch, daB ihr Held nicht mehr als praktisch handelnder oder gar die aubere Wirklichkeit verändernder aktiver Agent auftritt, sondern als passiv erlebendes, distanziert registrierendes, analytisch erinnerndes, theoretisch reflektierendes Bewubtsein." 
Gewicht. Sie besitzt jedoch nicht unbedingt die Dominanz uber äuBere situationsabläufe, sondern ist in der Regel in diese integriert.

Von größerer Signifikanz erscheint eine Unterscheidung zwischen.. Handlung und Geschehen. ") Für einen relevanten Teil der Dorfprosa der sechziger Jahre läbt sich die Dominanz des Geschehensprinzips über das Handlungsprinzip feststellon, - hier liegt der entscheidende Bezug zur literaturkritischen Diskussion um den aktiven bzw. passiven Helden (s.IV.2.1.). Die innovatorische Funktion gegenuber M.2 konkretisiert sich in der Autonomisierung der Situationsablaufe gegenüber den Bewegungsgesetzen des gesellschaftlichen Makrokosmos, welche durch progrediente Veränderungen mithilfe des aktiven Handelns der gesellschaftlichen Subjekte gekennzeichnet waren. Die Agenten sind nun nicht mehr Subjekte progredienter Bewegung, sondern Objekte - bzw. integrierte Glieder einer unabhängig von ihrem willen sich vollziehenden zyklischen Bewegung. In der Regel werden diese Bewegungsgesetze mit den Bewegungsgesetzen des gesellschaftlichen Makrokosmos konfrontiert und wirken z.T. auch auf diese zurück. ${ }^{2}$

Ein paradigmatischer Text unter diesem Aspekt ist "Privytnoe delo". Der hier im dargestellten zeitausschnitt von einem Jahr sich vollziehende Situationsablauf läBt sich deutlich in die unterschiedlichen welten und ihre Bewegungsgesetze differenzieren. In der folgenden schematischen Darstellung werden die in der Vertikalen in ihrem Ablauf eingetragenen situationen auf der horizontalen den entsprechenden Kosmen zugeordnet:

1) Letzteres entspricht dem von Schmid festgesteliten "passiven Erleben". Passives Erleben und Dominanz der inneren Handlung sind aber nicht unbedingt aufeinander angewiesen.

2) Unter genreevolutionärem Aspekt korrespondieren dieser Tendenz die Phänomene sowohl des "fabellosen Rasskaz" als auch der "Povest' in Novellen" (s.III.3.). Die Ereignislosigkeit des "fabellosen Rasskaz" hängt eng mit der Autonomisierung vom Ereigniszwang (im Sinne obligatorischer 'revolutionärer' Progredienz) des gesellschaftlichen Makrokosmos zusammen. Die "Povest" in Novellen" autonomisiert sich durch ihr zyklisches bzw. nichtlineares Prinzip von den makrokosmischen Bewegungsgesetzen. 


\begin{tabular}{|c|c|c|}
\hline & $\begin{array}{l}\text { GESELLSCHAFTLICHER } \\
\text { MAKROKOSMOS }\end{array}$ & $\begin{array}{l}\text { GESELLSCHAFTL. MIKROKOSMOS } \\
+ \text { NATURLICHER KOSMOS } \\
\end{array}$ \\
\hline 1 & $\begin{array}{l}\text { Dienstvergehen Ivans } \\
\text { und Bestrafung }\end{array}$ & $\begin{array}{l}\text { Geburt des neunten Kindes } \\
\text { durch Katerina }\end{array}$ \\
\hline 2 & \multicolumn{2}{|c|}{$\begin{array}{l}\text { Schwăcheanfall Katerinas } \\
\text { (wahrend Arbeit im Stall) }\end{array}$} \\
\hline (Kap.3) & & $\begin{array}{l}\text { Rückkehr Katerinas aus dem } \\
\text { Krankenhaus }\end{array}$ \\
\hline (Kap.4) & \multicolumn{2}{|c|}{$\begin{array}{l}\text { Aufdeckung verbotener } \\
\text { privater Heumahd Ivans } \\
\text { (Ausfragung des Sohns } \\
\text { durch fremden Funktionăr) }\end{array}$} \\
\hline (Kap.4) & \multicolumn{2}{|c|}{$\begin{array}{l}\text { Ankunft Mitjas } \\
\text { (Bruder Katerinas } \\
\text { aus Murmansk) }\end{array}$} \\
\hline (Kap. . 4) & \multicolumn{2}{|l|}{$\begin{array}{l}\text { ( } 2 \text { wischenepisode: } \\
\text { Verhaftung Mitjas wegen } \\
\text { verbotener Heumahd) }\end{array}$} \\
\hline 7 (Kap.5) & \multicolumn{2}{|c|}{$\begin{array}{l}\text { Abfahrt Ivans und } \\
\text { Mitjas nach Murmansk }\end{array}$} \\
\hline 8 & \multicolumn{2}{|r|}{ Tod Katerinas während Heumahd } \\
\hline 9 & \multicolumn{2}{|c|}{$\begin{array}{l}\text { Ruckkehr Ivans nach } \\
\text { gescheiterter stadtfahrt, } \\
\text { Nachricht von Katerinas } \\
\text { Tod }\end{array}$} \\
\hline $\begin{array}{l}10 \\
(\mathrm{Kap} .7)\end{array}$ & & $\begin{array}{l}\text { Verirrung Ivans im Wald, } \\
\text { Finden von Katerinas Tuch, } \\
\text { Todesangst }\end{array}$ \\
\hline $\begin{array}{l}11 \\
\text { (Kap.7) }\end{array}$ & $\begin{array}{l}\text { Strafe wegen Bahn- } \\
\text { fahrt ohne Fahrkarte }\end{array}$ & $\begin{array}{l}\text { Finden eines Lebenssinns durch } \\
\text { Ivan, Besuch an Katerinas } \\
\text { Grab }\end{array}$ \\
\hline
\end{tabular}

\section{Erläuternder Kommentar}

Im Bereich des gesellschaftlichen Makrokosmos finden drei Situationsveränderungen statt (Sit.1,4,11), in denen die Hauptfigur Objekt ist (Strafe). Diese Situationsveränderungen sind nicht in Form einer Handlungslinie miteinander verbunden; aus ihnen entwickeln sich keine Konflikte, in denen die Hauptfigur Subjektagenten-Funktionen wahrnimmt. Sie stehen in keinem anderem Zusammenhang als dem der Wiederholung, zusätzlich signalisiert durch die Dreizahl. 
Im Bereich des Mikrokosmos gibt es hingegen eine zusammenhängende Entwicklungslinie, markiert durch die beiden Pole Geburt und Tod $($ Sit. 1,8$)$. Dieser ProzeB verläuft jedoch abseits von der hauptfigur: Ivan ist nicht anwesend bei der Geburt des Kindes (Sit.1, er erfährt erst anschlieBend davon), beim Schwächeanfall Katerinas (Sit.2) und ihrer Rückkehr aus dem Krankenhaus (Sit.3); seine Abseits-Position gipfelt in der Situierung von Katerinas Tod (Sit.8) unmittelbar zwischen Abreise und Rückkehr Ivans (Sit. 7,9 ).

Die Situationenfolge $7,8,9$ stellt zugleich die Wende in der Zuordnung der Hauptfigur zu den beiden Bereichen dar. Die Abfahrt Ivans (Sit.7) ist in erster Linie ein versuch der Situationsveränderung im gesellschaftlichen Makrokosmos (vgl. die unmittelbar vorhergehende zuspitzung von Ivans Schwierigkeiten daselbst: nach der Heumahdaffäre wird Ivan starkem Druck von seiten der Funktionsträger des Makrokosmos ausgesetzt, Erpressungsversuche und Drohungen). 1) Dieser einzige Versuch einer Situationsveränderung durch Ivan Afrikanovid scheitert, wiederum unter Hervorhebung seiner Objektrolle; Ivan wird förmlich von den Reisefahrzeugen geworfen:

"/.../ ja na samom verchu motajus', togo i gljadi - v kanavu spikiruju." (BP 70)

"Tol'ko tak podumal, kak motanet menja, nið̌ego bol'se ne pomnju, otuchalsja na zemle, glazu, mašina vverch kolesami /.../" (BP 70)

Die anschlieBende Zugfahrt scheitert, da Mitja mitsamt den Fahrkarten den Zug verpaBt; Ivan, der sich allein und ohne Fahrkarte im Abteil befindet, wird des zuges verwiesen. Unmittelbar mit der Rückkehr Ivans (Sit.9) ist die Nachricht von Katerinas Tod verbunden. Ivans Handlungsunfähigkeit im Makrokosmos wird von seiner Handlungsunfähigkeit im Mikrokosmos ubberlagert. (Ein zusätzlicher sujetstruktureller Hinweis ist der AnschluB eines Kapitels über das willenlose und passive Leben der Kuh Rogulja in Form eines inneren Monologs des Tiers, Kapitel 6.)

Die letzten beiden Situationen reproduzieren den bisher vollzogenen ProzeB von Leben und Tod in konzentrierter Aufeinanderfolge für die hauptfigur selbst, diesmal in umgekehrter Reihenfolge: Auf die Selbstmordabsichten und den drohenden Tod im wald (Sit.9,10) folgt die Rettung Ivans und die anschlieBende Entdeckung eines Lebenssinns (Sit.10, 11). Entscheidend ist, daB in diesem ProzeB die Figur nun ausschlieBlich dem Mikrokosmos zugeordnet ist. Der ProzeB setzt ein mit dem Finden von Katerinas Tuch im Wald und endet mit einer fiktiven Anrede Katerinas durch Ivan an deren Grab. Der Bereich des gesellschaftlichen Makrokosmos wird jetzt zu einem marginalen Nebenfeld, was deutlich wird im Wandel zwischen den beiden Strafsituationen 4 und 11. Wurde Sit.4 zum Höhepunkt in der Auslieferung Ivans an die Gesetze des Makrokosmos, so ist mit Sit. 11 der extremste Punkt von dessen

1) Hier wird Ivan zum ersten und einzigen Mal selber als Funktionsträger fremdcharakterisiert. Der "fremde" Funktionsträger (neznakomyj telovek) (BP 47) zu Ivan: "Gde vaśa kolchoznaja sovest", tovarił̌ Drynov? Vy ze deputat sel'soveta." (BP 47) 
Marginalität erreicht; während der Vorbereitungen zur Totenfeier für Katerina benachrichtigt der Kolchosvorsitzende Ivan uber eine Geldstrafe wegen der Bahnfahrt ohne Fahrkarte. Ivans unbeteiligte Reaktion und die anschlieBende Entfernung des Funktionstrăgers signalisieren diese Marginalităt: "BCl'Se predsedatel' nilego ne skazal, zatoropilsja. Sel na lošad' i uechal /.../." (BP 91)

Der entscheidende Zusammenhang besteht darin, das das wiederfinden eines Lebenssinns erst durch Ivans Integration in den Mikrokosmos und seine Bewegungsgesetze ermöglicht wird. Dieser Kosmos verliert seinen gesellschaftlichen Charakter. Leben und Tod als die ihn konturierenden Bewegungspole werden als Elementargesetzlichkeiten eines natürlichen Kosmos erfaBt. In einem langen inneren Monolog erkennt Ivan Afrikanovit die Integration des eigenen Lebens in den ewigen Kreislauf ("I net konca étomu krugovorotu.") (BP 90) von Leben und Tod. Das ständige Absterben und Aufblühen der Natur wird für inn zum Sinn des eigenen Lebens. 1)

Aus einer ganzen Reihe von symbolischen Verfahren, welche die Dominanz dieses Bewegungsgesetzes sowie seine enge Verknüpfung mit dem familiären Mikrokosmos unterstreichen, sei besonders verwiesen auf das Leitmotiv der Quelle, die immer im Zusammenhang mit Katerina erscheint (gemeinsame Rast Ivans und Katerinas an der Quelle nach der Geburt des Kindes; Abschied Ivans von Katerina vor der Fahrt nach Murmansk an der Quelle; Treffen mit dem FuBgänger und Uberbringer der Todesnachricht bei Ivans Rückkehr an der Quelle). Besonders die letzte Markierung der Quelle im Zusammenhang mit Katerinas Tod macht ihre symbolische Funktion für die zyklik von Leben, Tod und neuem Leben deutlich. Die Quelle ist zunächst verschwunden, bricht dann aber erneut hervor (BP 69).

Die Familie wird in der letzten situation selbst zum symbol für das zyklische Bewegungsgesetz. Grab und Geburt werden kombiniert, Ivan schildert in seiner an Katerina gerichteten Grabrede das Aufwachsen des neugeborenen Kindes. (BP 92)

1) Die Abfolge eines Jahreszeitenzyklus (Frühling bis Winter) ist gleichzeitig organisierendes Prinzip in der zeitstruktur des Texts: Frühling (Kap. 1 bis 3) - Kindesgeburt; Sommer (Kap.4,5) - Kulmination der Ereignisse in beiden Bereichen; Herbst (Kap.7) - Reproduktion des Todesprinzips auf Ivan; Winter (Kap. 7, Ende + Aussicht auf neuen Frühling) - Erwachen neuer Lebensfreude. 
VIII.2.2. Autonomes Bewegungsgesetz: Schicksalhaftes Ereignis

(A. Soltenicyn, "Matrenin dvor")

Eine andere Variante der Autonomisierung der Situationsabläufe von den Bewegungsgesetzen des gesellschaftlichen Makrokosmos ist das schicksalhafte Ereignis. Auch diese Variante ist dominant nach dem Geschehensprinzip organisiert. Die Hauptfiguren sind in ihrem Tun wenn nicht schicksalhaft gelenkt, so doch zumindest auf das Erleiden eines auf sie hereinbrechenden Ereignisses beschränkt. Das Ereignis kann dabei im Rahmen des gesellschaftlichen Makrokosmos stattfinden und auf den Mikrokosmos ausstrahlen. Dies ist in "Den'gi dlja Marii" der Fall, wo die Finanzrevision und anschlieBende Beschuldigung gegen Marija zum Auslöser für den Kampf gegen den drohenden familiären Ruin wird. ' Der 'unerhörte' Charakter des Ereignisses begründet sich hier in der Umkehr der Bewegungsrichtung: Das Ereignis entspricht nicht einer positiv progredienten Entwicklung im sozialen Bereich, sondern einem statischen wenn nicht negativ progredienten Prinzip.

Das Ereignis kann auch isoliert vom Makrokosmos stattfinden und die Uberlegenhelt der Bewegungsgesetze einer anderen Welt demonstrieren. Dies macht zugleich seinen vom offiziellen Weltbild her 'unerhbrten' Charakter aus. Ein paradigmatext dieser Variante ist "Matrenin dvor". In den drei Kapiteln dieser Novelle werden die Bewegungsgesetze der verschiedenen Welten miteinander konfrontiert.

Im ersten Kapitel wird das alltägliche Zusammenleben des Erzählers und seiner Wirtin Matrena dargestellt. Es steht in enger Beziehung zum gesellschaftlichen Makrokosmos. Dies betrifft bereits die Ankunft des Erzählers (Wunsch, nach der Verbannung als Lehrer $z$ arbeiten; Begegnung mit Funktionsträgern, die ihm eine Schule zuweisen, Begegnung mit einer Milchverkauferin und Aufklärung über soziale und ¿konomische Verhältnisse des orts). Im folgenden dominiert

1) Hier gibt es zwar eine aktive Gegenreaktion der Figuren (Versuch, das Geld zu beschaffen), diese ist aber auf die familiare Dimension beschränkt und hat ein offenes Ende. 
die Darstellung von Matrenas Leben, einerseits ihrer alltäglichen hausarbeit, andererseits ihrer gesellschaftlichen Beziehungen (Bemühungen um eine Rente, wiederholte Besuche auf Amtern, illegale Beschaffung von Torf, Scherereien mit dem Kolchosvorsitzenden und seiner Frau, Ausnutzung Matrenas sowohl durch den Kolchos als auch durch die Nachbarn zu unbezahlten Arbeiten). In diesem Kapitel dominiert die Statik uber die Dynamik. (Das einzige Bewegungselement ist die schliebliche zubilligung einer Rente.) Hier liegt bereits ein Normenbruch gegenüber dem im M.2 für den Makrokosmos verbindlichen dynamischen Prinzip vor. Es finden keine Situationsveränderungen statt, die Hauptfigux ist passiv erleidendes objekt eines Dauerzustandes der Ungerechtigkeit.

Das einzig markierte "Ereignis" (sobytie) in diesem Kapitel findet in einem vom dominierenden gesellschaftlichen und raum/zeitlichen Kontext isolierten Bereich statt: In der Kirche wird Matrena wăhrend des Wasserweihfestes der Weihwasserkessel gestohlen. Dieses Ereignis verweist als "Vorzeichen ("odno tol'ko sobytie ili predznamenovanie") (SM 51) auf die im folgenden Kapitel dargestellten Ereignisse im Kontext einer anderen Welt.

Mit Beginn des zweiten Kapitels wird eine neue Dimension förmlich 'eröffnet'. Nach einem einleitenden Kommentar des Erzahlers uber die gegenseitige Respektierung der Geheimnisse der Vergangenheit des anderen ("ne beredil ee proslogo") (SM 52) bricht die Vergangenheit unso intensiver hervor. Es folgt die erste Begegnung mit dem alten Faddej, dem Schwager Matrenas. Dem Erzähler wird im AnschluB an diese Begegnung von Matrena deren Familiengeschichte enthüllt; es stellt sich heraus, daB Matrena bereits mit Faddej verlobt war, als der erste Weltkrieg ausbrach, dann aber, im Glauben, Faddej sei gefallen, dessen Bruder heiratete. - Diese an Faddejs Erscheinen geknüpte Reaktivierung der familiaren Vergangenheit wird nun in einen direkten zusammenhang mit der anschlieBenden Darstellung des schicksalhaften Ereignisses - beginnend mit dem AbriB des Hauses und endend mit dem tödlichen Unfall auf der Eisenbahnlinie - gebracht. Der Zusammenhang wird über die Figur Faddejs hergestellt, der 
die entscheidende Triebkraft in der zerstörung des Hauses ist:

Den Höhepunkt von Matrenas Schilderung der Vergangenheit bildete die Rückkehr Faddejs und dessen drohendes Erheben der Axt gegen seinen Bruder und Matrena. Diese Drohung wird durch verschiedene Verfahren als schicksalhafte Vorherbestlmmung des anschließend dargestellten Ereignisses gekennzeichnet. Die Szene wird vom Erzähler als "lebendige Vorstellung" ("ja Zivo predstavil") (SM 54) der fiktiven Realitätsebene angenahert:

"Ot ee nadryva ili stracha ja zivo predstavil, kak on stoit tam, Cernyj, $v$ temnych dverjach $i$ toporom zamachnulsja na Matrenu." (SM 54)

Durch die wiederholung dieser Szene am Ende des Kapitels wird ein Binnenrahmen geschaffen, der die gesamte in diesem Kapitel dargestellte Ereigniskette von den Bewegungsgesetzen des vorhergehenden und nachfolgenden Kapitels abtrennt. Hier wird zudem in einem Erzählerkommentar noch deutlicher die schicksalhafte Drohung der fiktiven Realitätsebene angenăhert:

"Sorok let prolezala ego ugroza v uglu, kak staryj tesak, a udarila-taki..." (SM 59) 1)

Das letzte Kapitel stellt die Totenfeier und die Beerdigung Matrenas sowie die Fortsetzung des Erbstreits unter den Fanilienangehörigen dar. Hier wird wieder - nun aber als Folgeerscheinung der schicksalhaften Bewegungsgesetze des zweiten Kapitels - die reale, gesellschaftliche Handlungsebens aus Kapitel 1 hergestellt. Die Totenklagen verfolgen eine bestimmte "Politik" (svoego roda politika) (SM 59); die Institutionen des Makrokosmos werden aktiv (Aufklärung der Unfallursache, Gerichtsverfahren) ${ }^{2)}$; die juristischen Umstände des Falls werden vom Erzähler ausfuhrlich dargestellt. Es herrscht nicht mehr die schicksalhafte Vorherbestimmung,

1) $\mathrm{Zu}$ weiteren Verfahren der Verknüpfung beider Ereignisse vgl. bes. die Markierung der Axt im Zusammenhang des Hausabrisses: "I Faddej s synov'jami i zjat"jami prisli kak-to fevral'skim utrom $i$ zastucali v pjat' toporov /.../." (SM 55) sowie die Bezeichnung der vom zug zermalmten Matrena als "erschlagen" (ubit) (SM 58).

2) Vgl. dagegen das Erscheinen der Funktionsträger in Kapitel 2. Die nach dem Unfall den Erzähler in Matrenas Haus aufsuchenden Untersuchungsbeamten erfullen hier lediglich eine Botenfunktion und realisieren ihren Auftrag (Informationsbeschaffung) ihrerseits nicht. 
sondern das "menschliche Gericht" (1judskij sud) (SM 61). Der Fortsetzung des Erbstreits werden von den Institutionen des Makrokosmos die Bedingungen diktiert:

"Faddej, ne prosazivajas', metalsja to na poselok, to na stanciju, ot nałal'stva k naral'stvu /.../." (SM 61)

'UZ delo upiralos' pisat' $v$ sud, no primirilis', rassudja, $t_{\text {to }}$ sud otdast izbu ne tem i ne drugim, a sel'sovetu." (SM 62)

VIII.2.3. Modellvariante: Handlungsfeld Makrokosmos Der autonome bauerliche Agent

(B. Možaev, "Iz zizni Fedora Kuz'kina")

Eine weitere Modellvariante behäl den gesellschaftlichen Makrokosmos als die zentrale Sphäre situativer Abläufe. Hier ist nach wie vor das Handlungsprinzip dominant, die Figuren als Subjektagenten sind die Triebkrafte progredienter Situationsverăderung. Das innovatorische Moment gegenuber dem M. 2 besteht darin, daB die băuerlichen Figuren uber eigene Handlungspotenzen gegenüber den Funktionsträgern des gesellschaftlichen Makrokosmos verfugen und in der Regel in einen offenen Konflikt mit den letzteren geraten. Ein paradigmatischer Text ist "Iz Zizni Fedora Kuz'kina". Hier wird eine bäuerliche Figur mit einem Aktivitătsradius dargestellt, der dem der Funktionsträger zum Teil überlegen ist. Gleichzeitig labt sich in diesem - auf dem gegebenen normenevolutionären stand extrem innovatorischen - Text ${ }^{1}{ }^{\text {) }}$ deutlich die immer noch starke wirksamkeit der alten Normen erkennen.

Der Situationsablauf soll wieder in Form eines Schemas dargestellt werden, wobei die Horizontale in diesem Fall von den Agentenrelationen zwischen der bauerlichen Hauptfigur als Protagonisten und den Nebenfiguren gebildet wird. Die hier verwendeten Kategorien des Helfers bzw. des Schädigers sind als Handlungs-Typen im allgemeinsten sinne - und nicht im sinne einer Ruckfuhrung des Texts auf Märchenstrukturen - zu verstehen. Plus - und Minusmarkierungen bezeichnen Erfolg bzw. Nichterfolg der jeweiligen Agenten in den gegebenen Situationen.

1) Vgl. die scharfe Kritik an "Iz Kizni Fedora Kuz'kina" unter eben diesem Aspekt (s.IV.2.4.). 


\begin{tabular}{|c|c|c|c|}
\hline 1 & $\begin{array}{l}\text { Verlust Kolchos wegen Schikenen durch Rolchos- } \\
\text { leltung (AUTOiOn) }\end{array}$ & & $\begin{array}{l}\text { Gusenkov (Ebene: } \\
\text { Rolchos) }(+)\end{array}$ \\
\hline 2 & 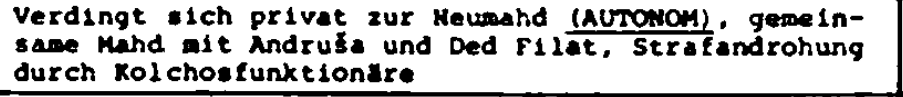 & Bavern $(+)$ & $\begin{array}{l}\text { Gusenkov (Ebene: } \\
\text { : Kolchos) }\end{array}$ \\
\hline 3 & H1rd au dein Kolchos augeschlosen & & Kolchosleitung $(+)$ \\
\hline 4 & 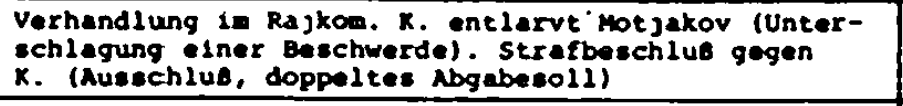 & $\begin{array}{l}\text { Deain (Ebene: } \\
\text { Rajkon) (-) }\end{array}$ & $\begin{array}{l}\text { Motjakov (Ebene: } \\
\text { Rajkon) }(+)\end{array}$ \\
\hline s & $\begin{array}{l}\text { Pfandungekcoulseion bel } K \text {., die leiterin entdeckt } \\
\text { verdecktes Geld, verschweigt den fund }\end{array}$ & $\begin{array}{l}\text { Kombsolonsleite- } \\
\text { rin Nastje }\end{array}$ & $\begin{array}{l}\text { Romisision (Ebene: } \\
\text { Rajon) }\end{array}$ \\
\hline 6 & $\begin{array}{l}\text { Besorgt sich Arbeitsbescheinigung unter Angabe } \\
\text { falecher Grunde (IIST/Auroman) }\end{array}$ & & $\begin{array}{l}\text { Kolchosbuchnalter } \\
(-1)\end{array}$ \\
\hline 7 & $\begin{array}{l}\text { Schickt beschelinigung und Beschwerde an Obkom unter } \\
\text { Ungehung des ortlichen Postnetzes (LISI/AUnowill) }\end{array}$ & & $\begin{array}{l}\text { Postzensur (Ebene: } \\
\text { Rajon) (-) }\end{array}$ \\
\hline 8 & 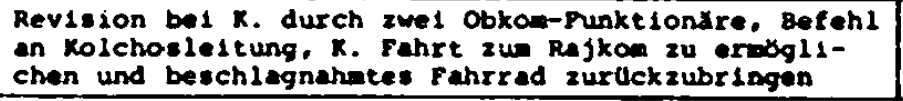 & $\begin{array}{l}\text { Obkonfunktiondre } \\
(+)\end{array}$ & $\begin{array}{l}\text { Rolchoslestung } \\
(-)\end{array}$ \\
\hline 9 & $\begin{array}{l}\text { Fuhre zum Rajkon, durchschaut dort elnen bestechung:- } \\
\text { versuch der Laiterin der Sozialabteilung }\end{array}$ & & $\begin{array}{l}\text { Sozlalabte } 1 \text { lung } \\
\text { (Ebene: Rajkom) }(-)\end{array}$ \\
\hline 10 & $\begin{array}{l}\text { Rajkor-S1tzung. Obkomfunktionlr veist Beschuldigun- } \\
\text { gen Hotjakovs und Gusenkovs gegen } K \text {. zurdck. Vor- } \\
\text { stzender der Hachbarkolchose bietet } X \text {. Arbelt an }\end{array}$ & $\begin{array}{l}\text { Obkonfunkt tonkr }(+) \\
\text { und P. Svonarev } \\
\text { (Hachberkolch.) }(+)\end{array}$ & $\begin{array}{l}\text { Gusenkov (Kolchos) } \\
\text { u. Motjakov (Raj- } \\
\text { kom) }(-)\end{array}$ \\
\hline 11 & $\begin{array}{l}\text { Arbeltet als Holzwirter (a zwelte Arbeitsbeschaffung } \\
\text { durch P. Svonarev) }\end{array}$ & $\begin{array}{l}\text { P.svonarev (t) } \\
\text { (wlederholung) }\end{array}$ & \\
\hline 12 & $\begin{array}{l}\text { Benotlgt zur Rettung von Holizfloben inen Traktor: } \\
\text { zwingt den Brigadier, Gusenkov anzurufen (Avmoin) }\end{array}$ & & $\begin{array}{l}\text { Br lgadier Voronin } \\
\text { (Kolchoo) (-) }\end{array}$ \\
\hline 13 & $\begin{array}{l}\text { Heigerung Gusenkovs. } X \text {. wendet ich an Bauern(AUT.). } \\
\text { Traktorlst besorgt den Trecker, Rettung d. Fibse }\end{array}$ & Bauern (+) & $\begin{array}{l}\text { Gusenkov (Kolchos) } \\
(-)\end{array}$ \\
\hline 14 & 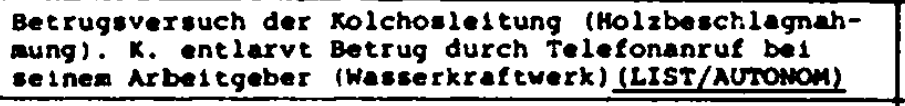 & $\begin{array}{l}\text { Leltung d. Wasear- } \\
\text { kraftwerks }\end{array}$ & $\prod_{(-)}^{T l o b k i n}$ (Kolchos) \\
\hline 15 & 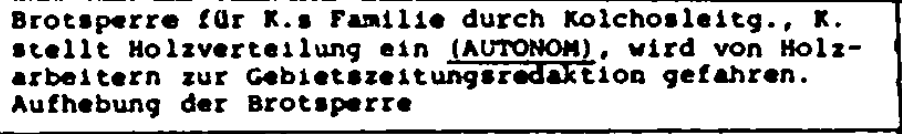 & $\begin{array}{l}\text { Holzarbeltex }(+) \\
\text { Obkoa }(+)\end{array}$ & $\begin{array}{l}\text { Kolchosleitung } \\
\text { und Rajkom }(-)\end{array}$ \\
\hline 16 & 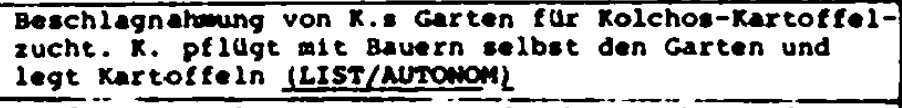 & Bavern $(+)$ & kolchosieitung $(-)$ \\
\hline 17 & $\begin{array}{l}\text { Verfahrenseinleitg. gegen } x \text {. durch Gusenkov und } \\
\text { wot jekov, verhor und inkiegeernebg. durch Jux leten }\end{array}$ & & $\begin{array}{l}\text { Rolchosle leg.é } \\
\text { najkon, Rlehier }(+)\end{array}$ \\
\hline 18 & 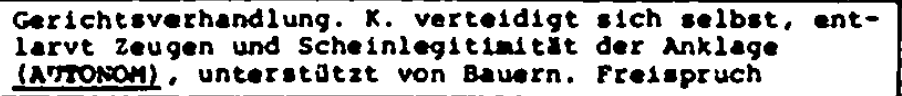 & $\begin{array}{l}\text { Bauern } \\
\text { Richeer }\end{array}$ & $\begin{array}{l}\text { Rolchosleitung. } \\
\text { Rajkom }(-)\end{array}$ \\
\hline 19 & $\begin{array}{l}\text { Bekcie neue Arbeit (auf Anlegekahn) vom } \\
\text { wasserkreftwerk }\end{array}$ & $\begin{array}{l}\text { Leteung des } \\
\text { wasserkraftwerks }\end{array}$ & \\
\hline 20 & 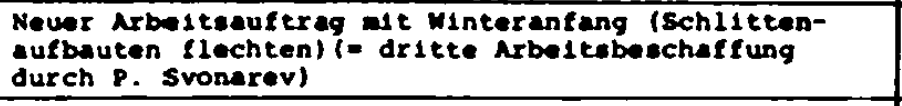 & $\begin{array}{l}\text { P.Svonarev (Nach- } \\
\text { barkolchos) } \\
\text { (Wiederholung) }\end{array}$ & \\
\hline 21 & $\begin{array}{l}\text { Labensgefahrilcher Unfall bel Holzsataln in Schree. } \\
\text { x. rettet sich selbst. }\end{array}$ & & \\
\hline 22 & Auflosung der Rajonverwaltung & $\begin{array}{l}\text { Demin }(+) \text { (Befor }- \\
\text { dert ins Obkon) }\end{array}$ & $\begin{array}{l}\text { Hot jakov }(-) \text { (ar- } \\
\text { beltglos) } \\
\text { Iimoskin }(-) \text { (Arbeit } \\
\text { als verk lufer) }\end{array}$ \\
\hline 23 & $\begin{array}{l}\text { Begegnung } \mathrm{R} \text {.. Oberst Agalin und Hotjakov. } \mathrm{K} \text {. } \\
\text { verspottet Notjakov }\end{array}$ & & Motjakov (-) \\
\hline 24 & $\begin{array}{l}\text { Auflósung von } \mathrm{R} \text {. Anlegestelie. Schikanen gegen } \mathrm{K} \text {. } \\
\text { (Mot jakov neuer Personalchef in Wasserkraftwerk). } \\
\text { Horalische Untersedtzung } K \text {. durch Holzerbelter }\end{array}$ & Holzarbelter & Motjakov $(+)$ \\
\hline 25 & $\begin{array}{l}\text { Beschliest, in Svonareve kolchos einzutreten (nach } \\
\text { septerberpienum) (Autrowon) }\end{array}$ & $\begin{array}{l}\text { Svonarev (Rolchos) } \\
\text { 2entralkom. (+) }\end{array}$ & Motjakov (-) \\
\hline
\end{tabular}


Erläuternder Kommentar

1) Die Traditionsbezüge zum M.2 betreffen v.a. die Funktion der positiven, die integrative Wirkung des Makrokosmos vertretenden und schlieblich durchsetzenden Funktionsträger: des Vorsitzenden der Nachbarkolchose, der am Ende $z$ um entscheidenden Reintegrationsfaktor für Kuz'kin wird (Sit. 25, vgl, vorher seine dreifach wiederholte Arbeitsbeschaffung für kuz'kin, Sit.10,11,20), sowie der in der gesellschaftlichen Hierarchie oberhalb der desintegrativen Funktionsträger auf Kolchos- und Rajonebene situierten Obkomfunktionäre (bzw. Leitung des Wasserkraftwerks), welche eine ihrer gesellschaftlichen Position entsprechende führende Stellung in der Agentenhierarchie einnehmen. Sie sind die entscheidende Instanz für die Niederlage der Kolchos- und Rajkomfunktionäre in Sit. 8,10,15. Der für das M.2 typische Konflikt $z$ wischen positivem und negativem Funktionsträger schlägt sich in den Relationen zwischen den Rajkomsekretären Demin ('Autorität der Argumente') und Motjakov ('Autorität der institutionellen Macht') nieder (Sit.4).

Gleichzeitig wird hier jedoch ein verfremdendes Verfahren angewandt. Ausgerechnet Demin, der Vertreter der 'Autorität der Argumente', wird unmittelbar vor der Beschlubfassung über die Bestrafung Kuz'kins zu einem Telefongespräch mit dem Obkom gerufen und ist damit praktisch als Helfer im entscheidenden Moment nicht anwesend (Sit.4).

Normenkontinuität besteht weiterhin in der Verknüpfung des positiven Endes (Reintegration) mit der landwirtschaftlichen Reformpolitik. Kuz'kins BeschluB, dem Kolchos Svonarevs beizutreten, folgt nach einem Gespräch mit den Holzarbeitern über die verbesserten Lebensbedingungen für die Bauern in der Folge des Septemberplenums (Sit.24,25).

2) Der integrative EinfluB der positiven Funktionsträger entfaltet sich jedoch unter veränderten Bedingungen. Er ist nicht mehr - wie im M.2 - Nebenresultat eines hermetisch innerhalb der Ebene der Funktionsträger ausgetragenen Handlungskonflikts ( $\mathrm{vgl}$. das Phänomen des transformierten Konflikts, VI.2.3.), sondern im Gegenteil Resultat eines autonomen Konflikts zwischen bäuerlichem Agenten und funktionstragenden Agenten (Funktion der 'Unterdrückung'). Die positiven Funktionsträger fungieren als Helfer-Agenten für den băuerlichen Protagonisten und werden erst von diesem in ihre Helferfunktionen eingesetzt. In Sit.4 überführt Kuz'kin zunächst eigenständig Motjakov seiner unterdrückerischen Praktiken und erweckt damit erst Demins MiBtrauen gegenuber Motjakov. Die wichtigste Funktion haben unter diesem Aspekt die Situationen 6 und 7 (Kuz'kins unter Uberlistung der ortlichen Institutionen an das obkom gesandter Beschwerdebrief): Sie initiieren erst die gesamte folgende situationenkette (bis sit.10), in welcher die Obkomfunktionäre ihre Helferfunktionen wahrnehmen. Weitere Beispiele sind die Gerichtsverhandlung (Sit.18), in der Kuz'kin sich selbst verteidigt und selbständig die Ungültigkeit der gegen ihn erhobenen Anklage nachweist, woraufhin der Richter ihn freispricht. In Sit. 14 zitiert Kuz'kin sich seinen Helfer förmlich herbei: Nachdem der Kolchosbeauftragte Timoskin versucht hat, den Leiter des Wasserkraftwerks durch einen 
firgierten Telefonanruf als Schädiger Kuz'kins einzusetzen (angebliche Aufforderung des Leiters an Kuz'kin, das Holz abzugeben), ruft Kuz'kin selbst bei dem hasserkraftwerk an, entlarvt damit den Betrug Timoskins und macht den Leiter zu seinem ielfer. 1)

3) Kuz'kin ist als subjektagent eine autonome handlungsinitiierende Instanz. Neben den genannten Situationen $(4,6,7,14,18)$ manifestiert sich dies in den situationen $1,2,12,13,15,16,25$. Die Situationen 1,2,25 (Austritt aus der Kolchose, innanme privater Arbeit, Eintritt in die Nachbarkolchose) sind autonome Entscheidungen Kuz'kins. In Sit. 12 und 14 ergreift Kuz' $k$ in aus eigenem Antrieb MaBnahmen hinsichtlich seines Arbeitsbereichs gegen die Schädiger, in Sit. 13 sucht er sich selber bäuerliche Helfer.

In verschiedenen Situationen erweist sich Kuz'kin darüberhinaus auch als handlungsentscheidende Instanz. Das Mittel hierfür ist die List: die List als Jberwindung eines stärkeren Gegners mit dessen eigenen Waffen. Dies ist in Sit.6,7,14,16 der Fall. Mit der List als Kampfmittel des Protagonisten gegen die unterdrückerischen Funktionsträger ist eine Relativierung des integrativen Potentials des Makrokosmos verbunden. Die Institutionen des Makrokosmos erweisen sich nicht aus eigenem Antrieb als integrativ, sondern müssen erst vom bäuerlichen Agenten 'umfunktioniert' werden, um dessen Interessen vertreten zu können. Da sie jedoch nicht als neutrales Instrument sowohi den Bauern als auch den Funktionsträgern gleichermaßen zur Verfügung stehen, sondern von den letzteren monopolisiert werden, ist die List das einzige Mittel, die institutionalisierte Macht zu hintergehen (Sit.7,16), sie zu täuschen (Sit.6) oder sie durch die Aufdeckung ihrer eigenen Mechanismen zu sciwächen (Sit.4,14).

Weitere Relativierungen der integrativen Funktion der makrokosmischen Institutionen liegen in Sit. 9 und 15 vor. In Sit. 15 wird v.a. die Funktion des öffentlichen Mediums als transfiqurale Handlungsinstanz relativiert: Nur auf den Druck höherer Ebenen hin wird von der Zeitungsredaktion intern (telefonisch) Motjakov die Aufhebung der Brotsperre empfohlen und nicht etwa - wie von Kuz'kin beabsichtigt eine offentliche Kritik geführt. In Sit.9 wird, indem $K$. einen Bestechungsversuch zurückweist, eine weitere Form des Durchschauens und Hintergehens der institutionellen Macht dargestellt.

4) Ein wesentliches innovatorisches Moment ist die Erweiterung der Helferreihe auf bäuerliche Figuren (bzw. Holzarbei-

1) Eine iusnahme bildet Sit.5. Die Leiterin der Pfändungsxommission vird ohne Kuz'kins initiierende sktivitäten $2:$ dessen HelEerin. Die Funktion dieser Situation ist i.- gesamestrukturellen Zusammenhang primär hinsichtlich des jater VIII.1.3. behandelten Stelleriverts der Funktionsträger in der konfigurationsstruktir zu verstehen. Sihnlich wie 1.7 "Vokrug da okolo" Jbertritt riter ein Funktionsträger die Gesetze seiner eigenen kelt. 
ter). Sie sind eine gegenüber den Helfern aus der Funktionsträgerreihe eigenständige und gleichwertige Helfergruppe.

Sie stellen die vom Standpunkt des Makrokosmos aus behauptete AuBenseiterposition Kuz'kins in Frage und manifestieren eine bäuerliche Interessenidentität unabhängig von der Frage der Kolchosmitgliedschaft. Bauern als Schädiger Kuz'kins kommen nicht vor.

Das erste Erscheinen bäuerlicher Figuren (Sit.2) ist mit materieller Hilfe für den gerade aus dem Kolchos ausgetretenen Kuz'kin verbunden. Ihr zweites Erscheinen in Sit.13 steht in Opposition zur Schädigerrolle der Funktionsträger: Der von Gusenkov verweigerte Traktor wird vom Traktoristen selbst geholt. Das gleiche gilt für Sit.15 (Unterstüzung Kuz'kins durch die Transportarbeiter nach der von Motjakov verhängten Brotsperre) und Sit. 16 (gemeinsames Pflugen des Gartens nach der Beschlagnahmung). Neben dieser unmittelbar praktischen Hilfe, in der sich die Uberlegenheit der gemeinsamen băuerlichen Handlung gegenüber den Schädigungsversuchen der negativen Funktionsträger erweist, besteht eine moralische Hilfe $($ Sit. 18, 24). 1)

\section{Zusammenfassend läBt sich das Verhältnis zwischen}

Normenkontinuität und Normenbruch folgendermaBen bestimen: Der bauerliche protagonist als autonom handlungsinitilerender, begrenzt auch handlungsentscheidender Agent stellt einen Normenbruch gegenüber M.2 dar. Die Grenzen dieses Normenbruchs liegen in der nach wie vor wirksamen Hierarchie der Agentenfunktionen. Entscheidende Instanzen fur die positive Lösung bleiben die positiven Funktionstrăger. Gleichzeitig wird jedoch das integrative Potential des Makrokosmos in seiner institutionalisierten Gesamtheit relativiert, während das bauerliche Handlungspotential aufgewertet wird.

1) Die Gemeinsamkeit der bäuerlichen Handlung wird unterstrichen durch die in Sit. 2 und 15 sichtbar werdende Gegenseitigkeit der Hilfsfunktionen. Kuz'kin hilft seinerseits dem alten Ded Filat, als er seine privaten Mahdaufträge mit diesem teilt, und den Holzarbeitern, als er diesen entgegen seinem BeschluB, die Holzverteilung rückgängig $z u$ machen, erlaubt, das aufgeladene Holz abzufahren. 
VIII.3. Raum/Zeit-Struktur

Die Raum/Zeit-Struktur besitzt neben der Konfigurationsstruktur die größte modellkonstitutive Relevanz. Der hohe textstrukturelle Stellenwert dieser Ebene bringt einen entsprechend hohen Komplexitätsgrad mit sich, besonders was die Verbindung $z u$ einem dichten Chronotopensystem sowie die Konfrontation zwischen den Raum/zeit-Systemen der verschiedenen Kosmen betrifft. Diese komplexen Beziehungen lassen sich nur in der Analyse von Einzeltexten in ihrem funktionalen zusammenwirken erfassen. Bevor dies geschieht, sollen in notwendig schematischer form einige der am häufigsten wiederkehrenden modelikonstitutiven Merkmale paradigmatisch aufgezählt werden.

1) In der räumlichen Dimension ist die Trennung zwischen dem Mikrokosmos 'Dorf' bzw. 'Bauernhaus' (izba) und dem Makrokosmos 'Land' bzw. 'Stadt' vorherrschendes Organisationsprinzip.

In deutlichem Normenbruch gegenuber der räumlichen Integration im M.2 wird in "Sel'skie Kiteli" (V. Suksin, 1962) die Unüberwindbarkeit der Grenzen zwischen den beiden Welten thematisiert. Die Dorfbewohner sind nicht in der Lage, einer Einladung nach Moskau $2 u$ folgen. Es ist gerade die im M.2 als Grenzüberwinder fungiorendo Technik, welche die Barrieren zwischen den beiden Welten und die Unbeweglichkeit der Bewohner des Mikrokosmos verstärkt. Ein bevorstehender Flug nach Moskau wird zum Thema der Auseinandersetzung zwischen den Dorfbewohnern; die mit einer gänzlich fremden Welt verbundenen Vorstellungen von diesem Ereignis sowie die damit verbundene Angst führen schlieblich zur Ablehnung der Einladung. Die Unbeweglichkeit der Figuren wird verstärkt durch die oppositive Aktivierung des Merkmals 'beweglich' - wiederum im Zusammenhang mit Technik/Flug - für die einladende Figur, den Sohn der alten Bäuerin Malan'ja, der als Pilot arbeitet. ${ }^{1)}$

1) Vgl. zur Unüberwindbarkeit der Grenzen zwischen Dorf und Stadt auch die Umwertung der raumintegrierenden Funktion der Technik bei Ivan Afrikanovics scheiternder Auto- und Zugfahrt nach Murmansk ("Privycnoe delo", s.VIII.2.1.) 
2) Das Dorf als eigenständiger, autonomer, vom ungebenden Makrokosmos abgegrenzter Raum ist v.a. in der Anfangsphase des Modells dominantes innovatorisches Prinzip.

Die Erinnerungen an das Dorf der Jugendzeit leitet der Erzahler in "Kaplja rosy" mit dem räumlichen Eintritt in diese Welt ein. Im Gespräch mit einem fiktiven Leser wird die Anreise von Moskau beschrieben, wobei die Erschliebung neuer räumlicher Dimensionen mit dem Ubergang von der 2ugfahrt zur Kutschfahrt einsetzt. Der zug als RaumerschlieBer des Makrokosmos ${ }^{1)}$ stठ̋bt an einer sehr abgelegenen Bahnstation auf seine Grenze, von hier aus fuhrt nur noch ein weg ins Dorf.

Der dorfliche Raum bildet den Vorstellungshorizont für die Erinnerungen des Erzählers. 2)

3) Von Anfang an bildet das Bauernhaus innerhalb des Gesamtkosmos 'Dorf' eine nochmalige räumliche Konzentrationsstufe. Es ist der spezifische Raum für das gesellschaftliche Integrationsfeld Familie. In der Regel ist es integrierter Bestandteil des dorflichen Raums. Dieser konstituiert sich aus der Gesamtheit der Häuser, welche allesamt dem Erzähler und den Figuren offenstehen. Erst in der Spätphase des Modelis läbt sich eine Konzentration auf die räumliche Dimension einzelner Häuser feststellen, etwa in "Plotnickie rasskazy" (V. Belov, 1968), "Poslednij srok" (V. Rasputin, 1970), "Za dolami, za lesami" (E. Nosov, 1966), "Uchan i Krjažik" (A. Leonov, 1968), "Derevjannye koni" (F. Abramov, 1970), was jedoch 2.T. bereits im Kontext der Auflosung des Modells zu verstehen ist (s.Kap.IX.).

Man kann - als grob zu verallgemeinernde Tendenz - von der Zdanov-Ara bis zum Ubergang zwischen sechziger und siebziger Jahren eine fortlaufende Reihe räumlicher

1) Der Erzähler über das Reisen mit dem zug: $n / \ldots /$ i cerez pjat' casov vy $v$ Moskve, a znacit, i gde ugodno - vplot' do Leningrada, Buénos-Ajresa i N'ju-Jorka." (SK 56)

2) Vgl. ebf. "Lipjagi" (S. Krutilin, 1965). - Der dorrfliche Raum als Vorstellungsbasis für die Jugenderinnerungen des Erzählers wird hier besonders deutlich im Kapitel "Ballada o kolodce" (KL 223-259), in dem die Brunnen als räumliche und gesellschaftliche Zentren des alten Dorfs den Erinnerungsstrom des Erzăhlers in Gang setzen. 
Konzentrationsstufen festmachen: vom erschlossenen Gesamtland uber die geographische Wirtschaftseinheit (Kolchos, Rajon) uber das Dorf zum Bauernhaus.

4) Eng verbunden mit dem Phänomen des abgelegenen und abgegrenzten Raums ist das phänomen der raumfremden Figuren. Als raumfremde figuren werden häufig Funktionsträger charakterisiert, deren gesellschaftlich desintegrative Funktion mit dem Eindringen in einen ihnen fremden Raum korrespondiert (vgl. etwa die Kollektivierungsbeamten in "Na Irtyse", den Finanzrevisor in "Den'gi dlja Marii", den "Unbekannten" (neznakomyj celovek) in "Privyčnoe delo")" . Ein unmittelbarer Zusammenhang zwischen der räumlichen und gesellschaftlichen Desintegrationsfunktion der fremden Figur ist in "Privylnoe delo" mit dem Erscheinen des Schwagers Mitja aus Murmansk gegeben. Die von ihm betriebene 'Entführung' Ivan Afrikanovits aus seinem Dorf ist gleichbedeutend mit der Destruktion dessen familiären Integrationsfeldes (s.VIII. 2.1.).

Es existiert auch die ungekehrte Variante: ehemals integrierte Figuren, die ihren dörflichen Raum verlassen und zu Fremden werden.

In "Pjatyj den' osennej vystavki" (E. Nosov, 1967) kommt es $z u$ einer überraschenden Begegnung zwischen der alten Bäuerin Anis ja Kvasova und elner ehemaligen Dorfbewohnerin, die aufgrund ihrer ungerechten Behandlung im Kolchos das Dorf verlassen hat. Diese Begegnung findet in einem fremden Raum statt ( in einem städtischen Restaurant - während einer Landwirtschaftsausstellung - , in dem sich auBerdem mehrere Funktionsträger befinden). Die ehemalige Dorfbewohnerin ist als Kellnerin dieses Restaurants deutlich dem fremden Raum zugeordnet. (NP 216ff)

Neben den raumfremden Figuren mit desintegrativer Funktion und den ehemals integrierten, nun extegrierten raumfremden

1) Eine fremde Figur, welche einen vertrauten Raum entfremdet, ist der Untersuchungsrichter in "Na Irtyse":

"A vot pogljadel Stepan sejcas na steny kontorskie, na okna, na stol pogljadel i udivilsja: budto $v$ pervyj raz vidit vse eto, vse zdes' emu neznakomoe. Potomu tak pokazalos', cto $v$ kontore sidit odin tol'ko telovek, i Eelovek étót - sover senno cuzoj, nezdesnij." (2N 38) 
Figuren existieren raumfremde Figuren, die vom dörflichen

- Raum und seiner integrativen Kraft angezogen werden. Bei ihnen handelt es sich in der Regel um die figuralen IchErzăhler, die als Gäste den dörflichen Raum besuchen. Wir werden auf dieses Phänomen im Abschnitt "Standpunktkomposition" zurückkommen. Doch auch nichterzăhlende Figuren können diese Rolle übernehmen. AufschluBreich für den vollzogenen wandel seit Mitte der fünfiger Jahre ist hier ein Vergleich zwischen "Poezdka na rodinu" ") und "Zapach chleba" (Ju. Kazakov, 1961). In beiden Texten wird die kurzfristige Reise einer städtischen Figur ins heimatdorf zur Beerdigung der Mutter dargestellt. Während in "Poezdka na rodinu" das Dorf jedoch noch keine integrative Kraft gegenüber dem Fremden entwickelte, sondern im Gegenteil von diesem als fremde und beinahe feindliche Welt empfunden wurde, entfaltet es in "Zapach chleba" eine starke Anzlehungskraft, die sich symbolisch verdichtet, als die von Erinnerungen und Reuegefuhlen überwältigte städterin sich am Grab der Mutter in der Erde wälzt und förmlich mit dieser eins wird ("Lico ee bylo Cerno ot zemli /../") (KC 78).

5) Das zentrale innovatorische Moment in der zeitstruktur ist die Existenz einer von der progredient und in Sprüngen verlaufenden historischen zeit unabhängigen zyklischen Naturzeit, deren wichtigste Bewegungseigenschaften die Iterativităt und die Kontinuităt sind. Mit diesen Eigenschaften korrespondiert eine starke Vergangenheitsorientierung. Die Gegenwart ist ursprünglich das Fortwirken, die kontinuine Existenz der Vergangenheit. Entsprechend den beiden Grundtendenzen kann dieses Vergangenheit-Gegenwart-Kontinuum als bereits weitgehend zerstort durch die historische Progredienz oder als von dieser weitgehend unberuhrt dargestellt werden. In der Regel ist die dafgestellte Gegenwart von der Konkurrenz der beiden zeitsysteme geprăgt.

Die modellspezifischen Räume - Dorf, Bauernhaus, Natur (Wald) - stehen in chronotopischer Beziehung zum ursprünglichen zeitsystem. Die chronotopische Eigenschaft des Bauern-

1) S.Anm. 1 auf S.161. 
hauses findet in "Plotnickie rasskazy" eine exponierte Kennzeichnung. Uber das Haus, welches "länger als hundert Jahre auf der Erde steht", heibt es:

"Vse zdes" sroslos' i skipelos' $v$ odno celoe, luţe ne trogat' etich srodnivsichsja breven, ne ispytyvat' ich ispytannuju vremenem vernost' drug drugu." (SR 9, Hvh. G.W.)

Auch diese chronotōpische Eigenschaft dēr Räume kann den Grundtendenzen entsprechend in unterschiedlichem Grad durch das konkurrierende Raum/zeit-System des Makrokosmos bedroht oder zerstort sein. ${ }^{1)}$

6) Die Auswirkungen der zeitstruktur auf die Konfigurationsstruktur zeigen sich v.a. im mit hohem Verbindlichkeitsgrad in den Texten wiederkehrenden Phänomen der alten Figuren. Diese Figuren verkörpern das Fortleben loder den drohenden Tod) der Vergangenheit, sie fungieren - im familiären Kontext - als Vermittlèr der Vergangenheit an die späteren Generationen.

Die Familie als generationenerzeugende und generationenverbindende Instanz ist neben ihrer gesellschaftlichen Integrationsfunktion damit zugleich die zentrale Instanz für die Integration der Figuren in den naturzeitlichen zyklus von Leben, Tod und neuem Leben. Das Generationenband reicht von den Großeltern bis zu den Enkelkindern, gerade diese beiden Extrempole werden haufig miteinander in Verbindung gebracht (vgl. die Erzählungen der GroBmutter Evstol'ja an ihre Enkel in "Privycnoe delo" und die Erzăhlungen der Großmutter Arsen'evna an ihre Enkelin in "Rodnye").

1) Der Extremfall einer von Fremdeinflüssen unberührten, ursprünglichen chronotopischen Eigenschaft des dörfilichen Raums als Substrat des Vergangenheit-Gegenwart-Kontinuums weist Ahnlichkeit mit dem Gattungschronotopen der Idylle auf. Vgl. Bachtin,aao, S.373ff. - Bachtin bezeichnet das verhaltnis zwischen Raum und zeit in der Idylle als von einer "organischen" Verbundenheit, "Verwachsenheit" des Lebens mit einem Ort bestimmt. Die zeitliche Einheit - besonders die Einheit der Generationen - werde wesentlich durch die Einheit des Orts garantiert. 
VIII.3.1. Modellvariante: Das überlegene Raum/Zeit-System des Mikrokosmos

(E. Nosov, "za dolami, za lesami")

In "Za dolami, za lesami" wird der Aufenthalt eines Schriftstellers oder Journalisten (ICh-Erzahler) in einem weit abgelegenen Walddorf dargestellt. Die Vorgeschichte bildet das Treffen des Erzählers mit dem Erben eines alten Bauernhauses, der ihm dieses für seinen Dorfaufenthalt zur Verfügung gestellt hat. Während seines Aufenthalts lernt der Erzahler die wenigen im Dorf lebenden Figuren kennen: den Kolchosbrigadier Lutkov und seine Familie - besonders die Kinder Veruska und Mit'ka, sowie einige alte Figuren den Ded Michajla, die Greisinnen Evdokija und Mar'ja. Der Erzähler freundet sich mit den Kindern an. Hier kommt es gegen Ende - vor dem Hintergrund des ereignisschwachen Geschehensablaufs wăhrend des Dorfaufenthalts - zu einer Miniaturhandlung, als der Erzahler Veruska verspricht, eine Puppe zu kaufen. Die gemeinsame Wanderung zu einem Geschäft im Nachbardorf bleibt erfolglos - es gibt keine Puppen. Das Ende des Texts bildet die Abreise des Erzählers.

Raumöffnung von 'klein' nach 'grob'

Die räumliche Dimension der dargestellten Welt bildet eine vielfach gestaffelte struktur von 'klein' bis 'grob' ('eng' bis 'weit', 'innen' bis 'auBen'). Die einzelnen Stufen sind durch Grenzen voneinander geschieden. Diese Grenzen offnen sich in einem kontinuierlichen ProzeB in der Richtung von 'klein' nach 'grob'.

1) Der Text beginnt mit einer Beschreibung des Inneren des Bauernhauses unter Markierung der Grenze zur AuBenwelt (Tür).

2) Dann folgt eine vom Hausinnern aus vorgenommene Beschreibung der AuBenwelt. Das Fenster wird wiederholt als Grenze markiert. Es stellt einen ersten - visuellen - Offnungsgrad dar:

"Svet ètot vsju noc brezill v oknach." (N2 71)

"Da i vse iz moego okna videlos' mne zdes' skazocnym /.../" (NZ 73)

"Ja gljadel iz okołka svoej izby, slusal Zuravlej/.../." (N2 74 )

3) Die nächste Stufe der Grenzoffnung ist der visuelle und kommunikative interfigurale Kontakt (durch das Fenster): "Iz okna $v$ okno לerez dorogu bylo viano mne, kak Semen Lutkov pil Eaj." (N2 75)

Es folgt die Darstellung der ersten Dialoge (mit Lutkov, der alten Bäuerin Mar'ja und den Kindern Veruska und Mit'ka) (N2 75f). 
4) Die nächste Stufe ist der Grenzübertritt der dörflichen Figuren in das haus des Erzählers, zunächst der Greisin Evdokija (Grenzmarkierung: erste Dialogreplik erfolgt "von der Schwelle aus") (N2 78), dann der kinder Veruska und Mit'ka (Grenzmarkierung: "Ona vošla neslysno - tol'ko kaðnulas' zanaveska na okne - i ostanovilas u poroga /.../ Smusteno perestupaja na poroge $/ \ldots /$ ". ) (N2 80).

5) Auf der nächsten Stufe tritt der Erzähler aus seinem ursprünglichen Raum hinaus. Er besucht die Kinder im haus Lutkovs (Grenzmarkierung: "Uvidev menja na poroge" $/ \ldots /$ ") (N2 83).

6) Der Erzähler und Veruska verlassen das Dorf (Wanderung zum Nachbardorf, Grenzubertritt: "Vybezali za okolicu, prosli gorbatym mostikom /.../") (N2 86).

Eine neue Raumdimension offnet sich mit dem Blick von einer Hügelspitze auf die Umgebung:

"Vzosli na gorusku, ogljanulis'. Temnye lesa razbezalis" vo vse storony. Na bugre mezdu dvuch ozerkov - Veruski-sorozki dereven'ka." (N2 86)

\section{Zeitkontinuum}

Die zeitliche Bewegung hat den Charakter der Iterativität, wiederholt markiert durch entsprechende zeitdeiktika ("opjat")(NZ 71), ("každoe utro") (NZ 75), ("kak obyčno") (N2 82). Im Generationenband manifestiert sich das Vergangenheit-Gegenwart-Kontinuum. Im Kind ist die Frau und Mutter anwesend"), im kindlichen Spiel die Arbeit der Erwachsenen ${ }^{2)}$, und umgekehrt in der Greisin die Jugend ${ }^{3}$ ).

\section{Chronotopensystem}

Die dargestellten räumlichen und zeitlichen Dimensionen verbinden sich in einem Chronotopensystem, das eine raumzeitliche Einheitlichkeit der dorffichen Welt bis in den makrokosmischen Bereich hinein organisiert.

Der zentrale Chronotop auf mikrokosmischer Ebene ist das Bauernhaus. Es wird mehrfach als Verkörperung des Genera-

1) Der Erzähler über Verułka: "Izdali ona ełte bol'se pochodila na malen'kuju Zenstinu." (N2 90) Vgl. ebf. das mutterliche Verhalten Veruskas gegenüber ihrem Bruder sowie die Ubernahme der Rolle der Gastgeberin und Hausfrau von ihrer Mutter (Anrede des Gasts mit "vy", Nachahmung der Mutter: "/.../ Cem bogaty, tem rady, pribavila ona, podrażaja Parasevke." (NZ 83)

2) Mit'ra spielt den Beruf seines Onkels (Chauffeur), Veruska spielt das Bündeln von Flachs mit Gräsern (82)

3) "Glaza u nee na udivlenie molodye /../." (N2 78, uber die Greisin Evdokija) 
tionenbandes, als Lebensspur der ausgestorbenen Generationen gekennzeichnet:

- durch die lebendige Vorstellung des Erzählers vom Erbauer der Hijtte: "I opjat' ja s nevol'nym uvazeniem zadumyvalsja - Keloveke, srubivłem iz mogutich stvolov étu vysokuju zvonkuju izbu /.../." (Nz 71)

- durch die Beschreibung des Hauses als Erbe einer vergangenen Generation; der Erzăhler bekomut das Haus vom Erben in der Stadt vermittelt: "Molodogo naslednika étoj lesnoj chorominy, otpryska tret'ego, ne to detvertogo kolena, ja sluðajno povstreðal v Zeleznogorske /.../." (NZ 72)

- durch die von der Greisin Evdokija bei ihrem Besuch in dem Haus wachgerufenen Erinnerungen: " - A byvalo, begala v ètu vot izbu-to..." (N2 78)

- durch die noch vorhandene Aufhăngevorrichtung für eine Kinderwiege (NZ 71).

Innerhalb des Hauses bildet das Bett ein nochmaliges chronotopisches Konzentrat. Es wird mit einer Arche verglichen ("krovat"-kov'eg") (NZ 71), womit eine zeitliche Dimension menschheitsgeschichtlicher Uranfänge mit dem Merkmal räumlicher Beweglichkeit und Integration in den ungebenden Raum von Seen verknüpft wird. ${ }^{1)}$

Die am hăufigsten markierte Eigenschaft dieser Chronotopen ist ihre hölzerne Materialbeschaffenheit. Die chronotopische Eigenschaft des Holzes wird deutlich im Kommentar des Erzählers uber das "Reich des Holzes" (carstvo dereva) (N2 71), in welches er geraten sei. "Carstvo" enthält sowohl ein zeitliches Integrationsmerkmal (Vergangenheit-GegenwartKontinuum) als auch ein räumliches Integrationsmerkmal (Reich als räumlicher Makrokosmos).

Das Holz ist zugleich das Aquivalenzmerkmal zum zweiten zentralen Chronotopen neben dem Bauernhaus: dem wald.

Der wald als Raum integriert sowohl das Haus - vgl. die Benennung des Erbauers als "lesnoj Zitel'" (NZ 71) und die Vorstellung von der Bärenjagd des Erbauers im Wald (N2 71) als auch die einzelnen Dörfer (vgl. den Panoramablick vom Hügel, s.o.) ${ }^{2 l}$.

1) Vgl. ebf. den Vergleich des Betts mit "Kon-Tiki" (NZ 71) und den Vergleich der Kinderwiege in Lutkovs Haus mit einer "Meeresbarkasse" (morskoj barkas) (N2 83).

2) Vgl. ebf.: "I lesa, lesa ... Lesa, v kakuju storonu ni gljan': $/ \ldots /^{n}$ (NZ 74) 
Der wald ist ebenfalls eine Verkörperung des Vergangenheit-Gegenwart-Kontinuums (vgl. U.a. die Äquivalenz zwischen pilzeessendem Hauserbauer/Vergangenheit und pilzesammelnder Mar'ja/Gegenwart) (NZ 71,76).

Das solchermaBen organisierte chronotopische system findet im Leitmotiv der Kraniche seinen Höhepunkt. Die Kraniche stelien die höchste Stufe der räumlichen Integration dar, sie vermitteln die Vorstellung von der Weite des räumlichen Kosmos aus wäldern, sümpfen und seen, mit dem sie eng verbunden sind:

"Gde-to na bolotach kricali Zuravli." (N2 73)

"/.../ golos ich, protjaznyj i pecal'nyj, kazalos', zapolnjal soboj vse nebo $i$ vsju zemlju, pronikal $v$ samye gluchie lesnye tasci i $v$ samye bezdonnye glubiny ozer." (Nz 90)

Die Ausdehnung des Naturraums bekommt hier nach oben und unten grenzenlose Dimensionen ("Vse nebo", "bezdonnye glubiny").

Zugleich fungieren die Kraniche als Verkörperung des iterativen zeitflusses. Die Greisin Evdokija komentiert die Tatsache, daB sie die Kranichschreie nicht mehr hört, neben ihrer Taubheit mit der Gewöhnung:

"A to, možet, i obvyklasja. Vsju-to Zist' krikat dak..." (N2 8O) 1)

Das gesamte so organisierte Raum/Zeit-system bekomnt einen besonderen Charakter durch seine Verbindung mit dem Gattungschronotopen des Märchens. Die Markierung dieses Chronotopen erfolgt

- durch die in die räumlich und zeitlich abgelegene Welt des Märchens einfürende Anfangsformel: "V nekotorom carstve, $\checkmark$ nekotorom gosudarstve, za dolami, za lesami..." (N2 78, vgl. $: \because 275$ und Titell

- durch entsprechende Erzăhlerkommentare ("vse videlos' mne zdes' skazocnym") (N2 73)

- durch einen ausgefuhrten Vergleich zwischen den Tieren und Menschen des Dorfs mit Märchengestalten ("sestrica Alenuska") sestra Veruska": "bratec Ivanusek"/"bratec Mit'ka";

"ded da baba"/"ded Michajla" und "babka Evdokija"; "kurockarjaba" im Märchen und im Dorf) (N2 74).

1) Vgl. ebf. die zeitliche Merkmalaktivierung (VergangenheitGegen'wart-Kontinuum): "/../ i po-preznemu pecal'no vyklikali kogo-to za lesom zuravli." (NZ 77) 
Die spezifisch chronotopische Beziehung der dargestellten Welt zur Welt des Mărchens wird expliziert:

"A zdes' (räuml.) prodolzalo (zeitl.) Zit'." (N2 74)

Die mit dieser raumgebundenen zeitkontinuităt verbundene Ursprïnglichkeit bildet das Aquivalenzmerkmal der Chronotopensysteme der dargestellten Welt und des Marchens. Sowohl das Märchen als auch das Dorf sind mit Kindheitserinnerungen und kulturgeschichtlichen Uranfängen verbunden. ")

\section{Raum/Zeit-System der fremden Welt}

In strenger Abgrenzung von diesem System befindet sich das Raum/Zeit-system des Makrokosmos. Besonders der fabelstrukturelle Rahmen - Anfang: Treffen des Erzählers mit dem Erben des Bauernhauses in der stadt und Ankunft des Erzählers im Dorf, Ende: Abreise aus dem Dorf markiert die räumliche Abgrenzung der beiden Welten, zwischen denen sich der Erzähler bewegt. 2)

Die Welt, aus der er kommt, wird in Treffen mit dem Erben als stadtisch, industrialisiert, verkehrstechnisch erschlossen dargestellt. Das Treffen findet in "Zeleznogorsk" im Zentrum des Kursker Industriegeblets statt, der Erbe ist Chauffeur eines "gepanzerten" (bronirovannyj) LKW. (NZ 72), die straben sind "betoniert" (po betonnomu serpantinu) (NZ 72). Die Materialbeschaffenheit dieser Welt (Eisen, Beton) steht in Opposition zur Materialbeschaffenheit der Dorfwelt (Holz).3)

1) Vgl. bes.: "Ja gljadel 12 okoska svoej izby, slusal Zuravlej $i$ dumal, tto, konecno $z e$, ne $v$ stepnoj solomennoj Rusi rozdalis' skazki moego detstva /.../ Vse èto $u$ menja na rodine ostalos' tol'ko $v$ pamjati ljudej da v knizkach. A zdes' prodolzalo Zit'." (Nz 74)

2) Fabel- und Sujetanfang sind nicht identisch: Der Text beginnt mit dem Aufwachen des Erzählers im răumlichen Konzentrationspunkt des Mikrokosmos (dem Bett im Bauernhaus), erst danach folgt als Rückblende die Erinnerung an das Treffen und die Ankunft im Dorf. Die raum/zeitliche Perspektive ist somit von Anfang an die des Mikrokosmos, die 'eigene' Welt wird aus der neuen Welt heraus, in die der Erzähler "geraten ist" ("v kotoroe popal") (NZ 71), erinnernd wahrgenommen.

3) Vgl. die Markierung der Opposition in einem Satz: "Molodogo naslednika ètoj lesnoj chorominy /.../ ja slutajno povstrecal v Zeleznogorske $/ . . . / . "$ (NZ 72, Hvh.G.W.) 
Die raum/zeitliche Opposition zwischen beiden Welten komnt deutlich zum Ausdruck im Wechsel der Fortbewegungsarten wăhrend der Anreise, - einer graduellen Abstufung von 'schnell' zu 'langsam', 'technisiert' zu 'natürlich': 1) Flugzeug 2) zug 3) Autobus 4) Milchfuhrwerk 5) zu FuB (N2 73).

Der Eintritt in das Haus wird ausfuhrlich als Grenzubertritt dargestellt:

"Kljucej ot doma on, razumeetsja, mne ne vruxal. Priechal, otodral ot sennych dverej naiskos' prikolotennuju plachu, robko podnjalsja po rassochకejsja lestnice, vosel $v i z b u$, vzdochnuvšju navstrecu styloj ped'ju, tolknul stvorki stavnej i prisel na pustuju krovat'." (N2 73).

Auch die Abreise ist mit einem Grenzubertritt verbunden. Die anfangs geöffnete Grenze wird wieder geschlossen: "Ja vysel iz izby, nasel staruju plachu i prinjalsja 2akolacivat' sennuju dver'." (N2 88)

Aufeinandertreffen beider Raum/Zeit-Systeme. Uberlegenheit des Mikrokosmos

Im fabelstrukturellen Zentrum (Anwesenheit des Erzăhlers im Dorf) treffen beide Raum/Zeit-Systeme aufeinander.

Das mikrokosmische system erweist sich dabei als uberlegen. Die Bedrohung durch das fremde Raum/Zeit-System ist gering, einerseits erweisen sich die räumlichen Grenzen des Mikrokosmos als stark genug, storrende Faktoren zu extegrieren, andererseits werden figurale oder dingliche Repräsentanten des Makrokosmos innerhalb des Mikrokosmos in dessen Raum/ Zeit-System integriert.

1) Eine relativ scharfe Konfrontation ist mit dem Erscheinen eines Flugzeugs während des Besuchs des Erzählers bei den Kindern verbunden. Das Flugzeug als der wichtigste räumliche Integrationsfaktor des Makrokosmos (Bewegung des Fliegens) gewinnt hier unmittelbar chronotopische Funktion. Das Geräusch des Flugzeugs ist signal für Veruska, die Uhr zu stellen. Ein neues - numerisches - Zeitsystem wird aktiviert: 
"Akkurat $v$ dvenadcat" nad nami proletaet." (N2 85)

Dieses Zeitsystem wird unter wiederum deutlich răumlicher Grenzmarkierung als extegriertes, fremdes gekennzeichnet:

"Ja vzgljanul na svoi tasy i toze popravil: podvel na dve minuty - po vysokomu zaoblaḱnomu gulu." (NZ 85, Hvh.G.W.) 1)

Das Flugzeug als exponierter Trăger des makrokosmischen Raum/zeit-Systems steht somit in Opposition zu den Kranichen als exponierten Trägern des mikrokosmischen Raum/ZeitSystems :

\section{KRAN ICHE}

(Bewegung des Fliegens

als extreme Raumintegration des Mikrokosmos)

\section{FLUGZEUG}

(Bewegung des Fliegens als extreme Raunintegration des Makrokosmos) răumlich-körperliche

Integration in Mikrokosmos

(Stime in waldern und

Seen, s.o.)

iterative zeit (Naturzeit)

hăufiges Erscheinen

natürliche Bewegung

"Stimme" (golos) räumliche Extegration aus Makrokosmos (zaoblačnyj: nad nami)

numerische zeit (historische zeit)

einmaliges Erscheinen

technische Bewegung

"dumpfes Getöse" (gul)

Eine uberlegene Position der Kraniche besteht sowohl hinsichtlich ihrer textquantitativen Dominanz als auch hinsichtlich der semantischen Merkmale und ihrer Konnotationsfelder (Stimme = 'naturlich', 'lebendig', Getose = '(-) natürlich', '(-) lebendig').

2) Al's räumlich fremde Welt gekennzeichnet ist der Kolchos. Auch diese Welt ist extegriert, sie liegt "irgendwo" abseits vom "Hier" des Mikrokosmos:

"Kolchoz vse uchodil 1 uchodil kuda-to ot zdełnych ljudej /.../." (N2 75, Hvh.G.W.)

Die chronotopische Opposition zwischen beiden Welten wird

1) Vgl. ebf.: "nad nami proletaet" (s.o.). Für den Träger dieses zeitsystems innerhalb des Hauses - die Uhr - wird wiederum eine Abgrenzung vom ungebenden Raum markiert: "/.../ i podbezala $k$ chodikam, vstavlennym v special'nyj skafxik - s dverej i zasteklennym okoncem." (NZ 87) 
in der Figur des Brigadiers Lutkov deutlich, der als einziges Kolchosmitglied im Dorf geblieben ist und damit im Gegensatz zum Kolchos das an den Dorfraum gebundene VergangenheitGegenwart-Kontinuum und die räumliche Integration aufrechterhält:

"Odin Semen, starodavnij bessmennyj brigadir (figurale Verkörperung des zeitkontinuums), prodolzal zit iz uprjamstva na preznej nasizennoj koßke (raumgebundenes zeitkontinuum). A mozet byt', i ne iz odnogo tol'ko uprjanstva, a iz tichoj, besslovesnoj ljubvi $k$ zdeśnoj zemle (räumliche integration) /.../." (NZ 76)

Lutkov wird also nicht als Funktionsträger des Makrokosmos desintegrativ wirksam, sondern ist in das Raum/Zeit-System des Mikrokosmos integriert. ${ }^{1)}$

3) Ein weiteres Aufeinandertreffen vollzieht sich zwischen Dorfraum und fremdem Raum als Kulturräumen. Die Greisin Evdokija meint in der Reproduktion eines Madonnenbildes von Leonardo da Vinci eine Ikone zu besitzen. Dieses Aufeinandertreffen bildet keine chronotopische opposition. Das fremde Bild wird vielmehr ebenso wie die russische Greisin zur Verkörperung des Generationenbandes im Mutterprinzip:

"I mne stal ponjaten gorestnyj vzgljad baby Evdokii, stoskovavsejsja po budniCnoj domasnej zabote o drugom Xeloveke. Velikaja potrebnost' materi, ne ostavljajustaja ee do poslednego dychanija, to samoe svjastennoe Kuvstvo, kotoroe $i$ izobrazil da vinci v svoej litte." (NZ 79)

4) Ein letztes - parabelhaftes - Aufeinandertreffen beider welten vollzieht sich in der Miniaturhandlung, dem Versuch des Erzählers, eine Puppe für Verułka zu kaufen.

Die chronotopische opposition wird durch die Gegenuberstellung der versprochenen Puppe mit einer von Ded Michajla geschenkten Puppe ("kukla Kat'ka") markiert:

1) Vgl. auch die Aktivierung des Märchenchronotopen in der Beschreibung von Lutkovs Arbeitsbereich: "Udel'noe knjazestvo ego sostojalo iz sesti - vos'mi sil'no poredevłich posadov, sprjatannych drug ot druga za dolami, 2 a lesami /...". (N2 75) 
KUKLA KAT'KA

naturlich

(Material: Holz, Wald)

("derevjannyj Eelovek")

(N) 84 )

("vyrezannyj iz kuska

ol'chi") (NZ 84)

("staricok-lesoviCok")

(N2 84)

(-) fremd

(von Ded Michajla selbst geschnitzt)
VERSPROCHENE PUPPE

künstlich

(künstliches Material)

("s kositkami i plat'ice")

(NZ 85)

Die durch die beiden Puppen reprăsentierte chronotopische Opposition zwischen den Welten wird beim Verlassen des Dorfs durch den Erzăhler und Veruska intensiviert. Sie treffen Ded Michajla, den Schöpfer der Holzpuppe, der mithilfe verschiedener Verfahren als Grenzwächter dargestellt wird (Unbeweglichkeit: amputiertes Bein; erneute enge Verbindung mit Holz: Bearbeltung eines Birkenholzes; Identifizierung mit der Holzpuppe: "sovsem tak, kak ee derevjannaja kukla" (N2 86); Erstaunen, als er vom geplanten Puppenkauf erfährt und Angebot an Veruska, ihr stattdessen eine Puppe zu schnitzen).

Der mit der Grenzwăchterrolle des Ded Michajla aktivierte Măchenchronotop wird im anschlieBenden Gang durch den Wald weiter entfaltet (Veruska in roten kleid, anthropomorphisierte Waldwelt).

Mit der Ankunft am Dorfgeschät wird die Grenzmarkierung zwischen beiden Welten wiederholt. Alte Frauen sitzen als Grenzwăchter auf der Turschwelle des Geschafts (dreimalige Frage an Veruska nach ihrer Herkunft; Herstellung einer Verbindung zum ersten Grenzwăchter mit der Frage nach Ded Michajla).

Das Geschaft repräsentiert die fremde Welt (fremdlandische Waren, kunstliches Material). Das Vordringen bis zur Theke wird als ein schwieriger Grenzübertritt dargestellt:

1) Die zuordnung zum fremden chronotopischen System wird unterstrichen durch die unmittelbar an das versprechen anschliebende, die Miniaturhandlung unterbrechende Flugzeugepisode (s.o.). 
"Veruska-sorozka mys'ju probralas' pod nogami k prilavku /.../ Ja toß̌e protisnulsja." (NZ 88, Hvh.G.W.)

Die Fremdheit der beiden hier aufeinandertreffenden Welten steigert sich im anschliebenden Dialog mit der Verkäuferin bis zur Unverständlichkeit:

" - /.../ Nam kuklu.

- Kurtku?

- Kuklu.

- Kakuju kuklu? - ne ponjala prodavsica. - Ach, kuklu?

Igrusku? - obradovalas' ona znakomomu, no kak-to vyskołivłemu iz golovy slovu." (N2 89)

Das Puppenmotiv wird hier - uber die Opposition 'fremde' vs. 'nicht fremde' Puppe hinaus - allgemein mit der

Chronotopizität der Ursprünglichkeit (Kindheit, Erinnerung, Märchen) in Verbindung gebracht. ${ }^{1}$

Gleichzeitig bleibt die erste Oppositionsschicht erhalten. Hier erweist sich die von der Holz- und Waldfigur repräsentierte Welt als überlegen. Der momentane Schmerz Veruskas legt sich mit dem wiedereintritt in die 'nicht fremde' Welt (Wald):

"Na doroge ona poveselala /.../ i uže kriCala mne iz lesu, iz gustych zavalov: $/ \ldots /$ " (N2 88)

VIII.3.2. Modellvariante: Das zerstörte Raum/Zeit-System des Mikrokosmos (A. Solzenicyn, "Matrenin dvor")

Raumerschliebung von 'groB' nach 'klein' (Suche)

Auch die in "Matrenin dvor" dargestellte Welt ist in ihrer raumlichen Dimension vielfach gestaffelt. Ihre Erschliebung erfolgt jedoch in ungekehrter Richtung. Der Raum wird von 'groB' nach 'klein' unter dem Motiv der Suche durchquert. Der Erzähler - aus der asiatischen Verbannung kommend - sucht das "ursprüngliche RuBland" (kondovaja Rossija) (N2 44). In dieser Suche wird er auf einen

1) Vgl. ebf. die Opposition (in unmittelbarer Replikenfolge): "Kukla - pervoe delo" (Erzähler) vs. "Kukla - nechodovoj tovar" (Verkäuferin) (N2 88). 
immer kleineren Raum verwiesen.

Die wichtigsten Stufen der räumlichen Dimensionierung sind:

a) Asien/(-) RuBland

b) RuBland

c) Eisenbahnstation Torfoprodukt

d) Dorf $T a l$ 'novo

e) Hof Matrenas

Der Ubergang von a nach b bildet den Beginn des Textzentrums :

"Letom 1953 goda iz pyl'noj gorjað̌j pustyni ja vozvrastalsja naugad - prosto $v$ Rossiju." (SM 42)

Mit der Ankunft in $c$ erweist sich die Schwierigkeit, das ziel "RuBland" $z u$ finden. Grenze ist die Eisenbahnlinie. zu ihrer Uberwindung mus sich der Erzähler an die entsprechenden Grenzwächter wenden (Verwaltungsbeamte fungieren als Grenzwächter der nichtrussischen Welt):

"Skažite, ne nužny li vam matematiki gde-nibud' podal'se ot Zeleznoj dorogi?" (SM 43)

Die Station Torfoprodukt wird als schwer zu uberschreitender Grenzpunkt zwischen zwei Welten beschrieben:

"V Torfoprodukt legko bylo priechat'. No ne uechat'." (SM 43)

Der Ubergang von $c$ nach $d$ wird erneut mit einer Markierung der Eisenbahnlinie als uberwundener Grenze verbunden ( $/ \ldots$ ) vse pogluse, ot Zeleznoj dorogoj podale, $k$ ozeram.") (SM 44). Es folgt die erste Begegnung mit einer Reprasentantin der russischen Welt (Milchverkauferin) ${ }^{1)}$. Sie fungiert als "Begleiterin" (provodnica) (SM 43, 44) in das Dorf Tal'novo.

In Tal'novo findet der Erzähler kein Quartier. Als letzte zufluchtstätte erscheint der Hof Matrenas. ${ }^{2)}$ Um ihn $2 u$ betreten, ist ein erneuter Grenzubertritt notwendig:

"Kalitka byla na zapore, no provodnica moja ne stala stucat", a prosunula ruku pod nizom i otvernula zavertku /.../." (SM 44)

1) $" / .$. / i slova ee byli te samye, za kotorymi potjanula menja toska iz Azii/.../." (SM 44)

2) " - Nu, razve tto k Matrene zajdem, - skazala provodnica, uže ustavSaja ot menja." (SM 43) 


\section{Konkurrenz zweier zeitsysteme}

Neben der räumlichen Dimension hat das 2 iel der Suche (RuBland) von Anfang an eine deutlich markierte zeitliche Dimension. Bereits die räumliche Trennung des Erzählers (Verbannung) ist gleichbedeutend mit einer zeitlichen Unterbrechung:

"Ni $v$ odnoj tołke ee nikto menja ne ždal i ne zval, potomu Eto ja zader zalsja s vozvratom godikov na desjat'." (SM 42)

Die Suche nach dem Raum ist zugleich die Suche nach einer Zeit, von der nicht sicher ist, ob sie noch "lebt":

"Mne chotelos' zatesat'sja $i$ zaterjat'sja $v$ samoj nutrjanoj Rossii - esli takaja gde-to byla, Kila." (SM 42)

Diese Suche nach einem zeitlichen Kontinuum findet statt vor dem Hintergrund einer Konkurrenz zweier Zeitsysteme, die den gesamten Text durchzieht. Die Oppositionen zwischen den beiden zeitsystemen sind vielfach markiert:

(S. nächste Seite) 
Naturzeit

(Jahreszeitenablauf Sommer

bis Winter)

("letom") (SM 42)

("V tu osen" ") (SM47)

("pugajušee dychanie zimy")

(SM 47)

("k toj zime") (SM 50)

Zyklik

(wald und schnee als

Substrate) 1)

Vergangenheit-Gegenwart-

$\frac{\text { Kontinuum }}{\text { (wald als substrat) }}{ }^{2)}$

(Jahreszeiten) 3)

(fliebende Zeit: "I 511

goda, kak plyla voda...")

(SM 54)

Generationenband ${ }^{4)}$

Iterativität

Tagesablauf Matrenas: unvollendeter Verbaspekt; Zeitdeiktika "vsegda" (SM 46),

"vsjakij raz" (SM 47):

"zakonomernyj porjadok"

(SM 48), "vse iz togo ze"

(SM 47))

(Gewöhnung: "Ja so vsem

svyksja, Cto bylo $v$ izbe

Matreny. ") (SM 46)
Historische zeit

("1953 god") (SM 42) $\frac{\text { Bruch/Progredienz }}{\text { (Revolution als Substrat) }}{ }^{1)}$

Diskontinuum

(Revolution, Torfabbau und Kolchos als substrat) 2)

(Technik) 3)

1) "Obletali list'ja, padal sneg - i potom tajal. Snova pachali, snova sejali, snova zali. I opjat' obletali list'ja, i opjat padal sneg. I odna revoljucija. I drugaja revoljucija. I ves' svet perevernulsja." (SM 53)

2) "A i na étom meste stojali preźde $i$ perestojali revoljuciju dremutie, neprochozie lesa. Potom ich vyrubili - torforazrabotciki i sosednij kolchoz. Predsedatel' ego, Saskov, svel pod koren' izrjadno gektarov lesa $i$ vygodno sbyl v Odesskuju oblast.". (SM 43)

3) Matrena kommentiert Radionachrichten uber Technisierung: "- oj-oj-ojin'ki, cego-nibud' izmenjat, zimu ili leto." (SM 51) Vgl. zur Technik als diskontinuine Kraft: "Ja predstavil ich rjadom: smoljanogo bogatyrja s kosoj לerez spinu: ee, rumjanuju, obnavక̌ju snop. I - pesnju, pesnju pod nebom, kakich teper', pri mechanizmach, ne spoes'." (SM 53)

Vgl. ebf. den Kommentar zur Elektrifizierung des Dorfs: "V gazetach pisali togda 'lampotki Il'ita', i muziki, glaza tarasta, govorili: 'Car' Ogon'!'" (SM 45)

4) "KaŽetsja, i Faddeju ne o Zem bylo Zalet': rodila emu vtoraja Matrena toze Sesterych detej /.../ - i vyzili vse, a u Matreny s Efimom deti ne stojali: do trech mesjacev ne dozdivaja i ne boleja niðem, umiral kazdyj." (SM 54) 
Antagonistisches Durchdringen beider Raum/Zeit-systeme. Uberlegenheit des Makrokosmos

Wie in "Za dolami, za lesami" verschmelzen die räumlichen und zeitlichen Dimensionen in einem System von Chronotopen. Doch im Gegensatz $z u$ einer relativ hermetischen Abriegelung zweier Raum/Zeit-Systeme existiert hier ein antagonistisches Sich-Durchdringen der beiden Systeme. Der Mikrokosmos ist nicht in der Lage, sich ein Chronotopensystem zu schaffen, das bis zu makrokosmischen Dimensionen reicht (vgl. etwa die Kraniche in "Za dolami, za lesami"), sondern wird im Gegenteil in von 'groB' nach 'klein' abgestuften Graden in seiner autonomen Chronotopizität zerstört. Entscheidend ist, daß auch der außerste konzentrationspunkt dieser Chronotopizität, das Haus, den Destruktionskräfen unterliegt.

1) Den höchsten Zerstörungsgrad weist der Grenzraum Torfoprodukt auf. Bereits der Name signalisiert die zerstörung des ursprünglichen, mit dem Begriff "Rußland" verbundenen Raum/Zeit-Systems :

"Torfoprodukt? Ach, Turgenev ne znal, $\ell_{t o}$ mokno po-russki sostavit" takoel" (SM 43)

Torfoprodukt ist beherrscht von der Technik, der Eisenbahn und dem Torfabbau ( = Waldzerstörung) als Verkörperungen des zeitlichen Diskontinuums :

"Nad poselkom dymila fabricnaja truba. Tuda i sjuda skvoz" poselok proložna byla uzkokolejka, i parovoziki, tołe gusto-dymjastie, pronzitel'no svistja, taskali po nej poezda $s$ burym torfom, torfjanymi plitami i briketami." (SM 43)

Der Wald als Chronotop des Kontinuums und der zyklik ist zerstört.

2) Noch nicht vollends zerstort, doch von einer scharfen Konkurrenz beider Raum/Zeit-Systeme beherrscht ist die Umgebung des Hofs (Dorf und Nachbardörfer). Das Dorf Tal'novo wird als ursprünlicher Chronotop des mikrokosmischen Raum/Zeit-Systems gekennzeichnet: 
"/.../ i derevnja èta - Tal'novo, ispokon (zeitl.) ona zdes' (räuml.), esce kogda byla baryn'ja-'cyganka' (zeitl.) $i$ krugom (räuml.) les (chronotop.) lichoj stojal." (SM 44) 1)

Gleichzeitig aber beherbergt die Ungebung die Kräte der Zerstörung und des Diskontinuums (Verwaltung, Kolchos). Das konkurrierende Nebeneinander dieser beiden systeme in der räumlichen Umgebung wird offensichtlich während der Darstellung von Matrenas Bemulhungen um eine Rente. Nach dem wiederholten Durchwandern der raumlichen Umgebung auf dem Weg $z u$ den Amtern folgt oppositiv die Lokalisierung Matrenas in der räumlichen Umgebung:

"A to $s$ pletenym kuzovom - po jagody $v$ dal'nij les. I ne stolam kontorskim klanjajas', a lesnym kustam, da nalomavi spinu nosej, $v$ izbu vozvrascalas Matrena uze prosvetlennaja, vsem dovol 'naja, so svoej dobroj ulybkoj." (SM 47, Hvh.G.W.)

Auch der noch verbliebene wald als ursprünglicher Chronotop des mikrokosmischen Raum/Zeit-systems ist in seiner Autonomie bereits weitgehend eingeschränkt. Er wird mit den fremden Räumen Bahndamm und Kolchos äquivalentisiert:

(Matrena erklärt die Schwierigkeiten, Heu zu bekommen:) "U polotna ne kosi - tam svoi chozjaeva, i v lesu kosit' netu - lesnicestvo chozjain, 1 v kolchoze mne ne veljat ne kolchoznica, mol, teper'." (SM 48)

3) Das haus selbst wird mehrfach in seiner ursprünglichen Eigenschaft als Chronotop der mikrokosmischen Welt markiert. Es verkörpert das Generationenband ("Ichnij byl dom. Ichnim otcom stroennyj.") (SM 53) und beherbergt in sich die spuren einer sehr alten zeit (Ofen und Webstuhl) ${ }^{2}$ ).

Glelchzeitig aber ist es mit den Merkmalen des Todes, des Absterbens und Faulens behaftet. Die Aktivierung dieser Merkmale erfolgt wiederholt im zusammenhang mit dem Alter als ursprünglicher Manifestation des Vergangenheit-GegenwartKontinuums :

1) Spuren dieser ursprünglichen Chronotopizität in der Gegenwart sind v.a. in der naturidyllischen Beschreibung der năheren Umgebung des Hofs zu finden (recuska s mostikom, miloe mesto, ivy, i zbuska, prud, utki) (SM 44).

2) Uber den Ofen heiBt es: " $/ . . /$ prisla ona $k$ nasim predkam 12 samogo kamennogo veka $/ \ldots / /^{m}$ (SM 46 , Hvh.G.W.)

Uber Matrenas Wunsch, neben dem Webstuhl fotografiert $z u$ werden, heibt es: "Vidno, privlekalo ee izobrazit" sebja v starine." (SM 50, Hvh.G.W.) 
"/../ izgnivala ščepa, posereli ot starosti brevna sruba /.../." (SM 44)

"Gnila i starela kogda-to sumnaja, a teper' pustynnaja izba i starela $v$ nej bespritul'naja Matrena." (SM 54)

Die hier mit dem Alter kombinierte Auflösung des zeitkontinuums ('Tod') betrifft auch die Auflösung des Generationenkontinuums. Die alte und kranke Matrena wird als "bespritul'naja" (d.h. kinderlos"), bezeichnet. Das haus verliert damit seine Funktion als Chronotop des familiaren Generationenbandes:

"Stroeno bylo davno i dobrotno, na bol'suju sem'ju, a Kila teper' odinokaja Zenstina let pod Sest'desjat." (SM 44)

Auch in seiner Eigenschaft als räumlicher Träger der iterativen zeitbewegung (Alltag) ist das haus mit den Merkmalen der Zerstörung und der Fäulnis behaftet. Die im Haus lebenden Tiere als Träger dieser Merkmale (Mäuse, welche die Tapeten zerfressen, und Schaben) verkörpern zugleich in leitmotivischer wiederholung die iterative zeitbewegung. ${ }^{2}$ )

Neben dieser zerstörung von innen findet eine zerstörung von auBen statt. Das Eindringen einer fremden Chronotopizität wird leitmotivisch durch die Wanduhr als Merkmalträger a) der historisch-kalendarischen zeit und b) eines fremden Raums signalisiert:

1) Vgl. die im Russischen übliche Verwendung des Verbs "pritulit'sja" für das Anschmiegen des Kinds an die Mutter.

2) zur Verkörperung der Iterativität vgl. bes. die Beschreibung des Geräuschs der Schaben als "einheitlich und ununterbrochen" (edinyj, nepreryvnyj) (SM 46).

Ein Vergleich mit den leltmotivischen Trägern zeitlicher Iterativität in " $\mathrm{Za}$ dolami, za lesami" - ebf. Tieren drängt sich auf. Dort hieb es uber die Kraniche: "Vsju-to zist' krikat dak..." ( $1 \mathrm{iz} 80)$, hier über die Schaben: "Surకan'e ich - byla ich Kizn"."(SM 46) Das iterative zeitsystem wird einmal als Lebensprinzip in extrem großen räumlichen Dimensionen (vgl. die Aktivierung des Merkmals 'lebendig' für die Kraniche: "golos"), das andere Mal in extrem kleinen räumlichen Dimensionen plus einer Aktivierung des Merkmals ' $(-)$ lebendig' signalisiert. 
"Chodikam Matreninym bylo dvadcat" sem" let (historische zeit), kak kupleny v sel'po (fremder Raum)." (SM 46) 1)

Als Fremdkörper wirken ebenfalls zwei Propagandaplakate.

Das Eindringen der fremden welt in das Haus findet auch auf figuralēr Ebene statt. Als Eindringlinge fungieren der Kolchosvorsitzende und seine Frau (beide neben ihrer Funktionstrăgerschaft für die destruktive und diskontinuine Institution Kolchos mit dem Merkmal des fremden Raums 'stadt' behaftet ${ }^{2)}$, und die Untersuchungsbeamten. Das Eindringen wird jedesmal als 'feindlich' charakterisiert:

"Ona vchodila $v$ izbu $i$, ne zdorovajas', strogo smotrela na Matrenu." (SM 49, uber die Frau des Kolchosvorsitzenden) "/.../ rezkij కtuk razdalsja $v$ vorota. ¿uzoj vlastnyj golos krical, Etob otkryli." (SM 57, uber die Untersuchungsbeamten)

4) In der schlieblichen Zerstorung des Hauses gipfelt der antagonistische ZusammenstoB der beiden Raum/ZeitSysteme. In diametralem Gegensatz zur Handlung in "za dolami, za lesami" erweist sich hier - wiederum parabelhaft - die Uberlegenheit der destruktiven Kraft des makrokosmischen systems.

Die raum/zeitliche Konfrontation wird zunächst signalisiert durch die Charakterisierung der zerstorer als raumfremd - Matrenas Pflegetochter und ihr Mann als Erben der Hutte leben in der Stadt - und Trăger des Merkmals 'Technik' (Beruf des Mannes: Maschinist).

Technik und Natur als Substrate der konkurrierenden zeitsysteme (s.o.) treten in einen regelrechten Kampf:

1) Im Unterschied zur Uhr in "za dolami, za lesami" befindet sich die Uhr hier in unmittelbarer und wesentlich dichterer Konfrontation mit dem mikrokosmischen Raum/Zeit-System. Vgl. etwa die Kombination von Schabengerausch und Uhrticken: "/.../ rabotal $v$ tisine izby pod కoroch tarakanov i postuk chodikov /.../." (SM, Die Uhr wird wesentlich stärker als in das Haus eindringend ("v tiłine izby") charakterisiert als die räumlich eher extegrierte uhr in "za dolami, za lesami". Die Uhr Matrenas geht auBerdem vor (SM 46), die in "Za dolami, za lesami" nach, - konnotierbar ist die Dominanz der 'schnellen' fremden zeit im ersten, die Dominanz der 'langsamen' eigenen zeit im zweiten Fall.

2) (Vorsitzender:) "prislannyj iz goroda" (SM 49)

(Ehefrau:) "Kenstina gorodskaja" (SM 49) 
"/.../ zjat'-masinist uechal v Cerusti za traktorom. No $v$ tot den nacalas' mete ${ }^{\prime} / .$. / i zamela dorogu nepomernymi sugrobami." (SM 55, Hvh.G.W.) 1)

(Zusätzliche räumliche Grenzaktivierung: Schneewehen als Schutzbarriere.)

Die extremste Konfrontation findet an der zentralen Grenze zwischen den beiden Welten - der Eisenbahnlinie - statt. Das Ubertreten dieser Grenze durch Matrena während des Abtransports der Hutte - $d . h$. das Verlassen des eigenen Raum/Zeit-Systems - ist gleichbedeutend mit ihrem Tod (Matrena gerät unter eine Lokomotive). 2)

\section{Eine vergleichende Zusammenfassung ergibt:}

Beide Texte stellen das Nebeneinander zweier Welten in scharfen raum/zeitlichen Oppositionen dar.

In "Za dolami, za lesami" dominiert die hermetische Abgrenzung der raum/zeitlichen Dimensionen beider Welten. Der Mikrokosmos behält eine relativ ungebrochene Autonomie, er ist in der Lage, sich räumlich zu autonomen makrokosmischen Dimensionen zu entfalten, er realisiert das zeitkontinuum. Einbrüche der fremden Welt sind untergeordnet, werden Z.T. integriert. Parabelhaft erweist sich die Uberlegenheit des Mikrokosmos (Puppenmotiv).

In "Matrenin dvor" dominiert das antagonistische Sich-

1) Vgl. ebf. die zuspitzung der Opposition 'Technik' vs. 'Haus': "Dve nedeli ne davalas' traktoru razlomannaja gornica!" (SM 55)

Weitere Signalisierungen der Konfrontation der Raum/ zeit-systeme sind

- räumlich: die Kombination von Grenzoffnung und Eindringen der AuBenwelt mit dem Merkmal 'kalt' $(" / \ldots) v$ broßennoj izbe, vystužennoj častym otkryvaniem dverej.") (SM 57)

- zeitlich: der Wechsel von iterativer zu nicht-iterativen Aktionsarten.

2) Die Zuspitzung des Antagonismus zwischen beiden Systemen auf die Opposition 'Leben' vs. 'Tod' wird im AnschluB an das Ungluick auf symbolischer Ebene wiederholt. Unmittelbar nach einem Erzählerkomnentar uber den Tod Matrenas ("Ubit rodnoj telovek.") (SM 58) folgt die symbolische Verlebendigung eines Plakatbildes: "Razrisovannaja krasnoKeltaja baba s kniznogo plakata radostno ulybalas'." (SM 58) - Der Tod des einen Systems ist gleichbedeutend mit dem Leben des andern. 
Durchdringen beider Welten und die zerstörung der ehemals autonomen raum/zeitlichen Dimensionen des Mikrokosmos. Dieser ist auf einen ăuBersten räumilchen Konzentrationspunkt zusammengedrängt und selbst hier den destruktiven und diskontinuinen Kraften des Makrokosmos (Kolchos, Technik, Torfabbau) ausgesetzt. Er ist zudem Opfer eines inneren Verfalls (Alter = 'Tod', Auflösung des Zeitkontinuums). In der Zerstörung des Bauernhauses sowie im Tod seiner Bewohnerin erweist sich parabelhaft die destruktive Uberlegenheit des Makrokosmos.

\section{VIII.4. Standpunktkomposition}

Zentrales Innovationsprinzip auf der Ebene der Standpunktkomposition ist die Annäherung des Erzählstandpunkts an den Standpunkt der băuerlichen Figuren. Diese Umorientierung des Erzăhlsubjekts im Verhältnis zwischen den Rigurenreihen entspricht einer Sympathie- bzw. Parteinahme für den Mikrokosmos, die sich in sehr unterschiedlichen erzählerischen Grundhaltungen - satirische Kritik an den Funktionsträgern, Trauer über den drohenden Tod der dörflichen Welt, Romantisierung dieser Welt - äuBern kann. Die erzählerischen Grundhaltungen entsprechen in der Regel der Geste des Textsubjekts, von welchem durchaus eine sinnkonstituierende Aktivität ausgeht. " In der weitgehenden Kongruenz aller Strukturebenen wird diese sinnkonstituierende Aktivitat manifest. Die Dorfprosa der sechriger Jahre zeichnet sich gerade durch ein relativ ungebrochenes Verhältnis zu der von ihr dargestellten Welt aus, prinzipielle Verfremdungen, Irritierungen, Relativierungen der von den Erzahlsubjekten bzw. von den băuerlichen Figuren eingenommenen Haltungen existieren nicht.

1) W. Schmid sieht hingegen diese sinnkonstitulerende Aktivitat in den sujetgenerierenden Verfahren, zu denen er auch die standpunktkomposition zahlt, "verschleiert" (Schmid, aao, S.64). Vgl. ebd., S.70: "Mit der Abkehr von sozialpadagogischen zielsetzungen stellte man die Sinnhaltigkeit der dargesteliten Geschichten uberhaupt in Frage." 
Allerdings ist diese Geste auf der Ebene der Standpunktkomposition nicht mehr an eine strikte Wertungsmonologizität wie in den vorhergehenden Modellen gebunden. Das hängt in erster Linie mit dem Charakter des mikrokosmischen Wertesystems selbst zusammen, welches nicht den universellen und absoluten Gültigkeitsanspruch des makrokosmischen Wertesystems besitzt. Das Fehlen eines solchen Absolutheitsanspruches wirkt sich in verschiedenen Formen der Entautorisierung des Erzählstandpunkts gegenüber dem Figurenstandpunkt aus. Dies darf allerdings nicht schematisch mit einem unterschiedslos hohen Grad an Polyphonie verwechselt werden. Hingegen existieren verschiedene Varianten von einer deutlichen Konfrontation der standpunkte bis hin $2 u$ einer neuen Form der Monologizität: der bruchlosen Ubereinstimmung des Erzählstandpunkts mit einem auch in sich nicht dialogisierten Figurenstandpunkt. Im Zusammenwirken aller Ebenen läbt sich für den Hauptstrom der Modelltexte als dominantes Kompositionsprinzip eine (z.T. prozessuale) Annaherung der Standpunkte auf einer gemeinsamen Wertungsbasis feststellen.

VIII.4.1. Die Ebenen der Psychologie und der Phraseologie

Auf der Ebene der Psychologie lassen sich zwei Standpunkte mit einem relativ hohen Verbreitungsgrad feststellen:

a) der von einem Ich-Erzähler eingenommene AuBenstandpunkt

b) der von einem nichtfiguralen Erzählsubjekt eingenomene Innenstandpunkt gegenüber den Figuren. 1)

1) $\mathrm{zu}$ einer anderen Klassifizierung komnt K.H. Kasper in seinem - fur die gesamtliterarische Reihe vorgenommenen Versuch einer Erzăhlertypologie für die kleinen Prosaformen (Rasskaz, Povest') der funfziger und sechziger Jahre. Kasper unterscheidet

a) den autobiographischen auktorialen Erzähler

b) den fiktiven Ich-Erzăhler

c) den Ich-Erzähler als gleichzeitigen Helden

d) den auktorialen Erzăhler (der den Standpunkt einer Figur annimmt).

Vgl. K. Kasper. Funktionen des Erzählers in der russischsowjetischen prosa nach 1956, in: Zeitschrift für

Slawistik, 1968, Nr.1, S.61-68 und: Ders., Der Erzähler in der russisch-sowjetischen kleinen Prosa (Povest' und Erzählung), Jena (Habil.) 1966. - Die Unterscheidungskriterien zwischen $a, b$ und $c$ beziehen sich dabei auf 
Als autorenspezifische Ausnahme muB demgegenüber der Aubenstandpunkt eines nichtfiguralen Erzählsubjekts angesehen werden, wie er in vielen Erzahlungen Suksins anzutreffen ist.

Der Ich-Erzähler im Typ a fungiert in der Regel lediglich als erzählende Instanz, er ist selten Agent. ${ }^{1)}$ Dieser Erzähler ("Matrenin dvor", "Plotnickie rasskazy", "Za dolami, $2 a$ lesami", "Kaplja rosy", "Brjanskie", "Lipjagi" u.a.) ist häufig raumfremd, wobei unterschiedliche Grade möglich sind:

- Er ist entweder ganz neu zugereist (Matrena: "Znaju odno dal'nij on.") (SM 51, Hvh. im Text) und bleibt lang ("Matrenin dvor") oder kurz ("za dolami, za lesami"), kommt regelmäвig ("Brjanskie") oder einmal ("Za dolami, za lesami")

- oder er kehrt in sein heimatdorf zurück, regelmäBig ("Kaplja rosy") oder seit langer zeit zur erstenmal ("Plotnickie rasskazy").

Elgenschaften des Erzählers ('fiktiv', 'autobiographisch', 'Held'), die nicht mit der standpunktkomposition zusammenhängen. Auf die Standpunktebene der Psychologie bezogen läuft auch Kaspers Typologie auf eine Unterscheidung in Ich-Erzăhler mit AuBenstandpunkt und Erzählsubjekt. mit nicht-synthetischem Innenstandpunkt hinaus. (Ein nichtsynthetischer Innenstandpunkt betrifft nur eine oder wenige Figuren, auch im letzten Fall können die Innenstandpunkte der Figuren dabei nicht gleichzeitig, sondern nur nacheinander eingenommen werden. Vgl. Uspenskij, aao, S.102ff.)

Kaspers Begriff vom Erzăhler engt diesen zudem ein auf eine Instanz zur "Umsetzung der ideologischen Positionen des Autors" (Kasper 1966, S.14, vgl. ebf. Kasper 1968, S.62). So kommt Kasper zu normativen Bewertungen des Standpunktverhältnisses zwischen Erzähler und Figuren wie der Kritik an einer "fehlenden Hohe des Blickpunkts" (Kasper 1966, S.206) b2w. der "ideellen Entmündigung des Autors" (Kasper 1968, S.66).

1) 2.T. ubernimmt der Erzähler geringfugige Agentenfunktionen, wie etwa in "Matrenin dvor", wo er durch die nach dem Ungluck ins Haus dringenden Untersuchungsbeamten gegen seinen willen in die Handlung einbezogen wird (Verhor durch die Beamten), oder in "plotnickie rasskazy", wo ein den gesamten Text durchziehender Handlungsstrang (das Reparieren eines Badehauses durch den Erzahler und die zimerleute) den Erzähler einbezieht. Dieser Strang ist jedoch lediglich als einheitsstiftender Hintergrund für die Darstellung der beiden $z$ immerleute und ihrer Erzählungen zu betrachten. 
Typ b herrscht in den gröBeren Paradigmatexten seit Mitte der sechziger Jahre vor ("Privychoe delo", "Na Irtyకe", "Den'gi dlja Marii", "Prošaj Gul'sary", "Iz Zizni Fedora Kuz'kina"). Er beschränkt sich entweder auf den Innenstandpunkt einer, meist der hauptfigur ("Na Irtysen, "Den'gi dlja Marii", "Iz Zizni Fedora Kuz'kina") oder auf den weniger Figuren (Katerina und Ivan Afrikanovic in "Privylnoe delo"), wozu auch das Verfahren der Annahme des Innenstandpunkts eines Tiers (das Pferd Gul'sary in "Prostaj Gul'sary", die Kuh Rogulja in "Privyčnoe delo") gehören kann.

Auch im zweiten Fall wird jedoch kein synthetischer Innenstandpunkt eingenommen. Die Standpunkte losen sich ab (vgl. bes. den regelmäbigen Wechsel der Innenstandpunkte Gul'sarys und Tanabajs in "Prostaj Gul'sary").

Das Verhältnis zwischen Erzähl- und Figurenstandpunkt auf der Ebene der Phraseologie 1st bereits mehrfach untersucht worden. Ronsensuelles Resultat dieser Forschungen ist die gesteigerte Bedeutung des Figurenworts - sowohl in der Form der direkten Rede als auch in der Form der Interferenz zwischen Erzähl- und Figurenrede. Der Dorfprosa wird in diesen auf gesamtliterarischer Ebene angestellten Untersuchungen ein besonderes Gewicht entsprechend ihrem innovatorischem stellenwert beigemessen. 1)

1) Vgl. bes.:

- N.A. Kozevnikova, o tipach povestrovanija $v$ sovetskoj proze, in: Voprosy jazyka sovremennoj russkoj literatury, Moskau 1971, S.97-163.

- M. Cudakova, Zametki o jazyke sovremennoj prozy, in: Novyj Mir, 1972, Nr.1, S.212-245

- N.V. Dragomireckaja, Slovo geroja kak princip organizacil stilevogo celogo, in: Mnogoobrazle stilej sovetskoj literatury. Voprosy tipologii, Moskau 1978, S.446-459.

Kozevnikova hebt für die Dorfprosa den stellenwert des Figurenworts in Form der direkten Rede und der "uneigentlich direkten Rede" (nesobstvenno-prjamaja rec') hervor: besonders der Funktionsbereich der letzteren habe sich erweitert und sich beispielsweise auf die Darstellung der Erinnerungen der Figuren ausgedehnt. Als dominanten Erzähltyp nennt sie die weitgehende - nicht nur lexikalische, sondern auch syntaktische - Beeinflussung des. "Autorenworts" durch das $F$ igurenwort in der "uneigentlichen Erzählung des Autors" (nesobstvenno-avtorskoe povestvovanie), deren Funktion sich auf alle Erzählmodi und Textteile einschlieblich der "Beschreibung" (opisanie) und "Figurencharakterisierung" (charakteristika perso- 
Besonders auf dieser Ebene scheint eine vom Zusammenhang der anderen Ebenen isolierte Modellkonstruktion wenig sinnvoll. Entscheidend ist vielmehr der funktionale Zusammenhang der Ebene der Phraseolgie mit der Ebene der Wertung.

Ein weiterer, gesamtliterarisch normenevolutionärer Aspekt, der in diesem Zusamenhang nicht berücksichtigt werden kann, ist die mit der Einführung der bäuerlichen

nazej) ausweite. (Wir werden im weiteren die Abkürzungen NPR fur "nesobstvenno-prjamaja rec'" und NAP fúr "nesobstvenno-avtorskoe povestvovanie" verwenden, weisen aber nochmals auf die Uneinheitlichkeit des "avtor"Begriffs hin, der hier im Sinne des Erzählsubjekts zu verstehen ist. Man könnte die NPR auch als "uneigentliche Figurenrede" und die NAP als "uneigentliches Erzählen" bezeichnen; entscheidend ist ihre Zuordnung $z u$ unterschiedlichen Redesubjekten - Figur bzw. Erzahlsubjekt. S. dazu ausfuhrlicher S.250/51 der Arbeit.) KoZevnikova versteht NAP und NPR - stilistisch oft ununterscheidbar - in einem engen Wechselverhaltnis. Gemeinsame Funktion beider sei es, die Illusion des figuralen Standpunkts zu vermit = teln ("sozdat' 1lljuziju tocki zrenija geroja", S.159). Dabei wird als typisch die Herstellung der Redeinterferenz zwischen dem Erzahlsubjekt und einer Figur bezeichnet, wăhend die Rede der anderen figuren nur in Form der direkten Rede existiere (S.162). (Letzteres entspricht der Standpunktvertellung auf der Ebene der Psychologie.) Cudakova unterscheidet vier Evolutionsphasen in den Beziehungen zwischen Erzahl- und Figurenwort, die sie folgendermaben kennzeichnet:

a) "samoutverzdenie" (Selbstbehauptung der persönlichen Meinung und Sprache des Erzahlers, besonders in der Jungen Prosa)

b) "samoopravdanie" (Konzentration auf die Figurenrede, besonders in der Dorfprosa, Suksin)

c) "samootrecenie" (Dominanz der Figurenrede uber Erzăh1rede, starke Interferenzen, besonders in der Dorfprosa, Suksin, Rasputin)

d) "samoopredelenie" (Dominanz der Erzăhlrede, F. Iskander). Speziell mit der Figurenrede befabt sich Dragomireckaja, wiederum unter starker Berúcksichtigung der Dorfprosa. Sie stellt das Phänomen des "'autorlosen' Erzăhlens"

('bezavtorskoe' povestrovanie) fest, d.h. die kontextfreie, rahmenlose Einfuhrung und Entfaltung des Figurenworts, hăufig schon in den Titeln (vgl. "Privyčnoe delo", "Srezal" u.a.) (S.449ff).

Vgl. ebf. Schnid, aao, hier S.73-84 und J. Holthusen, Stilistik des "uneigentlichen" Erzahlens in der sowjetischen Gegenwartsliteratur, in: Welt der Slawen, 1968, S.225-245. Holthusens These von der Weiterentwicklung der "erlebten Rede" zur "erlebten Erzahlung" entspricht weitgehend der Unterscheidung von NPR und NAP. Holthusens Arbeit zeichnet sich durch eine Auflistung der stilistischen Merkmale dieser Erzählform aus. 
Sprache (Dialekte, "narodnaja rex'") verbundene stilinnovatorische Funktion der Dorfprosa."

1) Vgl. zu diesem Aspekt bes. die materialreiche Arbeit von I.A. Ossoveckij, Dialektnaja leksika $v$ proizvedenijach sovetskoj chudožestvennoj literatury 50-60ch-godov, in: Voprosy jazyka .... aao, S.301-385. - Ossoveckij untersucht an Texten der Dorfprosa mithilfe eines Systems von Differenzmerkmalen - beginnend auf sublexematischer Ebene - die Beziehungen zwischen dialektaler und literatursprachlicher Lexik. Seine Untersuchung ist von streng funktionalen Aspekten geleitet: a) dem Aspekt der innovatorischen Funktion des dialektalen Worts hinsichtlich literatursprachlicher Normen, b) dem Aspekt der textstrukturellen Funktion des dialektalen Worts (Textzonen- und Sprecherzuordnung, Vertellung auf Figuren- und Erzahlerrede etc.), wobei hier unterschiedliche Expressivitätsgrade in Abhängigkeit von Dialektizitätsgrad und anderen Faktoren festgestelit werden. Die "narodnaja ret'" als Verfahren der Standpunktbestimmung des Erzählsubjekts - nicht im

Verhältnis zu einzelnen Figuren, sondern zu einer "Schicht" bzw. einem "Milieu" (sreda) - beschreibt Kozevnikova, aao, S. 161: "V proze 60-ch godov razvivaetsja forma povestvovanija, orientirovannaja na rel' izobrazaemoj sredy, a imenno rex' narodnuju. Povestvovatel' ne otdeljaet sebja ot 1 zobrazaemoj sredy, on nachoditsja vnutri - nee, on cast' ee, esli on daze ne utastnik i ne otevidec sobytij. Ego rasskaz vedetsja $v$ ramkach krugozora sredy $i$ vyder $i$ ivaetsja $v$ stilistiCeskom kljuCe, ej svojstvennom 1....."

Vgl. ebf. G.A. Belaja, Rozdenie novych stilistiteskich form kak process preodolenija "nejtral'nogo" stilja, in: Mnogoobrazie..., aao, 5.460-485. - In dieser Arbeit ist hinsichtlich der Dorfprosa besonders die Gegenuberstellung von Junger Prosa und Dorfprosa unter dem Aspekt der sozialen Trăgerschaft der jeweiligen stile interessant. Der Stil der Dorfprosa wird als "Stil eines Ganzen (eines Volkes)" (stil' celogo (naroda)) dem Stil der Jungen Prosa als "stil eines Kreises" (stil' kruga) positiv gegenubergestellt (S.476f). Die Dorfprosa nehme damit eine MaBstaberweiterung vor; sie orientiere sich nicht mehr am individuellen Horizont eines figuralen Erzăhlers, gebe nicht nur die verküzte sicht des Helden wieder, sondern den Horizont eines hinter dem Helden stehenden Ganzen, des volks $(5.477)$. - Hier wird somit vorgefuhrt, daB eine rein phraseologische Standpunktanalyse noch nichts uber den Monologizitätsgrad des Texts aussagt. Wichtig ist der ort der jeweiligen Sprachen im ideologischen und sozialen inner- wie auBertextuellen Kontext. Die stilistische 'Verwurzelung" der Dorfprosa im "Volk" wird von der Literaturkritik eher $2 u$ einem Faktor der monologischen Funktionalisierung gemacht (s.IV.2.6.). 
VIII.4.2. Standpunktannäherung auf der Ebene der Wertung

Die dominante Ebene in der Annaherung des Erzählstandpunkts an den Figurenstandpunkt ist die Ebene der Wertung. Die anderen Ebenen sind dieser Ebene funktional untergeordnet, aus dem zusammenwirken der Ebenen ergeben sich verschiedene Varianten, von denen einige exemplarisch dargestellt werden sollen.

\section{1) Der wertungskompetente Erzähler (Wertung von 'unten')}

Die Ich-Erzähler treten in der Regel mit explizit wertendem Anspruch auf, der sich in entsprechenden Kommentaren, wertenden Auberungen etc. manifestiert. Im Unterschied $z u$ den vorhergehenden Modellen beruht dieser wertende Anspruch aber nicht mehr auf einer gröBeren Wertungskompetenz des Erzählers gegenüber den Figuren, sondern ist im Gegenteil durch eine Unterordnung des eigenen Wertesystems unter das der Figuren, durch die Selbstabwertung gegenuber deren moralischen Qualitäten, durch ein Lernen von diesen gekennzeichnet. Diese variante reicht von einer monologischen Ubereinstimmung der Wertungsperspektiven von Erzähler und Figuren bis $z$ einer dialogischen, prozeBhaften Beziehung zwischen beiden.

\section{Lichonosov, "Brjanskie"}

Ein extrem monologisches Verhältnis existiert in "Brjanskie". Der Erzähler steht in einem deutlich wertenden Verhältnis $2 u$ dargestellter Umgebung und Figuren. Es äubert sich in

- der Formulierung wertintensiver Oppositionen zwischen Stadt- und Landleben ("Kažetsja, nikogda by ne ostavil étogo mesta, ni na kakie gorodskie prelesti ne promenjal by etoj tisiny $i$ odinokosti lesa /.../.") (LB 7)

- wertintensiven EmotionsäuBerungen ("radostno"/"radovat'sja" als Grundgefuhl) (LB 7,8,9), ("blagodarno-radostno gljazu na babku") (LB 8), ("ujutno") (LB 7), (vor der Abreise: "grustno") (LB 12)

- der Formulierung der "Sehnsucht" (toska) (LB 12) nach der dargestellten Welt ("Uezzat' mne vsju $Z_{i z n} v$ derevnju, vezzat' i vozvrasłat'sja, uezzat' i vozvrałtat'sja!") (LB 10). 
Die Grundlage seines Verhältnisses $z u$ den Figuren wird in identischer Wertungsperspektive von der Figur des alten Bauern Terentij Kuz'miC und vom Erzähler selbst formuliert: " - Ivanovicl - kritit ded. - Molodoj ty esce, a my vremja prozili.

Molodoj ja eకce, no blizki mne slova ego: ja vyros sredi takich, i mat' moja takaja, i sosedi, i navsegda ja budu privjazan k nim." (LB 10)

Es besteht im Respekt des Jüngeren vor der Lebenserfahrung der alten Figuren und in der durch gemeinsame Herkunft begründeten Verbundenheit. " Es gibt nichts Fremdes zwischen dem Erzähler und den Figuren.

Auf der Basis dieser Wertungsmonologizitat (thematisiert: "Potomu $\ell_{t o}$ my počti svoi $i$ vse nam ponjatno drug v druge.") (LB 8) fungiert die Ubernahme stilistischer Elemente der Figurenrede in die Erzählerrede (Verkleinerungsformen wie "vederko" (LB 7) und "poljusko" (LB 11)) nicht als Interferenzbildung 2 wischen fremden phraseologischen standpunkten, sondern dient lediglich der oberflächlichen folkloristischen stilisierung. 2 )

\section{A. SolZenicyn, "Matrenin dvor"}

Ein dialogischeres Verhältnis existiert in "Matrenin dvor". Die Fremdheit von Erzähler und Hauptfigur wird betont; der Erzähler muB seine Figuren erst in einem langen ProzeB kennenlernen, Beobachtungen machen ("Ja zametil") (SM 47), ("prigljadyvajas" $k$ Matrene, ja zamexal")(SM 48), ("razočtja, ja ponjal")(SM 53); er muB Informationen zusammentragen ("Ja tol'ko potom uznal") (SM 45), ("Ach, vot ono tto! Teper" ja ponjal") (SM 54), ("vychodilo, Eto") (SM 54). Er kann sich auch in seinen figurencharakterisierenden Urteilen täuschen, 2.B. gegenuber dem charakterlich schwachen und habgierigen Faddej, den er bei der ersten Begegnung als "würdig"

1) Vgl. ebf.: "znakomy my davro" (LB 7), "kak syna" (LB 8)

2) Zum Verhältnis zwischen Erzähler- und Figurenrede bei Lichonosov vgl. Xudakova, aaO, S.221ff. - Zudakova stellt fest, daß die Hauptfiguren bei Lichonosov häufig als zweites Ich des "Autors" fungieren. Sie kritisiert besonders die nur oberflächlich "volkstümlich gefärbte" Rede des Erzăhlers (S.225). 
beschreibt (SM 52).

Der ErkenntnisprozeB hinsichtlich der Hauptfigur macht einen ersten Sprung mit der Eröffnung der Vergangenheit Matrenas nach dem Besuch Faddejs ("Tak $v$ tot veter otkrylas" me Matrena spolna.") (SM 55), wird aber erst nach dem Tod Matrenas vollendet, diesmal verbunden mit dem Erfassen der moralischen qualitäten der Figur:

"I tol'ko tut - iz étich neodobritel'nych otzyvov zolovki vyplyl peredo mnoju obraz Matreny, kakoj ja ne ponimal ee, daze żivja s neju bok o bok." (SM 63) 1)

Erst jetzt ist die Basis geschaffen für die im SchluBabsatz erfolgende wertende Verallgemeinerung des Erzählers, welche einen deutlich monologischen Anspruch hat, der sich jedoch auf der eigenen wertungsmäBigen Unterordnung unter die Figur begründet:

"Vse my iili rjadom s nej i ne ponjali, tto est' ona tot samyj pravednik, bez kotorogo, po poslovice, ne stoit selo. Ni gorod.

Ni vsja zemlja nasa." (SM 63)

(Unterordnung: "ne ponjali": moralische Erhöhung der Figur gegenuber sich seibst: "tot samyj pravednik"; Monologizität: universaler Anspruch der Wertung ("vsja zemlja"), Absicherung durch Sprichwort.)

Die Standpunktkomposition auf der Ebene der Phraseologie ist funktional der Wertungsebene untergeordnet. Der Erzähler nähert seinen phraseologischen Standpunkt ausschlieblich dem Matrenas an. Dies geschieht wiederholt dann, wenn Matrenas Verhältnis zur feindlichen Umwelt (Kolchos, Verwaltung, Diebstahl des Weihwasserkessels) dargestellt wird. Das Verfahren dieser Standpunktannăherung besteht in einem schnellen Wechsel zwischen eigentlicher (interferenzfreier) Erzählerrede und den verschiedenen Formen der Redeinterferenz,

1) Dem korrespondiert eine gegen Ende zunehmende wăhe zur Figur im Gegensatz zur anfangs betonten Fremdheit, sowohl im räumlichen als auch im gesellschaftlichen Sinn. Der Erzähler spricht von "unserem Haus" (nasa izba) (SM 61), er bezeichnet die verstorbene Matrena als "verwandten Menschen" (rodnoj Zelovek) (SM 58). Auch für die anderen Figuren wird erst an Ende eines langen KennenlernenProzesses eine Wertung durch den Erzähler moglich: "Perebrav tal'novskich, ja ponjal, tto Faddej byl $v$ derevne takoj ne odin." (SM 61) 
oft innerhalb eines Satzes.

"Iz kanceljarii v kanceljariju i gonjali ee dva mesjaca to za tokkoj, to za zapjatoj. Kazdaja prochodka - den' $/ 1 /$. Schodit $v$ sel'sovet, a sekretarja segodnja net $/ 2 /$, prosto tat vot net $/ 3 /$, kak èto byvaet $v$ selach $/ 4 /$. zavtra, znacit, opjat' idi $/ 5 /$. Teper' sekretar' est', da pexati u nego net $/ 6 /$. Tretij den' opjat' idi. A Cetvertyj den' idi potomu, tto soslepu oni ne na toj bumazke raspisalis' $17 /$, bumazki-to vse u Matreny odnoj packoj skoloty /8/." (SM 47)

11: interferenzfreie Erzählerrede

2: von Figurenrede beeinflubte Erzählerrede, kombiniert mit raum/zeitlicher Standpunktannäherung, Zeitdeiktikum "segodnja", Präsens

3: von Figurenrede beeinflubte Erzählerrede, demonstrative Partikel "tak vot"

4: interferenzfreie Erzăhlerrede, verallgemeinernder Kommentar

5: uneigentliche Figurenrede, Imperativ des inneren Monologs, Zeitdeikitkum "zavtra"

6: von Figurenrede beeinflubte Erzählerrede, Zeitdeiktikum "teper" demonstrative Partikel "da"

7: uneigentiliche Figurenrede, Imperativ des inneren Monologs

8: von Figurenrede beeinflußte Erzählerrede, Diminutiv plus Demonstrativsuffix "bumazki-to", zugleich Behauptung des Erzählers als Redesubjekt durch Figurenbenennung, Ubergang zu interferenzfreier Erzählerrede.)

Im Gegensatz dazu werden die phraseologischen Standpunkte aller anderen Figuren deutlich vom Erzählerstandpunkt getrennt, ihre Rede wird nur in direkter Form wiedergegeben, wobei der Erzähler z.T. seine Distanz zu dieser Rede - wiederum unter wertenden Aspekt - thematisiert. So erfolgt die Darstellung der Totenklagen an Matrenas Sarg in einem ständigen Wechsel von direkter Figurenrede und kritischer Interpretation durch den Erzähler (SM 59f).

\section{2) Der wertungsinkompetente Erzäbler (Wertung von 'oben')}

\section{(V. Belov, "Plotnickie rasskazy")}

In "Plotnickie rasskazy" erscheint ein Erzăhler, der sich beständig un ein wertendes Verhältnis $2 u$ sich und den anderen Figuren bemüht, dabei jedoch nicht in der Lage ist, sich die notwendige Distanz, 'Höhe' zur Einnahme eines wertungskompetenten Standpunkts $2 \mathrm{u}$ verschaffen, obwohl er diese für sich beansprucht. Das wird wiederholt deutlich in Kommentaren des Erzählers, in denen er mit emotionaler Hilflosig- 
keit (Wut, Verzweiflung) auf die Ereignisse des Dorflebens und sein eigenes Beteiligtsein reagiert. Dieser Widerspruch spitzt sich am Ende zu mit dem Versuch des Erzählers, einen Streit der beiden alten $z$ immerleute zu lösen, der den gesamten Text durchzieht und sich - ahnlich wie in "Sosedi" an den unterschiedlichen politischen und gesellschaftlichen Anschauungen der beiden Figuren entzündet. Hier wird zugleich ein deutlicher Normenbruch hinsichtlich der Wertungskompetenz des uberlegenen, das Wertesystem des Makrokosmos vertretenden Erzahlers im M. 2 vollzogen.

Der Erzăhler stellt sich in der Formulierung seines Wertungsanspruchs deutlich in den Kontext des makrokosmischen Wertesystems :

"/.../ prigotovilsja govorit' red', rec' o ich zizni: mne kazalos', Eto nado nakonec postavit' tokku nad 'i'." (BR 52, Hvh.G.W,)

"/.../ vzyval k progresu i sypal istoriceskami primerami." (BR 52, Hvh.G.W.)

Seine Intention schlägt jedoch ins Gegenteil um. Die beiden Zimmerleute, die sich zuvor "friedlich unterhielten" (mirno besedovali) (BR 52), lassen mit Erwähnung der gesellschaftlich-öffentlichen Thematik ihren streit bis zu einer Schlägerei eskalieren. Der Erzahler, der in einem erneuten emotionalen Verzweiflungszustand seine Machtlosigkeit registriert, wird am nachsten Tag mit der fur inn unerwarteten Situation der Fortsetzung des friedlichen Gesprächs zwischen den beiden 2 immerleuten konfrontiert. In dieser SchluBsituation wird deutlich, daB die Grundlage fur das friedliche zusammenleben der beiden Figuren in einer Welt jenseits des makrokosmischen Wertesystems liegt, einer Welt, die dem Erzahler letztlich verschlossen bleibt. Der Schlubsatz lautet:

"Potom oni oba s Avinerom, klonja sivye golovy, ticho, strojno zapeli starinnuju protjaznuju pesnju. Ja ne mog im podtjanut' - ne znal ni slova iz étoj pesni..." (BR 56)

Die Wertungsinkompetenz geht hier einher mit einer phraseologischen ("ne znal ni slova") und zeitlichen ("starinnuju") 
Fremaheit dieser welt. ${ }^{1)}$

3) Der Wertungsverzicht des nichtfiguralen Erzählsubjekts (S. Zalygin, "Na Irtyše")

Das in den Povesti seit Mitte der sechziger Jahre verbreitete nichtfigurale Erzählsubjekt (mit dem psychologischen Innenstandpunkt einer oder weniger Figuren) besitzt keinen eigenen standpunkt auf der Wertungsebene. Dies kann zumindest als allgemeine Tendenz - unter Absehung von untergeordneten Wertungszusammenhängen - festgestellt werden. Das Erzählsubjekt distanziert sich nicht als selbständige wertformulierende Instanz von den Figuren, sondern überläBt die Wertung diesen selbst. Es ist die spezifische Art der Wertformulierung, welche das Erzählsubjekt als bloBes sprachliches Medium der Wertungsstandpunkte der Figuren ausweist. Hier liegt die zentrale Funktion der phraseologischen standpunktkomposition.

Am markantesten ist diese Tendenz in "Na Irtyse" ausgeprägt. Die phraseologischen Standpunkte von Erzahlsubjekt und Hauptfigur durcharingen einander in solchem MaBe, daB eine eindeutige zuordnung $2 u$ den jeweiligen äuBerungseignenden Subjekten oft nicht mehr möglich ist. Das zentrale Verfahren ist ein ständiges Sich-Durchdringen, flieBendes Ineinanderubergehen zwischen NAP und NPR. Diese beiden Formen der Redeinterferenz unterscheiden sich ja gerade hinsichtlich ihrer Redesubjekte. Die NAP ist Rede des Erzählsubjekts, welches lediglich im Erzählen einen phraseologisch fremden standpunkt einnimnt. Die NAP ist somit eine

1) Dementsprechend werden auf der Ebene der Phraseologie die Standpunkte eindeutig getrennt in Erzählerrede und direkte Figurenrede. Letztere autonomisiert sich gegenuber der Erzählerrede und bekommt dominanten Stellenwert (kapitellange Erzählungen der beiden Hauptfiguren in Monologform). Der Text markiert auBerdem wiederholt scharfe Stiloppositionen zwischen den beiden Welten (vgl. etwa die Konfrontation von bäuerlicher Sprache und Funktionärssprache während einer Kolchosversammlung (BR 33f) und die Konfrontation von folkloristischer und bürokratischer sprache in den Eintragungen eines zweckentfremdeten Poesiealbums (BR 38f).) 
Erzählweise. Die NPR hingegen ist Figurenrede, welche in "uneigentlicher" (d.h. dem eignenden Subjekt entzogener Form) wiedergegeben wird. Sie ist somit ein Verfahren der Wiedergabe von Figurenrede. "1)

Eben diese Unterscheldung wird in "Na Irtyse" stellenweise unröglich. 2.T. fallt es für ganze Kapitel schwer zu entscheiden, ob sie aus einem ausgedehnten inneren Monolog der Hauptfigur oder aus einer stark vom Figurenwort beeinflubten Erzahlweise bestehen. Das Erzahlsubjekt verleugnet gleichsam seine eigene Redesubjektivitat.

Die Verschmelzung errelcht einen besonders hohen Grad im Zusammenhang mit wertintensiven figurencharakterisierenden Xuberungen. Dabei lst zunachst von Bedeutung, daB sie unabhăngig von den moralischen, gesellschaftlichen, weltanschaulichen Implikationen dieser Wertungen zustandekomet. Hinsichtlich Causovs Frau Klavdija z.B. werden wiederholt Wertungen formuliert, die als 'rückschrittlich', 'patriarchallsch' bezelchnet werden können:

1) Vgl. KoǨevnikova, aao, S.105: "Nesobstvenno-prjamaja rę" - priem peredali reli geroev, nesobstvenno-avtorskoe povestvovanie - sposob opisanija 1 povestvovanija. $v$ Cistom svoen vide onl imejut raznuju - konstruktivnuju, ne stilistileskuju sootnesennost': nesobstvenno-prjamaja rex' sootnesena s prjamoj rec'ju personaza, nesobstvennoajtorskoe povestvovanie - s avtorskoj rec'ju." - Diese Definition widerspricht der Definition Uspenskijs, der den Terminus "uneigentlich-direkte Rede" (NPR) "In engem Sinne, nämlich zur Bezeichnung einer Ubergangserscheinung zwischen direkter und indirekter Rede" unter Bezugnahme auf volosinov versteht (Uspenskij, aaO, S.46). Uspenskij grenzt sich explizit von der Subsumierung verschiedener formen der Wledergabe des fremden Worts wie etwa des inneren Monologs unter die NPR ab. Diese ist fur ihn ein spezifisches Verfahren der Beeinflussung des "Autorenworts" durch das fremde Wort, wahrend er den inneren Monolog $z u$ den Verfahren der Beeinflussung des fremden Worts durch das "Autorenwort" rechnet. Im Sinne einer klaren subjektstrukturelien zuordnung der verschiedenen Interferenzverfahren scheint jedoch die Definition Kozevnikovas sinnvoller. (Uspenskij selbst nennt als synonymen Begriff fur die NPR die "uneigentliche Autorenrede" (nesobstvenno-avtorskaja rec') (Uspenskij, aao, S.197, Anm.31) und vergrobert damit eher die terminologische Verwirrung.) 
"Inoj raz Kivet $v$ izbuske vo vremja pasni libo $v$ talovom Kalase na senokose $i$ vorug ni s togo ni s sego zaprjagaet, gonit domoj /1/. Priezzaet na Klasku zloj, glazy by na nee ne gljadeli, a ona ochaet da vzdychaet, da este i zaleet ego, kak éto neotlozno zaponadobilos' emu echat', i, vzdychaja-ochaja, bezit topit banju. Pokuda on paritsja moet $v$ gornice, poduski vzbivaet vyse grjadok $/ 2 \%$. To $1 i$ ona smeetsja nad nim $/ 3 /$ ?

... Ne uznat'. I ni 'k Xemu uznavat', razgovor zavodit'. Ne ee, bab'ego, uma delo /4/." (2N 23)

(zum Verhältnis zwischen den Redesubjekten:

Nachdem in den ersten drei Einheiten sowohl Erzählsubjekt als auch $F i g u r$ als Redesubjekte in Erscheinung treten - wobei hier bereits ein fliebender Ubergang besteht - wird für die wertintensivste AuBerung /4/ eine Trennung unmöglich:

1: Redesubjekt = Erzählsubjekt, zeitunspezifische Beschreibung "inoj raz", geringe Redeinterferenz (Diminutiv "izbuska")

2: Redesubjekt = Erzählsubjekt, starke Interferenz (Benennung "Klaska", Partikel "da" und "da eske i"; besonders das "da eske i" kann aber bereits als erlebte Figurenrede aufgefabt werden)

3: Redesubjekt $=$ Figur, Frageform und Präsens der erlebten Rede bzw. des inneren Monologs

4/zentrale WertungsäuBerung: kein eindeutiges Redesubjekt, unpersönliche Infinitivkonstruktion als Merkmal sowohl der NAP als auch der NPR.)

Insgesamt lassen sich allerdings eindeutige Dominanzen bezuglich der Wertungsimplikationen feststellen. Der qualitativ und quantitativ höchste Grad der Standpunktverschmelzung wird in der hertformulierung gegenuber den desintegrativen Funktionsträgern des gesellschaftlichen Makrokosmos und ihrer Helfer im Dorf (Untersuchungsrichter: korrumpierter Bauer Egor'ka Gilev; Kollektivierungsbeanter Korjakin; bedingt auch: Kolchosvorsitzender Pecura) erreicht. Im Kern geht es un die Formulierung der politischen und sozialen Gerechtigkeitsvorstellungen der bäuerlichen Hauptfigur gegenuber der sozial ausbeuterischen und politisch repressiven struktur des Makrokosmos.

Ein Beispiel ist die Kolchosversammlung, auf der sich die Anschuldigungen gegenuber Causov zuspitzen (Kapitel 8).

Die gesamte Versamlung ist aus der phraseologischen, psychologischen und raum/zeitlichen Perspektive Stepan Causovs dargestellt, markiert bereits in der Eroffnung des Kapitels mit dem Eintritt Causovs in den Versamlungssaal: 
"Narodu bylo $v$ izbe- ${ }^{\prime}$ ital'ne - ne prodochnut'sja. Na nogach stojali uže /1/. No stepan vse taki ischitrilsja $/ 2 / / \ldots /$." (2N 67)

1 1: Răumliche Perspektive Causovs, Sicht auf das Saalinnere vom Standort des Eintretenden; phraseologischer Standpunkt Causovs, syntaktische Konstruktion entsprechend der Emotion des Eintretenden (Fulle): unpersönliche Wendung "ne prodochnut'sja", Voranstellung der Präpositionalkonstruktion "na nogach";

2: Figurenbenennung "Stepan" verweist auf phraseologischen Standpunkt des Erzählsubjekts, das sich als Redesubjekt behauptet.)

Im folgenden wird besonders die phraseologische Standpunktinterferenz - in Opposition zur ausschlieblich in direkter Form wiedergegebenen Rede der Funktionsträger weiter entfaltet (beständiger wechsel zwischen direkter Versammlungsrede und interferierender Rede Erzahlsubjekt/ Causov) und stellenweise auf die băuerlichen figuren insgesamt ausgedehnt ${ }^{1)}$.

Ein Beispiel:

"A za Mitej esce odnogo razgljadel Stepan Celoveka, ne srazu priznal $/ 1 \%$. A etto Korjakin byl $/ 2 /$. Korjakin, iz krutolucinskich muzikov, samyj byl pervyj predsedatel' kombeda $/ 3 /$. Posle posel i posel po sluzbe /4/. Uze i ne muzik, a naXal'nik /5/. UŽe $v$ Krutye Luki poZaloval esli - tak ne dlja togo, ¿toby, skazem, po seno za reku ezdit' $/ 6 /$.

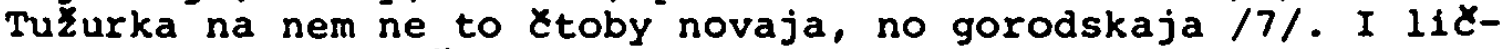
nost' stala ne muzickaja: bezborodyj, i gljadet' na nego očen' strogij. Zamucennyj este ... /8/ Verno, po derevnjam ezdit, iz kosevki ne vylazit $/ 9 \%$ Molodoj 11 , staryj 11 ne srazu pojmes' /10/.

Vot ono, kakoe sobranie-to nynce - Korjakin zdes' /11//...." (2N 72)

(1: Redesubjekt = Erzählsubjekt, Figurenbenennung "Stepan" weist eigenen phraseologischen Standort des Erzählsubjekts aus:

2: kein eindeutiges Redesubjekt, Präteritum verweist auf Erzăhlsubjekt, einleitendes "a" verweist auf erlebte Figurenrede;

1) Vgl. die Redeinterferenz mit den bäuerlichen Figuren gegenuber dem eintreten Juristen:

"Teper', eželi on sredi muzikov primostilsja slusat', to i dolzen uslysat'. I ponjat' dolžen, ¿to muziki krutolucinskie ne meskom pugannye, tto i u nich mysli v golove.

Tut vse pogljadeli, s kem on ugadal na lavku sest', komu s nim vypalo razgovor vesti. S nim ili promez soboj, no dlja nego, Ctoby slusal." (2N 67) 
3: kein eindeutiges Redesubjekt, nachgestellte prädikatlose Beschreibung der Herkunft Korjakins verweist auf Figur als Redesubjekt, präteritaler Bericht ("byl pervyj predsedatel'") verweist auf Erzählsubjekt;

4: Redesubjekt $=$ Erzählsubjekt, präteritaler Bericht

5: Redesubjekt = Figur (nicht eindeutig), Ubernahme der figurenperspektivischen Opposition 'muzik' vs. 'natal'nik', einleitendes "uže" verweist auf erlebte Figurenrede;

6: Redesubjekt $=$ Figur, einleitendes "ǔ̌e" plus Präteritum verweist auf Erinnerungsrede der Figur, "skazem" verweist auf inneren Monolog:

7: kein eindeutiges Redesubjekt, äuBere Beschreibung mit starken Interferenzen ("ne to ttoby"):

8: kein eindeutiges Redesubjekt, präteritale Beschreibung der Entwicklung Korjakins, unpersönliche Infinitivkonstruktion sowohl der NAP als auch der NPR;

9: Redesubjekt $=$ Figur, einleitendes "verno" plus Präsens verweist auf erlebte Figurenrede:

10: kein eindeutiges Redesubjekt, 2.Person Sgl. als Konstruktionsform sowohl der NAP als auch der NPR;

11: Redesubjekt = Figur, graphische Abgrenzung (Absatz) von bisher primär berichtendem Teil sowie elliptische Syntax verweisen auf erlebte Figurenrede.)

Zusammenfassend kann festgestelit werden:

Die mit der Entautorisierung des Erzählsubjekts als uberlegener wertender Instanz verbundene Entmonologisierung füht nicht $z$ u einer radikalen Polyphonie unterschiedlicher Wertungsstandpunkte, sondern $2 u$ einer relativ einheitlichen Bezugnahme auf ein neues (mikrokosmisches) Wertesystem besonders unter dem Aspekt der bäuerlichen Gerechtigkeitsvorstellungen im Gegensatz zur politischen und sozialen Struktur des Makrokosmos. Die Wertungspolyphonie innerhalb dieses systems besitzt demgegenuber einen untergeordneten Stellenwert: sie wird zudem auf gesamtstruktureller Ebene durch implizite Wertungsverfahren weiter eingeschrănkt. Durch implizite Information wird beispielsweise die patriarchalische Anschauung Stepan Causovs kritislert. So steht seine AuBerung über den "Weiberverstand" (s.o.) im Widerspruch zu der Tatsache, daB Klavdija sein hauptsächlicher Kommunikationspartner und seine wichtigste moralische wie gesellschaftliche stütze ist (s.VIII.1.2.). Solche Inkongruenzen bestehen hinsichtlich des dominanten Wertungsaspekts nicht. 
IX. Der desintegrierte Mikrokosmos

(v. Suksin, "Srezal")

Ende der sechziger/Anfang der siebziger Jahre erscheinen Texte, welche die für M.3 konstitutiven Normen reproduzieren, un sie als Folie für einen erneuten Bruch $z u$ benutzen. wie in den Ubergangstexten zwischen M.2 und M.3 wird das Inventar des alten Modells gleichsam vorgefuhrt, um entscheidenden Umwertungen unterzogen zu werden.

Diese Umwertungen sind von sehr unterschiedlichen Intentionen bestimmt. Sie konnen eimmal auf die Rehabilitierung des gesellschaftlichen Makrokosmos abzielen, indem dieser als neues Integrationsfeld dem Mikrokosmos, welcher sein Integrationspotential eingebübt hat, entgegengesetzt wird. Hier ist besonders auf einige Erzählungen A. Leonovs hinzuweisen, in denen die dörfliche Welt, besonders ihre Figuren und ihre raumlichen Dimensionen, als nicht nur extegriert vom umgebenden gesellschaftlichen und răumlichen Feld, sondern. als in sich weitgehend desintegriert dargestellt werden. In "Uchan $1 \mathrm{Krjazik"} \mathrm{(1968)} \mathrm{wird} \mathrm{das} \mathrm{Leben} \mathrm{zweier}$ alter Bauern in einem verlassenen Dorf - abseits des Kolchos dargestellt. Dieses Leben ist vom bevorstehenden Tod gekennzeichnet. Der Dorfraum ist extrem desintegriert (geschlossene Grenzen zwischen den beiden Häusern der Alten, Unbeweglichkeit der Figuren, Unerreichbarkeit des Dorfbrunnens als ehemaligem räumlichen und gesellschaftlichen Mittelpunkt des Dorflebens). Die gesellschaftliche Desintegration hat die stufe der Komunikationslosigkeit erreicht (die Figuren treffen sich nicht mehr, beobachten sich nur durch das Fenster). Der Makrokosmos trăgt demgegenuber das Merkmal 'Leben', er ist räumlich und gesellschaftlich integriert. In "Gluchaja" wird der Topos des Dorfheimkehrers aufgegriffen und umgewertet. Der städtische Gast trifft im Dorf eine fruhere Bekannte wieder und verbringt mit ihr gegen den Widerstand der alten Schwiegermutter (starucha) die Nacht. In antagonistischer Form treffen zwei Wertesysteme aufeinander. Die Opposition wird figural von den beiden jungen Figuren (d.h. sowohl städer als auch Dorflerin) auf 
der einen Seite und der "Alten" auf der anderen Seite repräsentiert. Letztere wird eindeutig negativ bewertet ('rückschrittlich', 'Tod', räumlich und gesellschaftlich extegriert, Titel "Gluchaja"), das Leben der jungen Frau in dieser extegrierten welt als z.T. unfreiwillig, Z.T. durch "Gewöhnung" (privykla) (LG 16) bedingt erklärt.

Die Umwertung der Modellelemente kann andererseits zu einer weitgehenden Verselbständigung der dargestellten (philosophischen) problemdimensionen gegenüber den gesellschaftlichen und raum/zeitlichen Dimensionen der dargestellten Welt führen, etwa bei V. Rasputin, dessen Figuren z.T. in raumlicher und gesellschaftlicher Isolation vom umgebenden dörflichen Mikrokosmos dargestellt werden. Hingewiesen sei auf "Poslednij srok" (1970) mit einer starken räumlichen Konzentration auf das Bauernhaus sowie auf "Živi $i$ pomni" (1974), dessen Hauptfigur - ein Deserteur - abseits und versteckt vor der eigenen Dorfgemeinschaft lebt.

Die raum/zeitliche Integration des dörflichen Mikrokosmos wird in verschiedenen Texten einer Umwertung unterzogen. Neben den erwähnten Erzăhlungen A. Leonovs sei hingewiesen auf "Derevjannye koni" (F. Abramov, 1970). Hier wird der Chronotop des alten Bauernhauses prozessual umgewertet. zunächst in den Augen des Erzählers (wiederum eines städtischen Dorfurlaubers) ein reiches "Museum" der Dorftradition, wird es mit den Erzählungen der alten Bewohnerin in seiner historischen Vergänglichkeit bewubt (Opposition 'holzerne Pferde' vs. 'lebendige Pferde'). Der Topos der alten Figur wird ebenfalls einer Umwertung unterzogen. Die alte Bäuerin Milent'eva erweist sich als sehr distanziert gegenüber der Dorfvergangenheit und besitzt - im Gegensatz zum Erzähler einen hohen Grad räumlicher Beweglichkeit (wiederholte schwierige Grenzüberschreitungen/FluB sowie schliebliche Abreise zur Tochter in die stadt).

Korrespondierend $z u$ diesem erneuten ProzeB der Modellauflösung gewinnen die autorenspezifischen Besonderheiten gröBeren literaturevolutionären Stellenwert. Die Personalstile einzelner Autcren, die sich schon während der Phase des M. 3 herausbildeten, sprengen jetzt dessen Rahmen. 
Unter beiden Aspekten ist $V$. Suksin von besonderem Interesse. Sein lakonisch-nüchterner Erzählstil gekennzeichnet durch die Konzentration auf den Figurendialog bei extremer zurückhaltung des Erzählsubjekts - , der bisher noch häufig innerhalb einer Geste der Sympathienahme für den Mikrokosmos gegen den Makrokosmos wirkte, steht jetzt im Funktionszusammenhang einer ironisch-distanzierten, desillusionierten Bestandsaufnahme der Destruktion des Mikrokosmos. Exemplarisch soll dies an "Srezal" (1970) gezeigt werden.

Der Text reproduziert zunächst eine typische situation des M.3: Ein ehemaliger Dorfbewohner, jetzt Städter und Wissenschaftler, kehrt in sein Heimatdorf zurük, um dort den Urlaub $2 u$ verbringen. In der Begegnung mit den Bauern kommt es jedoch $z u$ einem Skandal, als der Gast vom Dorfbewohner Gleb Kapustin mit provokatorischen Fragen uberrumpelt wird, die statt des beabsichtigten friedlichen Gesprächs eine situation unverhullter Feindseligkeit schaffen.

Dieser auf der Ebene der Fabel situierte Konflikt zwischen Dörfler und Städter, Mikrokosmos und Makrokosmos, bildet die Folie für einen Bedeutungsaufbau, der das auBere Ergebnis (Sieg des Dörflers über den Städter, Uberlegenheit des Mikrokosmos) unwertet und $z u$ einer dem M.3 fremden Distanz gegenúber dem Mikrokosmos führt. Die dominanten Strukturebenen, auf denen sich dieser Bedeutungsaufbau vollzieht, sind

- die Ebene der Konfigurationsstruktur, hier besonders die Beziehungen zwischen Haupt- und Nebenfiguren; diese Ebene ist eng verbunden mit der Ebene der Handlungsstruktur, da sich die interfiguralen Beziehungen auf der kommunikativen Interaktion (Interaktion zwischen den Hauptfiguren und Interaktion zwischen Haupt- und Nebenfiguren) als dominanter Handlungsform begründen. Eine analytische Trennung beider Ebenen erscheint angesichts des engen funktionalen Zusamenhangs zwischen sujetstruktureller Modifizierung des fabeldominierenden Handlungskonflikts und 
Konfigurationsstruktur nicht sinnvoll (s.u.): ${ }^{1}$

- die Ebene der Standpunktkomposition.

Die Ebene der Raum/Zeit-struktur ist als eigenständige Strukturebene schwach entwickelt, fügt sich jedoch in ihrem Zusammenwirken mit anderen Ebenen (besonders der Konfigurationsstruktur unter dem Aspekt der Altersrelationen und der Familie) diesem Bedeutungsaufbau ein.

IX.1. Konfigurationsstruktur

IX.1.1. Interaktion der Hauptfiguren als Ausdruck sozialer Desintegration

Das antagonistische Aufeinandertreffen der beiden Welten geschieht in der Interaktion zwischen den beiden Hauptfiguren Gleb Kapustin und Konstantin Ivanovic Zuravlev, dem "Kandidaten" (kandidat). Diese Interaktion wird in verschiedenen - textuell deutlich markierten - Ebenen dargestellt:

a) der Ebene der Intention

b) der Ebene der verbalen Strategie

c) der Ebene der nonverbalen Interaktion. Wir konzentrieren uns zunächst auf die ersten beiden Ebenen, da sie im Unterschied zur dritten Ebene den beiden Hauptfiguren vorbehalten sind.

\section{Die Ebene der Intention}

Diese Ebene wird nicht nur implizit - in der Interaktionsstrategie der beiden Figuren - sondern explizit entwickelt, und zwar schon vor Beginn des Dialogs. Der Dialog selbst setzt erst ein, nachdem die Unvereinbarkeit beider Intentionen bekannt ist.

1) Zur "Sinnumwandlung" (pereosmyslenie) der Fabel bei Suksin vgl. I.I. Plechanova, Osobennosti sjužtoslozenija $v$ tvortestve $v$. Suksina, Ju. Trifonova. V. Rasputina. $K$ probleme chudozestvennoj uslovnosti, in: Russkaja literatura, 1980, Nr.4, S.71-88, hier bes. S.72f. Plechanova erarbeitet eine Typologie der Sukłinschen Sujetfügungsverfahren unter diesem Aspekt. Für "Srezal" hebt sie dabei die besondere Bedeutung der Nebenfiguren (die "muziki", s.u.) für die "Modifizierung" des Konflikts 2wischen den Hauptfiguren hervor (S.77). 
Die Intention Glebs wird in den expositorischen Kommentaren des Erzählsubjekts und in der Begegnung Glebs mit den "Männern" (muziki) expliziert. Glebs erklărtes ziel ist es, den "Kandidaten" "durchfallen zu lassen" (srezat"), d.h. ihn in eine prufungssituation zu stelien und zu blamieren. Dieser Intention liegt ein sozialpsychologisches Motiv zugrunde: Gleb erteilt diese Blamage allen ehemaligen Dorfbewohnern, die als "bedeutende Leute" (znatnye ljudi) ihr Dorf wieder besuchen (Šs 182). Besonders durch die wiederholte oppositive Kombination von "Männern" als Dorfbewohnern und "bedeutenden Leuten" als Gästen wird hier das Motiv sozialer Minderwertigkeit deutlich, das im Fall des "Kandidaten" durch dessen Ankunft im Taxi geschürt wird:

" - Na taksi priechal...

- Nu, marku-to nado podderzat'। ... - posmejalsja Gleb." (\$s 184)

Das Minderwertigkeitsgefühl ist besonders stark hinsichtlich der wissens- und bildungsmäBigen Unterlegenheit ausgeprăgt.

Die Intention des "Kandidaten" ist es demgegenuber, ein friedliches Gespräch mit seinen ehemaligen Dorfgenossen zu führen. Die sozialen Barrieren werden durch die Erinnerung an die gemeinsame Kindheit überbrückt:

"Gosti skromno podozdali, poka babka Agaf'ja nakryla stol, pogovorill s kandidatem, povspominall, kak $v$ detstve on 1 vmeste...

- Ech, detstvo, detstvo! - skazal kandidat. - Nu, sadites' za stol, druz'ja." (Ss 184)

Im Aufeinandertreffen dieser beiden Intentionen im nun folgenden Dialog finden entscheidende Modifikationen statt. Die feindliche Intention Glebs erweist sich nicht nur als überlegen, sie führt auch $2 u$ einem entsprechenden Intentionswechsel beim "Kandidaten", der sich am Ende des Dialogs in unverhülter Feindseligkeit gegenuber Gleb àubert:

" - Eto nazyvaetsja - 'pokatil bołku', - skazal kandidat. Ty Xto, s cepi sorvalsja?" (SS 187)

" - Tipilnyj demagog-kljaulnik, - skazal kandidat /.../." (SS 188) 
Mit diesen AuBerungen wird in verschiedenerlei Hinsicht die anfänglich 'freundschaftliche' Intention des Kandidaten als Schein entlarvt:

- plötzliche Anrede mit "du" (Ausdruck des Bewubtseins seiner sozialen Position)

- Vulgarismen (Ausdruck der sozialen Verachtung des Gegners)

- politisch-denunziatorische Unterstellungen (in beide Richtungen: denunziatorische Beleidigungen gegen Gleb ("s cepi sorvalsja") und Vorwurf denunziatorischen Verhaltens ("kljautnik")).

Diese erste Schicht des Dialogs - 'Entlarvung' des "Kandidaten" - kulminiert in der SchluBreplik Glebs, in der er die scheinbare Liebe des stadters zur dörflichen Heimat als versteckte Ausdrucksform der sozialen Gegensätze (soziale Arroganz) angreift:

"Mozno sotni raz pisat' vo vsech stat'jach slovo 'narod'. no znanij ot étogo ne pribavitsja. Tak tto kogda uz vyezzaete $v$ etot samyj narod, to bud'te nemnogo sobrannej. Podgotovlennej, tto $1 i / \ldots /$. Prijatno provesti otpusk ... sredi naroda." (SS 188) 1)

Gleichzeitig unterliegt aber auch die Intention Glebs im Verlauf des Dialogs einer Modifizierung. Das Motiv der sozialen Minderwertigkeit wird von Gleb wiederholt thematisiert:

" - Vy izvinite, my tut ... daleko ot obscestvennych centrov /....." (Ss 184)

" - Vopros, konetno, ne global'nyj, no s todxi zrenija nasego brata, bylo by interesno uznat'." (SS 185)

" - My ne mysliteli, u nas zarplata ne ta." (SS 186)

" - /../ Nas, konečno, možno tut udivit': Podkatit' k domu na taksi, vytastit iz bagažnika pjat' ¿emodanov..." (SS 187)

Die von Mal zu Mal zunehmende Aggressivitat dieser Thematisierungen signalisiert, daB im Verlauf des Dialogs selbst das Motiv emotional geschürt wird und zur von Gleb nicht mehr bewuBt kontrollierbaren Triebkraft seines Interaktionsverhaltens wird. ${ }^{1)}$

Der paradoxe zusamenhang besteht nun darin, daB Gleb im Versuch, durch die Entlarvung des "Kandidaten" die sozialen Gegensätze zur Sprache zu bringen, gleichzeitig

1) Vgl. den Kommentar "ego neslo" (క̌s 187). 
deren Nichtexistenz beweisen will. Er mist sich mit dem "Kandidaten", un seine bildungs- und wissensmäBige Gleichwertigkeit $z$ u beweisen. Dabei legt er die Maßstăbe der fremden, gehabten Welt für sich selbst und das ganze Dorf an:

"No vy zabyvaete, tto potok informacii sejCas rasprostranjaetsja vezde ravnomerno /.../ Mozno ponadejat'sja, Cto tut kandidatov $v$ glaza ne videli, a ich tut videli - i kandidatov, i professorov, i polkovnikov. I sochranili o nich prijatnye vospominanija, potomu tto èto, kak pravilo, ljudi ođen" prostye." (Ss 187)

Das Paradoxon besteht in der Inanspruchnahme eben jener "bedeutenden Leute", denen gegenüber früher bereits sein sozialer HaB zum Ausdruck kam, zur eigenen Aufwertung.

\section{Ebene der verbalen Strategie}

Der Fremdmotivierung beider Hauptfiguren auf der Ebene der Intention entspricht eine jeweilige orientierung an fremden verbalen Strategien. Wiederum setzt sich Gleb mit seiner Strategie durch. Das Bewegungsgesetz des Dialogs besteht darin, daB Gleb die verbalen Strategien aus der Welt seines Gegeners diesem selbst aufzwingt.

Der erste Replikenwechsel signalisiert das Aufeinandertreffen der beiden Fremdstrategien in Form einer stilopposition:

" - V kakoj oblasti vyjavljaete sebja? - sprosil on (Gleb, G.W.).

- Gde rabotaju, ¿to 1i? - ne ponjal kandidat." (Sss 184)

(Gleb: elaborierter akademischer S:11;

"Kandidat": ungangssprachlicher Stil;

zusătzliche Markierung der Fremdheit: Nicht-Verstehen.)

In der nächsten Frage Glebs werden über die Stilopposition hinaus die unvereinbaren Themenerwartungen konfrontiert, erneut mit einer Signalisierung der Fremaheit durch das Nicht-Verstehen verbunden:

" - Nu, i kak nasCet perviCnosti?

- Kakoj pervicnosti? - ne ponjal kandidat /.../.

- PerviXnosti ducha i materi1." (SS 184)

Mit der Antwort auf diese Frage durch den "Kandidaten" - 
unter erneuter Aktivierung des ihm fremden ungangssprachlichen Stils ("A duch - potom.")(SS 184)-wird Glebs thertendiktierende Rolle bestatigt, die sich im folgenden in einer prufungsăhnlichen Frage-antwort-Folge festigt.

Die Fremdheit der im folgenden von Gleb eingeschlagenen verbalen Strategie schlägt sich in verschiedenen 'Pehlern' nieder:

- naturwissenschaftlich falsche Vorstellungen (z.B. Bezeichnung der Schwerelosigkeit als "Naturelement": " $\forall$ kaxestve odnogo iz élementov prirody nedavno obnaružena nevesomost'. ") (SS 185)

- Fehler in der philosophischen Logik ("pervicnost' duch 1 materii" anstelle "perviknost" duch ili materii") (SS 184)

- Anthropomorphisierung kosmischer vorstellungsdimensionen ("/.../ nasu, tak skazat', sosedku po kosmosu /.../") (ss 186$),(\mathrm{l} / \ldots /$ cto $v$ odin prekrasnyj moment razumnye suskestva ne vyderzat' i vylezut $k$ nam navstrecu. ") (SS 186), ("Dopustim, na poverchnost" Luny vylezlo razumnoe sustestvo..." ) (Ss 186)

- methodisch 'unzulässige' Raum/zeit-Relativierungen weltanschaulich/wissenschaftlicher Axiome ("Kak sejtas filosofija opredeljaet ponjatie nevesomosti?") (Ss 185) (die 'Anormalität' der Frage wird hier zudem als - zur Absurditat gesteigerte Konsequenz der Orientierung am fremden ideologischen Normensystem erkenntlich: die Philosophie "bestimmt" "definiert" einen naturwissenschaftlichen Forschungsgegenstand):

("Kak vy lixno otnosites' $k$ problemu Samanizma $v$ otdel'nych rajonach Severa?") (ŠS 185) (zusătzliche Signalisierung der Fremdheit des Stils: Opposition zwischen der akademischen Floskel "Kak vy litno otnosites" und umgangssprachlichem "Du" im selben thematischen Kontext: "Tvoe otnosenie $k$ problemu Samanizma.") (SS 185)

Diese Fehlex beeinträchtigen jedoch nicht Glebs Uberlegenheit. Sie zwingen den Kandidaten $z$ einer neven,

'ideologischen' verbalen Strategie: der Absicherung seines eigenen Wertesystems gegenüber den als systemfremd empfundenen Fragen Glebs. Sämtliche Repliken des "Kandidaten" sind von dieser 'ideologischen' Strategie bestimmt:

- Tabuisierung weltanschauungsstörender Probleme ("Da net takoj problemy!") (SS 185, uber Schamanentum), Tabuisierung der Historizitat von weltanschaulich-philosophischen Positionen (2weimal Antwort "kak vsegda") (SS 184,185)

- Nichtanerkennung systemfremder Fragen (Poðemu sej飞as?") (SS 185), ("Vy o Kem voobకte-to?") (SS 185), ("Da kakoj vopros-to?") (Ss 185)

- Versuche, rhetorische Jberlegenheit auszuspielen: methodischer Code ("Davajte ustanovim, - ser'ezno zagovoril kandidat. - o tem my govorim.") (Šs 185), I ronisierung von Fragen ("Vy kogo sprasivaete?") (SS 186), Rückgabe von Fragen ("A vy gotovy?") (SS 186). 
Diese Strategie erweist sich jedoch der ebenfalls 'ideologischen' Strategie Glebs als unterlegen. Letztere kann man als Strategie der Prufung bezelchnen. Sie gewinnt inre Uberlegenheit aus dem Umstand, daB sie sich einerseits auf dem thematischen und methodischen Gebiet des Gegners bewegt, andererseits jedoch dieses immer wieder verlabt und mit den eigenen vorstellungskategorien konfrontiert. Die hierin begrundete innere widerspruchlichkeit von Glebs verbaler Interaktion, die Fehlerhaftigkeit seiner Fragen (8.0.) erweisen sich als stärke: sie reproduzieren und sprengen zugleich das fremde system.

So provoziert Gleb einerseits durch die eigene Thematisierung weltanschaulicher Axiome (" - Da, no est' dialektika prirody $/ \ldots / /^{\prime \prime}$ ) (Ss 185) den weltanschaulichen Rechtfertigungsdrang des "Kandidaten" und greift andererseits dessen weltanschauliches Axiomdenken an (besonders, nachdem der "Kandidat" die Frage liber den Schamanismus für ungultig erklärt: " - Problemy netu, a eti... - Gleb cto-to pokazal rukami zamyslovatoe, - tancujut, zvenjat buben $\boldsymbol{C}_{1 k a m i}$... Da? No pri Zelanii... - Gleb povtoril: - pri Ze-la-nii - ich kak by netu.") (ss 186)

Weitere Verfahren der Strategie der Prüfung sind:

- Uberraschung des Gegners durch Themenwechsel

("- Davajte ustanovim, - ser'ezno zagovoril kandidat, - o tem my govorim.

- Choroßo. Vtoroj vopros: /.../n) (Ss 186)

- Verwirrung des Gegners durch Schnelligkeit (vgl. abschlieBenden Kommentar der "Männer": "On, Kostja-to, chotel, konexno skazat.... A tot emu na odno slovo - pjat'.") (Ss 189)

- Orientierung auf Wissenslucken des Gegners durch Formulierung fachfremder Fragen (zunehmende Konzentration auf naturwissenschaftliche Fragen). 1)

1) Zur Ebene der verbalen Strategie vgl. ebf. die Textanalyse yon L. Geller, Opyt prikladnoj stilistiki. Rasskaz V. Suksina kak ob-ekt issledovanija 8 peremennym fokusnym rasstojaniem, in: Wiener Slawistischer Almanach, Bd.4, 1979, S.95-123, hier die Abschnitte 7 ("Semantika ékzamena") und 8 ("Analiz jazyka"). - Geller weist auf den zusammenhang zwischen der fremden, voller Fehler steckenden verbalen Strategie und dem rituellen Charakter der "ideologischen Diskussion" für Gleb und die "Mănner" hin: "Ideologiceskaja diskussija dija Gleba - 1 tem bolee, konecno, dlja drugich iitelej derevni, - ne obmen informaciej, a obmen signalami, Zestami, smysl kotorych sam po sebe ne imeet nikakogo znaxenija. Eto i est temnyj magiceskij ritual, sekret kotorogo tak choroso znakom Glebu." (S.110) Insgesamt ist Gellers Analyse des '1deolo- 
Die in diesem Dialog der Hauptfiguren zutagetretenden Strukturen der Desintegration werden in einem Vergleich mit "Kosmos" noch deutlicher. Dort wurde das fremde verbale Interaktionsverhalten Jurkas mit der nicht fremden Interaktion des alten Naum konfrontiert, wobei sich letztere als überlegen auch für Jurka erwies. Hier aber werden die fremden Interaktionsformen von einem Repräsentanten des Mikrokosmos gegen einen Repräsentanten des Makrokosmos durchgesetzt, der sich ursprünglich der mikrokosmischen Interaktionsformen bedienen wollte. " War in "Kosmos" die gemeinsame Lebenssituation im Mikrokosmos Ursache für die letztendliche Dominanz der nicht fremden, auf gemeinsamen Intentionen beruhenden Interaktion, so ist hier die durch scharfe soziale Gegensätze gekennzeichnete zugehorigkeit der Figuren zu verschiedenen Kosmen die Ursache für die Dominanz der fremden, auf der Intention von Feindschaft beruhenden verbalen Interaktion. Die Uberlegenheit des Makrokosmos setzt sich indirekt

gischen' Charakters der Interaktion als wichtiger anzusehen denn der Versuch ihrer 'Magisierung'. Letzteres wird den primär sozialen Implikationen der dargestellten Interaktion nicht gerecht.

Geller sieht die Ursache für Glebs Uberlegenheit gegenüber dem "Kandidaten" in der Beherrschung der Formen des "Rituals" und weist gleichzeitig auf die damit zusammenhängende Funktion Glebs für die "Männer" hin ("Borot'sja s magiej możno l1s' koldovstvom boloe sil'nodejstvujustim otsjuda i missija Gleba.") (S.110), ohne allerdings die damit verbundenen Auswirkungen auf das soziale Verhältnis zwischen Gleb und den "Männern" zu erkennen, dem ein entscheidender Stellenwert im Bedeutungsaufbau des Textes zukommt, wie zu zeigen sein wird.

zur Funktion der Stiloppositionen bei Suksin vgl. Belaja, aao, S. $479 \mathrm{ff}$. - Belaja weist auf die für Suksin typische Verwandlung der Helden in Trăger fremder Sprachrolien hin, welche die momentane Ubernahme sozialer Fremdrollen begleitet.

1) Die Differenzen werden offensichtlich in dem von beiden Texten aufgegriffenen Themenkomplex "Lebewesen im Kosmos". In "Srezal" wird das Thema von Gleb eingebracht, in "Kosmos" hingegen von Jurka als vermeintlichem Repräsentanten des Makrokosmos. In "Srezal" ist mit diesem Thema der Hohepunkt von Glebs Uberlegenheit erreicht (Schweigen des "Kandidaten"), in "Kosmos" setzt eine besonders intensive Gegenreaktion des alten Naum ein, der auch Jurka seine vorstellungskategorien diktiert. 
- über die Beeinflussung von Intention und verbaler Strategie des Dorfbewohners - durch.

IX.1.2. Funktion der Nebenfiguren

Reproduktion der sozialen Hierarchie im Mikrokosmos

Der Dialog der beiden Hauptfiguren entwickelt.sich

in einer sozialen Interaktionssituation, die wesentlich durch die Anwesenheit der Nebenfiguren - "Mănner" auf der einen, Val'ja (Frau des "Kandidaten") auf der anderen Seite geprăgt ist. Die zentrale Funktion der Nebenfiguren wird durch verschiedene Verfahren signalisiert:

- durch den sujetstrukturellen Aufbau des Texts

- durch die Existenz eines neben der verbalen Interaktion sich vollziehenden zweiten, nonverbalen Interaktionssystems, an dem sowohl die Hauptfiguren als auch die Nebenfiguren beteiligt sind

- durch die Standpunktkomposition.

\section{Die Relation Gleb - "Männer" in den Rahmenteilen}

Sujetstrukturell bildet der Dialog zwischen den beiden Hauptfiguren das Textzentrum, welches eingerahmt wird von der Darstellung des Verhältnisses zwischen Gleb und den

"Männern". Dieses Verhăltnis definiert sich uber die "bedeutenden Leute". Nach der Ankunft des "Kandidaten" treten zunächst die "Mănner" - noch vor Gleb - situativ in Erscheinung. Die Figur Glebs wird über die "Mănner" expositorisch eingefuhrt:

"VeXerom Ze u Gleba Kapustina na kryl'ce sobralis' muziki. Zdali Gleba." (Es schliebt sich der expositorische Kommentar an: "Pro Gleba Kapustina nado rasskazat" $/ \ldots /$ ".) (\$s 182)

Diese wartende Haltung der "Männer" konkretisiert sich zu einer erwartenden Haltung gegenuber Gleb als Herausforderer der "bedeutenden Leute":

"/.../ no mnogie, muziki osobenno, prosto Zdali, kogda Gleb Kapustin srezet znatnogo." (SS 182)

Diese erwartende Haltung ist einerseits Ausdruck der intentionalen Gemeinsamkeit mit Gleb, d.h. Ausdruck des gemeinsamen 
Minderwertigskeitsgefühls gegenüber den "bedeutenden Leuten", andererseits Ausdruck eines hierarchischen Verhältnisses zwischen Gleb und den "Männern". Die "Mănner" betrachten Gleb als ihren Anführer. Sie stehen in einem Gefolgschaftsverhältnis zu ihm.

Das erste Erscheinen Glebs zeigt diesen bereits in exponierter Position gegenüber den "Männern":

"Vysel k muzikam na kryl'co." (Śs 183)

Das Gefolgschaftsverhältnis wird besonders in der anschlieBenden Darstellung des gemeinsamen Gangs zu den Gästen deutlich:

- Gleb gibt das Kommando: " Nu, posli poprovedaem kandidatov, - skromno skazal Gleb. I posli." (SS 183)

- Gleb geht voran: "Gleb \&el neskol'ko vperedi ostal'nych /.../" (Šs 183)

- Kommentar: "Polukalos' voobše-to, દto muziki vedut Gleba. Tak vedut opytnogo kulaknogo bojca, kogda stanovitsja izvestno, Cto na vrazdebnoj ulice ob-javilsja nekij novyj uchar." (Śs 183) 1)

In einem anschlieBenden Dialog (Informationsfragen Glebs uber den "Kandidaten", Antworten der "Männer") stellt Gleb seine wissensmäBige Uberlegenheit vor den "Männern" heraus:

("Männer":) "-Po kakoj special'nosti? A Cert ego znaet... Mne baben'ka skazala - kandidaty." (Gleb:) " - Est' kandidaty techniCeskich nauk, est' ob\$ceobrazovatel'nye, èti $v$ osnovnom trepalogiej $z$ animajutsja." (Ss 183)

Auf dieser wissensmäBigen Uberlegenhelt begrindet sich die hierarchische Position Glebs. Er als einziger ist in der Lage, mit dem "Kandidaten" in dessen Sprache zu kommunizieren. Der Dialog der beiden Hauptfiguren bekommt so einen zusatzlichen Sinn. Hier kulminiert die Uberlegenheit Glebs uber die "Männer". Die Funktion der von Gleb eingeschlagenen fremder. verbalen Strategie besteht neben der Blamierung des "Kandidaten" darin, Gleb auf ein gemeinsames soziales Niveau mit jenem gegenüber den sprachlosen "Männern" zu heben.

1) Vgl. ebf. den expositorischen Kommentar: "Daße ne to ¿to Żali, a కli ran'se $k$ Glebu, a potom uz - vmeste - $k$ yost"ju." (కs 182) 
Der Dialog erweist sich als Prüungssituation nicht nur fur den "Kandidaten", sondern ebenfalls fur Gleb im sinne einer Bewährung seiner fuhrenden position in der sozialen Hierarchie des Dorfs. Eins bedingt das andere: Die Blamierung des "Kandidaten" gelingt nur unter voraussetzung der verbalen Inkompetenz der "Männer", welche die Fehler und damit die Fremdheit der von Gleb praktizierten Interaktionsformen nicht durchschauen.

Im Schlubteil erweist sich diese Funktion des Dialogs als dominante. Bereits der letzte Satz des zentrumteils signalisiert die mit dem Dialogverlauf gesteigerte soziale Uberlegenheit Glebs gegenuber den Männern:

"On vsegda odin uchodil ot znatnych ljudej." (Śs 188)

In Opposition zum gemeinsamen Anmarsch (als Ausdruck des gemeinsamen sozialen Minderwertigskeitsgefuhls) kome jetzt im alleinigen Weggehen Glebs seine soziale Distanz zur eigenen Urwelt zum Ausdruck.

Die diesbezügliche Funktion der fremden verbalen Interaktionsformen wird im anschliebenden Dialog der "Mănner" of fenbar:

" - Ottjanul on ego!... Došlyj, sobaka. Otkuda on pro Lunu-to tak znaet?

- Srezal.

- Otkuda Eto beretsja!" (\$s 188)

Gemab Glebs eigener Intention, sich mit den Masstaben einer fremden Welt zu messen, wird er - besonders durch die Fragen nach der Herkunft seines Wissens ("otkuda") - von den "Männern" in die fremde, unbegreifliche, ihnen selbst unzugangliche Welt gestellt. "1)

Die fremde verbale Interaktion zwischen den Hauptfiguren als Ausdruck sozialer Desintegrationsstrukturen (soziale Hierarchie zwischen Makro- und Mikrokosmos) reproduziert damit zugleich diese strukturen fur den Mikrokosmos.

1) Hier liegt ein weiterer bezeichnender Unterschied zur Funktion des Kosmos-Themas in "Kosmos" vor. Die extrem falschen Vorstellungen Glebs uber dieses Thema (Lebewesen im Innern des Mondes) bilden gleichzeitig den Hohepunkt in der Anerkennung seines wissens durch die "Mănner". 


\section{Nonverbale Interaktion}

Die deutliche Trennung der Interaktion in eine verbale und eine nonverbale Ebene wirkt bereits als solche verfremdend auf die verbale Ebene. Deren Uneigentlichkeit wird durch den parallelen Verlauf eines eigenen Interaktionssystems signalisiert, in dem sich die Faktoren niederschlagen, die in der verbalen Interaktion verschwiegen werden bzw. nur einen 'ideologischen' Ausdruck finden.

Die Ebenentrennung wird hergestellt durch die sujetstrukturell differente Verteilung der beiden Interaktionsebenen auf Haupt- und Nebenfiguren. Der ausschlieblich zwischen den Hauptfiguren gefürten verbalen Interaktion im zentrum steht die verbale Interaktion zwischen Gleb und "Männern" in den Rahmenteilen gegenüber. Auf der Ebene der nonverbalen Interaktion hingegen sind die "Männer" sowohl in den Rahmenteilen als auch im Zentrum beteiligt. Uber diese Ebene wird die Verbindung 2 wischen dem Hauptfigurendialog und der Relation Gleb - "Männer" hergestellt; die nonverbale Interaktion ist der Indikator der sozialen strukturen, in denen sich der Hauptfigurendialog entfaltet.

Die nonverbale Ebene besteht aus zwei Faktoren: Blicken und Lachen. Eine Funktionsbestimmung dieser Faktoren ist abhăngig a) von der jeweiligen vertellung der subjektbzw. Objektrollen der Interaktion, b) von inrer sujetstrukturellen Position, c) von ihrer chronologischen Entwicklung im Zusammenhang mit der Entwicklung auf der verbalen Ebene. Eine Auflistung aller Markierungen unter Berücksichtigung dieser Aspekte ergibt folgendes Bild: 


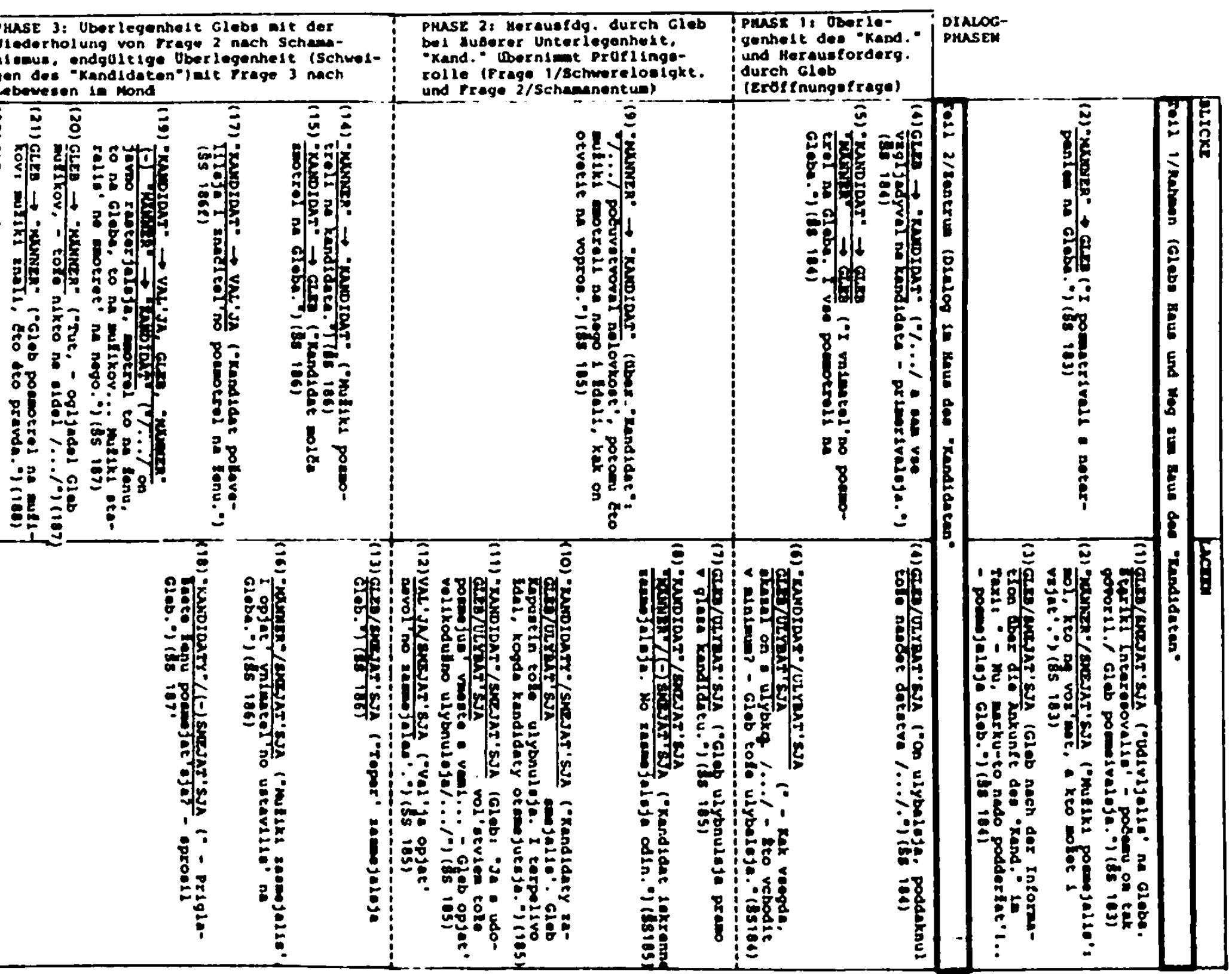




\section{Erläuternder Kormentar}

Es ergeber. sich folgende Funktionen:

1) Das Lachen ist Indikator der interaktiven Machtverhältnisse a) im BewuBtsein der beiden Hauptfiquren

b) im Verhältnis zwischen Haupt- und Nebenfiguren

Ad a) Das Lachen fungiert als Ausdruck des Machtgefühls der beiden Haupt iquren, wobei die Opposition 'ULYBAT'SJA' vs. 'SMEJAT'SJA' einen wichtigen stellenwert besitzt. In der ersten phase des Dialogs ist das 'ULYBAT'SJA' v.a. für Gleb aktiviert und drückt hier das Bewubtsein seiner auberen Unterlegenheit aus 14 : Gleb ordnet sich noch der Intention des "Kandidaten" - Kindheitserinnerungen - unter). Mit Dialogbeginn stehen sich das 'ULYBAT'SJA' Giebs und das 'ULYBAT'SJA' des "Kandidaten" konkurrierend gegenüber (Konkurrenzmarkierung: "toze") (6), indizieren jedoch noch eine äuBere Uberlegenheit des "Kandidaten" (Lächeln über die fehlerhafte Frage Glebs) und eine herausfordernde Position Glebs ("prjamo v glaza") (7).

Eas "bberlegenheitsgefühl des "Kandidaten" wird durch die in 8, 10 und 11 wiederholte Markierung des 'SMEJAT'SJA' ausgedrückt, dem das 'ULYBAT'SJA' Glebs als Ausdruck der äuBeren Unterlegenheit ("terpelivo Zdal, kogda kandidaty otsmejutsja") gegenübersteht (11).

Das erste 'SMEJAT'SJA' Glebs (13) indiziert (in Verbindung mit dem zeitdeiktikum "teper" ") den Wandel in den interaktiven Machtverhältnissen. Ab hier setzt sich auch auf der verbalen Ebene die Jberlegenheit Glebs durch (unmittelbar anschlieBend komit der erfolgreiche Angriff auf die Tabuisierung des Schamanen-Problems durch der. "Kandidaten"; Defensive des "Kandidaten": Schweigen auf Glebs dritte Frage (Thema Mond): Ausdehnung der Repliken Glebs zu monologhafter Länge). Das 'SMEJAT' SJA' wird in der Endphase des Dialoys in Opposition zum '(-)SMEJAT'SJA' der "Kandidaten" (18) und unter Axtivierung elner zusatzlichen semantischen Komponente (Spott: 'USMECHNU''SJA') zum Indikator von Glebs Machtposition.

Ad b) Innerhalb des zentrums ist das Lachen der Nebenfiguren Indikator für Gunst bzw. Nichtgunst der Nebenfiguren a's Publikum der Hauptfiguren. Die Opposition zwischen dem 'SMEJAT'SJA' des "Kandidater" und dem ' $(-)$ SMEJAT'SJA' der "Männer" in 8 indiziert die isolierte position des "Kandidaten" ("odin"). :it dem unmittelbar anschliebenden Herbeirufen der Gattin Val ja durch den "Kandidaten" werden zwei deutlich geschiedene Haupt-/Nebenfigurenreihen geschaffen ("Kandidat"/Val'ja vs. Gleb/"Männer"): Das Lachen Val'jas ist im folgenden Ausdruck ihres Gunstbeweises für den "Kandidaten" (10) und ihrer Verachtung für Gleb (12), das Lachen der "Männer" ist Ausdruck ihres Gunstbeweises für Gleb (16).

Das 'SMEJAT'SJA' als Indikator von Machtverhältnissen betrifft auch die Reproduktion dieser Verhältnisse auf die Relation Gleb - "Mänier" in den Rahmenteilen. Die ersten drei tarkierungen des 'SMEJAT'SJA' stehen in eindeutigem zusammenhang mit dem hierarchischen Verhältnis zwischen Gleb und den "Männern": (1) iachen Giebs nach der 
Information uber seine Anerkennung im Dorf, (2) Lachen der "Männer" in Kombination mit ihrer Erwartungshaltung gegenüber Gleb, Ausdruck ihres Gefolgschaftsverhältnisses, (3) Lachen Glebs als Ausdruck seiner Verachtung gegenüber dem Statussymbol Taxi im Gegensatz zur ehrfurchtigen Erwahnung durch die "Männer". Das 'USifECHNUT'SJA' Glebs im SchluBteil (24) steht wiederum in deutlichem zusammenhang mit seiner durch den Dialogverlauf bestätigten Machtposition gegenüber den "Männern" (vgl. die Situierung des "USMECHNUT'SJA' zwischen der Frage Glebs nach der Beurteilung des "Kandidaten" und der bestätigenden Antwort der "Männer": "Srezal ty ego /.../").

2) Die Blicke sind einerseits Indikatoren des Machtverhälnisses zwischen den Hauptfiguren, hier in Verbindung mit dem Schweigen als Indikator der jeweiligen Unterlegenheitsposition des Blickers:

- in der ersten Phase (vor der ersten Frage Glebs, Uberlegenheit des "Kandidaten") für Gleb markiert (4) (vorherige

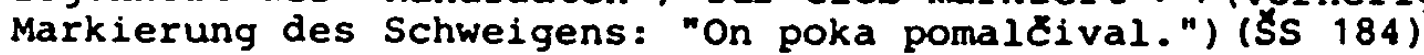
- mit dem Wechsel im Machtverhältnis für den "Kandidaten" markiert (15).

wichtiger ist jedoch die Funktion der Blicke als Indikatoren der Relationen zwischen Haupt- und Nebenfiguren. Hier lassen sich zwei indizierte Relationen unterscheiden: - In der ersten Dialoghälfte indiziert der Wechsel von Blickobjekten und Blicksubjekten den Wandel in der Ubernahme von objekt-bzw. Subjektrollen der prüfung/Bewährung durch die beiden Hauptfiguren. Die Blicke sind zunächst auf Gleb als objekt der Erwartung durch die "Männer" gerichtet. Die "Männer" sind hier sogar gemeinsam mit dem "Kandidaten" Blicker (5). Die einzige Markierung der Blicke im Anfangsteil hat die gleiche Funktion (Erwartung, "s neterpeniem") (2). Der später erfolgende Wechsel in der Blickrichtung ("Männer" $\rightarrow$ "Kandidat") $(9,14)$ indiziert die Ubernahme der Rolle des Prüfungsobjekts durch den "Kandidaten".

- In der zweiten Dialoghalfte - d.h. nach der Festigung der Machtverhältnisse zugunsten Glebs - werden die Blicke ähnlich dem Lachen zusätzlich zu Indikatoren der Gunstverhältnisse zwischen Hauptfiguren und Publikum, wiederum unter deutlicher Trennung der Figurenreihe "Kandidat"/Val "ja und Gleb/"Männer":

- "Kandidat/Val'ja: Blickkontakt mit Val'ja (17) als Ausdruck der Ubereinstimmung ("znaditel'no"); oppositiv hierzu gestorter Blickkontakt mit "Männern" (19)

- Gleb/"Männer": Blickkontakt mit "Männern" als Ausdruck der Ubereinstimmung und der bestandenen Bewährung (Blicksubjekt: Gleb), vgl. die Basierung seiner AuBerung in 20 auf gemeinsame Erfahrungen ("toße ntkto ne sidel") und den zusatz in 21 ("muziki znali, cto éto pravda"). 1)

1) $\mathrm{Zu}$ den nonverbalen Interaktionsformen als Indikatoren der Veränderungen in der Interaktionssituation vgl. Geller, aao, Abschnitt 6 ("Struktura teksta"), S.103-107. Die beiden - von Geller als Organisatoren der syntagmatischen Achse bezeichneten - lexikalischen Reihen des 
IX.2. Standpunktkomposition

Desintegration bestimnt auch die Ebene der Standpunktkomposition. Das entautorisierte Erzählsubjekt im M. 3 war ja durchaus noch in den wertungsmäBigen und phraseologischen Kontext des Mikrokosmos positiv integriert, die Entautorisierung hatte nicht die Destruktion eines den Figuren und dem Erzählsubjekt gemeinsamen Wertesystems zur Folge. Das Erzählsubjekt in "Srezal" findet einen solchen Kontext nicht. Seine Entautorisierung gegenüber den Figuren korrespendiert mit deren Integration. Dies schlagt sich in einem Schwanken des Erzählstandpunkts 2 wischen verschiedenen Figurenstandpunkten und in einer Inkongruenz von erzahlerischer wertungsperspektive und gesamtstruktureller Geste nieder.

Lachens und des Blickens werden in ihrer semantischen Verschränkung mit den ebenfalls frequenzstarken lexikalischen Reihen des "Nichtverstehens" und der "bedeutenden Leute" (bzw. "Kandidaten") als Registratoren der sozialen Hierarchie - paradigmatische Achse - untersucht.

Diese im Prinzip unserer Funktionsbestimung der nonverbalen Interaktion entsprechende Analyse labt sich allerdings nicht mit der in der gleichen Arbeit vorgenommenen Rückführung des Texts auf das Proppsche Mărchenschema in Einklang bringen (Abschnitt 5, "Povestvovatel'naja schema rasskaza", S.99-102). Zwischen der einerseits in der Märchenstruktur entdeckten "archetypischen Situation" des zusammentreffens zweier helten und der andererseits erkannten - marchenuntypischen - Spezifik des Weltenkonflikts im Text (gekennzeichnet durch die sozialhierarchische Beziehung zwischen den Welten und die 'ideologischen' Ausdrucksformen dieses Antagonismus) läbt sich in diesem Text schwerlich ein struktureller zusammenhang - auch nicht im Sinne der Rückführung des sozialen Konflikts auf ein tiefenstrukturelles Märchenschema - entdecken. Gellers eigene Bemuhungen weisen erhebliche Schwächen auf. So werden in einer Synopse von Proppschen Handlungsfunktionen und Handlungsfunktionen im Text entscheidende Funktionen des Proppschen Schemas - wie etwa die Schadenszufügung durch den Schädiger - als fehlend registriert bzw. auf textuell nicht markierte Ereignisse in der vorgeschichte verlegt. Einen groBen Beliebigkeitsgrad weist daruberhinaus die zuordnung einzelner - aus ihrem sozialen Interaktionszusammenhang geloster - Dialogrepliken zu Proppschen Funktionen auf. Schlieblich ist bereits die Einteilung der Agenten ("Kandidat" = "Held", Gleb = "Schädiger") sehr problematisch. Sie entspricht nicht der vielfach signalisierten dominanten Funktion Glebs (quantitativ: sujetstrukturell. vgl. bes. die Rahmenteile: Verhältnis zu den Nebenfiguren: Exposition etc.). 
Psychologisch nimmt das Erzăhlsubjekt einen AuBenstandpunkt ein. Es weiB nicht mehr über das Innenleben einer Figur als die jeweiligen Fremdfiguren, und es konzentriert sich in der Beschreibung der Figur auf die Eigenschaften, die aus der Perspektive der Fremdfiguren bedeutsam erscheinen, nähert sich also zugleich deren Wertungsperspektive an. Korrespondierend dazu übernimnt es den phraseologischen standpunkt der jeweiligen Figuren. ${ }^{1)}$

Der Wechsel zwischen den figuralen Standpunkten bestimmt v.a. den ersten Teil:

1. Absatz/Ankunft des "Kandidaten"

Phraseologische Interferenz mit dem Standpunkt des "Kandidaten" (NAP, Infinitivkonstruktion "poprovedovat", otdochnut" ") (SS 182).

2. und 3. Absatz/ Beschreibung des "Kandidaten"

Standpunkt des gesamten Dorfs:

"Srazu vsja derevnja uznala: K Agaf'e priechal syn s sem'ej, srednij, Kost'ja, bogatyj, ukenyj.

$K$ veceru uznali podrobnosti: on sam - kandidat, Zena tołe kandidat, dot' - skol'nica. Agaf'e prive 1 i ellektriCeskij samovar /.../." (Ss 182)

(Wertungsebene: Konzentration auf die aus der Perspektive der Dorfbewohner interessanten Eigenschaften Familienzugehörigkeit, sozialer Status, Geschenke;

Phraseologische Ebene: Benennung "Kost'ja" = alte Benennung whrend der Kindheit Im Dorf, syntaktische orientierung an mündlicher Rede durch asyndetische Attributreihung, nachgestellte Benennung des Gasts nach seiner familiären zuordnung zur unmittelbar benannten Mutter als den Dorfbewohnern bekannter Person).

4. bis 8. Absatz/ Beschreibung der auf Gleb wartenden "Männer" und expositorischer Kommentar uber Gleb

Ubernahme des Standpunkts der "Mănner"

(Wertungsebene: Konzentration auf die Rolle Glebs im

1) Zur phraseologischen Standpunktinterferenz bei Suksin vgl. Dragomireckaja, aao, S.454ff, Belaja, aao, $479 \mathrm{ff}$ und Cudakova, aao, S.221 und 233. - Belaja interpretiert "Srezal" als Beispiel für die Ubernahme der Perspektive des "Ganzen" bzw. "Volks" durch das Erzählsubjekt, stützt sich jedoch ausschlieblich auf die ersten Absätze (der geglatteten zweiten Textfassung), ohne die Standpunktwechsel und Inkongruenzen als Ironiefaktoren $2 u$ beachten. Kudakova kritisiert demgegenuber die mangelnde Standpunktinterferenz bei Suksin als Ausdruck einer zu schwachen Position des "Autors" gegenuber seinen Helden. Das "Autorenwort" beschränke sich auf "Anmerkungen" (bzw. "Bühnenanweisungen" : remarki) zur Dialogrede der Figuren. Beide Redezonen seien voneinander isoliert. 
sozialmotivierten Нав gegen die Dorfgăste;

Phraseologische Ebene: lexikalische interferenzen, wiederholte Ubernahme von "srezat" und "znatnye ljudi" als wörtern der "Männer" im allgemeinen Teil des expositorischen Kommentars; im konkreten Teil (Erinnerung an die Blamierung eines Obersten) erweitert durch syntaktische Interferenzen: "V proslom godu Gleb srezal polkovnika - s bleskom, krasivo." ( $(S s$ 182) (Ubernahme emotionaler viertungsäuBerungen aus der Perspektive der "Männer" in syntaktischer Nachstellung): in der Darstellung des "Kandidaten" zusätzliche Interferenz durch demonstrative partikel:

"I vot teper" griechal kandidat Zuravlev..." (Šs 183)

"I vot teper' Zuravlev - kandidat." (SS 182) (hier auBerdem syntaktische Nachstellung des Titels als phraseologische Korrespondenz zur wertungsmäBigen Exponierung).

Mit dem Erscheinen Glebs im 9. Absatz wird die direkte Figurenrede dominant. Es kommt aber weiterhin zu phraseologischen Interferenzen zwischen Erzählstandpunkt und Standpunkt der "Männer" bzw. Glebs:

"Muziki posmejalis': mol, kto ne voz'met /.../." (Ss 183)

"Gleb /.../ Surilsja na izbu babki Agaf'i, gde teper' nachodilis" dva kandidata." (SS 183, Hvh.G.W.)

Man kann einen ProzeB der zunehmenden Konzentration auf den Standpunkt der "Männer" als figuraler Fremdperspektive auf beide Hauptfiguren feststellen. Dieser ProzeB kulminiert in der Beschreibung des Dialogs der Hauptfiguren. Hier wird zugleich mit der Inkompetenz des erzăhlerischen Wertungsstandpunkts - entsprechend der Inkompetenz des "Männer"-Standpunkts - seine Inkongruenz zur Gesamtgeste offensichtlich, indem das Erzählsubjekt den fremden Dialog, der als Herrschaftsreproduktion auch gegenüber den "Mănnern" deutlich wurde, aus deren subalterner Perspektive miterlebt, ohne selbst dessen Mechanismus zu durchschauen. Durch diese Inkongruenz entsteht ein ironischer Effekt.

Die Standpunktinterferenz auf der Wertungsebene manifestiert sich v.a. in den wiederholten Kommentaren, die den Dialog in den Wertungskategorien eines Duells beschreiben:

"kor Sunom vzmyl" (కs 183); "ostalsja pobeditelem" (Ss 183): "podbiralsjak pryzku" (SS 185): "primerivalsja" (SS 184): "poper na kandidata" (SS 184): "Gleb brosil per ̌atku. Gleb kak by stal $v$ nebreznuju pozu i Zdal, kogda pertatku podnimut. Kandidat podnjal perCatku." (SS 189); "vzmyl vvys"" (SS 187); "I ottuda, s vysokoj vysi, udaril po kandidatu." (Šs 187).

Der Inkompetenz der "Mănner" gegenüber der verbalen Interaktion der Hauptfiguren entspricht eine Darstellung in 
nonverbalen Vorstellungskategorien. Den Motiven der

"Männer" - Feindschaft, soziale Aggression - entspricht eine Darstellung in den Kategorien kriegerischer Verhaltensmuster.

Das Erzählsubjekt ist nicht nur auf der Ebene der Wertung, sondern auch auf den anderen drei Ebenen in den Rang der "Männer" als Publikum verwiesen. Die Publikumsrolle der "Mănner" wird anfangs thematisiert:

"Prjamo kak na spektakl' chodili." (Šs 186)

Vom gleichen Publikumsstandpunkt ist die Perspektive des Erzählsubjekts geprăgt:

- răumlich: "vidno bylo" (SS 184)

- psychologisch: Vermutungen uber den inneren Zustand der Kampfer: "On, naverno, Zdal takogo momenta, radovalsja emu /.../." (Ss 187, Hvh.G.W.) "Sprosil spokojno, no vnutri nego, naverno, vse vzdragivalo." (కs 187, Hvh.G.W.)

- phraseologisch: emotionale Zuschauerkommentare in elliptischer Syntax:

"Zrja on tak. Ne nado by tak." (Šs 185)

"Eto on tože zrja." (ŚS 187).

Im letzten Teil schlieBlich wird die Standpunktinterferenz wahrend der nachtrăglichen Beurtellung des Kampfs durch die "Mănner" gesteigert bis zur Ubernahme von deren subalterner Wertungsperspektive gegenuber Gleb:

"Gleb Ž po-prežnemu neizmenno udivljal. Izumljal. Voschišal daže." (Š 189)

(Das den drei Verben gemeinsame semantische Merkmal des Uberrationalen verweist auf die dem eigenen Vorstellungsbereich nicht zugänglichen, unbegreiflichen, in der Partizipation an der fremden Welt der Bildung und des wissens begrindeten Fahigkeiten Glebs.)

Gleichzeitig kommt es an dieser stelle zum einzigen 'Hobhen'gewinn des Erzăhlsubjekts in dessen verallgemeinerndem Kommentar über das Verhältnis zwischen den "Mănnern" und Gleb:

"Chot' ljubvi, polozim, tut ne bylo. Net, ljubvi ne bylo. Gleb Zestok, a zestokost' nikto, nikogda, nigde ne ljubil eše." (Ss 189) 
Dieser Kommentar besitzt insofern eine neue Qualität, als hier eine Inkongruenz zwischen Wertungsebene und phraseologischer Ebene entsteht: Obwohl phraseologisch stark am Standpunkt der "Männer" orientiert (mündliche Redeorientierung entsprechend dem vorhergehenden Gespräch zwischen den "Männern"; "položm", "chot", Aussagewiederholung, überstrukturierte Verneinung), wird gleichzeitig der Wertungshorizont der "Männer" uberschritten, incem ihr Verhältnis $z u$ Gleb als eines der Desintegration ('Zestokost' vs. 'ljubov') erkannt wird.

IX.3. Raum/Zeit-Struktur

Die Ebene der Raum/Zeit-Struktur besitzt untergeordneten Stellenwert. Doch sind auch die wenigen Markierungen dieser Ebene im Sinn der Destruktion des M.3 funktionalisiert.

Räumlich ist besonders die Anfahrt des Dorfgastes in einem Taxi von Bedeutung, da sie in offensichtlichem Gegensatz zum für das M. 3 typischen Bewegungswechsel von 'technisch' $2 u$ 'natürlich', 'schnell' zu 'langsam' steht.

Zeitlich ist ein deutliches Signal mit der Benennung des Doifs - "Derevnja Novaja" - gegeben. Das Dorf verliert seine Eigenschaften als Chronotop des Vergangenheit-GegenwartKontinuums, als răumliches Substrat des Alters.

Dem korrespondieren die Altersrelationen innerhalb der Konfigurationsstruktur. Die beiden Hauptfiguren gehoren der gleichen mittleren Erwachsenengeneration an, im Gegensatz zum für das M. 3 typischen Aufeinandertreffen eines jüngeren Dorfgastes mit alten bäuerlichen Figuren. Der Verlust der zeltlichen und gesellschaftlichen Integrationsfunktionen der alten Figuren wird mittels eines Minusverfahrens signalisiert: Die Mutter des "Kandidaten", die "Alte" (starucha) Agaf'ja Zuravleva"), wird - obwohl im ersten Satz als

1) Der Name "Zuravleva" kann als verfremdendes intertextuelles Konnotationssignal für die mit den alten Figuren im M.3 verbundenen chronotopischen Integrationsfunktionen aufgefaBt werden (vgl. die "Kraniche" (Kuravli) in "Za dolami, za lesami"). (Auch der Name "Kapustin" kann als Verfremdung - hinsichtlich der Primitivisierung bäuerlicher Figuren im $M .3$ - aufgefaBt werden.) 
Eeigentliche Gastgeberin bzw. besuchte Person erwähnt sspäter ausgeschlossen. Wăhrend des Dialogs, der in ihrem I Haus stattfindet, tritt sie nicht mehr in Erscheinung. I Die Familie als zeitliches und gesellschaftliches Integrat tionsfeld - für den städischen Gast immerhin noch in (Gestalt der Mutter erwähnt - ist für die Hauptfigur aus c dem dörflichen Mikrokosmos ganzlich minusmarkiert. Sie ist ausgestauscht durch die "lieblose" ("ljubvi ne bylo",s.0.) l Männergemeinschaft.

Schlieblich steht der gesamte Fabel-'Skandal' - die I Destruktion der Intention des Dorfgastes, ̈̈ber die I Kindheitserinnerungen $z u$ sprechen - in einem normennegierenden Verhaltnis zu den zeitlichen Dimensionen im M.3. Das

- Vergangenheit-Gegenwart-Kontinuum ist zerstört, die (faktisch oder vermeintlich) integrativen strukturen - der gemeinsamen Dorfvergangenheit haben keinen EinfluB auf die desintegrativen Strukturen der Gegenwart. 


\section{Literaturverzeichnis}

1) Verzeichnis der Primärtexte und ihrer Abkürzungen

AD F. ABRAMOV, Derevjannye koni, in: Novyj Mir, 1970, Nr.2, S.73-99.

AO F. ABRAMOV, Vokrug da okolo, in: Neva, 1963, Nr.2, S. 109-137.

AP ¿. AJTMATov, Prošcaj Gul'sary, in: Novyj Mir, 1966, Nr.3, S.9-99.

M. ALEKSEEV, Chleb - imja suščestvitel'noe, in: zvezda, 1964, Nr.1, S.9-108.

$A B$ S. ANTONOV, Bibliotekarła, in: Rasskazy russkich sovetskich pisatelej v trech tomach, Moskau 1952, Bd.1, S.144-152.

AV S. ANTONOV, Vesna, in: Rasskazy russkich sovetskich pisatelej $v$ trech tomach, Moskau 1952, Bd.1, S. 122-143.

S. BABAEVSKIJ, Cumaki, in: Rasskazy russkich sovetskich pisatelej v trech tomach, Moskau 1952, Bd.1, S.192-215.

BR V. BELOV, Plotnickie rasskazy, in: Novyj Mir, 1968, Nr.7, S. 7-56.

BP V. BELOV, Privy̌̌noe delo, in: Sever, 1966, Nr.1, S.7-92.

DD E. DOROS, Derevenskij dnevnik, in: Literaturnaja Moskva, Bd.2, Moskau 1956, S.549-626.

DN E. DOROS, Novyj sekretar', in: Rasskazy russkich sovetskich pisatelej $v$ trech tomach, Moskau 1952, Bd.1, S. 686-697.

$\triangle$ JR A. JAŠIN, RYľagi, In: Literaturnaja Moskva, Bd.2, Moskau 1956, S.502-513.

KN A. KALININ, Na srednem urovne, in: $V$ kolchoznoj derevne, Moskau 1955, S.3-24. (Ebf. in: Na krutom pod-eme. OKerki - kolchoznoj Zizni, Moskau 1954.)

A. KALININ, Lunnye noti, in: $V$ goru. OCerki kolchoznoj Zizni, Moskau 1955, S.82-181.

KC JU. KAZAKOV, Zapach chleba, in: Tarusskie stranicy, Kaluga 1961, S.76-78.

KL S. KRUTILIN, Lipjagi. Iz zapisok sel'skogo utitelja, Moskau 1967.

LG A. LEONOV, Gluchaja, in: Ders., Jabloki padajut. Rasskazy 1 povest', Leningrad 1968, S.5-17.

LU A. LEONOV, Uchan i Krjazik, in: Ders.: , Jabloki padajut. Rasskazy i povest', Leningrad 1968, S.59-85.

LB V. LICHONOSOV, Brjanskie, in: Ders., VeCera. Rasskazy, Moskau 1966, S.7-12. (Zuerst in: Novyj Mir, 1963, Nr.11) 
LR V. LICHONOSOV, Rodnye, in: Novyj Mir, 1967, Nr.2, S. 145-159.

MK B. MOŽAEV, Iz Zizni Fedora Kuz'kina, in: Novyj Mir, 1966, Nr.7, S.42-118.

MS A. MUSATOV, Sirokoe pole, in: V kolchoznoj derevne, Moskau 1955, S.472-484.

NC JU. NAGIBIN, Chazarskij ornament, in: Literaturnaja Moskva, Bd.2, Moskau 1956, S. 380-396.

$\rightarrow$ NN JU. NAGIBIN, Novyj predsedatel', in: Novyj Mir, 1955, $\mathrm{Nr} .8, \mathrm{~S} .3-14$.

G. NIKOLAEVA, Povest' 0 direktore MTS in glavnom agronome, in: Znamja, 1954, Nr.9, S.9-62. (Ebf. tn: V kolchoznoj derevne, Moskau 1955.)

NP E. NOSOV, Pjatyj den osennej vystavki, in: Ders.., I uplyvajut parochody. Povesti 1 rasskazy, Moskau 1975, S.199-224. (Zuerst in: Novyj Mir, 1967, Nr.8.)

N2 E. NOSOV, 2 a dolami, za lesami, in: Ders., I uplyvajut parochody. Povesti i rasskazy, Moskau 1975, S.71-90. (Zuerst in: Novyj Mir, 1966, Nr.2.)

OR V. OVEXKIN, Rajonnye budni, In: Novyj M1r, 1952, Nr.9, S. 204-221. (Ebf. in: Rasskazy 1951 - 1952, Moskau 1954.)

RS G. RADOV, Sef, in: Ders., Na ulice Kaza''ej, Leningrad 1959 , S. 160-175.

RT G. RADOV, Teł丈a, In: Rasskazy 1958 goda, Moskau 1959, S. 357-368.

RD V. RASPUTIN, Den'gi dlja Maril, in: Sibirskie ogni, 1967, Nr.9, S.9-72.

V. RASPUTIN, Poslednij srok, in: Nał Sovremennik, 1970, $\mathrm{Nr} .7, \mathrm{~S} .3-52$ und $\mathrm{Nr} .8, \mathrm{~S} .8-54$.

V. RASPUTIN, Zivi i pomni, Moskau 1975. (Zuerst in: Nas sovremennik, 1974, $\mathrm{Nr} .10$ und 11.)

Sk V. SOLOUCHIN, Kaplja rosy, in: Znamja, 1960, Nr.1, S. 54-106 und $\mathrm{Nr} .2, \mathrm{S.3-76}$.

SM A. SOLZENICYN, Matrenin dvor, in: Novyj Mir, 1963, Nr.1, S. 42-63.

SK V. YUUKSIN, Kosmos, nervnaja sistema 1 Jmat sala, in: Ders., Zemljaki. Rasskazy, Moskau 1970, S.15-25.

v. SukŠIN, Sel'skie Ziteli, in: Oktjabr', 1962, Nr.5, S.113-132.

SS V. YUKSIN, Srezal, in: Ders.. Besedy pri jasnoj lune. Rasskazy, Moskau 1974, S.182-199. (Zuerst in: Novyj Mir, 1970, Nr.7.)

TP V. TENDRJAKOV, Padenie Ivana Cuprova, in: Novyj Mir, 1953, Nr.11, S.103-134. (Ebf. in: V kolchoznoj derevne, Moskau 1955.) 
TO G. TROEPOL'SKIJ, Odin den'. Iz zapisok agronoma, in: Novyj Mir, 1954, Nr.1, S.99-122. (Ebf. in: V kolchoznoj derevne, Moskau 1955.)

TS G. TROEPOL'SKIJ, Sosedi, in: Novyj Mir, 1954, Nr.4, S.80-98. (Ebf. in: Na krutom pod-eme. Oderki o kolchoznoj zizni, Moskau 1954.)

I. VINICENKo, Liven', in: Nam pišt iz derevni. Sbornik, Moskau 1967.

ZN S. ZALYGIN, Na Irtyłe, in: Novyj Mir, 1964, Nr.2, S.3-80.

zV S. ZALYGIN, Vesnoj nynesnego goda, in: Na krutom pod-eme. Ołerki o kolchoznoj Zizni, Moskau 1954, S.55-148. (Zuerst in: Novyj Mir, 1954, Nr.8.)

N. ZDANOV, Poezdka na rodinu, in: Literaturnaja Moskva, Bd. 2, Moskau 1956, S.404-414.

2) Verzeichnis der Sekundärtexte

Bibliographie:

G.A. HOSKING, A Selected Bibliography of Recent Village Prose in the Soviet Union, in: ABSEES (Soviet and East European Abstract Series), 1973, Nr.2, Special Section, S.i-xiv.

F. ABRAMOV, Ljudi kolchoznoj derevni v poslevoennoj proze, in: Novyj Mir, 1954, Nr.4, S.210-231.

V. AKIMOV, Cto otkryvaet derevenskaja proza?, in: $V$ konce semidesjatych. Literatura nasich dnej (Sost. I.S. Eventov), Leningrad 1980, S.59-94.

V. AKIMOV, Gde Ze iskat' otvet?, in: Zvezda, 1968, Nr.5, S. 207-213.

B. ANASENKOV, ... kak zerkalo NTR, in: Literaturnaja Gazeta, 17.10.1979, S.4.

D. ANGEL'EV, Na novoj derevenskoj ulice, in: Literaturnaja Gazeta, 19.12.1979, S.4.

L. ANNINSKIJ, Tolka opory. Éticeskie problemy sovremennoj prozy, in: Don, 1968, Nr.6, S.168-181 und Nr.7, S.178-187.

S. ANTONOV, Pis'ma o rasskaze, Moskau 1964.

L. ANTOPOL'SKIJ, Korni Xeloveka, in: Junost', 1969, Nr.1, S. 67-70.

L. ANTOPOL'SKIJ, Puti i poiski, in: Novyj Mir, 1973, Nr.7, S.247-257.

V.A. APUCHTINA, Sovremennaja sovetskaja proza. 60-e - nacalo 70-ch godov, Moskau 1977.

V. ASTAF'EV, Rasskaz - ljubimyj zanr, in: Literaturnaja Gazeta, 19.4.1967, S.4. 
M. BACHTIN, Formy vremeni 1 chronotopa $v$ romane. Ozerki po istorizeskoj poetike, in: Ders., Voprosy literatury i éstetiki. Issledovanija raznych let, Moskau 1975, S.234-407. S.234-407.

E.A. BAL'BUROV, Lirikeskaja proza $v$ literaturnom processe 1950-1960ch godov, in: Russkaja literatura, 1979, Nr.2, S.55-72.

K. BARSKAJA, M. SNEERSON, za osvoenie masterstva, in: Zvezda, 1953, Nr.3, S.159-166.

G.A. BELAJA, Rozdenie novych stilistileskich form kak process preodolenija "nejtral nogo" stilja, in: Mnogoobrazie stilej sovetskoj literatury. Voprosy tipologii (Red. N.K. Gej u.a.), Moskau 1978, S.460-485.

V. BONDARENKo, $v$ novuju derevnju - na telege?, in: Literaturnaja Gazeta, 5.12.1979, S.4.

G. BROVMAN, Talant i napravlenie, in: Don, 1967, Nr.7, S.159-168.

D. BROWN, Nationalism and ruralism in recent Soviet Russian Literature, in: Review of National Literatures, 1972, Nr.1, S. 183-209.

D. BROWN, Soviet Russian Literature since Stalin, Cambridge 1978 .

v. CaLmaEv, Problemy charaktera $v$ oterkach V. Tendrjakova, in: Ob oterke. Sbornik statej (Red. P.F. Jusin), Moskau 1958, S. 100-119.

v. CaLMAEV, Literatura sud'by narodnoj, in: Moskva, 1957, Nr.11, S.199-208.

v. CaLmaEV, Raspachannoe pole, in: Literatura i sovremennost'. Sbornik 6. Stat' 1 o literature 1964-1965 godov (Sost. L. Jakimenko, S. Małinskij, E. Osetrov), Moskau 1965, S.91-119.

v. Kalmaev, Neizbeźnost', in: Molodaja Gvardija, 1968, Nr.9, S.259-289.

v. Calmaev, Velikie iskanija, in: Molodaja Gvardija, 1968, Nr.3, S.270-295.

F. Cap Cachov, V ugodu koncepcii, il. - Literaturnaja Gazeta, 25.6.1969, S.7.

Celovek na zemle, in: Literaturnaja Gazeta, 3.4.1968, S.7.

Cetvertyj s-ezd pisatelej SSSR. 22-27 maja 1967 goda. Stenograficeskij otcet, Moskau 1968.

A. CHAJLOV, Poklonjat'sja ili issledovat'. Razmyslenija o derevenskoj proze, in: Sever, 1969, Nr.3, S.111-146.

N.S. CHRUSCHTSCHOW, Reden zur Kulturpolitik. 1956 - 1963, Berlin 1964.

A. ChVATOV, Certy narodnosti, in: Nas sovremennik, 1973, Nr.1, S.179-186.

M. CUDAKOVA, Zametki o jazyke sovremennoj prozy, in: Novyj Mir, 1972, Nr.1, S.212-245. 
M. ¿udakova, A. Čudakov, .... togda prichodit povest', in: Literaturnaja Gazeta, 29.8.1973, S.6.

L. DAETZ, Die bäuerliche Literatur und ihre Traditionen, in: G. Lindemann (Hg.), Sowjetliteratur heute, München 1979, S. 100- 122 .

I. DEDKOV, Stranicy derevenskoj Zizni, in: Novyj Mir, 1969, $\mathrm{Nr} .3, \mathrm{~S} .231-246$.

A. DEMENT'EV, O tradicijach i narodnosti, in: Novyj Mir, 1969, Nr.4, S.215-235.

Derzat' ruku na pul'se zizni (Sost. V.P. Tel'pugov), Moskau 1958. (Diskussion der Moskauer Sektion des Schriftstellerverbands vor dem ersten KongreB des Schriftstellerbands der RSFSR: "Tema sovremennosti v proizvedenijach prozy poslednich let". Mit Beitrăgen von G. Brovman, G. Nikolaeva, T. Trifonova, F. Pevnev, S. Surtakov, L. Sobolev u.a.)

N.V. DRAGOMIRECKAJA, Slovo geroja kak princip organizacii stilevogo celogo, in: Monogoobrazie stilej sovetskoj literatury. Voprosy tipologii (Sost. N.K. Gej u.a.), Moskau 1978, S.446-459.

E. DURKHEIM, Die Regeln der soziologischen Methode, Neuwied-Berlin 1961.

A. DYMSIC, Rasskazy o rasskazach, zametki o povestjach, in: Ogonek, 1963, Nr.13, S.30-31.

N. DŽUSOJTI, Nacional'naja samobytnost' - svojstvo talanta, in: Literaturnaja Gazeta, 24.9.1969, S.4.

K. EIMERMACHER, Literaturpolitik, in der UdSSR, in: Sowjetsystem und demokratische Gesellschaft. Eine vergleichende Enzyklopădie, Freiburg-Basel-Wien 1971, Bd.4, Sp.91-117.

K. EIMERMACHER, Der literarische Normenwandel in der russischen Literatur der fünfiger Jahre, in: wiener Slawistischer Almanach, 1980, Bd.6, S.109-129.

A. El-JASEvIC, Cto est' povest?, in: Zvezda, 1968, Nr.5, S. 190-198.

E. ETKIND, Unblutige Hinrichtung. Warum ich die Sowjetunion verlassen muBte, München-zürich 1978.

G. FIS, Na kolchoznuju temu, in: Novyj Mir, 1955, Nr.8, S.235-255.

L. FOMENKo, Ne stoit selo bez truženika, in: Moskva, 1964, Nr. 11, S. 200-207.

L. FOMENKO, Charaktery, in: Zvezda, 1967, Nr.6, S.196-203.

JU. GALKIN, Derevnja - literaturnaja i podlinnaja, in: Voprosy literatury, 1973, Nr.3, S.56-62.

L. GELLER, Opyt prikladnoj stilistiki. Rasskaz V. Sukšna kak ob-ekt issledovanija s peremennym fokusnym rasstojaniem, in: Wiener Slawistischer Almanach, 1979, Bd.4, S.95-123. 
L. GLADKOVSKAJA, Sovetskij rasskaz, in: zvezda 1953, Nr.3, S. 169-175.

P. GLINXIN, Zemlja 1 asfalt, in: Molodaja Gvardija, 1967, Nr.9, S.240-255.

P. GLINKIN, Pafos vremen1, in: Volga, 1968, Nr.8, S.126-137.

A.J. GREIMAS, Elemente einer narrativen Grammatik, in: H. Blumensath (Hg.), Strukturalismus in der Literaturwissenschaft, Koln 1972, S.47-67.

H. GUNTHER, Die Konzeption der literarischen Evolution im tschechischen Strukturalismus, in: alternative, 1971 , Nr. 80, S.183-200.

H. GUNTHER, Sozialistischer Realismus, in: Reallexikon der deutschen Literaturgeschichte. Begrundet von P. Merker und W. Stammler, Bd.4 (Hg. K. Kanzog, A. Masser), Berlin-New York (2. Aufl.) 1979, S.57-64.

v. GuSEv, o proze, derevne 1 cel'nych ljudjach, in: Literaturnaja Gazeta, 14.2.1968, S.6.

A.A. HANSEN-LOVE, Der russische Formalismus. Methodologische Rekonstruktion seiner Entwicklung aus dem Prinzip der Verfremdung, Wien 1978.

M. HAYWARD, The Decline of Socialist Realism, in: Survey, 1972, Nr.1, S.73-97.

G. HILDEBRANDT, Ein Beitrag zur sowjetischen Dorfprosa der Gegenwart, in: Die Welt der Slawen, 1973, s.190-200.

J. HOLTHUSEN, Stilistik des "uneigentlichen" Erzahlens in der sowjetischen Gegenwartsliteratur, in: Die Welt der Slawen, 1968, S.225-245.

G.A. HOSKING, The Russian Peasant Rediscovered: "Village Prose" of the 1960s, in: Slavic Review, 1973, Nr.4, S.705-724.

G. HoskING, Beyond Socialist Realism. Soviet Fiction since Ivan Denisovich London 1980.

D.F. IVANOV, Izobrazenie konfliktov $v$ literature o kolchoznoj zizni. In: Partijnost' literatury 1 problemy chudozestvennogo masterstva (Red. A.S. Mjasnikov), Moskau 1961, S. 77-130.

v. IVANOV, Nacional'nyj charakter i literatura, in: Literaturnaja Gazeta, 7.5.1969, S.3-4.

L. JAKIMENKO, 0 chlebe, zemle i nasej literature, in: Literatura i sovremennost'. Sbornik 5. Stat' 1 o literature 1963-1964 godov (Sost. L. Jakimenko, S. Masinskij. E. Osetrov), Moskau 1964, S.109-134.

L. JAKOVLEV, Protiv antiistorizma, in: Literaturnaja Gazeta, 15.11.1972, S.4-5.

A. JANOV, Polozitel'nyj geroj ili Don Kichot?, in: Voprosy literatury, 1966, Nr.8, S.3-22. 
A. JANOV, Esli zagljanut' $v$ buduskee, in: Literaturnaja Gazeta, 28.2.1968, S.6.

I. JANOVSKIJ, Trudnyj put', in: Literatura i sovremennost'. Sbornik 6. Stat' 1 o literature 1964-1965 godov (Sost. L. Jakimenko, S. Mašinskij, E. Osetrov), Moskau 1965, S. 120-138.

I. JANOVSKIJ, Iz polemiČeskich zametok, in: Sibirskie ogni, 1968, Nr.4, S.165-175.

P.F. JUSIIN, O Kanre oterkovoj literatury, in: Ob oterke. Sbornik statej (Red. P.F. JuSin), Moskau 1958, S.36-54.

v. KAMJANOV, Ne dobrotoj edinoj.... in: Literaturnaja Gazeta, 22.11.1967, S.4.

A. KARAGANOV, Trubnikov snova pod ognem, in: Voprosy literatury, 1966, Nr.8, S.22-31.

V. KARDIN, Iskatel' ili obyvatel'. Zametki o molodom geroe, in: Molodaja gvardija, 1956, Nr.1, S.203-217.

K. KASPER, Der Erzähler in der russisch-sowjetischen kleinen Prosa (Povest' und Erzahlung), Jena (Habil.) 1966.

K. KASPER, Funktionen des Erzahlers in der russisch-sowjetischen Prosa nach 1956, in: Zeitschrift für Slawistik, 1968, Nr.1, S.61-68.

K. KASPER, Die Entfaltung der sowjetischen Skizze und ihr Einflub auf die Erzahlung in der Nachkrieqszeit, in: Zeitschrift für Slawistik, 1971, Nr.3, S.419-430.

JU. KAZAKOV, Ne dovol'no 1i?, in: Literaturnaja Gazeta, 27.12.1967, S.6.

2. KERDINA, Obrašajas' $k$ istokam, in: Literaturnaja Gazeta, 18.6.1969, S.4.

G. KNAPP, Textarten - Typen - Gattungen - Formen, in: H.L. Arnold, V. Sinemus (Hg.), Grundzüge der Literaturund Sprachw1ssenschaft, Bd. 1: L1teraturw1ssenschaft, München (5. Aufl.) 1978, S.258-268.

R. KONIG, Soziale Normen, in: W. Bernstorf (Hg.), worterbuch der Soziologie, Stuttgart (2. Aufl.) 1969, S.978-983.

A. KOGAN, Zizn', Zanr, masterstvo. Zametki ob ołerkach i rasskazach I. Antonova, S. Zalygina, G. Baklanova, G. Troepol'skogo, in: Ob olerke. Sbornik statej (Red. P.F. Jusin), Moskau 1958, S.145-206.

v. KONOV, Pogoda na zavtra, in: Literaturnaja Gazeta, 13.2. 1980, S.4.

JU. KONSTANTINOV, Oblik anja. Sovremennyj ocerk o sovetskoj derevne, in: Puti sovetskogo olerka. Sbornik lit.-kritiz. statej, Leningrad 1958, S.337-366.

N.A. KOŽEVNIKOVA, o tipach povestvovanija $v$ sovetskoj proze, in: Voprosy jazyka sovremennoj russkoj literatury

(Red. V.D. Levin), Moskau 1971, S.97-163. 
N.A. KOŽEVNIKOVA, O sootnosenii reči avtora i personaža, in: Jazykovye processy sovremennoj russkoj chudozestvennoj literatury. Proza (Sost. A. Gorskov), Moskau 1977, S.7-98.

v. KozInOV, Cennosti istinnye i mnimye, in: Literaturnaja Gazeta, 31.1.1968, S.5.

v. KoZINOV, Nacional'naja literatura: Prosloe ili budušee?, in: Literaturnaja Gazeta, 23.6.1969, S.4.

L. KRJAČKo, Listy 1 korni, in: Literaturnaja Gazeta, 29.11.1967, S.5.

v. KULEłov, Narodnost': Istorija i sovremennost', in: Literaturnaja Gazeta, 3.6.1970, S.5.

JU. KUZ'MENKO, Sovetskaja literatura vCera, segodnja i zavtra, Moskau 1981.

F. KUZNECOV, Novoe $v$ Kizni i novoe $v$ literature, in: Novyj Mir, 1961, Nr.1, S.229-245.

F. KUZNECOV, $k$ zrelosti.

1. Konec 'Cetvertogo' pokolenija, in: Junost', 1966, Nr. $11, S .83-86$.

2. Ot ispovedanija - $k$ issledovaniju, in: Junost., 1967, $\mathrm{Nr} .3,5.59-64$.

3. SopriCastnost' Kizni, in: Junost', 1967, Nr.5, S.83-88.

F. KUZNECOV, "Dobirat'sja do pervopriCin!", in: Literaturnaja Gazeta, 21.3.1973, S.4.

F. KUZNECOV, Sud'by derevni $v$ proze i kritike, in: Novyj Mir, 1973, Nr.6, s.233-250.

v. LAKSIN, Ivan Denisovix, ego druz'ja i nedrugi, in: Novyj Mir, 1964, Nr.1, S.223-245.

v. LAKSIN, Pisatel', Xitatel', kritik, in: Novyj Mir, 1966, Nr. 8, S.216-256.

A. LANSXIKov, Ostorozno, koncepcija!, in: Molodaja Gvardija, 1969, Nr.2, S.275-297.

M. LAPSIN, "Rajonnye budni" Valentina Oveðkina, in: Ob ołerke. Sbornik statej (Red. P.F. Jusin), Moskau 1958, S.55-99.

R. LAUTMANN, Wert und Norm. Begriffsanalysen für die Soziologie, Opladen (2. Aufl.) 1971.

v. LAVROV, Rasłirenie gorizonta. O derevenskoj proze, in: $V$ seredine semidesjatych (Sost. I. Eventov), Leningrad 1977, S.121-140.

F. LEVIN, Obosnovana li trevoga?, in: Literaturnaja Gazeta, 17.1.1968, S.6.

G. LICHTHEIM, Das Konzept der Ideologie, Frankfurt/M. 1973.

M. LOBANOV, ProsveCennoe mestanstvo, in: Molodaja Gvardija, 1968, Nr.4, S.294-306.

G. LOMIDZE, Ne mif, a real'nost'!, in: Literaturnaja Gazeta, 3.6.1970, S.5. 
JU. LOTMAN, Die Struktur literarischer Texte, Müchen 1972.

JU. LOTMAN, Die Entstehung des Sujets typologisch gesehen, in: Ders., Aufsätze zur Theorie und Methodologie der Literatur (Hg. K. Eimermacher), Kronberg/Ts. 1974, S. 30-66.

JU. MAL'CEV, Promezutocnaja literatura $i$ kriterij podlinnosti, in: Kontinent, 1980, Bd.25, S.285-321.

M.A. MAKINA, Tvor Cestvo krest'janskoj "plejady" v russkoj literature natala XX veka $i$ "derevenskaja" proza nasich dnej, in: Russkaja literatura, 1980, Nr.4, S.73-91.

G. MARKOV, Sovremennost' i problemy prozy, in: Ketvertyj s-ezd pisatelej SSSR. 22-27 maja 1967 goda. StenografiZeskij otそet, Moskau 1968, S.12-25.

G. MARKOV, Sovetskaja literatura $v$ bor'be za kommunistileskoe stroitel'stvo $i$ ee zadaci $v$ svete resenij XXIV s-ezda KPSS, in: Pjatyj s-ezd pisatelej SSSR. 29ijunja - 2ijulja 1971 goda, Sten. otcet, Moskau 1972, S.8-28.

A. MCCAULEY, Kolkhoz Problems in Recent Literary Magazines, in: Soviet Studies, 1964, Nr.3, S.308-330.

P. MEDVEDEV, Die formale Methode in der Literaturwissenschaft (Hg. H. Glück), Stuttgart 1976.

A. METEENKo, Sovremennoe i vecnoe, in: Moskva, 1969, Nr.1, S. 198-211.

v. MICIAL'SKIJ, Boj s ten'ju, in: Literaturnaja Gazeta, 7.11.1979, S.6.

M.V. MINOKIN, Problema narodnogo charaktera $v$ sovremennoj sovetskoj proze, in: Zanry i stili literatury socialistiCeskogo realizma. Sbornik trudov (Red. F.Ch. Vlasov u.a.), Moskau 1973, s.3-17.

B. MOKAEV, Prodolzim dialog, in: Literaturnaja Gazeta, 24.12.1964, S.2.

B. MoZAEV, Gde dy\$it duch?, in: Literaturnaja Gazeta, 31.10 .1979$, S.4.

E. MOZEJKo, Der sozialistische Realismus. Theorie, Entwicklung und Versagen einer Literaturmethode, Bonn 1977.

J. MUKARovSKÝ, Probleme der ästhetischen Norm, in: P.V. Zima (Hg.), Textsemiotik als Ideologiekritik, Frankfurt/M. 1977 , S.165-180.

J. MUKAŘovSKÝ, Ásthetische Funktion, Norm und ästhetischer Wert als soziale Fakten, in: Ders., Kapitel aus der Asthetik, Frankfurt/M. (3. Aufl.) 1978, S.7-112.

T. NAPALOVA, Nacional 'naja samobytnost' pisatelja i duchovnyj oblik geroja, in: Volga, 1972, Nr.10, S.147-177.

Novoe selo, novye geroi. Kruglyj stol, in: Ifteraturnaja Gazeta, 23.10.1974, S.2,4. 
Novoe $v$ kolchoznoj derevne $i$ literature, in: Voprosy literatury, 1979, Nr.1, S.3-38.

A. OGNEV, Russkij sovetskij rasskaz 50-70ch godov, Moskau 1978.

A. OKOPIEN-SZAWIŃSKA, Die personalen Relationen in der literarischen Kommunikation, in: R. Fieguth (Hg.), Literarische Kommunikation. Sechs Aufsätze zum sozialen und kommunikativen Charakter des literarischen Werks und des literarischen Prozesses von K. Bartoszynski, M. Glowihski, W. Grajewski und A. Okopien-slawitska, Kronberg/Ts. 1975, S.127-147.

A. OKOPIEN-SLAWINSKA, Die Rolle der Kommunikation im itterarischen ProzeB, in: R. Fieguth (Hg.), Literarische Kommunikation. Sechs Aufsätze..., Kronberg/Ts. 1975, S.23-42.

I.A. OSSOVECKIJ, Dialektnaja leksika $v$ proizvedenijach sovetskoj chudožestvennoj literatury 50 - 60-ch godov, in: Voprosy jazyka sovremennoj russkoj literatury (Red. V.D. Levin), Moskau 1971, S.97-163.

V. OVEXKIN, Kolchoznaja $X^{\prime} n^{\prime} 1$ literatura, in: Novyj Mir, 1955, Nr.12, S.116-145.

V. OzEROV, Um, Zest' 1 sovest' nałej époch1, in: Novyj Mir, 1957, Nr.10, S.213-235.

V.N. PAVLOV, Spory o slavjanofil'stve i russkom patriotizme $v$ sovetskoj nauknoj literature 1967 - $1970 \mathrm{gg}$. , in: Grani, 1971, Nr.82, S.183-211.

A.I. PAVLOVSKIJ, 0 lirileskoj proze. Ol'ga Berggol'c 1 vladimir Solouchin, in: Vremja, Pafos, Stil'. Chudozestvennye tekenija $v$ sovremennoj sovetskoj literature (Red. V.V. Buznik, V.A. Kovalev), Moskau-Leningrad 1965, S. 247-271.

A.I. PAVLovSKIJ, Rasskaz 50-ch godov, in: Russkij sovetskij rasskaz. Ołerki istorii Zanra (Red. V.A. Kovalev), Leningrad 1970, S.573-625.

Y. PERRET-GENTIL, Der Kolchosbauer in der heutigen russischen Dorf-Literatur, in: Osteuropa, 1978, Nr.9, S.794-810.

J.U. PETERS, Réalisme sans rivages? Zur Diskussion uber den sozialistischen Realismus in der Sowjetunion seit 1956 , in: Zeitschrift für slavische Philologie, 1974, S.291-324.

M. PFISTER, Das Drama. Theorie und Analyse, Munchen 1977.

Pjatyj s-ezd pisatelej SSSR. 29ijunja - 2ijulja 1971 goda. Sten. otzet, Moskau 1972.

I.I. PLECHANOVA, Osobennosti sjuzetoslozenija $v$ tvorðestve v. Sukšina, Ju. Trifonova, V. Rasputina. $K$ probleme chudozestvennoj uslovnosti, in: Russkaja literatura, 1980, Nr.4, S.71-88. 
Po trebovaniju $Z_{i z n i}$. S IV plenuma vsesojuznogo soveta po kritike, in: Voprosy literatury, 1971, Nr.8, S.26-39. (Beiträge von L. Jakimenko, V. Piskunov, F. Abramov, I. Vinitenko, L. Fomenko, I. Drucé, L. Terakopjan, I. Janovskij u.a.)

G.N. POSPELOV, $K$ sporam o socialističeskogo realizma, in: Filologi Ceskie nauki, 1975, Nr.1, S.3-16.

A. PROCHANOV, Metafora sovremennosti, in: Literaturnaja Gazeta, 12.9.1979, S.4.

V.I. PROTCENKO, Sovremennaja povest' o derevne. K probleme narodnogo charaktera, in: Russkaja literatura, 1970, $\mathrm{Nr} .4, \mathrm{~S} .62-79$.

V.I. PROTCENKO, Povest' 60-ch - nacala 70-ch godov, in: Sovremennaja russkaja sovetskaja povest. (Sost. N.A. Gromova, V.A. Kovalev), Leningrad 1975, S.161-223.

V.I. PROTCENKO, Nekotorye voprosy razvitija "derevenskoj prozy". in: Problemy russkoj sovetskoj literatury (Sost. V.A. Kovalev), Leningrad 1976

V.I. PROTCENKO, Sovremennaja "derevenskaja proza" v literaturnoj kritike. Real'nye dostizenija i spornye ocenki, in: Russkaja literatura, 1977, Nr.2, S.54-66.

Protiv Cego vystupaet "Novyj Mir"? Pis'mo v redakciju, in: Ogonek, 1969, Nr.30, S.26-29.

G. RADOV, Na novom ètape, in: Znamja, 1971, Nr.7, S.203-216.

Rasskaz segodnja, in: Voprosy literatury, 1967, Nr.7, S.55-93.

Redaktion Osteuropa, Umwege zur Agrostadt?, in: Osteuropa, 1954, Nr.2, S.124-129.

Redaktion Osteuropa, Neulandgewinnung, das neue Programm, in: Osteuropa, 1954, Nr.4, S.304-313.

V. ROSLJAKOV, Ironil ne podvlastno, in: Literaturnaja Gazeta, 17.1.1968, S.6.

T.I. RYBAL'CENKo, Besfabul'nyj rasskaz 60-ch godov i razvitie sovremennoj povesti, in: Problemy literaturnych Zanrov. Materialy vtoroj naucnoj mežvuzovskoj konferencil 30 sentjabrja - 4 oktjabrja 1975 goda, Tomsk 1975, S.180-183.

E.A. SAFRONOVA, Rasskaz $i$ oterk 50-ch godov. $K$ probleme vzaimovlijanija Zanrov. In: Problemy literaturnych žanrov. Materialy vtoroj naucnoj mezvuzovskoj konferencii 30 sentjabrja - 4 oktjabrja 1975 goda, Tomsk 1975, S.159-160.

G.I. SAKUN, Nekotorye osobennosti tipizacii $v$ sovremennoj povesti o derevne, in: Russkaja literatura, 1973, Nr.2, S. 164-167.

G.I. SAKUN, Nekotorye Zanrovye Certy povesti $v$ novellach, in: Zanry i stili literatury socialisticeskogo realizma.

Sbornik trudov (Red. F.Ch. Vlasov), Moskau 1973, S.234-246.

N. ŚaLOMA, Celovek $v$ kollektive, in: Kommunist, 1957, Nr.5, S.75-87. 
I. SAJTANOV, Reakcija na peremeny. Točka zrenija avtora $i$ geroja $v$ literature o derevne, in: Voprosy literatury, $1981, \mathrm{Nr} .5, \mathrm{~S} .34-60$.

o. SCHILLER, Der neue Kurs in der sowjetischen Agrarpolitik, in: Osteuropa, 1953, Nr.6, S.403-412.

H.R. SCHLETTE, Ideologie, in: H. Krings, H.M. Baumgartner, Ch. Wild (Hg.), Handbuch philosophischer Grundbegriffe, München 1973, Bd.3, S.720-728.

W. SCHMID, Thesen zur innovatorischen Poetik der russischen Gegenwartsprosa, in: Wiener Slawistischer Almanach, 1979, Bd.4, S.55-93.

K.D. SEEMANN, Die sowjetische Literaturpolitik seit Stalins Tod in historischer Sicht, in: Jahrbücher für Geschichte Osteuropas, 1965, Neue Folge 13, S.40-64.

JU. SELEZNEV, Novye puti neizbežny. No..., in: Literaturnaja Gazeta, 20.2.1980, S.5.

v. SEMENOV, o rodine "maloj" i bol'కoj, in: Molodaja Gvardija, 1966, Nr.10, S.288-300.

V. SEMENOV, Rodniki b'jut iz glubin, in: $\chi_{i t}$ strastjami i idejami vremeni. Sbornik statej o literature (Sost.

A. Lanstikov), Moskau 1970, S.31-50.

Sestoj s-ezd pisatelej SSSR. 21 ijunja - 25 ijunja $1976 \mathrm{~g} .$. Sten. otčet, Moskau 1978.

A. SHDANOW, Uber Kunst und Wissenschaft, Kiel 0.J..

N.N. SHNEIDMAN, Soviet Literature in the 1970's. Artistic Diversity and Ideological Conformity, Toronto-BuffaloLondon 1979.

A. '̌IKKINA, Zizn', liriCeskaja ispoved' 1 voprosy masterstva, in: Neva, 1964, Nr.2, S.181-188.

J. SLAWIŇSKI, Literatur als System und ProzeB. Strukturalistische Aufsäze zur semantischen, kommunikativen, sozialen und historischen Dimension der Literatur, München 1975.

Slovar' literaturövedCeskich terminov (Red.-Sost. L.I. Timofeev, S.V. Turaev), Moskau 1974.

L.S. SOBOLEV, Sovetskaja literatura $i$ vospitanie novogo Celoveka. Doklad predsedatelja pravlenija Sojuza pisatelej RSFSR L.S. Soboleva, in: Literaturnaja Gazeta, 4.3.1965, S.2-6. (Hauptreferat auf dem zweiten KongreB des Schriftstellerverbands der RSFSR.)

Sociologiteskij aspekt sovremennoj "derevenskoj prozy". Vystupajut: S. Galimov, Ju. Galkin, S. Surtakov, L. Ivanov, in: Voprosy literatury, 1973, Nr.3, S.45-78.

v. SolouchIN, Dialog, in: Literaturnaja Gazeta, 3.12.1964, S.2.

A. SOSKIN, Vozmoźnosti Zanra, in: Zvezda, 1953, Nr.3, S. 145-158. 
H. STACHOWIAK, Gedanken zu einer allgemeinen Theorie der Modelle, in: Studium Generale, 1965, Nr.7, S.423-467.

E. STARIKOVA, Rodnoe i blizkoe, in: Dies., Poèzija prozy. Stat'i, Moskau 1962, S.152-191.

E. STARIKOVA, SociologiCeskij aspekt sovremennoj "derevenskoj prozy", in: Voprosy literatury, 1972, Nr.7, S.11-35.

A. STEININGER, Literatur und Politik in der Sowjetunion nach Stalins Tod, Wiesbaden 1965.

$i$ K.H. STIERIE, Text als Handlung. Perspektiven einer systematischen Literaturwissenschaft, München 1975.

D. STOK, Zemlja moja rodnaja..., in: Grani, 1978, Nr.110, S. 182-198.

P. STROKOV, o narode - "Savrasuške", o "zagadkach" russkogo charaktera i iskanijach "pri svete sovesti", in:

Oktjabx', 1968, Nr.12, S.190-199.

P. STROKOV, Prostet ili zadannost'?, in: Literaturnaja Rossija, 7.6.1968, S.8-9.

P. STROKOV, Zemlja i ljudi, in: Ogonek, 1968, Nr.22, S.25-29.

P. STROKOV, Na polevom stane literatury,, in: Don, 1970, $\mathrm{Nr} .7, \mathrm{~S} .142-151$ und $\mathrm{Nr} .8, \mathrm{~S} .171-186$.

A.S. SUBBOTIN, O kategorii Zanra i ee otnosenijach s "rodami" i "vidami", in: Problemy literaturnych zanrov. Materialy vtoroj naučnoj mežvuzovskoj konferencii 30 sentjabrja - 4 oktjabrja 1975 goda, Tomsk 1975, S.3-5.

E. SUBIN, Zanr rasskaza v literaturnom processe, in: Russkaja literatura, 1965, Nr.3, S. 27-52.

E. SUBIN, Principy raskrytija charaktera $v$ sovremennom russkom rasskaze, in: Russkaja literatura, 1966, Nr.2, S.29-43.

V. SURGANOV, Iduscim dal'ße. Zametki o knigach pisatelej "derevenstikov", in: Voprosy literatury, 1971, Nr.8, s. 3-25.

v. SURGANOV, Celovek na zemle. Istoriko-literaturnyj oðerk, Moskau 1975.

V. SURGANOV, Pered zavtrašnim dnem, in: Literaturnaja Gazeta, 12.3.1980, S. 1,5.

JU. SURovCEV, Rodnye brat'ja, no ne bliznecy, in: zvezda, 1968, Nr.5, S.198-206.

s. SuRTAKov, o glavnom Eeloveke na zemle, in: Literaturnaja Gazeta, 5.12.1967, S.6.

S. SURTAKov, Živoj Zelovek, a ne obstie cifry, in: voprosy literatury, 1973, Nr.3, s.62-71.

G. SVIRSKIJ, Na lobnom meste, London 1979.

L. TERAKOPJAN, Pafos preobrazovanija. Zametki o sovremennoj derevenskoj proze, Moskau 1974. 
L.I. TIMOFEEV, Osnovy teor11 l1teratury, Moskau 1971.

T. TODOROV, Die Kategorien der literarischen Erzahlung, in: H. Blumensath (Hg.), Strukturalismus in der Literaturwissenschaft, Köln 1972, S.263-294.

Tretij 8-ezd pisatelej RSFSR. 24-27 marta 1970 goda. Sten. otzet, Moskau 1972 .

Tretij s-ezd pisatelej SSSR, 18-27 maja 1959 goda. Sten. otcet, Moskau 1959.

JU. TYNJANOV, Uber die literarische Evolution, in: Ju. Strledter (Hg.), Russischer Formallsmus. Texte zur allgemeinen it teraturtheorie und zur Theorie der Prosa, Bd.1, München 1969, S.433-461.

JU. TYNJANOV, R. JAKOBSON, Probleme der literatur- und Sprachforschung (1928), in: R. Jakobson, Poetik. Ausgewahlte Aufsatze 1921-1971 (Hg. E. Holenstein, T. Schelbert), Prankfurt/M. 1979, S.63-66.

B. A. USPENSKIJ, Poetik der Komposition. Struktur des klinstlerischen Textes und Typologie der Rompositionsform (Hg. K. Eimermacher), Frankfurt/M. 1975.

A. USTINOV, Kto "pervyj paren' na derevne"?, in: IIteraturnaja Gazeta, 10.10.1979, S.4.

I. VINOGRADOV, Derevenskie očerki Valentina Oveckina, in: Literatura 1 sovremennost'. Sbornik 6. Stat' 1 o ilterature 1964-1965 godov (Sost. L. Jakimenko, S. Masinskij, E. Osetrov), Moskau 1965, S.139-179.

F. VODICKA, Die Literaturgeschichte, thre Probleme und Aufgaben, in: Ders., Die Struktur der literarischen Entwicklung. Mit einer einleitenden Abhandlung von Ju. Strledter, Munchen 1976, S.30-86.

F. VODICKA, Die Totalitat des literarischen Prozesses. zur Entwicklung des theoretischen Denkens im Werk Jan Mukałovskys, in: Ders., Die Struktur der literarischen Entwicklung. Mit einer einleitenden Abhandlung von Ju. Striedter, Munchen 1976, S.1-29.

v. Volosinov, Marxismus und Sprachphilosophie. Grundlegende Probleme der soziologischen Methode in der Sprachwissenschaft (Hg. S.M. Weber), Franfurt/M.-Berlin-Wien 1975 .

K. VOLYNSKIJ, Narodnyj charakter: Model' 1 izn', in: Literaturnaja Gazeta, 16.6.1969, S.4.

N. VOROB 'EVA, S. ChITAROVA, Nazad, k "istokam", 111 ot "1stokov" $v$ budustee?, in: Literaturnaja Gazeta, 10.12.1969, S.4.

V. VORONOV, Este raz o cennostjach $18 t 1$ nnych 1 mnimych, in: Literaturnaja Gazeta, 13.3.1968, S.4.

A. YANOV, The Russian New Right. Right-wing Ideologies in the Contemporary USSR, Berkeley 1978. 
N. ZaLINSKIJ, Sloznosti mimye 1 real'nye, in: Literaturnaja Gazeta, 14.11.1979, S.4.

S. ZALYGIN, Mysli posle sovescanija, in: Novyj Mir, 1956, Nr.1, S.218-228.

T.P. ZAMORIJ, SOvremennyj russkij rasskaz, Kiev 1968.

G. ZEKULIN, Aspects of Peasant Life as Portrayed in Contemporary Soviet Literature, in: Canadian Slavic Studies, 1967, Nr.4, S.552-565.

G. ZEKULIN, The Contemporary Countryside in Soviet Literature: A Search for New Values, in: J.R. Millar (Hg.), The Soviet Rural Community, Urbana 1971, S.376-404.

Zemlja. Ljud1. Literatura., in: Druzba narodov, 1970, Nr.9, S. 247-275.

Zizn' kolchoznoj derevni 1 literatura. Tvorteskaja diskussija $v$ Sojuze Pisatelej SSSR (Red. K.I. Bukovskij), Moskau 1956. (Beitrăge von G. Baklanov, A. Dement'ev, V. Dorofeev, E. Doro8, R. DŽaparidze, G. Fis, A. Kalinin,

N. Lesjuževskij, G. Nikolaeva, V. Overkin, F. Pevnev, V. Tendrjakov, G. Troepol'skij, S. Voronin, S. Zalygin u.a.) 